\title{
Determination of Effectiveness of Energy Management System in Buildings
}

Vivash Karki

West Virginia University, vk0012@mix.wvu.edu

Follow this and additional works at: https://researchrepository.wvu.edu/etd

Part of the Energy Systems Commons, and the Industrial Engineering Commons

\section{Recommended Citation}

Karki, Vivash, "Determination of Effectiveness of Energy Management System in Buildings" (2021). Graduate Theses, Dissertations, and Problem Reports. 8263.

https://researchrepository.wvu.edu/etd/8263

This Thesis is protected by copyright and/or related rights. It has been brought to you by the The Research Repository @ WVU with permission from the rights-holder(s). You are free to use this Thesis in any way that is permitted by the copyright and related rights legislation that applies to your use. For other uses you must obtain permission from the rights-holder(s) directly, unless additional rights are indicated by a Creative Commons license in the record and/ or on the work itself. This Thesis has been accepted for inclusion in WVU Graduate Theses, Dissertations, and Problem Reports collection by an authorized administrator of The Research Repository @ WVU. For more information, please contact researchrepository@mail.wvu.edu. 


\title{
Determination of Effectiveness of Energy Management System in Buildings
}

\author{
Vivash Karki \\ Thesis submitted to the Benjamin M. Statler College of \\ Engineering and Mineral Resources at \\ West Virginia University \\ in a partial fulfillment \\ of the requirement for the degree of \\ Master of Science \\ in \\ Industrial Engineering \\ Bhaskaran Gopalakrishnan, Ph.D., P.E., Chair \\ Ashish Nimbarte, Ph.D. \\ Derek R. Johnson, Ph.D., P.E.
}

\section{Department of Industrial and Management Systems Engineering}

Morgantown, West Virginia

July 2021

Keywords: Buildings, Energy Management System, Demand Controlled Ventilation, Zoning Control, Supply Air Temperature Reset, Temperature Setback Control, Monte Carlo Simulation, eQuest

Copyright 2021 Vivash Karki 


\title{
Abstract \\ Determination of Effectiveness of Energy Management System in Buildings
}

\author{
Vivash Karki
}

Building Energy Management Systems (BEMS) are computer-based systems that aid in managing, controlling, and monitoring the building technical services and energy consumption by equipment used in the building. The effectiveness of BEMS is dependent upon numerous factors, among which the operational characteristics of the building and the BEMS control parameters also play an essential role. This research develops a userdriven simulation tool where users can input the building parameters and BEMS controls to determine the effectiveness of their BEMS. The simulation tool gives the user the flexibility to understand the potential energy savings by employing specific BEMS control and help in making intelligent decisions. The simulation is developed using Visual Basic Application (VBA) in Microsoft Excel, based on discrete-event Monte Carlo Simulation (MCS).

The simulation works by initially calculating the energy required for space cooling and heating based on current building parameters input by the user in the model. Further, during the second simulation, the user selects all the BEMS controls and improved building envelope to determine the energy required for space cooling and heating during that case. The model compares the energy consumption from the first simulation and the second simulation. Then the simulation model will provide the rating of the effectiveness of BEMS on a continuous scale of 1 to 5 ( 1 being poor effectiveness and 5 being excellent effectiveness of BEMS). This work is intended to facilitate building owner/energy managers to analyze the building energy performance concerning the efficacy of their energy management system. 


\section{Dedication}

This work is dedicated to my beloved parents, Bal Kumari and Tilak, for endless love, compassion and support, and my elder sister, Alina: my human diary and the pillar of my life. 


\section{Acknowledgement}

I would like to express my heartfelt gratitude and admiration to Dr. Bhaskaran Gopalakrishnan, my research advisor and committee chair, for his continuous guidance, motivation, and immense knowledge that he bestowed upon me throughout the journey. With his unwavering guidance and humility, he made me believe that learning from failures and continuous improvement mindset can help to achieve success in life. Needless to say, this research would not have been possible without his guidance and assistance. I would also like to express my gratitude to my committee member, Dr. Ashish Nimbarte, for assisting me academically and professionally throughout my graduate school. He was a constant mentor and a confidante, who always went out of his way to assist me. I would also like to express my deepest gratitude to my committee member, Dr. Derek R. Johnson for his time and support, as well as valuable feedbacks to the research.

I would also like to acknowledge my friends and family, who were always there for me, bringing me joy and support. Finally, I would like to thank my elder sister, who is more like a best friend to me, for always encouraging and supporting me. 


\section{Table of Contents}

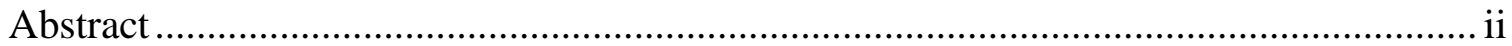

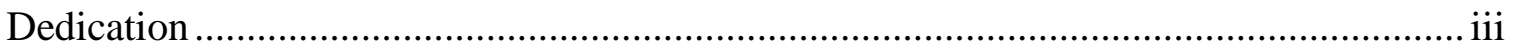

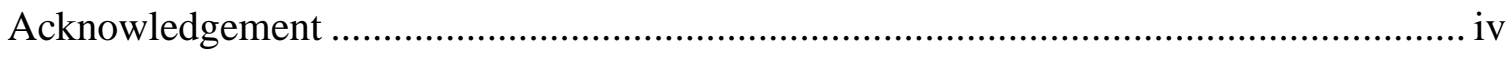

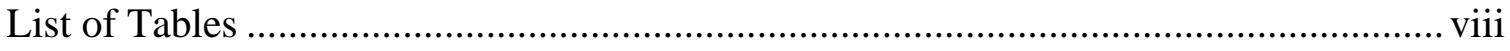

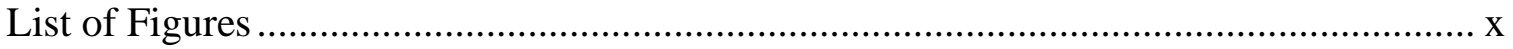

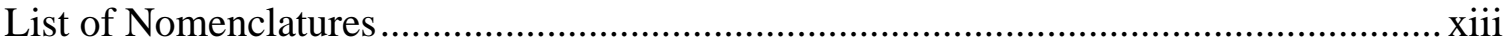

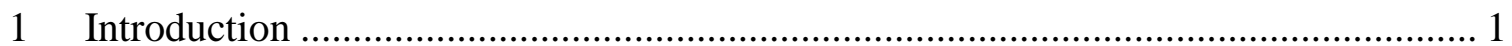

1.1 Introduction to Energy Management.................................................................. 1

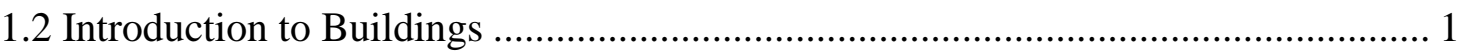

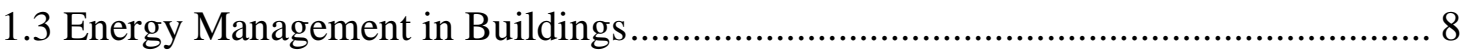

1.4 Building Energy Management System (BEMS) ................................................ 16

1.5 Artificial Intelligence (AI) for Self-learning Systems in BEMS......................... 21

1.6 Role of Historical Data in Energy Efficiency Controls for the BEMS .................. 22

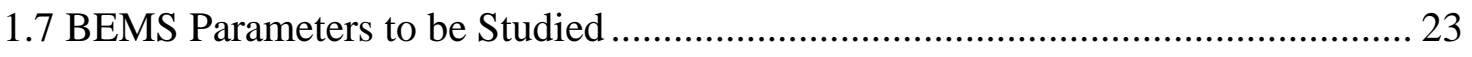

1.7.1 Demand Controlled Ventilation (DCV) .................................................... 23

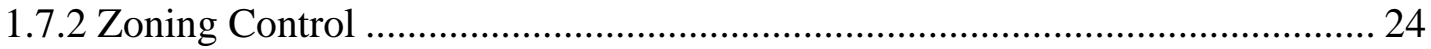

1.7.3 Temperature Setback Control .................................................................... 24

1.7.4 Supply Air Temperature Reset (SATR) Control ......................................... 24

1.8 Role of Various Factors on Effectiveness of BEMS ........................................... 28

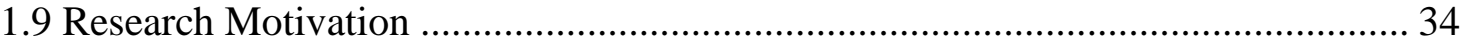

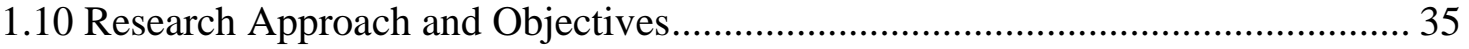

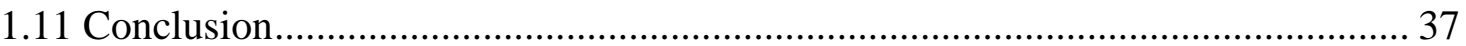

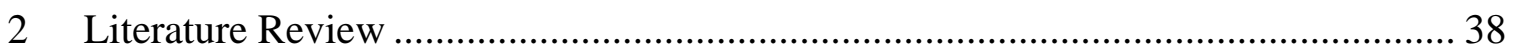

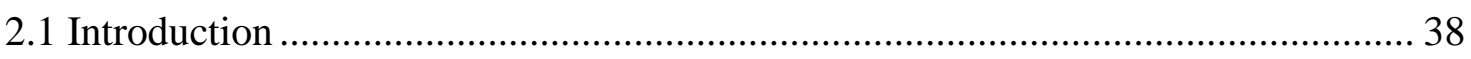

2.2 Current Scenario of Energy Consumption by Buildings................................... 38

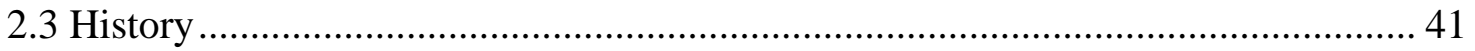

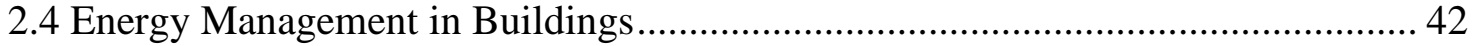

2.4.1 Energy Efficiency Index (EEI) ............................................................. 42

2.4.2 Energy Efficiency Study in Buildings ........................................................... 43

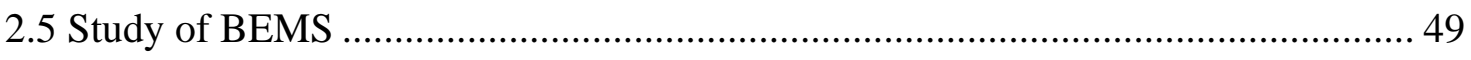

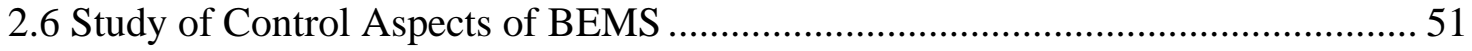

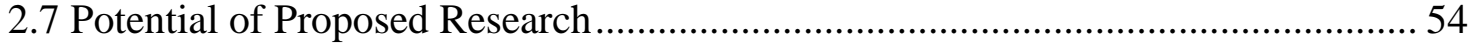




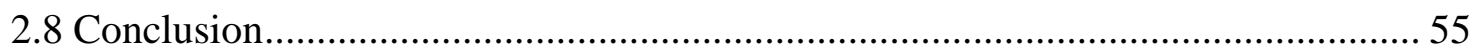

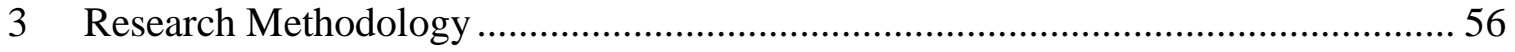

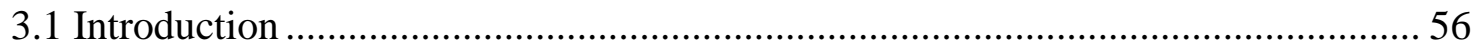

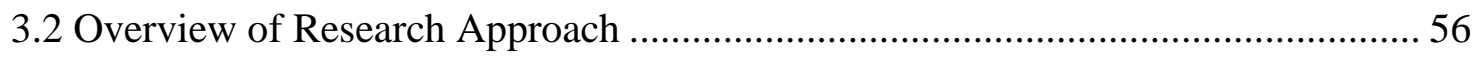

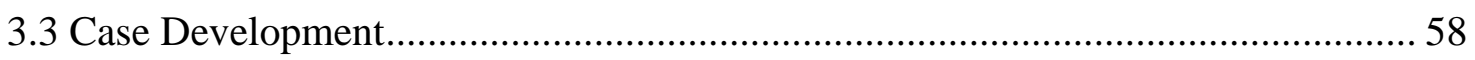

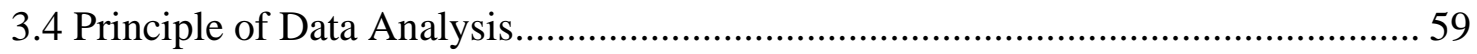

3.4.1 Monte Carlo Simulation (MCS) …………………….................................. 59

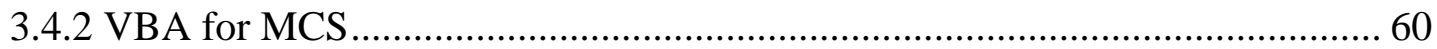

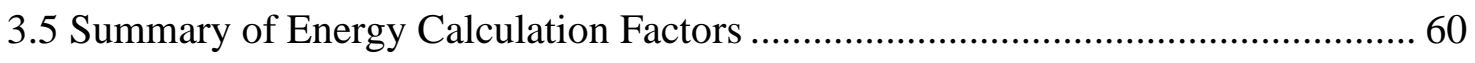

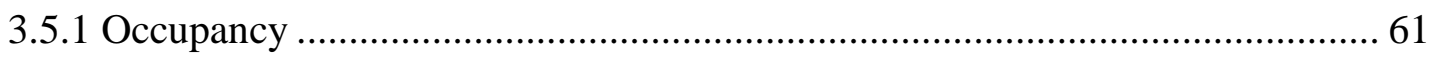

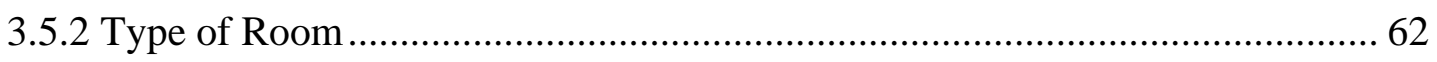

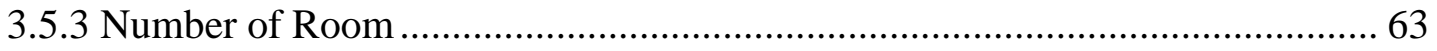

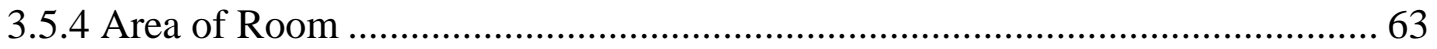

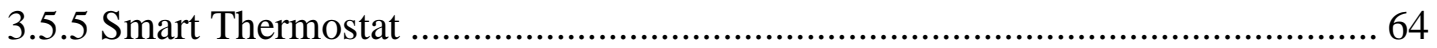

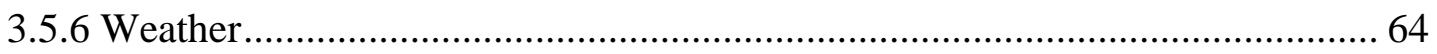

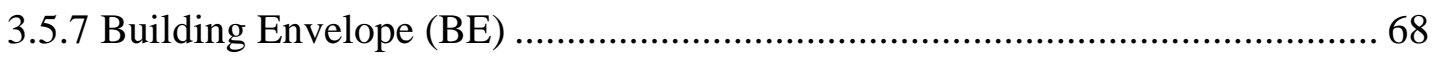

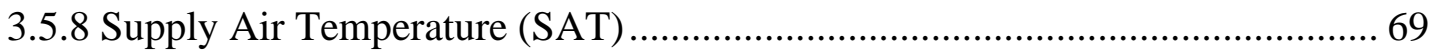

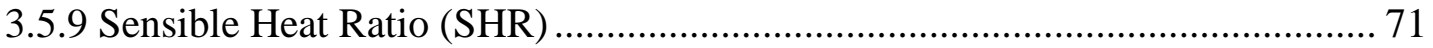

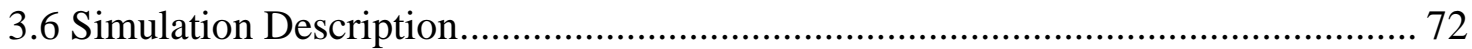

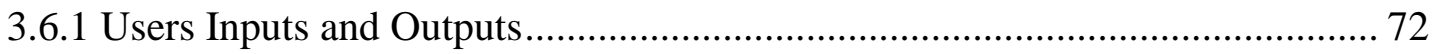

3.6.2 Description of Energy Consumption Calculation.............................................. 74

3.6.3 Rating for Effectiveness of BEMS ………………..................................... 82

3.6.4 Reduction of GHG Emissions for Site Energy and Source Energy ................ 84

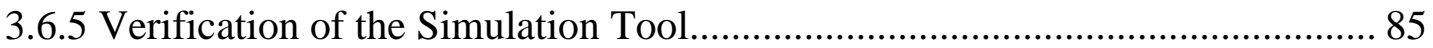

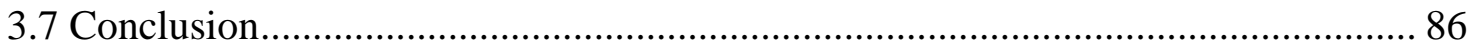

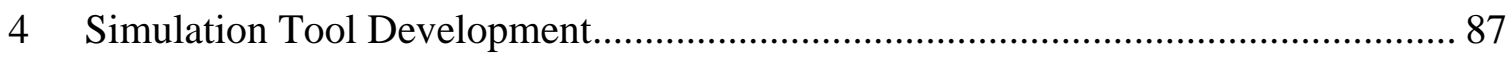

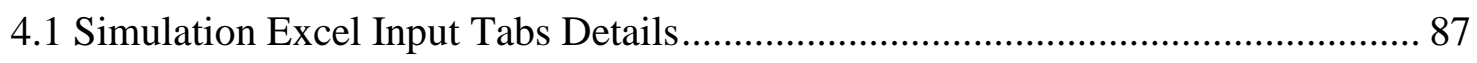

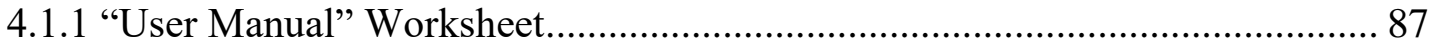

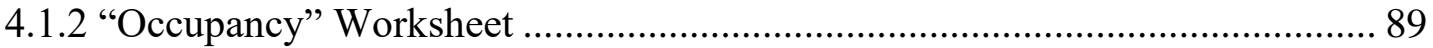

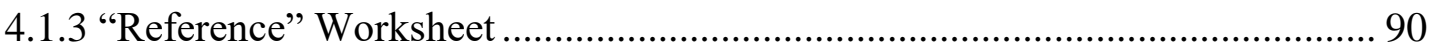

4.1.4 "Climatic Data" Worksheet ......................................................................... 90

4.1.5 "Inputs" Worksheet ..................................................................................... 92 


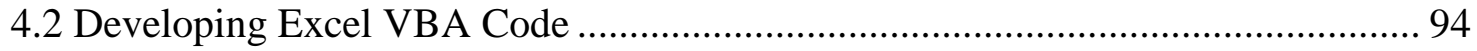

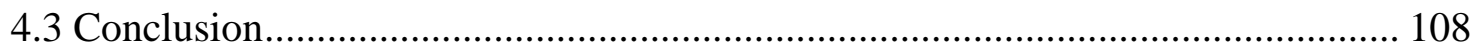

5 Simulation System Execution and Results .......................................................... 110

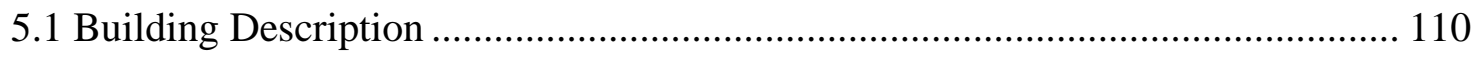

5.2 Simulation Demonstration with Community Center Building .............................. 112

5.2.1 Simulation with User-Defined / Base Case ....................................................... 113

5.2.2 Simulation with all BEMS controls and Improved Building Envelope ......... 119

5.3 Effectiveness of energy management system of the community center ................ 123

5.4 Verification of the Simulation Tool ................................................................... 127

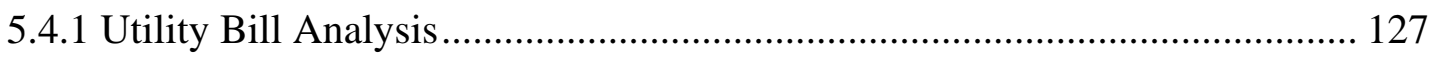

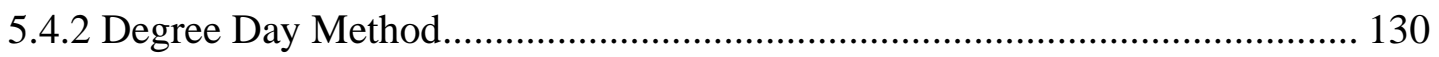

5.4.3 eQuest modeling and simulation of the community center ............................ 134

5.5 BEMS with the addition of BEMS controls ..................................................... 143

5.5.1 Case I - With improvement in Building Envelope only .................................. 143

5.5.2 Case II - With the Addition of DCV.......................................................... 147

5.5.3 Case III - With DCV and Building Envelope improvement .......................... 150

5.5.4 Case IV - With the addition of SATR controls, only ..................................... 153

5.5.5 Case V - With SATR and Building Envelope improvement............................ 157

5.5.6 Case VI - With DCV and SATR controls but poor BE .................................. 160

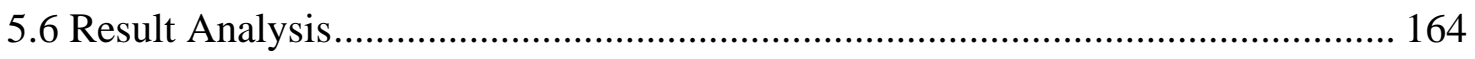

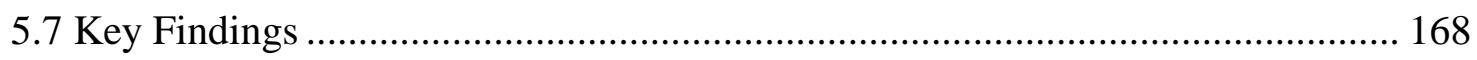

5.8 Discussion on Limitations of Factors Used in Simulation Model ........................ 169

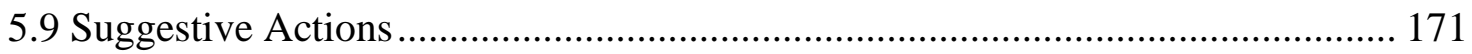

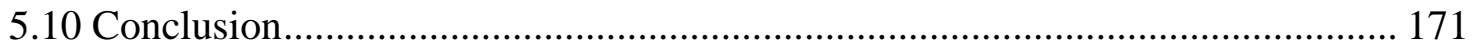

6. Conclusion and Future Work .............................................................................. 173

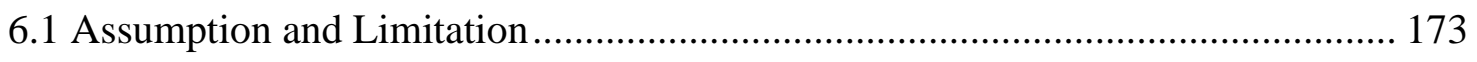

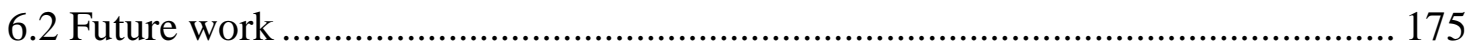

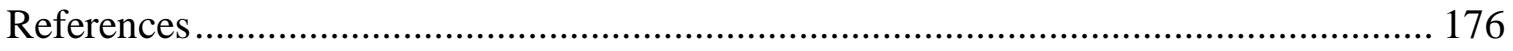

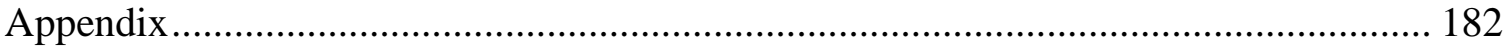




\section{List of Tables}

Table 1.1: Sample Data of Median EUIs in the United States [8] ................................. 9

Table 1.2: Modern development in the field of building energy technologies [12] ......... 15

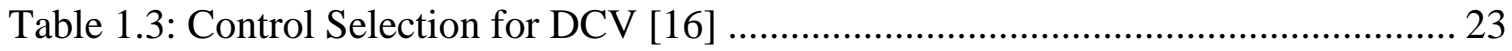

Table 2.1: Categorical energy consumption in commercial and residential buildings [25]

Table 3.1: Occupancy schedule chart for determining occupancy level for office space. 62

Table 3.2: ASHRAE Recommended Ventilation Rates and Typical Air Change Rates

[53] 63

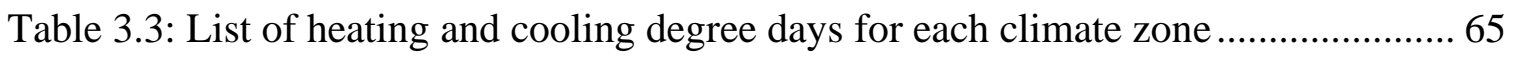

Table 3.4: Calculation of cooling ratio for the South Atlantic region ............................. 66

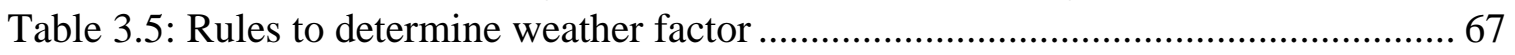

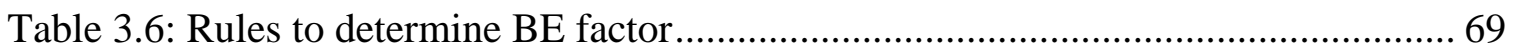

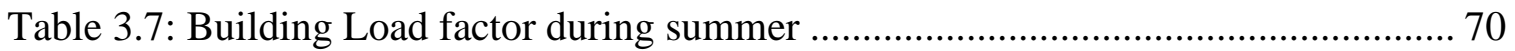

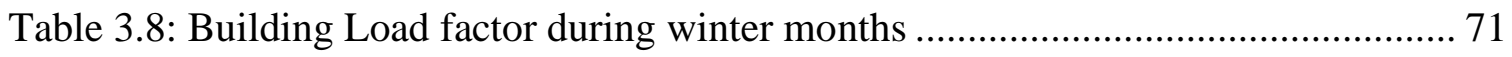

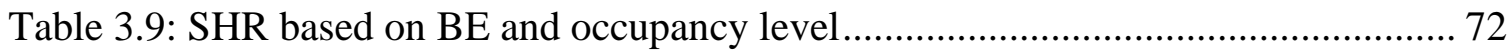

Table 3.10: User Guidance for representation of rating value ..................................... 84

Table 3.11: Example of determination of the effectiveness of BEMS ........................... 84

Table 3.12: Source-Site ratios for various energy types [57] ...................................... 85

Table 5.1: Worksheet of Supply Air Characteristics for the Base Case ........................ 116

Table 5.2: Worksheet of Mixed Air Characteristics for the Base Case ......................... 116

Table 5.3: Worksheet of Energy Calculation for the Base Case.................................... 118

Table 5.4:Worksheet of Summary of Energy Consumption for the Base Case.............. 118

Table 5.5: Monthly energy consumption for the Base Case ........................................ 119

Table 5.6: Worksheet of Supply Air Characteristics for the TEE Case........................ 121

Table 5.7: Worksheet of Mixed Air Characteristics for the TEE Case ......................... 121

Table 5.8: Worksheet of Energy Calculation for the TEE Case .................................. 122

Table 5.9: Worksheet of Summary of Energy Consumption for the TEE Case .............. 122

Table 5.10: Monthly energy consumption for TEE case ........................................... 123

Table 5.11: Comparison of energy consumption between Base Case and TEE case .... 124

Table 5.12: Summary of reduction of $\mathrm{CO}_{2}$ emission for TEE Case ............................. 124

Table 5.13: Monthly energy consumption from utility bill ......................................... 127

Table 5.14: Estimate of energy consumption by auxiliary units of the building ........... 128

Table 5.15: Estimate of energy required for space heating and cooling ........................ 129

Table 5.16: Comparison of energy consumption between Base Case and Utility case .. 129

Table 5.17: Energy required for space cooling and heating obtained from DD method 133

Table 5.18: Comparison of energy consumption between the Base Case and DD method

Table 5.19: Breakdown of energy consumption in community center using eQuest ..... 140

Table 5.20: Energy required for space cooling and heating obtained from eQuest........ 140

Table 5.21: Comparison of energy consumption between Base Case and eQuest method 
Table 5.22: Summary of energy consumption from various verification methods ........ 142

Table 5.23: Energy consumption for space heating and cooling for Case I ................. 144 Table 5.24: Comparison of energy consumption between Base Case, TEE Case, and Case

I 144

Table 5.25: Summary of reduction of $\mathrm{CO}_{2}$ emission for Case I . 145

Table 5.26: Energy consumption for space heating and cooling for Case II 147 Table 5.27: Comparison of energy consumption between Base Case, TEE case, and Case II. 148

Table 5.28: Summary of reduction of $\mathrm{CO}_{2}$ emission for Case II............................... 148

Table 5.29: Energy consumption for space heating and cooling for Case III................. 151 Table 5.30: Comparison of energy consumption between Base Case, TEE Case, and Case III 151

Table 5.31: Summary of reduction of $\mathrm{CO}_{2}$ emission for Case III ............................... 152

Table 5.32: Energy consumption for space heating and cooling for Case IV ............... 154 Table 5.33: Comparison of energy consumption between Base Case, TEE case, and Case

IV 154

Table 5.34: Summary of reduction of $\mathrm{CO}_{2}$ emission for Case IV 155

Table 5.35: Energy consumption for space heating and cooling for Case V..... 157

Table 5.36: Comparison of energy consumption between Base Case, TEE case, and Case $\mathrm{V}$ 158

Table 5.37: Summary of reduction of $\mathrm{CO}_{2}$ emission for Case $\mathrm{V}$ 158

Table 5.38: Energy consumption for space heating and cooling for Case VI 160 Table 5.39: Comparison of energy consumption between Base Case, TEE case, and Case VI 161

Table 5.40: Summary of reduction of $\mathrm{CO}_{2}$ emission for Case VI 161 


\section{$\underline{\text { List of Figures }}$}

Figure 1.1: Percentage of Commercial buildings by principal building activity [1] ......... 4

Figure 1.2: Shares of primary energy sources used in commercial buildings, 2012 [2].... 5

Figure 1.3: Total $\mathrm{CO}_{2}$ emission from Commercial Sectors (2016) [3] ............................ 5

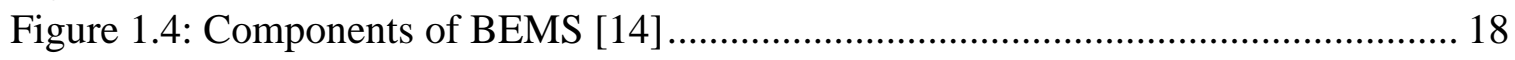

Figure 1.5: Fan curve to determine brake horsepower [22] ...................................... 30

Figure 1.6: Operating modes of air economizer system [23] ....................................... 32

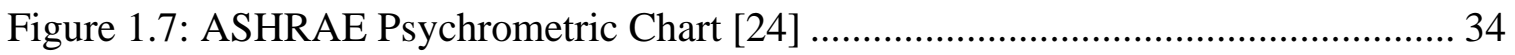

Figure 1.8: Basic Schematic Diagram of the System .................................................. 37

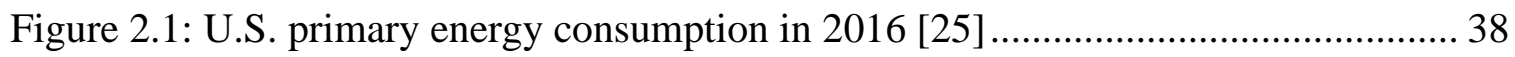

Figure 2.2: Breakdown of buildings energy consumption in the U.S. in 2016 [25] ........ 40

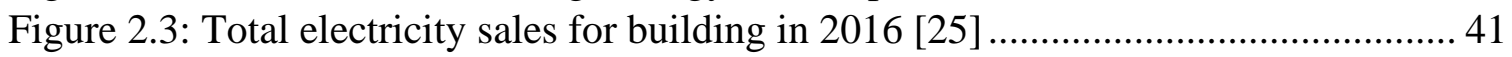

Figure 3.1: Steps for determining the effectiveness of BEMS ................................... 58

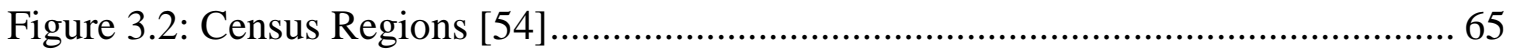

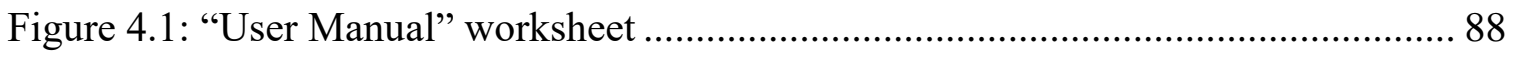

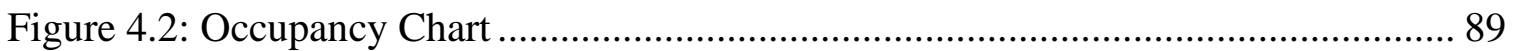

Figure 4.3: Climatic Data from 2017 ASHRAE Handbook [55].................................. 91

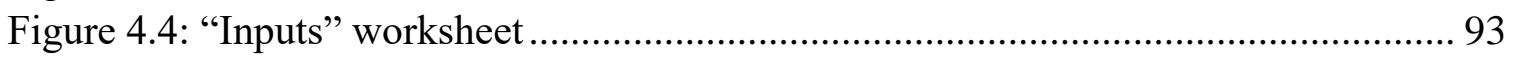

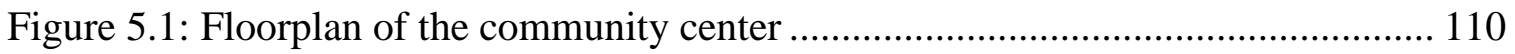

Figure 5.2: Input boxes for a user to provide general building information................... 113

Figure 5.3: Color-coded table for a user to input building data.................................. 114

Figure 5.4: Feasibility check for generating effective energy efficiency ...................... 114

Figure 5.5: Input boxes for the user to provide information about their location........... 115

Figure 5.6: Input Box for the user to input the source of heating ................................ 117

Figure 5.7: Input Boxes for the user to provide the average cost of energy .................. 123

Figure 5.8: Energy consumption pattern for the Base Case........................................ 125

Figure 5.9: Energy consumption pattern for TEE Case ........................................... 125

Figure 5.10: Comparison of electrical energy consumption between Base Case and TEE

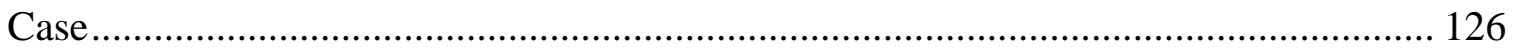

Figure 5.11: Comparison of natural gas consumption between Base Case and TEE Case

Figure 5.12: Effectiveness of BEMS for Base Case ................................................ 127

Figure 5.13: Comparison of electrical energy consumption between Base Case and Utility

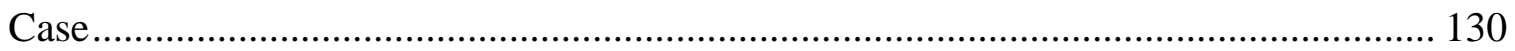

Figure 5.14: Comparison of natural gas consumption between Base Case and Utility Case

Figure 5.15: Comparison of electrical energy consumption between the Base Case and

DD approach

Figure 5.16: Comparison of natural gas consumption between the Base Case and DD

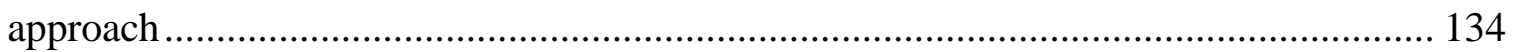

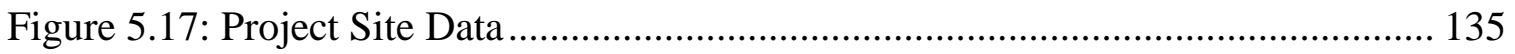

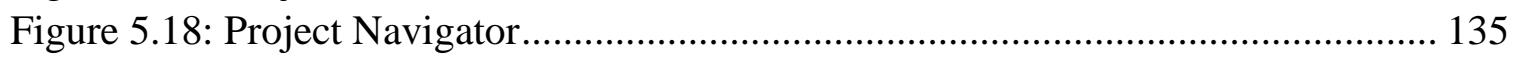


Figure 5.19: Building footprint for an office building (left) and gymnasium (right) .... 136 Figure 5.20: Building shell components for an office building (left) and gymnasium (right)

Figure 5.21: Activity area allocation for an office building (left) and gymnasium (right)

Figure 5.22: Zoning of the office building (left) and gymnasium (right) ...................... 137

Figure 5.23: HVAC system for an office building (left) and gymnasium (right).......... 138 Figure 5.24: Temperature control setting for an office building (left) and gymnasium

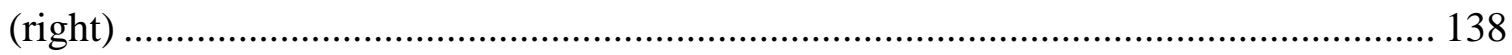

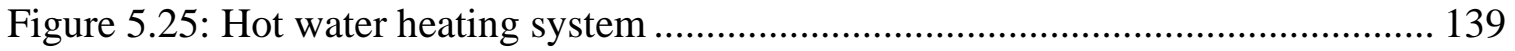

Figure 5.26: Energy consumption in community center obtained using eQuest ........... 139

Figure 5.27: Comparison of electrical energy consumption between the Base Case and

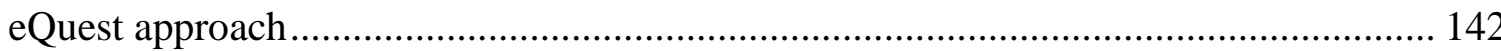

Figure 5.28: Comparison of natural gas consumption between the Base Case and eQuest

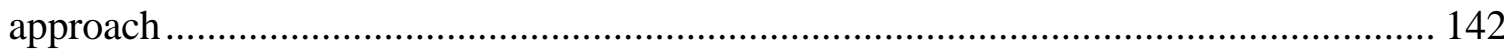

Figure 5.29: Comparison of energy consumption obtained from various methods........ 143 Figure 5.30: Comparison of electrical energy consumption between Base Case, Case I, and TEE Case

Figure 5.31: Comparison of natural gas consumption between Base Case, Case I, and

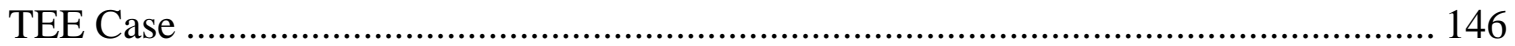

Figure 5.32: Change of effectiveness of BEMS from Base Case to Case I................... 146 Figure 5.33: Comparison of electrical energy consumption between Base Case, Case II, and TEE Case.

Figure 5.34: Comparison of natural gas consumption between the Base Case, Case II, and TEE Case

Figure 5.35: Change of effectiveness of BEMS from Base Case to Case II ................. 149

Figure 5.36: Comparison of electrical energy consumption between Base Case, Case III, and TEE Case.

Figure 5.37: Comparison of natural gas consumption between Base Case, Case III, and TEE Case

Figure 5.38: Change of effectiveness of BEMS from Base Case to Case III ................ 153 Figure 5.39: Comparison of electrical energy consumption between Base Case, Case IV, and TEE Case.

Figure 5.40: Comparison of natural gas consumption between Base Case, Case IV, and TEE Case 156 Figure 5.41: Change of effectiveness of BEMS from Base Case to Case IV ................. 156 Figure 5.42: Comparison of electrical energy consumption between Base Case, Case V, and TEE Case

Figure 5.43: Comparison of natural gas consumption between Base Case, Case V, and TEE Case

Figure 5.44: Change of effectiveness of BEMS from Base Case to Case V 159 Figure 5.45: Comparison of electrical energy consumption between Base Case, Case VI, and TEE Case. 
Figure 5.46: Comparison of natural gas consumption between Base Case, Case VI, and

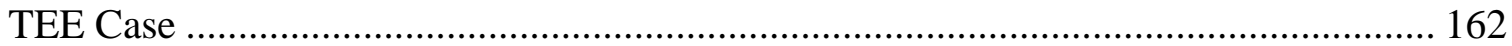

Figure 5.47: Change of effectiveness of BEMS from Base Case to Case VI................. 162

Figure 5.48: Interaction effect between BE improvement and DCV control ................. 164

Figure 5.49: Interaction effect between BE improvement and SATR control ............... 164

Figure 5.50: Interaction effect between DCV control and SATR control ...................... 164

Figure 5.51: Interaction effect between BE improvement, DCV control, and SATR

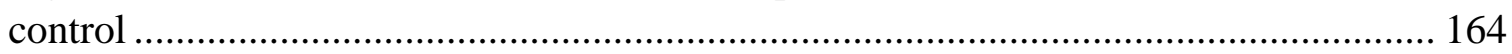

Figure 5.52: Annual electrical energy consumption $(\mathrm{kWh})$ for various cases................ 166

Figure 5.53: Annual natural gas consumption (MMBtu) for various cases..................... 167

Figure 5.54: Annual cost savings (\$/yr) for various cases............................................ 167

Figure 5.55: Rating of BEMS for various cases ........................................................... 167 


\section{List of Nomenclatures}

$\mathrm{ACH}$ - Air Change per Hour

AHU - Air Handling Unit

BMS - Building Management System

BEMS - Building Energy Management System

CFM - Cubic Feet per Minute

COP - Coefficient of Performance

CDD - Cooling Degree Days

CWTR - Chilled Water Temperature Reset

DAT - Discharge Air Temperature

DCV - Demand Controlled Ventilation

DD - Degree Days

DOAS - Dedicated Outdoor Air Supply

DOE - Department of Energy

EEI - Energy Efficiency Index

EIA - Energy Information Administration

EPA - Environmental Protection Agency

ERV - Energy Recovery Ventilation

EUI - Energy Use Intensity

HDD - Heating Degree Days

HVAC - Heating, Ventilation, and Air Conditioning

IAQ - Indoor Air Quality

MCS - Monte Carlo Simulation

SAT - Supply Air Temperature

SATR - Supply Air Temperature Reset

SHR - Sensible Heat Ratio

TEE - Target Energy Efficiency

VAV - Variable Air Volume

VBA - Visual Basic Application

VOC - Volatile Organic Compound

VRF - Variable Refrigerant Flow 


\section{Introduction}

\subsection{Introduction to Energy Management}

The term "Energy Management" encompasses strategic planning and operation of energy generating and/or consuming units. It can be broadly defined as the systematic, organized, and proactive management of energy use in organizations, industries, or buildings to meet the economic and environmental necessities. The main aims of energy management are the conservation of the resource, protection of the climate, and saving costs. At the same time, the consumers have continuous access to the energy they require. The core principles which are generally followed for energy management include but are not limited to collecting the energy data and metering the consumption of energy, seeking opportunities to save energy, implementing actions to save energy, and making a record of the progress and ongoing improvements.

In today's world, energy management is considered the groundwork for saving energy at an organizational level. Further, due to the increasing demand and decreasing supply of non-renewable natural resources such as gasoline and coal, costs are likely to rise. Also, the standards of sustainability are pushed more to higher limits by the regulations.

Managing energy use does not always involve a considerable investment of capital or complex analysis. It can be started by monitoring and evaluating the profile of energy consumption over time. Sometimes, making minor modifications to the energy spending behavior can lead to savings. Whatever the conditions, energy management is about developing a foundation of information for intelligent decision-making and using the information to reduce energy consumption.

\subsection{Introduction to Buildings}

A building is characterized as a structure with a roof and walls for permanent use. The building can be classified into various categories according to its design purpose. Some of the general types of buildings are discussed below: 


\section{Industrial Buildings}

These buildings usually have a large floor area, numerous heating, ventilation, and air conditioning (HVAC) units, loading docks for trucks, numerous electrical distribution points, and an easily accessible flat roof. Some of the industrial buildings may also have large spaces for refrigeration. The industrial buildings can be further subcategorized as Manufacturing facilities, Warehouses, and Flex. Manufacturing facilities are used for the manufacturing of materials or goods. Warehouses are generally used for the storage and distribution of materials and goods. Flex is generally a light manufacturing facility combined with an office space.

\section{Retail Buildings}

These buildings are used to sell goods and services to customers. The subcategories of these buildings mainly include Mall, Pad site, and Shopping Center. A mall is an enclosed shopping center with numerous outlets and may consist of department stores, movie theaters, food courts, and other commercial outlets. The shopping center is also referred to as strip malls or shopping plazas with open storefronts and numerous units under a single complex or within one roof. A pad site is a separate building, usually situated in front of a shopping center. These buildings encompass banks, restaurants, or fast-food chains.

\section{Office Buildings}

Business professionals generally use these buildings, technical firms, medical and dental professionals, and more. The office floor area is typically divided into separate rooms and includes a restroom and a kitchen. These buildings can be subcategorized as an office building, suite or condominium, and medical or dental office suite. An office building is mainly designed to accommodate a high occupancy level and vary in size from a singlestory to multi-storied buildings. A suite or condominium has separate areas: a floor, a unit, or a building wing. These individual units are leased or owned and maintained by their tenants while the owner or property manager keeps the building's exterior, roof, and common areas. The medical or dental office suite is a large space building divided into numerous small spaces incorporating exam and office space, treatment room, and waiting rooms. The complexity and size can differ significantly following the specific purpose of the building. 


\section{Multi-Dwelling Unit (MDU)}

An MDU is a complex or real estate development that houses several people. Multiple individual housing units for residential inhabitants are located within one building or numerous buildings within one complex. The units can be constructed on top of each other or next to each other. The example includes condominium units, apartments, townhouses, high rises.

\section{Luxury Home or Estate}

Luxury homes or the estate are usually considerable in size, designed with uncommon architectural details, constructed with high-end materials, located in optimal areas, and have exceptional amenities. Furthermore, these buildings tend to have more automated controls for optimizing the thermal comfort of the residents.

\section{Hotel and Lodging}

Like a multi-dwelling unit, this sort of property will involve a few individual private units. The most significant distinction is that housing is intended for brief inhabitance and will incorporate a business kitchen or on-location eatery as a rule. A few units, notwithstanding, might be suites that include different rooms, a kitchenette or potentially a wet bar, and perhaps at the same time an in-room spa.

\section{Restaurant}

This sort of property will change in size and intricacy yet will, for the most part, incorporate a kitchen with business apparatuses, an extra space or washroom, a refrigerated space (like a stroll in the fridge), an office, the eating territory, and public bathrooms.

Some business properties may not fall into any of these classes and are viewed as specific purpose structures. For example, clubs, houses of worship, schools, air terminals, and bowling alleys are classified as special-purpose structures.

The commercial building encompasses various building types such as hospitals, offices, schools, hotels, warehouses, and shopping malls. Since 2012, the number of facilities has grown by $6 \%$ and the floor space by $11 \%$ in the U.S. More than half of commercial buildings in the U.S. were built between 1960 and 1999, and 25\% have been made since 2000. The number of buildings has increased from 3.8 million to 5.9 million, and the 
amount of commercial floor area has increased from 51 billion square feet to 97 billion square feet. Among all commercial buildings, $48 \%$ were represented by warehouse and storage, service, and office buildings and had $42 \%$ of total retail building floor space [1].

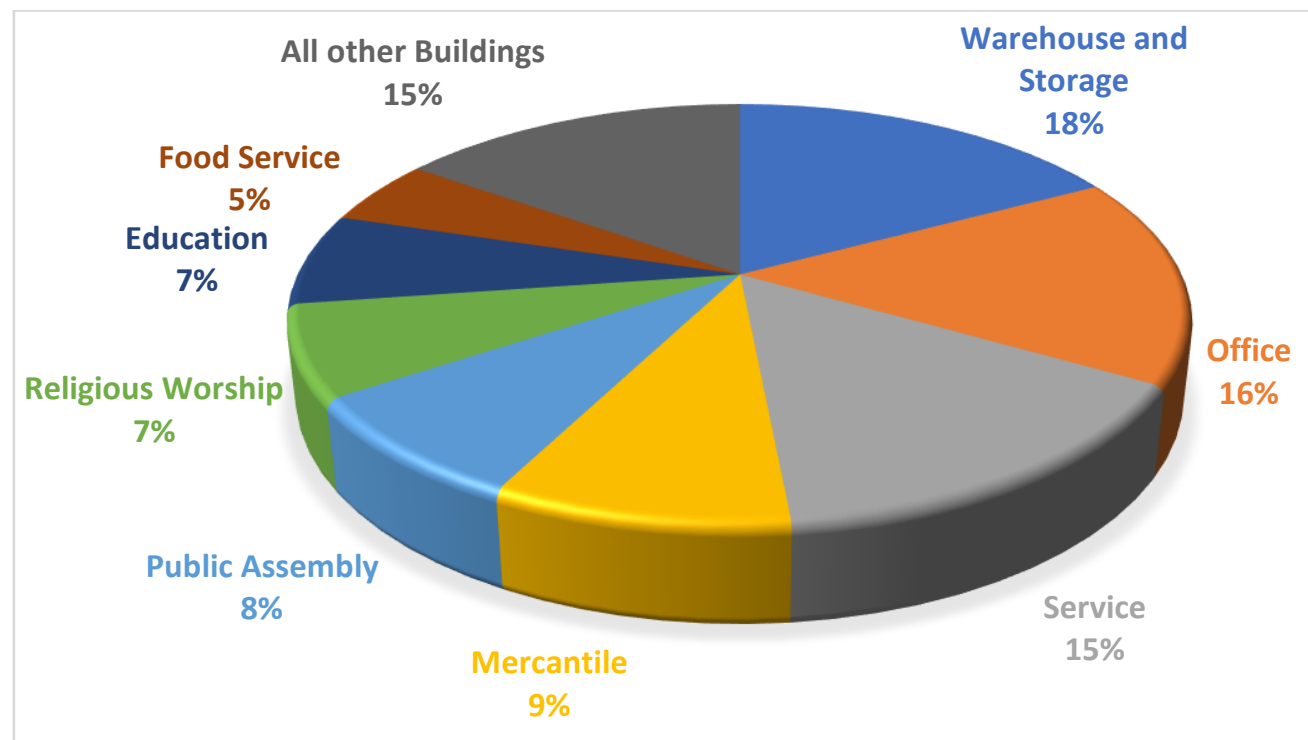

Figure 1.1: Percentage of Commercial buildings by principal building activity [1]

About $93 \%$ of the total energy consumed in commercial buildings in 2012 was electricity and natural gas. Natural gas is typically used to heat water, interior space, and operate cooling equipment in commercial buildings. About $32 \%$ of the total energy consumed in a commercial building in 2012 was from natural gas and $61 \%$ from electricity. The significant contribution to electricity in commercial buildings is due to lighting [2].

In 2012 , less than $1 \%$ of the buildings were larger than 200,000 square feet, but these buildings accounted for about $26 \%$ of total commercial building energy consumption. In contrast, about $88 \%$ of the commercial building in the U.S. had less than 25,000 square feet of floor area, but they accounted for only about $32 \%$ of total commercial building energy consumption. Also, about $11 \%$ of the commercial building were between the floor area of 25,000 - 200,000 square feet, and these buildings accounted for about $42 \%$ of the total energy consumption in commercial buildings [2]. 


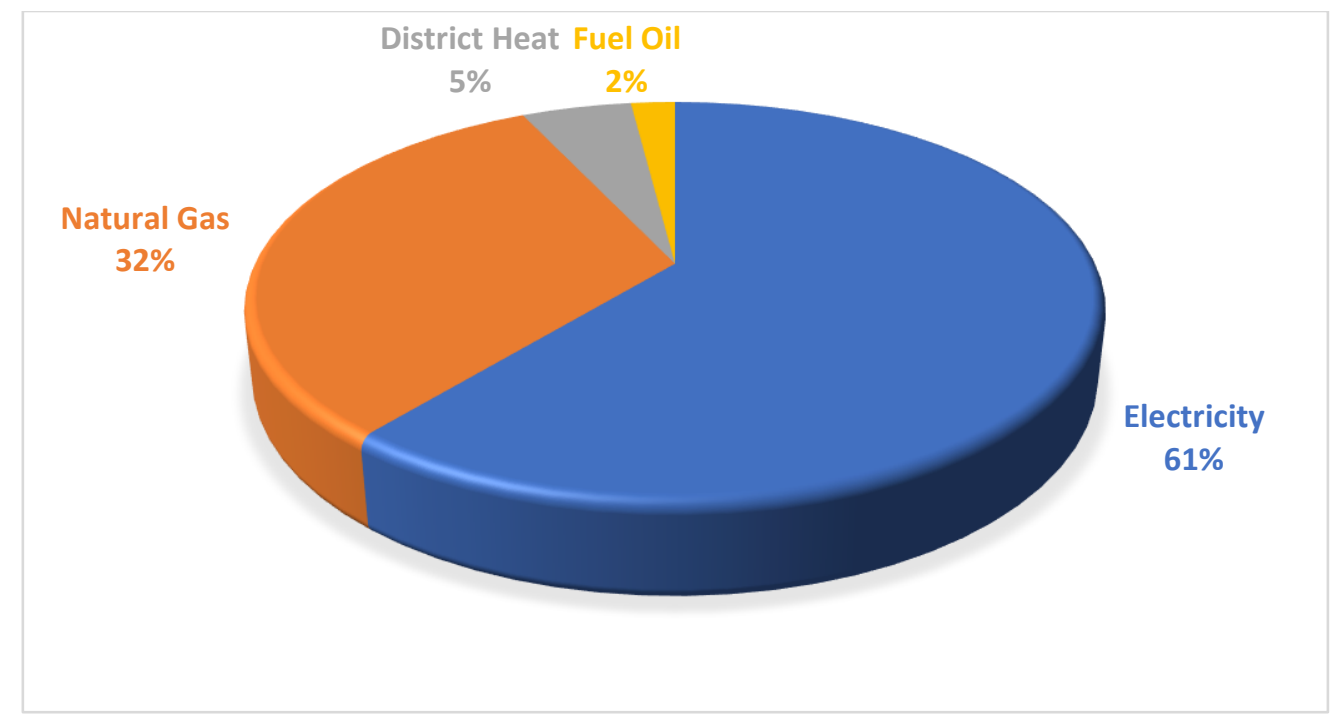

Figure 1.2: Shares of primary energy sources used in commercial buildings, 2012 [2] Greenhouse Gases (GHG) emissions from Buildings

The carbon dioxide $\left(\mathrm{CO}_{2}\right)$ emission from fossil fuels attributed to residential and commercial buildings increased by $20.4 \%$ and $7.8 \%$, respectively, from 1990 to 2015 . In 2015, $\mathrm{CO}_{2}$ emission from fossil-fuel combustion in the U.S. building sector produced 565.8 million metric tons of $\mathrm{CO}_{2}$ equivalent in direct emissions or about $8.6 \%$ of total U.S. GHG emissions making the building the fourth-highest emitting sector [3].

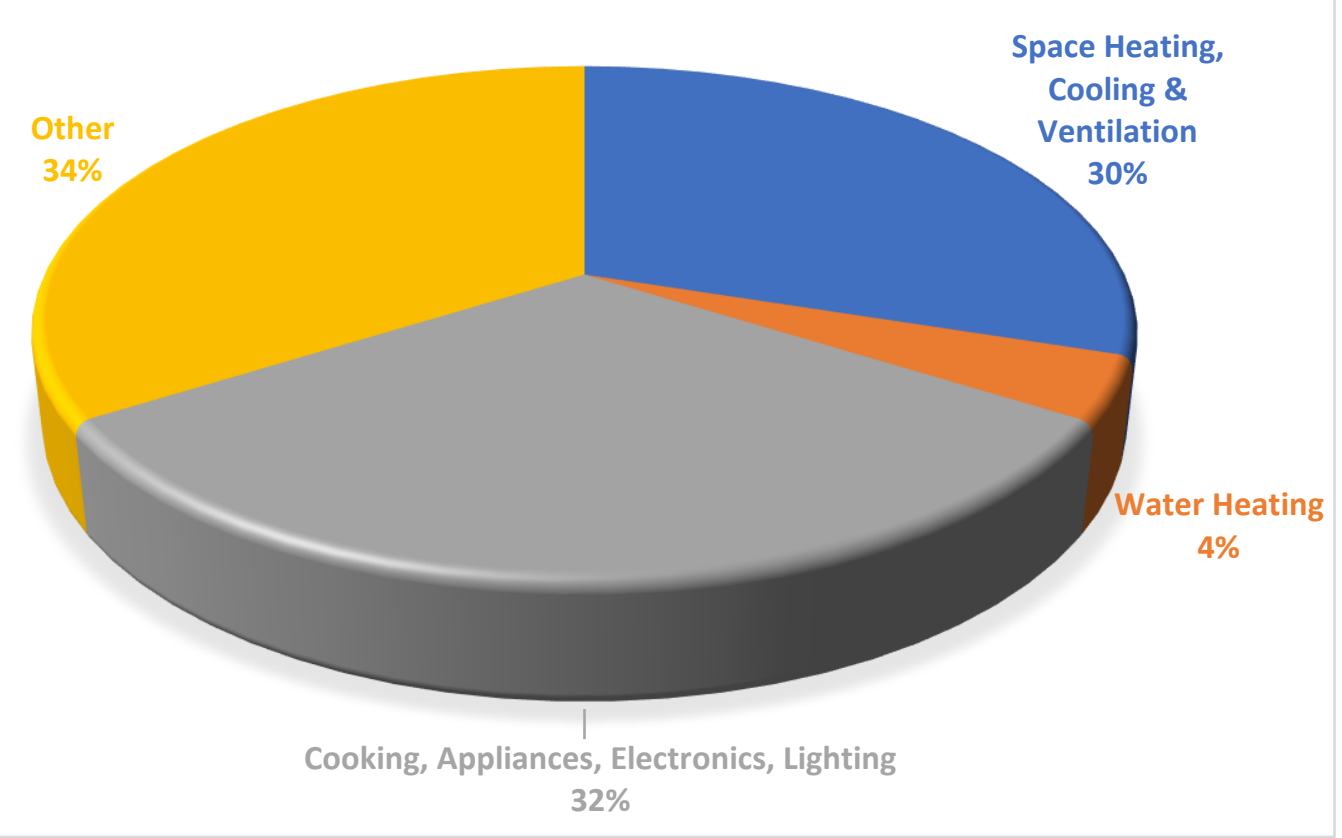

Figure 1.3: Total $\mathrm{CO}_{2}$ emission from Commercial Sectors (2016) [3] 
In 2015, the direct emission from on-site fossil-fuel combustion was a little more than half of the total emissions for the commercial sector. Commercial energy consumption is expected to rise by $19.7 \%$ and commercial floor space by $40.5 \%$ from 2016 to 2050 . Likewise, the direct emissions are also expected to increase by $20.4 \%$, driven by natural gas use [3].

\section{Current National and International Infrastructure Development Aspects for Buildings Energy Efficiency}

Decarbonizing the building and construction sector is crucial to meeting the Paris Agreement commitment and the Sustainable Development Goals (SDGs) of the United Nations (UN): Buildings and construction are responsible for about $40 \%$ of energy and process-related emissions, making them one of the most cost-effective ways to reduce emissions. As a part of the plans to limit GHG emissions, 184 countries contributed Nationally Determined Contributions (NDCs) under the United Nations Framework Convention on Climate Change (UNFCCC), focusing on mitigation of building emissions through switching to low-carbon and renewable energy sources, low-carbon building materials, building envelope improvements, nature-based solutions, and equipment and system efficiency [4].

Despite the need for greater ambition, policymakers, designers, builders, and other actors in the building and construction value chain worldwide are working to decarbonize and improve the global building stock's energy performance. Building codes are being introduced or strengthened in several nations, including India's Eco-Niwas Samhita, the country's first energy conservation code for the residential sector, and Rwanda's Green Building Minimum Compliance System. Building owners continue to adopt advanced certifications for high energy efficiency, low-carbon, and zero-carbon buildings, which encourages improvements in both new and existing buildings. Through its Net Zero Carbon Buildings Commitment, which is now being negotiated among its partners, the World Green Building Council supports such activities [4].

Dedicated products and funding schemes for low-energy and low-carbon buildings are being developed by investors worldwide. The EU Green Tagging strategy, for example, is the first to integrate suggestions for net-zero energy buildings (nZEBs) and green 
renovation in its regulations for European green financing. Some countries have also set goals to achieve a net-zero carbon building stock by 2050 or sooner. Japan and Canada, for example, are developing new rules to attain net-zero and net-zero-ready building requirements by 2030. More ambitious solutions to address existing building stocks will be proposed as more countries prepare their NDCs. In collaboration with regional members and stakeholders, the Global Alliance for Buildings and Construction (GlobalABC) and the International Energy Agency (IEA) are developing Regional Roadmaps for Latin America, Africa, and Asia to pave the way for efficient and resilient zero-emissions buildings and construction sectors [4].

Hence, the international drive towards the development of energy-efficient buildings creates multiple benefits: energy affordability, climate mitigation, and economic opportunities. Exploring ineffectiveness in the current energy management system of buildings can help achieve high energy performance goals or low-and zero-carbon buildings.

In 2020, the net generation of electricity from a utility-scale generator in the U.S. was about 4 trillion $\mathrm{kWh}$. About $60 \%$ of this generated electricity was produced from fossil fuels (coal, natural gas, and petroleum), about 20\% was from nuclear energy, and about $20 \%$ was from renewable energy sources. Residential buildings consumed around 38.9\% (1.46 trillion $\mathrm{kWh}$ ), and $34.8 \%$ (1.28 trillion $\mathrm{kWh}$ ) was consumed by commercial buildings [5]. Considering the trajectories of fertility, mortality, and immigration, U.S. population growth between 2020 and 2060 would be 22\% (404 million people) [6]. The increase in population demands more buildings that would require development in more energy-related infrastructure such as power plants, energy storage, and distribution infrastructure. Hence, energy-efficient technologies for less energy consumption in buildings would help offset the demand for more power and its cost.

The national action plan for energy efficiency has established several goals of achieving all cost-effective energy efficiency by 2025 , presenting ten implementation goals for states, utilities, and other stakeholders to consider achieving the goals. The benefits of achieving the set goals of energy efficiency nationally can be estimated to be more than $\$ 100$ billion 
in lowering of energy bills in 2025 than would otherwise occur, over $\$ 500$ billion in net savings, and substantial reduction in GHG emissions [7].

This research can contribute to achieving a few of the goals, such as establishing costeffective energy efficiency as high-priority resource, implementing advanced technologies for reduction of energy usage by identifying ineffectiveness in the BEMS system, and help to achieve the energy efficiency potential of the building.

\subsection{Energy Management in Buildings}

Energy management in a building is one of the branches of the engineering discipline of building services. An effective program of energy management ensures that the energy in a building is used efficiently. Savings made on annual energy bills from energy management systems can be significant. Energy management in building consumption and conservation is an essential concern for both occupants and building managers. The building's energy consumption mainly includes heating, cooling, lighting, and domestic hot water. Equipment at the facility is only powered through the energy management system when necessary. This eliminates the redundant use of utilities that are not occupied all around the clock for many installations, such as heating, lighting, and cooling buildings. By optimizing the use of controls and enhancing the ability to change comfort and air quality throughout the building, the current mechanical system of the building can be improved. Therefore, when necessary, using equipment and reducing idle energy use, the energy management system can extend the life of the energy-consuming systems of the building and also reduce the cost of maintenance.

\section{a) Ways of Managing Energy Consumption}

Typically, there are three different methods for the management of energy consumption in a building. The three methods are:

\section{i) Energy Conservation:}

Energy conservation refers to decreasing the energy consumption of the building by eliminating the wastage of energy. For instance, avoiding high demand charges on the electric utility bills by effectively scheduling the operations of energy-consuming 
equipment. Energy conservation can be achieved either through the economy or through more rational use.

\section{ii) Energy Recovery:}

Energy recovery refers to reutilizing of byproduct energy from one system as input energy in another system. This results in a reduction in the total energy consumption of the building. For instance, using waste heat from a boiler combustion process to heat the building's water supply.

\section{iii) Energy Substitution:}

Energy substitution refers to replacing the usual energy source with a more economical source of energy. For example, in locations where the electrical demand rate is very high, it might be more economical to use gas-powered heating systems instead of electrical heating systems.

\section{b) Energy Use Intensity (EUI)}

EUI is the amount of energy consumed (measured in British Thermal Units (BTUs)) divided by the gross conditioned area in square feet. It is used to compare the different building and energy types. When used to compare functionally similar structures, this value will show those with lesser EUI are more efficient than those with higher EUI's.

Typically, for a building, the EUI is characterized as source EUI and site EUI. Source EUI gives insight into the combination of primary energy (raw fuel, e.g., natural gas) and secondary energy (converted product like district steam or electricity) into a single standard unit. Site EUI contains a mixture of primary and secondary energy from the utility bills. Table 1.1 gives sample data of median EUIs for certain property types in the united states.

Table 1.1: Sample Data of Median EUIs in the United States [8]

\begin{tabular}{|c|c|c|}
\hline Property Type & Source EUI (MBtu/ft & Site EUI \\
\hline College/ University & 180.6 & 84.3 \\
\hline K-12 School & 104.4 & 48.5 \\
\hline Office & 116.4 & 52.9 \\
\hline Restaurant & 573.7 & 325.6 \\
\hline Supermarket/ Grocery Store & 444 & 196 \\
\hline Hotel & 146.7 & 63 \\
\hline Laboratory & 318.2 & 115.3 \\
\hline
\end{tabular}




\section{c) Benchmarking}

Benchmarking is a technique used to determine whether a building consumes more or less energy than its peer buildings with similar sizes, occupancies, and climatic conditions. Benchmarking is typically performed by calculating the total energy use of the building (usually taken in MBtu) and dividing it by the entire building's gross floor area. This number is known as EUI. This energy benchmarking tool is beneficial since the facility can pursue energy auditing more effectively after knowing which buildings are inefficiently consuming energy. Many benchmarking tools can track more than just energy, such as water usage, greenhouse gas emissions, and waste and materials.

\section{d) ENERGY STAR}

ENERGY STAR is a program run by the U.S. Department of Energy (DOE) and the U.S. Environmental Protection Agency (EPA) that promotes energy efficiency. It provides simple, credible, and unbiased information that businesses and consumers rely on to make well-informed decisions. To deliver cost-saving energy efficiency solutions and improve air quality and protect the climate, thousands of commercial, industrial, local organizations partner with U.S. EPA. Since 1992, ENERGY STAR and its partners have helped businesses and American families conserve more than 4 trillion $\mathrm{kWh}$ of electricity and reduce over 3.5 billion metric tons of greenhouse gas [9].

The resources and tools available in ENERGY STAR help businesses identify costeffective plans to utilize energy in their plants and buildings. This has helped private sectors to save energy, increase profits and strengthen their competitiveness. ENERGY STAR Portfolio Manager is an online tool used in benchmarking the building in terms of its energy, water usage, waste and material, and greenhouse emissions. EPA's ENERGY STAR tools for industrial plants consist of industry-specific Energy Performance Indicators (EPIs) that deliver information to businesses to make intelligent investment decisions [9].

\section{e) Building Energy Codes}

Building energy codes are regulatory standards that specify minimum standards for energy efficiency for commercial and residential building sectors. These codes commonly 
mandate specific characteristics regarding energy efficiency in building technologies. However, it can be voluntary as well. The building technologies and design elements incorporated in building codes are the lighting system, the building envelope, the service water heating system, and the HVAC system.

The building sector in the U.S. accounted for about 39\% (38 quadrillion BTUs) of primary energy consumption in 2016 [10]. To bolster the reduction of energy consumption in the building sector, specific energy codes are set that define the minimum energy efficiency standards for the building design elements and technologies. With an effective implementation plan, these codes can enhance energy cost savings, improve air quality, and reduce greenhouse emissions.

The U.S. does not have a national energy code or standard, so the energy codes are adopted at the state and local levels of government. Due to this, the regulations in places vary widely. The U.S. DOE maintains information on adopted energy codes and assists localities and states in adopting and enforcing them. The most commonly adopted energy codes are International Energy Conservation Code (commercial and residential buildings) and ANSI/ASHRAE/IES Standard 90.1 Energy Standard for Buildings Except Low-Rise Residential Buildings (commercial buildings). Some jurisdictions, like California, have developed their own energy codes [11].

\section{Operational Characteristics of Building}

There are various operational characteristics of a building that come into play when deciding the potential energy-saving opportunities. Determining the most relevant factor to a building and performing a sensitivity analysis to know which has a significant impact on energy-saving potential is imperative for a successful energy management system. It is also crucial to achieving the desired savings to correctly set these operational characteristics according to the required comfort and environmental conditions. Some of the building operating characteristics are further discussed below:

\section{a) Building Envelope}

The foundation, walls, roof, and windows of a building couple the interior environment of the building with the exterior environment in a complex manner. How heat and moisture 
flow in and out of the structure depends on the insulating properties of the building envelope and the quality of construction. Other factors like the color of the building envelope and various other optical properties play a role in determining the reflection of the sunlight and radiation of thermal energy by the building. The energy and light from the sun enter the building through the windows. However, almost $60 \%$ of the heating load in the commercial construction and $50 \%$ of the heat load in the residential building results from the flow from the foundations, walls, and roof [12].

\section{b) Windows and Skylights}

An ideal window can be considered a window that would provide required lighting levels without any glare, allow infrared light to enter for heating but block if it adds to the cooling load, high level of thermal insulation, and block ultraviolet light. Windows should be considered a practical part of maintaining the building's climate control and lighting system. There has been significant innovation in window glass that decrease the reemission and absorption of infrared light, improvement in thermal conductivity (e.g., filling gaps between panes of glass with xenon, krypton, argon, use of multiple glass panes, and improved design of frame), and improvement in visibility using low-iron glass.

\section{c) Building Foundations, Walls, and Roofs}

The control of the flow of air, heat, and moisture is also affected by the building's foundation, walls, and roofs. Their optical properties affect how the structure absorbs the heat and how it radiates back to the atmosphere. An ideal material should be light, thin, easy for installation, and should deliver opportunities for adjusting its resistance to the flow of moisture and heat. Generally, flexible insulation materials with good resistance value (R-value) are expensive and primarily used in industrial applications. Current technologies do not allow the dynamic control of the performance of the building insulating material performance. For example, when there is more load on the air-conditioner, the roof should reflect the sunlight instead of absorbing it. Future research should be greatly focused on a building near to ideal building insulating materials with dynamic control. 


\section{d) Lighting}

An essential element in the appeal and safety of the interior, as well as exterior spaces, is the quality of lighting. About $6 \%$ of all U.S. energy consumption and $18 \%$ of U.S. electricity consumption deliver power to interior and exterior lightings [12]. There has been significant improvement in lighting technology, allowing users to control the lighting system's color and intensity, matching the existing lighting system performance using less energy, and operating for decades without any replacement or maintenance. Lighting and good building design, lighting devices, lighting sensors and controls, windows and window covering technologies play an essential role in the efficiency and the quality of the lighting system. A good light design can match the required lighting level according to the nature of the work, such as detailed results might require intense task lighting while a low level of illumination may suffice in the hallways. It is also necessary to critically evaluate the use of daylighting instead of using lighting devices since it will have a considerable impact on the heating and cooling loads. Further, appropriate use of sensors, scheduling of the lighting control, using technologies that can dim the light level according to the intensity of light provided by the daylighting, or using energy-efficient lighting equipment where appropriate can also make the lighting system more efficient consume less energy.

\section{e) Heating, Ventilation, and Air-conditioning (HVAC) System}

Heating, ventilation, and air-conditioning systems contribute a significant part to the building energy consumption. The design of the HVAC system depends on several factors such as the climatic condition, requirement of indoor conditions, outdoor weather condition, availability of materials and resources, economic feasibility, and user comfort level. It is imperative to design the HVAC system as it can directly affect the user's comfort and health.

Some standards typically require different rates of minimum ventilation depending on the density of occupant and space use. However, the increased ventilation rates mean more energy consumption as the outside unconditioned air must be heated or cooled, removed, or add moisture according to the user's comfortless level. Many measures can be adopted to decrease the energy consumption for the ventilation system, such as using natural ventilation where possible, reducing the leaks in the ducts and building shell, using 
advanced sensor and control system for providing ventilation only when and where it's needed, using efficient variable speed motors and using heat and moisture exchange devices.

Even though the building being well-designed can reduce the cooling and heating load, there will always be the requirement to condition the air. The fresh air needs to be brought inside the building to maintain the indoor air quality (IAQ). There are distinctly two operations during space conditioning: decreasing or increasing the temperature of air (change in sensible heat) and humidifying or dehumidifying the air (change in latent heat). The heating system usually needs to be integrated with humidification and cooling with dehumidification because the warmer air can also contain more moisture. Conventionally, furnaces and heat pumps are used as air heating equipment. However, in a large commercial building, boilers heat the water, passed through coils where the air is blown that transfers the heat into building spaces.

\section{i) Cooling System:}

The air conditioning system is responsible for both cooling the air as well as removing moisture. Conventionally, vapor-compression refrigeration systems are used to condition the air. Most residential systems with a smaller system usually move the conditioned air, but the large commercial building transfers heat from the water to air closer to the occupied space by using central chillers to cool the air. Dehumidification involves removing moisture from the air by inefficiently cooling the air to condense the moisture present in the air and then heating the air to the required temperature. Efforts in efficiently heating or cooling air and efficiently removing the moisture from the air are required for improving the HVAC system.

\section{ii) Heating System:}

Heat pumps are generally used for heating where the availability of natural gas is scarce. Heat pumps have the advantage of lowering the initial costs of the HVAC system as they can provide both heating and cooling with a single unit. Several heat-pump technologies can enhance the efficacy of the system and eliminate refrigerants with high GWP. These heat pumps use vapor-compression with water, $\mathrm{CO}_{2}$, ionic liquids, and various combinations as working fluids. 


\section{Modern technologies for enhancing operational characteristics of buildings}

Innovators ranging from small venture-supported firms to large global companies are contributing considerably to improving the functional features of the building such that modern facilities become more energy efficient. Some of the contemporary technologies in the field of building energy technologies are discussed in Table 1.2.

Table 1.2: Modern development in the field of building energy technologies [12]

\begin{tabular}{|c|c|}
\hline Area & Modern developments \\
\hline Windows and Skylights & $\begin{array}{l}\text { - Low emissivity, glazing windows, improved framed } \\
\text { design (R-value up to 8.1) } \\
\text { - Light transmittance of } 0.71 \text { and solar heat gain } \\
\text { coefficient (SHGC) from } 0.29-0.62 \text {. }\end{array}$ \\
\hline $\begin{array}{l}\text { Buildings Walls, Roofs, } \\
\text { and Foundations }\end{array}$ & $\begin{array}{l}\text { - Reduce cooling loads in the building and lengthen the } \\
\text { life expectancy of roofing materials. }\end{array}$ \\
\hline $\begin{array}{c}\text { Ventilation and Air } \\
\text { Quality }\end{array}$ & $\begin{array}{l}\text { Development of materials that can be sprayed into } \\
\text { existing ducts to seal leaks from the inside. } \\
\text { - Development of sensors and controls for improved } \\
\text { economizer operation. } \\
\text { - Use of advanced sensors such as } \mathrm{CO}_{2} \text { sensors for } \\
\text { demand-controlled ventilation. } \\
\text { - Use of efficient, variable speed motors. }\end{array}$ \\
\hline $\begin{array}{l}\text { Space Conditioning } \\
\text { Equipment }\end{array}$ & $\begin{array}{l}\text { Development of heat pump technologies that increase } \\
\text { system efficiency. For instance, closed-loop } \\
\text { geothermal heat pump systems reach relatively high } \\
\text { COP ranging } 2.9 \text { to } 4.9 \text { for heating efficiency at } 32^{\circ} \mathrm{F} \\
\text { inlet water temperature and } 10.6 \text { to } 27 \text { EER for } \\
\text { cooling efficiency at } 77^{\circ} \mathrm{F} \text { inlet water temperature. } \\
\text { Moreover, open-loop geothermal heat pumps reach } \\
\text { COP ranging from } 3.1 \text { to } 5.5 \text { for heating efficiency at } \\
50^{\circ} \mathrm{F} \text { water inlet temperature and } 11.8 \text { to } 31.1 \text { cooling } \\
\text { efficiency at } 59^{\circ} \mathrm{F} \text { water inlet temperature [13]. } \\
\text { Improved ways to control moisture transfer into and } \\
\text { out of buildings using membrane technologies. }\end{array}$ \\
\hline Lighting & $\begin{array}{l}\text { - High-efficiency LEDs } \\
\text { - } \quad \text { Advanced sensors and controls for lighting } \\
\text { - Lower cost retrofit solutions for lighting fixtures. }\end{array}$ \\
\hline Thermal Storage & $\begin{array}{l}\text { - Chillers store cooling capacity by pre-cooling chilled } \\
\text { water during night hours and shutting off the vapor } \\
\text { compression systems during peak cooling demand in } \\
\text { the afternoon. } \\
\text { - Use of solar or wind energy systems for shifting the } \\
\text { energy demand away from peak periods. }\end{array}$ \\
\hline
\end{tabular}




\begin{tabular}{|c|c|}
\hline Area & \multicolumn{1}{|c|}{ Modern developments } \\
\hline - & $\begin{array}{l}\text { Control room temperature, ventilation rates, } \\
\text { humidity, dimmable lights. }\end{array}$ \\
- & $\begin{array}{l}\text { Sophisticated adjustment of the operation of } \\
\text { appliances rather than just on or off state. }\end{array}$ \\
System-level & Use of weather forecast to develop optimum \\
& strategies for cooling or preheating the building. \\
Use communication capabilities from utilities to \\
adjust to optimum rate structure to minimize the \\
overall costs.
\end{tabular}

\subsection{Building Energy Management System (BEMS)}

Building Energy Management Systems (BEMS) are computer-based systems that aid in managing, controlling, and monitoring the building technical services and energy consumption by devices used in the building. The system also helps to provide the information crucial to building managers for understanding the energy consumption of the building and better control the building's energy performance. The sector of BEMS is burgeoning as corporations realize that it is one of the most effective ways for optimizing the energy efficiency in a building which helps to provide the quick win. BEMS was typically considered most beneficial for large buildings since the return on investment (ROI) from the installation would be relatively high for those buildings. But, due to advancements in technologies, the BEMS system can be cost-effectively installed even in smaller buildings and extend the savings significantly.

The expression BEMS is now and again utilized with Building Management Systems (BMS). However, BMS can be used to monitor and regulate a broad scope of building frameworks, including fire, smoke recognition, and alerts, movement indicators, closedcircuit television (CCTV), security, and access control lifts. BEMS relate explicitly to energy-related frameworks. For instance, during a demand response event from a utility company, a BEMS can receive that external signal from the utility company and send control signals to building systems accordingly. To extenuate the overall load in the design, BEMS may control the lighting system to dim in specific areas, adjust the temperature setpoints, and potentially move from utility generation to a battery storage system.

The ability to save energy and enhance productivity by creating a comfortable working environment is the critical attribute of BEMS. However, to ensure that desired energy 
management benchmark is met, regular building energy audits and fine-tuning are imperative. The optimization of BEMS depends on various factors such as the architecture of the plant, operator, zoning, level of controls, and the nature of the environment to which the system is being applied. There are several advantages of BEMS installation, which are discussed below:

- Energy-saving control functions that will reduce energy bills (e.g., weather compensation).

- Provision of events or quality information about the plant status in real-time.

- Identification of maintenance requirements for both planned and unplanned conditions (e.g., the number of hours a motor has run or the filter on the air supply which has been blocked can be easily identified with the help of the system).

- During equipment failure conditions or violation of the standard requirements, the alarms can be automatically generated, showing the time and reason for the discrepancy in the system.

- Ability to $\log$ and archive data as well as show the trend of current energy consumption.

- Close control of ambient conditions, providing better comfort for occupants.

- Ease of expansion to monitor and regulate the energy consumption of buildings, plants, or spaces.

\section{a) Components of BEMS}

BEMS is comprised of various layers of the infrastructure. Numerous field devices are connected to the BEMS system either through a wireless or wired medium. Some examples of field devices are HVAC systems, lighting devices, sensors and actuators, individual machinery, ventilation systems, refrigeration units, hot water systems, and heat pumps. The optimum control of these field devices is achieved by advanced building and predictive analysis of information obtained from weather data, historical building performance data, and occupancy data.

Generally, there is at least one central station or principal operator position. Some various other remote outstations or controllers are connected to the central station. The user preferences set by the user are stored in the system and processed to control the systems 
accordingly. Also, the real-time data of the building state is continuously sent to the BEMS. These data are used for the optimum control of the building systems. A schematic diagram of a typical BEMS is shown in Figure 1.4 below:

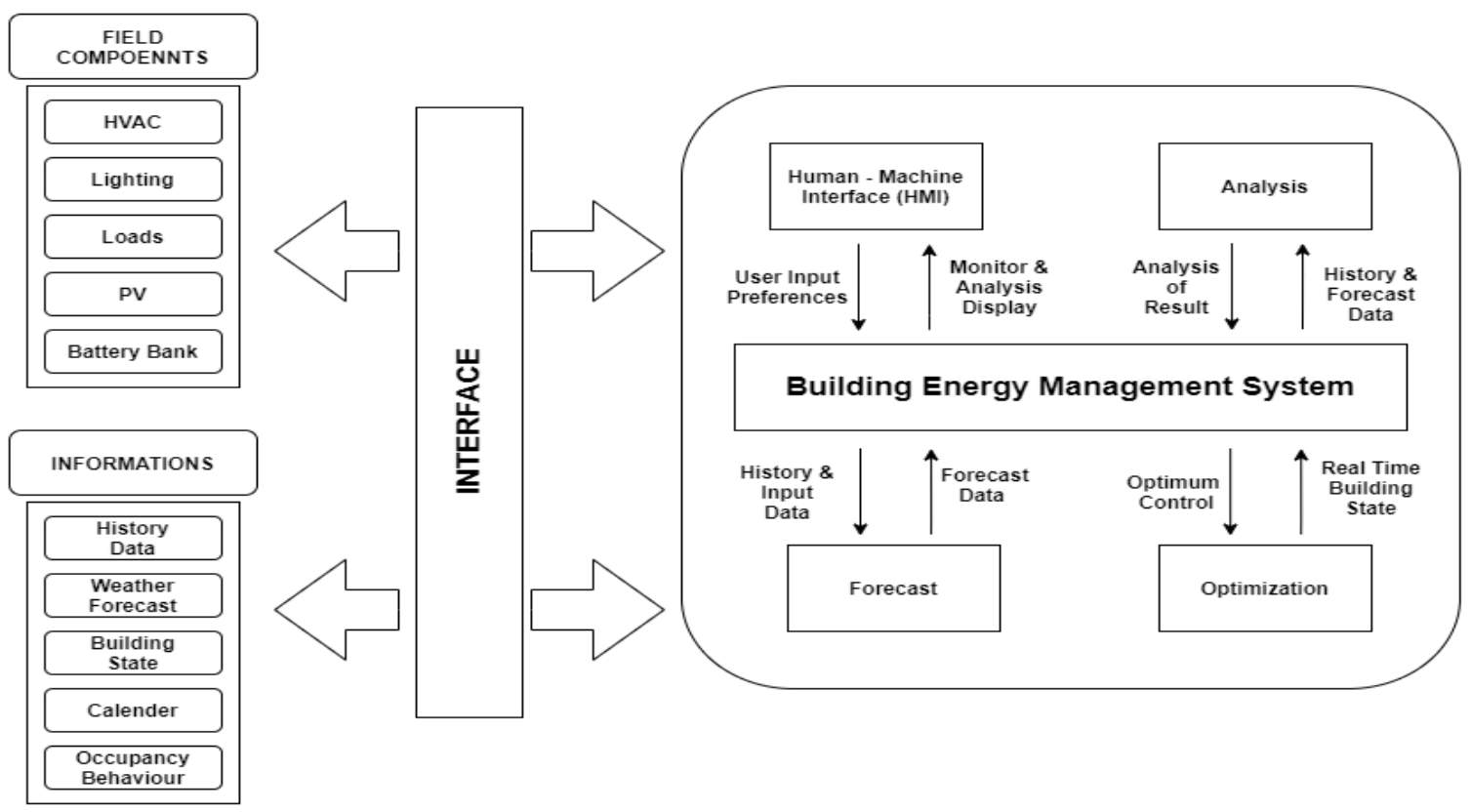

Figure 1.4: Components of BEMS [14]

\section{b) Features of BEMS}

There are various types of BEMS available to meet the varying needs of different building types. The same energy management system will not work efficiently for all kinds of buildings. Depending upon the specific condition of the building, the BEMS of a suitable function should be selected. The few main features that a BEMS might include are:

\section{Advanced building analytics:}

With this element, the BEMS can evaluate the energy performance of the building by utilizing in-depth recorded data and real-time data. The performance issues can also be resolved automatically with the help of this function.

\section{Advanced metering infrastructure analysis:}

With the help of this feature, the system can collect Advanced Metering Infrastructure (AMI) data from a utility company at specific intervals of time. By analyzing these data, one can understand the needs and pattern of energy consumption of the building. 


\section{Automated demand response:}

This function of BEMS helps to reduce the peak load/demand of the building automatically. The peak demand reduction is achieved by automating various building system components such as lighting and thermostat settings.

\section{Energy consumption benchmarking:}

This function helps to evaluate and compare the current energy consumption pattern with the historical energy data. This will help to understand the ongoing performance of the building better.

\section{Automated building control:}

This function of BEMS makes it easier to control the system components of the building. It allows the system to interact with the field devices and system in the building effectively. Hence, effective management can help prevent the wastage of energy by optimizing the system performance on a real-time basis.

\section{Measurement and verification:}

This function allows the user to measure various system components of BEMS and ensure that the desired results are achieved. Further, by evaluating the energy efficiency measures, the user can also determine the ROI.

\section{c) Factors to Consider Before Installing a BEMS}

Each building has specific needs for energy management, which means that some functions of BEMS might be redundant or lacking to the requirement of building needs. Hence, to determine various factors for the installation of BEMS, the following things can be considered:

\section{Size of Building:}

A sophisticated BEMS that has a wide variety of features may not be required for smaller buildings. There are specific features that should be considered depending upon the size of the building. For instance, smaller-sized facilities can benefit most from the BEMS, which offers a primary energy information portal, provides historic billing analysis, information on incentive availability, provides educational, behavioral, and basic retrofit suggestions. A BEMS that includes energy monitoring, retro and continuous commissioning, 
maintenance and trouble ticket management, advanced metering infrastructure data analysis, and retrofit program suggestions might benefit medium-sized buildings. Finally, for large-sized buildings, features such as advanced building and predictive analytics, automated demand response integration, building optimization, continuous optimization, and automated building control might be helpful in the management of the energy of the building [15].

\section{Location of the Building:}

The consumption of energy by the building heavily depends upon the climatic condition where the building is located. If a building is located in a climatic region that experiences extreme temperature changes, a BEMS that can deal with such weather-related energy effects should be installed. This encompasses advanced field sensors to deal with such climatic influences and the system's sensitivity.

\section{Number of Buildings:}

The number of the buildings also determines what type of BEMS is essential. A BEMS that can compare and summarize energy data from each site can benefit energy management for a multi-building purpose. Also, the level of controls that the BEMS can offer should be determined according to the number of buildings for energy management.

\section{Use of Building:}

Different types of buildings are used for various purposes. For example, a hospital requires more controls for maintaining the quality of air than a warehouse. Furthermore, the occupancy level can also vary depending upon the building type. Hence, the BEMS should be used to meet the building purpose's requirement and maintain comfort to the occupants in the building.

\section{d) Potential Energy Saving Measures from BEMS}

Some of the potential energy cost reduction measures that the installation of BEMS can achieve are discussed below:

- HVAC and lighting systems scheduling to meet building occupancy schedules

- Adjust set-point of Discharge Air Temperature (DAT) for an Air-Handling Unit (AHU) based on Outside Air Temperature (OAT) 
- Adjust start-time of an AHU based on OAT

- Avoid simultaneous heating and cooling of air in summer

- Lower the duct static pressure setpoint for AHUs

- Adjust HVAC equipment schedule to match the building occupancy

- Adjust the chilled water supply temperature (CHWST) based on OAT

- Lower the amount of outside air introduced to the building by using Demand Controlled Ventilation (DCV)

- Optimize economizer operation

- Lower the Condenser Water Supply Temperature (CWST) set-point for the Cooling Tower (CT)

- Repair leaking chilled water / hot water valves on the AHU coils

- Isolate areas by closing off the isolation dampers during unoccupied periods

- Utilize multiple chilled water pumps

- Utilize multiple supplies and return fans on an AHU

- Lower the differential pressure setpoint for chilled water pumping system during lower cooling demand at night

\subsection{Artificial Intelligence (AI) for Self-learning Systems in BEMS}

The consumption of energy can be reduced through AI by improving reliability, better control, and automation. AI can help overcome the challenges in developing energyefficient buildings by increasing the rate of energy savings, facilitating on-site generation, detecting and minimizing operation faults, and controlling and ensuring continued energy savings.

A consistent challenge with buildings connected with hybrid micro-grids is the destabilization of the power supply generated from weather-dependent energy sources such as solar and wind. An AI-based approach can extract a combination of data from local satellite, meteorological stations to provide a precise hour-ahead estimation of weather conditions, including temperature, wind, lighting density, and humidity. This helps in balancing the energy supply and demand in intelligent buildings. For example, places that face electricity supply restrictions during heat waves could be problematic for building on hot summer days when the offices need air conditioning to maintain thermal comfort 
conditions inside building spaces. A power-savings programmed platform will ensure that the potential blackout does not disrupt services. Predicting upcoming energy shortages, the system will cool the building more in the morning to require less energy during the day.

Furthermore, AI helps monitor, collect information, control, evaluate, and manage energy consumption in buildings. It controls energy consumption, reduces it during peak hours, identifies and signals problems, and detects equipment failures before they occur. For instance, based on past data, the system will know that the temperature rose as the day progressed despite a chilly start to the day. Based on the latest weather forecast, it might decide that the solar heat gain will be sufficient to heat the building during the day. Then, while the sun is shining, the BEMS may allow up to one degree of overheat. The additional warmth will remain unnoticeable for the users as it will be stored in the elements of the building structure and office furnishings and be redeployed to warm up the building as temperature dips after sunset.

\subsection{Role of Historical Data in Energy Efficiency Controls for the BEMS}

The historical data obtained from the BEMS has the utmost importance in optimizing energy consumption in buildings. The past data can determine the nature of energy consumption and peak loads at different periods. Based on the load requirement, oversizing or under-sizing of the energy-consuming equipment can be avoided. Furthermore, past data can help develop algorithms that can predict the occupancy behavior in a building. This can be a significant improvement in the controls regarding energy consumption based on a prediction of occupancy level.

Moreover, any anomaly in the heating or cooling system in the building through the available data can also be analyzed. We could monitor how effectively the BEMS controls are working in the building. For instance, by analyzing the temperature profile of the spaces in the building, we can know whether the temperature setback controls are working correctly or not. In addition, by monitoring the data from the static pressure and supply fan status, we can know where the control system for the ventilation system is working as intended or not. Similarly, we could utilize the building energy management system's trending capabilities to monitor other parameters such as OAT, outdoor-air damper position signal (OAD), and DAT. 
We could investigate whether the controls for the night and weekend setbacks for unoccupied hours are working correctly by analyzing the past data if the cycling of supply fan is correct during occupied and unoccupied hours, the OAD position at different periods in a day. We could fine-tune the controls to enhance the energy savings and enhance the working life of the equipment used in the energy consumption of the building.

\subsection{BEMS Parameters to be Studied}

As discussed in section 1.4.2, BEMS can have various features based on the varying needs of different building types. Depending upon the BEMS system, it can have multiple control parameters to help the user attain better control over the operational aspects of the building. This study focuses on various BEMS parameters that aid in the reduction of HVAC energy consumption of the building while maintaining the thermal comfort to the users and IAQ as required by ASHARE Standard 62.1-2019. The parameters used in this study are described below in brief.

\subsubsection{Demand Controlled Ventilation (DCV)}

$\mathrm{DCV}$ is an energy-saving control strategy that minimizes the rate at which the air from outside is delivered to a zone during periods of partial occupancy. The ventilation rate at a particular zone of a building varies based on the number of people currently in the given zone. The main aim of DCV is to save energy and not to improve the IAQ. This ventilation strategy is required for spaces with spaces larger than $500 \mathrm{ft}^{2}$, with a design occupancy for ventilation of more than 25 people per $1,000 \mathrm{ft}^{2}$, and the total system design outdoor airflow greater than $750 \mathrm{cfm}$ according to ASHARE Standard 62.1 - 2019. Common technologies used for DCV are occupancy schedules, people counters, occupancy sensors, and $\mathrm{CO}_{2}$ sensors. Table 1.3 discusses the selection of the control approach for the DCV.

Table 1.3: Control Selection for DCV [16]

\begin{tabular}{|c|c|c|}
\hline Control Approach & Occupancy Level & Variation in Population \\
\hline Occupancy Schedule & Predictable & Low or Highly variable \\
\hline People Counter & Any & Highly variable \\
\hline Occupancy Sensor & Low-density & Minimal \\
\hline $\mathrm{CO}_{2}$ sensor & High-density & Highly variable \\
\hline
\end{tabular}




\subsubsection{Zoning Control}

A cost-effective way for energy savings in a building is through zoning the building spaces. A building has different types of rooms used for various purposes. For example, typically, a conference room in a building is not used daily, so there is no need to heat or cool the space when there is no occupancy. The zoning system can help separate these different rooms and only condition the air of that space when the occupancy is expected. This helps to reduce the HVAC energy consumption significantly.

A series of motorized dampers are present in the zoning system that controls the cool or warm air entering a specific zone. A bypass system diverts the excess conditioned air to another zone, common building areas, or return air system. An individual thermostat is present in each zone responsible for maintaining each zone's temperature according to the user set temperature settings.

\subsubsection{Temperature Setback Control}

Over $50 \%$ of the energy used in the building is used for space heating and cooling [17]. Enabling temperature setback control when the building is not occupied is one of the most cost-effective ways to reduce energy consumption. Generally, thermostats are set between $72^{\circ} \mathrm{F}$ to $78^{\circ} \mathrm{F}$ for cooling and $65^{\circ} \mathrm{F}$ to $70^{\circ} \mathrm{F}$ for heating. These settings vary based on the building owners' specific policies, the air tightness of the building, the age of occupants, and activity level. DOE projects an energy cost reduction of $5 \%$ to $12 \%$ with a $3^{\circ} \mathrm{F}$ to $10^{\circ} \mathrm{F}$ setback of temperature [18]. There are various programmable thermostats available in the market for varying the temperature of a building automatically based upon the use of a building.

\subsubsection{Supply Air Temperature Reset (SATR) Control}

SATR control plays an imperative role in the consumption of energy in a building. During the winter season, the air is supplied at high temperatures, and during the summer months, the air is supplied at low temperatures from the HVAC unit. The space in the building consists of various loads such as sensible and latent loads from people, plug loads, and the external environment. To maintain the room at thermal comfort, the air is supplied at a specific temperature. The provided air diffuses with the air in the space, reducing the sensible and latent loads. 
These sensible and latent loads are not constant at every period. When the space occupancy is low, the sensible and latent loads gained from the people are also low. Similarly, the sensible load accumulated from the plug load is also minimum during the low occupancy period. Furthermore, the external loads also change depending upon the external weather conditions. Hence, changing the supply air temperature (SAT) in the space depends on varying load conditions. Therefore, by adjusting the SAT to the room to meet the thermal comfort conditions, the energy used for heating or cooling the supply air can be conserved.

To attain various levels of SAT, the approach can be different for different types of systems. A brief process on how the SAT can be varied for multiple types of HVAC systems is discussed below:

CWST Reset: The buildings using chilled water for cooling the building spaces can program the controls such that based on the load on the building, the chilled water supply temperature is adjusted. In cooler months, increasing the chilled water supply temperature makes logical sense if the cooling load is less than the design load. Within a building's HVAC system, the chilled water supply is sent to the building's AHUs, which use the chilled water to achieve the set points on how cold the SAT needs to be. The system works in a loop, so when the water returns from the AHU to the chiller plant, the heat exchanger does not have to work as hard to reduce water temperature if the set point of water supply temperature has risen. This approach lessens the workload and energy consumption of the compressor. Different variables such as energy pricing, occupant behavior, and weather forecasts can be used to adjust the required setpoints for reducing energy consumption such that the thermal comfort is attained without violating the manufacturer's operational guidelines of the chiller system.

When adding a reset schedule for discharge air, the order of variable dependence should be zone conditions, return air temperature, and then outdoor-air temperature [19]. When basing the reset schedule on zone conditions, the system should calculate the warmest zone temperature, coolest zone temperature, and average zone temperature (when the AHU serves more than ten zones). For AHUs with fewer than ten zones, resetting the dischargeair temperature should be based on the return-air temperature and outdoor-air temperature. 
In this thesis, since there are less than ten zones, the SAT is adjusted based on the returnair temperature approach by evaluating the load in the specific zones.

Boiler Temperature Reset: Boiler reset is an automated algorithm that controls the temperature limit of a hot water boiler based on the outside temperature to obtain higher efficiency. A thermostat in the building signals a call for heat, causing the boiler to circulate hot water to that zone. If the circulating water is below a set limit, the burner will fire, heating the water in the boiler to a temperature limit set point. When this limit is reached, the burner shuts off, and hot water will continue to circulate until the demand for heat from the calling thermostat is satisfied. This may involve several burners on/off cycles. This process works effectively when it's $20^{\circ} \mathrm{F}$ outside and the heating load is considerable inside the zone, but the scenario is different when it is $65^{\circ} \mathrm{F}$ outside. In this case, with the limit set to $180^{\circ} \mathrm{F}$, the demand might satisfy in a single burner cycle that, by sending all that $180^{\circ} \mathrm{F}$ water into the zone, may overshoot the desired temperature, wasting heat. Furthermore, when the boiler shuts down, it may still have a large amount of heat generated in the heatup cycle, while it will simply dissipate as the boiler cools to ambient temperature.

By adding a reset control to this system, the boiler temperature limit can be automatically controlled based on specific parameters such as return air temperature and outside air temperature to match the energy supply to the anticipated demand. For example, in a $65^{\circ} \mathrm{F}$ day, perhaps the controller will limit the boiler to $140^{\circ} \mathrm{F}$. The system may need more than one cycle to satisfy the demand at this temperature, but these cycles will be much shorter and less likely to overshoot the desired zone temperature. Also, less heat will be wasted in the final cool down since the boiler begins at a lower temperature.

Variable refrigerant flow (VRF) system: The basic principle of operation of the VRF system is that it varies the flow of refrigerant to the indoor units based on the demand. This ability to control the flow of the refrigerant makes it an ideal system for the building where zoning is required. In a VRF system, multiple indoor units are connected to one outdoor unit. The outdoor unit has one or more inverter compressors that can vary their speed by varying the power supply frequency to the compressor. This change in speed of the compressor results in a difference in the amount of refrigerant flow delivered by the compressor. A metering device is connected to each indoor unit that sends demand to the 
outdoor unit, which provides the amount of refrigerant flow based on need. Hence, by varying the flow of the refrigerant to the zones based on the load, the temperature of the supply air can be controlled.

Rooftop VAV Systems: These systems provide comfort in a wide range of building types and climates. This system consists of a packaged rooftop air conditioner that serves several individually controlled zones. Each zone has a VAV terminal unit that is controlled by a temperature sensor in the zone. It is tempting to raise the SAT at a part-load condition in a VAV system to save compressor and reheat energy. Increasing the SAT reduces compressor energy because it allows the compressor to operate at a warmer suction temperature. When considering using SATR in rooftop VAV systems, it is essential to analyze the system to determine if the savings in compressor and reheat energy will outweigh the increase in fan energy. For interior zones with near-constant cooling loads during occupied periods, the design airflows for those zones based on the warmer reset SAT should be calculated. While this may require larger VAV terminals and ductwork, it allows the use of SATR during cooler weather while still providing the necessary cooling to those weather-independent interior zones. The air distribution system design or lowpressure losses is also essential that use the fan-pressure optimization strategy to minimize the fan energy penalty that accompanies a warmer SAT [20].

Dedicated Outdoor Air System (DOAS): The zone reset of SAT control strategy for a DOAS combines a wall-mounted zone sensor with a duct-mounted sensor to provide sensible supplemental heating or cooling to the conditioned space. The zone sensor completes a feedback loop to the controller such that the SAT setpoint is adjusted to maintain a targeted zone temperature due to changing conditions in the zone. When the system's compressor is energized, the controller will vary the amount of hot gas being rejected to the reheat coil. In the auxiliary heating mode, it changes the additional heating output. The controller varies the SAT within a fixed range (e.g., $60^{\circ} \mathrm{F}$ to $95^{\circ} \mathrm{F}$ ) to maintain a room's setpoint.

The DOAS unit becomes the first stage cooling or heating system in this strategy, with the primary air handler being the second stage. While a DOAS primarily focuses on dehumidifying and reheating the air, the unit provides a secondary benefit in the cooling 
mode. Should the space temperature rise above the setpoint, the system can switch to the cooling method and reject the resulting heat to the condenser. Because the DOAS assumes a large portion of the cooling load, the primary air handler's size can be reduced proportionally to provide second-stage cooling.

This strategy only works when modulating controls are used with the auxiliary heat source. When used with gas heating and an energy recovery wheel (ERW), they may not be appropriate with less than an 8:1 turndown ratio. (The gas heater minimum temperature must be less than the minimum part-load SAT of the ERW and the space setpoint temperature in the heating mode) [21].

\subsection{Role of Various Factors on Effectiveness of BEMS}

Several factors impact the effectiveness of BEMS. Some major factors discussed in this research are the degradation of building parameters such as building envelope condition, fan systems, ductwork design, economizer operation, and BEMS controls.

\section{a) Degradation of Building Parameters Over Time on Effectiveness of BEMS}

Different building parameters are responsible for maintaining the effectiveness of BEMS. Some of the significant building parameters are building envelope, windows and doors, and control system for DCV system, zoning system, temperature setback, SATR.

The building envelope starts degrading over the period. There could be various reasons for the degradation, such as harsh climatic conditions, inferior building envelope materials, improper design, and building insulation systems. There may arise multiple issues with poor building envelopes, such as infiltration of air and moisture and poor thermal insulation - the energy performance of the building changes with degradation in the building envelope. The HVAC system of the building consumes more energy to address

these issues. Hence, the effectiveness of the energy management system decreases. It is often a good practice to conduct a thermal performance assessment of a building in a specific time interval depending upon the type and nature of the building to assess the operational effectiveness of the building envelope.

The degradation of windows and doors occurs mainly in damaged weatherstripping, seal, interior/exterior caulking. These issues may lead to interior surface condensation and 
frosting problems in windows and doors and air infiltration. This increases the load on the HVAC system of the building and hence consumes more energy for maintaining thermal comfort. The energy management system cannot function effectively with the leaking of air inside the building. It is a good practice to inspect the sealing of the door and windows and retrofit with energy-efficient windows with features such as double, triple, or even quadruple-glazing, low-emissivity, and good airtightness.

Optimization of the DCV system contributes to an enhanced IAQ at lower operating costs. The system can only be optimized by accurate $\mathrm{CO}_{2}$ sensing. The sensing capability of the $\mathrm{CO}_{2}$ sensors does not last forever. The most common technology on the market for measuring $\mathrm{CO}_{2}$ is the non-dispersive infrared (NDIR) technology. The problem with this technology is the required light source that will lose its intensity over time and does not operate correctly when contamination of the light path has occurred. Hence, the sensors' calibration must be performed at regular time intervals to maintain the IAQ of the building. Moreover, other control systems for controlling the damper's position, speed of the fan, maintaining pressure in the air handling system also needs to be calibrated after a specific interval of time to optimize the performance of the DCV system.

The control system integrated with the thermostat in the zoning system could also deteriorate over the period. Primarily, the old thermostats do not correctly gauge the air temperature in the space due to the accumulation of dust, soot, and dirt in its internal components. Hence, the temperature of the space cannot be maintained at the user-defined setting and leads to overheating or cooling the room. Further, it can also cause frequent cycling of the HVAC system. Moreover, there are internal sensors in the thermostats that are factory calibrated to ensure accurate readings. Over time, the calibration of the sensors drifts and therefore leading to uneven temperature throughout the building.

\section{b) Fan Systems and Ductwork Design on Impact on Effectiveness of the BEMS}

Fan systems: From the fan curve chart shown in Figure 1.5, the brake horsepower of the fan motor can be determined by various levels of static pressure (in. wg), flow rate (cfm), and speed (rpm). Improper fan size selection leads to more consumption of electrical energy and decreases the effectiveness of the BEMS. 
Moreover, many HVAC systems use variable air volume (VAV) systems to provide a comparable heating or cooling effect. When the supply air temperature is lowered, a larger air volume is required to have the same heating effect. If the supply air temperature is set too high, more air is necessary to have the same cooling effect. This consumes more electrical energy from the supply fans. Hence, the effectiveness of BEMS can be negatively affected in some cases if the energy saved by varying the supply air temperature is less than the energy consumed by supply fan systems.

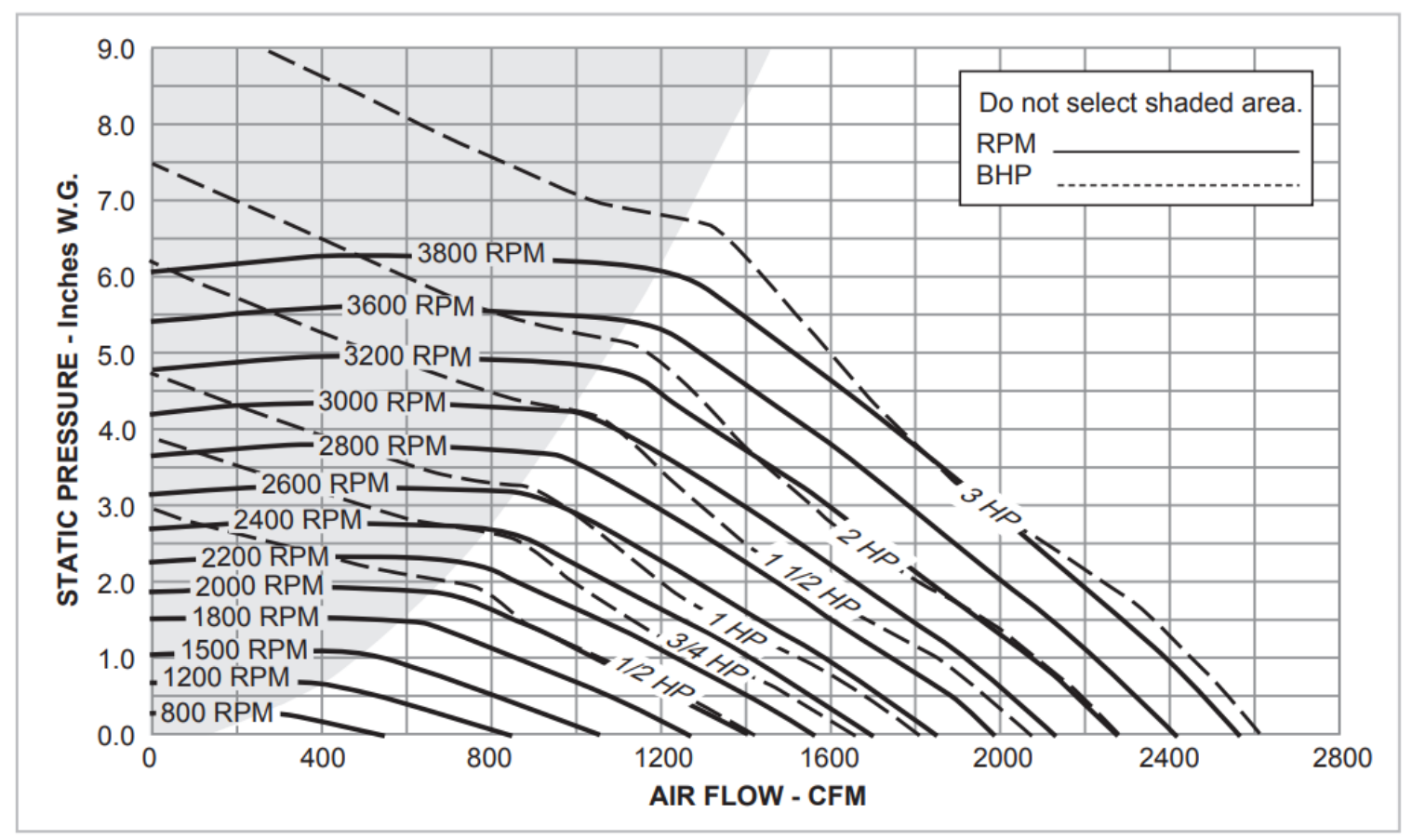

Figure 1.5: Fan curve to determine brake horsepower [22]

Ductwork Design: The ductwork design impacts the overall efficiency of the heating and cooling system. Even if the heating or cooling units are very efficient, it won't reduce HVAC energy consumption if the ducts are leaky, incorrect size, or possess some other design flaw. Because ductwork transports heated and cooled air to interior spaces, they are considered an integral part of the building's exterior and installed within the conditioned sections. This assures that any insulation flaws or air leaks will not heat or cool the unconditioned areas.

Duct dampers are an essential component of ductwork design. The dampers control the quantity of airflow to each of the conditioned areas. The choice of dampers is critical since it aids in balancing the airflow throughout the building according to the requirements. Poor 
damper design leads to unbalance airflow in the building, leading to higher energy consumption and disrupting the user comfort condition.

Correct duct sizing is just as critical as proper HVAC unit sizing. The air stream causes noise and uneven airflow if the ducts are small. The energy consumption will be higher since the blower or supply fan load will be higher to force air through the supply ducts that are too restrictive.

\section{c) Operational aspects of an economizer within the BEMS}

Economizing is the process of using outside air to cool a building. The annual hours of operation of the mechanical cooling system are reduced with this strategy. There are two types of economizers: air economizers and water economizers.

\section{Air economizer}

An air economizer is an integrated system of outside air and return air dampers, linkages, actuators, sensors, and controllers in an air handling system. The BEMS control elements automatically adjust the location of the outside and return air dampers to give $100 \%$ of the design supply air as the outside air. This also includes provision for the relief of this excess outside air to prevent the building from over-pressurization by the motorized control of relief air dampers. The air economizer control can be enabled by two methods: Dry Bulb and Enthalpy.

Dry Bulb - This method employs the standard temperature sensing in both outside and return air streams. If the outside air is cooler than the return air and cooling is necessary for the building, the BEMS control elements allow the economizer to be enabled, allowing the return air damper to be entirely closed and 100 percent of the design supply air to be supplied as the outside air.

Enthalpy - This approach is similar to the dry-bulb temperature economizer operation method. Still, it uses more precise enthalpy sensors to compare the energy content of the outside and return air streams to enable the economizer.

The control aspects can be programmed for mainly four operating modes in an air economizer system: Heating mode, Modulated economizer mode, Integrated economizer mode, and mechanical cooling mode. 
Heating mode - When the air handler is heating in the winter, the air economizer is turned off. The outside air damper is set to the lowest ventilation position to keep cold exterior air from mixing with the return air to a minimum.

Modulated economizer mode - When the air handler is cooling in the cold weather, the external air is mixed with the return air to produce a sufficient supply air temperature to condition the building. This is accomplished without the need for any mechanical heating or cooling. This is also known as "free cooling."

Integrated economizer mode - When the air handling system is cooling in warm weather, the external air temperature may be between supply and return air temperatures. The outside air damper is entirely open, the return air damper is fully closed, and the mechanical cooling system is turned on simultaneously under this configuration.

Mechanical cooling mode - The air economizer is disengaged while the air handler is cooling during hot weather, and the outside air damper is set to the minimum ventilation position. The mechanical cooling system provides all necessary cooling in this situation.

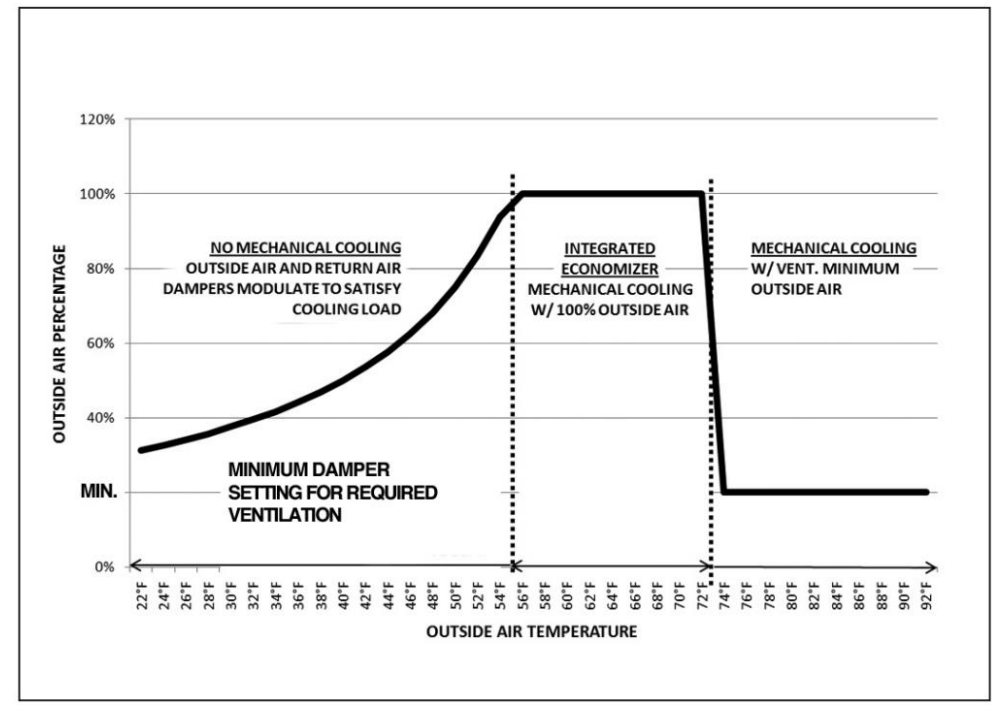

Figure 1.6: Operating modes of air economizer system [23]

\section{Water economizer}

A water economizer is a system that reduces or eliminates the need for mechanical refrigeration by cooling the return air of a cooling system directly, indirectly, or both via evaporation of water and other appropriate fluids such as glycol. Water economizers are divided into two categories: for systems with and without chillers. In both circumstances, the economizer enabling sensors to identify when the cooling tower fans should be cranked 
up to lower the fluid temperature below that of the supply air. When cold water or glycol is detected at the air handler or heat exchanger, pre-cooling valves open to maintain air temperature or chilled water supply temperature, with additional pumps running. A head pressure regulating valve may be required for refrigeration to operate appropriately in integrated economizer mode.

\section{d) Humidity Controls Through the Use of Psychrometric Charts}

The measurement of thermodynamic properties in wet air is known as psychrometrics. One of the reasons psychrometric data is critical today is traceable to the way most new buildings are heated.

Dehumidifiers must constantly compute the amount of moisture in the air that has to be removed. However, in most cases, it is operated knowing the information for dry bulb (DB) temperature and relative humidity or the DB and wet bulb (WB) temperatures. Therefore, psychrometric charts must be used to triangulate proper airflow levels.

Chart users must trace the lines of the two accessible variables and find the point where they intersect. From this point of intersection, following a horizontal line to the right leads to the volume of moisture content to be eliminated. Once the starting and ending moisture content is determined, the volume of moisture to be removed can be calculated.

Dehumidification systems operate based on these properties to optimize their moisture removal capabilities. Their design uses feedback from room temperature and humidity sensors to determine the most efficient operation mode. When the proper level of dehumidification has been reached, the system will stop removing moisture, but it will begin eliminating moisture again when it detects an increase in moisture levels.

Maintaining accurate psychrometric charts is necessary to calculate the proper volume of moisture to be removed from a dehumidification system's area of control. An adequately designed dehumidification system uses the parameters supplied by the charts in Figure 1.7 to maintain precise moisture removal levels. 


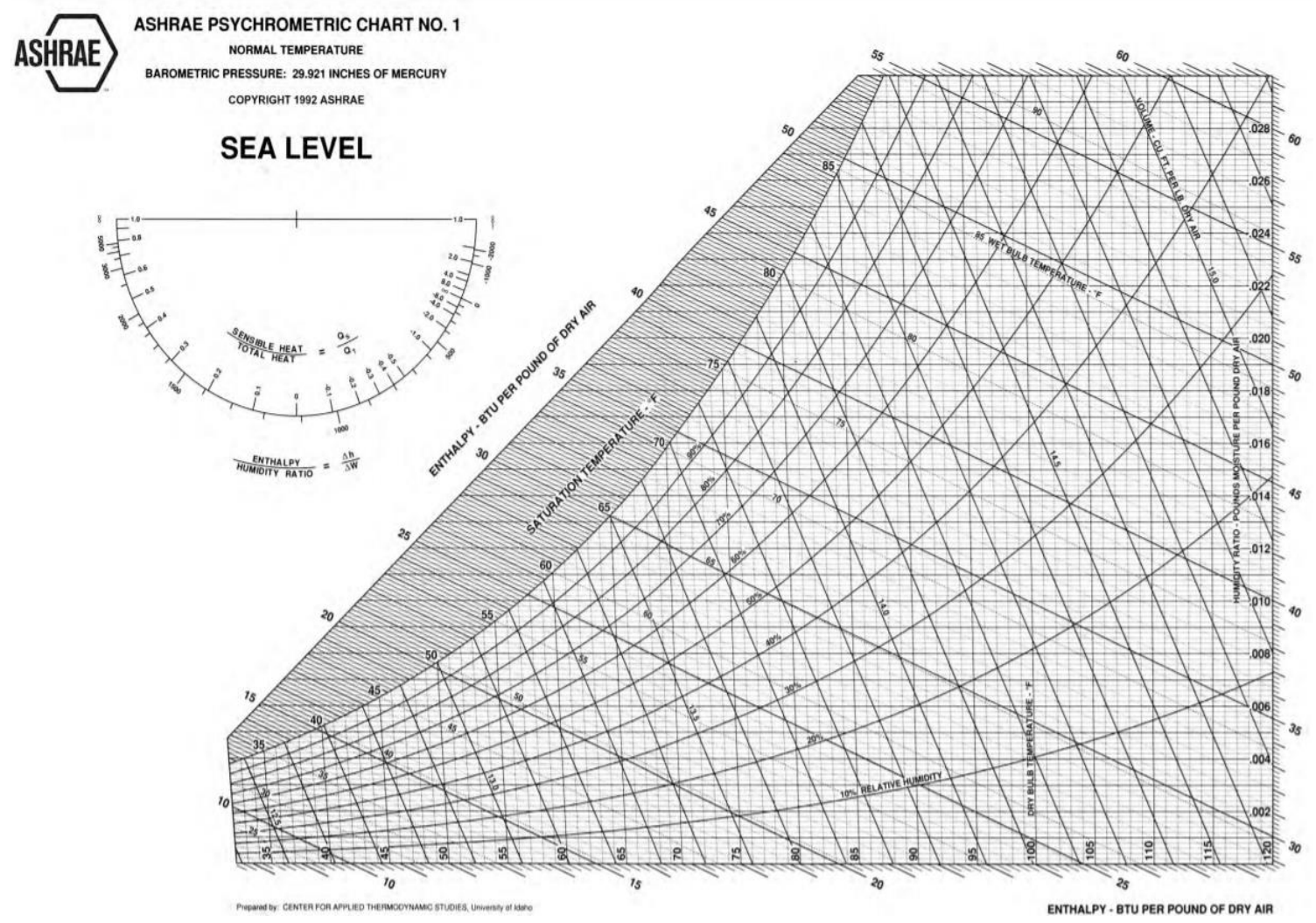

Figure 1.7: ASHRAE Psychrometric Chart [24]

\subsection{Research Motivation}

Everyone at some point in their lives has come across the term "Energy Management," particularly in recent years, where conservation of energy is getting foremost importance for the future of organizations worldwide. Due to increased fuel cost, increasingly aggressive environmental targets, and concerns over energy security, every organization is becoming competitive to reduce its operational cost. Savings in energy cost provides the organization a competitive edge to flourish in the market.

Many organizations install BEMS for the management of energy in their buildings. The reduced cost of sensors, analytics software, and data storage has made BEMS affordable to install, even for small businesses. The sensors are used in monitoring the operational conditions of the building and building equipment, such as monitoring airflow in the building, exposure to sunlight, and temperature. Then, the controllers of the devices process all the collected data from the sensors, and the actuators perform suitable actions for optimizing the physical settings. 
Installation of BEMS requires considerable capital investment, and any organization expects a lower payback period on investment through energy savings. If the operating characteristics of the building are not correct, then the performance of the BEMS cannot be achieved as expected. There are various conditions where BEMS cannot function efficiently, such as infiltration and exfiltration of air through cracks in the building envelope, doors and windows openings, poor building insulating material, single-pane doors and windows, and excessive internal heat loads. Moreover, the BEMS also does not run effectively during poor control system operation of the thermostat, excessive ventilation to the building than required, conditioning of unoccupied spaces, and constant SAT.

The transmission loss of heat is reduced with proper insulation of the building, upgrading of windows and doors. Furthermore, the heat loss due to infiltration is also reduced by installing appropriate frames in doors and windows and other sealing cracks in the building envelope. This reduces the load on the HVAC system. Hence, it does not have to run continuously. Moreover, by upgrading thermostat controls such that setback temperature could be set during unoccupied periods, the load on the HVAC system would decrease tremendously. In addition, using a $\mathrm{CO}_{2}$ sensor for demand-controlled ventilation, the HVAC system conditions only required amount of air to the building according to the number of occupants in the building.

Moreover, by setting up zonal controls, only the occupied spaces of the building are conditioned. A considerable amount of energy is saved that would otherwise be used for conditioning the unoccupied rooms. Also, by adjusting the SAT according to the total heat load present in a zone, the HVAC system consumes less energy for conditioning the given zone. Hence, it is imperative to ensure that these operating characteristics of the building are maintained adequately for BEMS to work effectively. Furthermore, BEMS must be continually assessed and fine-tuned as performance is usually better understood over extended periods.

\subsection{Research Approach and Objectives}

This research aims to simulate the energy consumption of the building by varying the control aspects of the BEMS. This research mainly focuses on BEMS control aspects such 
as DCV, temperature setback controls, zone control, and SATR controls to calculate the total annual energy consumption of the building. Initially, based on the number of rooms in the building and the type of rooms, the user can input various data such as dimensions of the rooms, thermostat setting (setpoint and setback temperature) for each room. Furthermore, users can also input the geographical position, energy source for heating and cooling the building. Microsoft Excel®, based on the discrete-event Monte Carlo Simulation (MCS), is used to simulate the energy consumption pattern. A heuristic approach is used for generating random variables for occupancy. This model calculates the energy consumption rate at 30-minute intervals for one year. Users can understand the energy consumption by HVAC units with the BEMS controls and compare them against their HVAC energy consumption data. A basic system diagram is shown in Figure 1.8. A detailed diagram illustrating the steps for determining potential energy savings through BEMS controls is shown in section 3.3. The objectives of this research are:

- Develop a Microsoft Excel-based (Visual Basic Application) Monte Carlo simulation, which can forecast the occupancy level at the different time frames of the day.

- Identify the requirement of outside air based on occupancy level for the specific time of the day to maintain the IAQ.

- Develop a user interactive simulation program where users input their building parameters and determine HVAC energy consumption based on varying BEMS controls.

- Determine the effectiveness of the BEMS on a continuous data scale of 1 to 5 based on user-defined building operating characteristics and BEMS controls. 


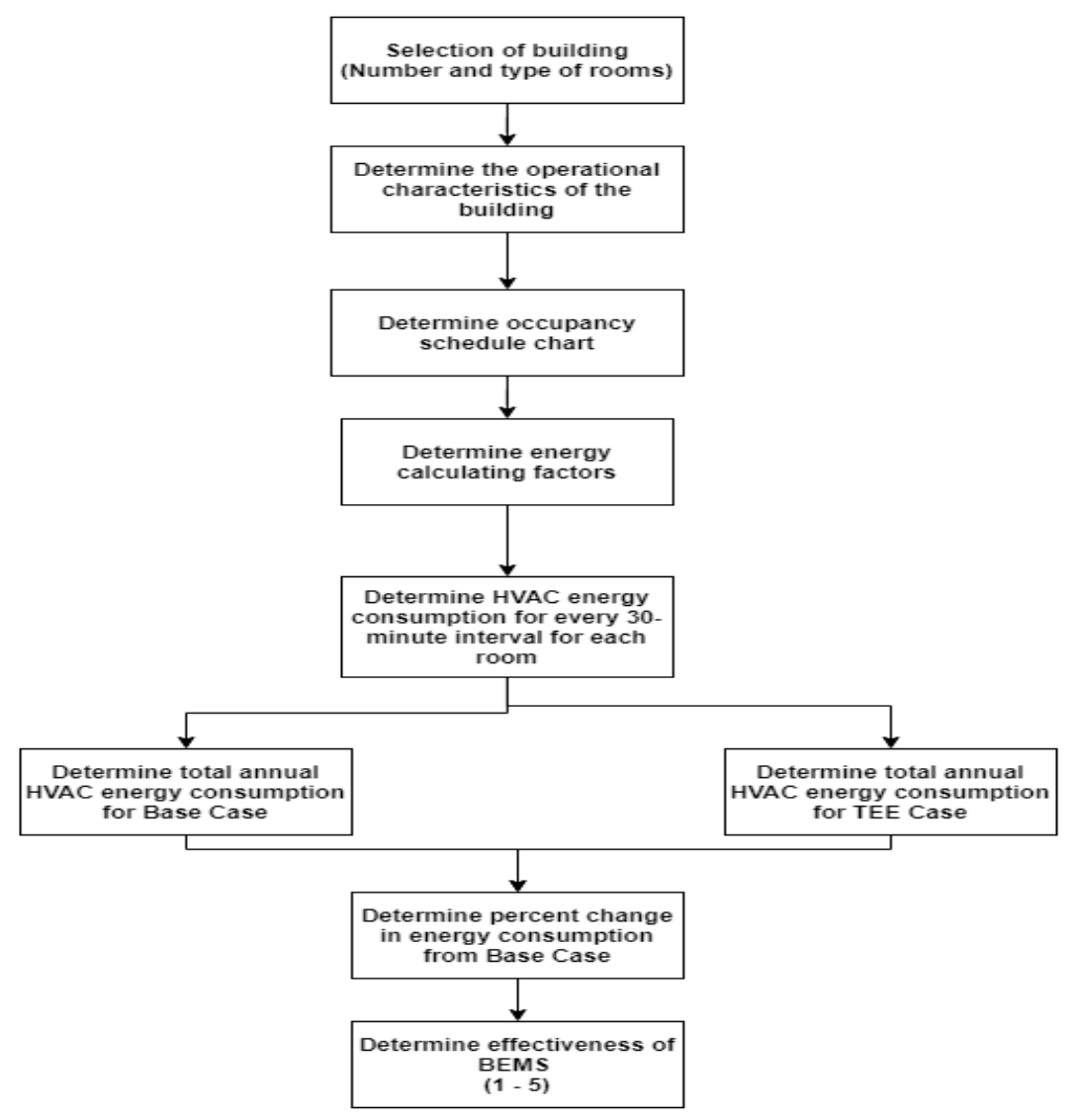

Figure 1.8: Basic Schematic Diagram of the System

\subsection{Conclusion}

BEMS is a powerful system that allows users to monitor, control, and automate the building system such as heating, ventilation, air conditioning, and lighting to enhance the energy efficiency of the building and enhance user comfort. But, installing a BEMS has a high initial cost for design costs, sensors, controllers, software, and analytics. Therefore, to maximize the energy savings from the BEMS, its control aspects must be fine-tuned, and a program for continuous improvement should be established. This research helps to provide an insight into energy consumption by HVAC systems by varying the control aspects of the BEMS. Monte Carlo Simulation has been used to simulate the behavior of the occupants by generating random numbers. The building owners or energy managers can use this tool to analyze the 30-minute interval data for ventilation requirements based on ASHARE 62.1-2019 standards, energy consumption between every 30-minute interval data, and monthly data. Further, it can also be a useful tool to analyze the energy savings with the addition of BEMS controls and determine the effectiveness of their BEMS. 


\section{Literature Review}

\subsection{Introduction}

The energy consumption in buildings depends on a combination of proper architecture design, energy systems design, and effective maintenance and operations of the facility. Energy consumption in buildings contributes to a significant amount of total energy consumption in the U.S. It is essential to focus research on developing energy-efficient technologies and measures for reducing energy consumption in buildings. Several modern technologies help reduce energy consumption in the building, such as efficient building envelope materials, advanced sensors, control systems for ventilation, and maintaining air quality, efficient heating, and cooling equipment. Moreover, the development of sophisticated control systems has led to effective energy management systems in buildings. However, there are a different group of researchers working towards increasing the effectiveness of BEMS by considering multiple factors affecting its operation such as accurate and reliable sensors, improved control system and algorithms for automatically optimizing building system performance, increased security on information, and efficient energy harvesting to power the sensors and control systems.

\subsection{Current Scenario of Energy Consumption by Buildings}

The building sector in the U.S. accounted for about 39\% (38 quadrillion BTUs) of primary energy consumption in 2016. This figure is more than the other two uses: transportation (29\%) and industry (32\%). The commercial and residential buildings were accountable for $18 \%$ and $21 \%$ of the primary energy consumption within the building sector [10]. Figure 2.1 shows the illustration of these data.

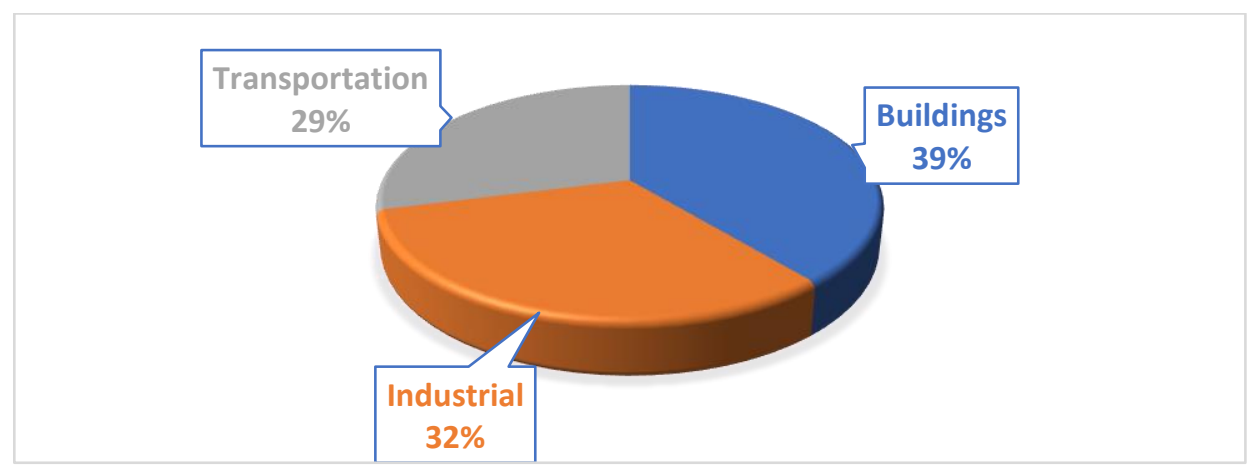

Figure 2.1: U.S. primary energy consumption in 2016 [25] 
Table 2.1: Categorical energy consumption in commercial and residential buildings [25]

\begin{tabular}{|c|c|c|c|}
\hline \multicolumn{2}{|c|}{$\begin{array}{c}\text { Buildings - Commercial } \\
\text { (18\% of building's energy consumption) }\end{array}$} & $\begin{array}{lrr} & \text { Building-Resider } \\
(21 \% & \text { of } & \text { building } \\
\text { consumption) } & \end{array}$ & ial \\
\hline Category of energy end-use & $\begin{array}{l}\text { Percentage } \\
\quad(\%)\end{array}$ & $\begin{array}{c}\text { Category of energy end- } \\
\text { use }\end{array}$ & $\begin{array}{l}\text { Percentage } \\
\quad(\%)\end{array}$ \\
\hline Other uses & 35.8 & Space heating & 24.2 \\
\hline Space heating & 12.4 & Other uses & 21.9 \\
\hline Refrigeration & 10.6 & Water heating & 13.3 \\
\hline Electronics & 9.7 & Space cooling & 12.5 \\
\hline Space Cooling & 9.3 & Lighting & 6.5 \\
\hline Ventilation & 8.6 & Electronics & 5.8 \\
\hline Lighting & 8.4 & Refrigeration & 5.2 \\
\hline Cooking & 3.1 & Clothes Dryers \& washer & 3.7 \\
\hline Water Heating & 2.0 & Cooking & 2.8 \\
\hline- & - & Pumps & 1.6 \\
\hline- & - & Dishwashers & 1.4 \\
\hline- & - & Freezers & 1.1 \\
\hline
\end{tabular}

In 2016, considering commercial and residential buildings, space heating was the most significant energy end-use category. Conditioning of spaces (cooling and heating) and lighting consumed about $43 \%$ of the total energy in residential buildings, whereas $39 \%$ of the total energy in commercial buildings. To sum up, about $34 \%$ of the total energy used in commercial or residential buildings is consumed by space conditioning. Furthermore, considering electronics and lighting such as computers, television, and related devices consumed about $7.6 \%$ and $7.4 \%$ of total energy in commercial and residential buildings. Moreover, refrigeration is considered the third-largest consumer of energy in the 
commercial sector, whereas water heater for the residential sector [10]. Figure 2.2 shows the detailed breakdown of energy consumption in buildings in the U.S in 2016.

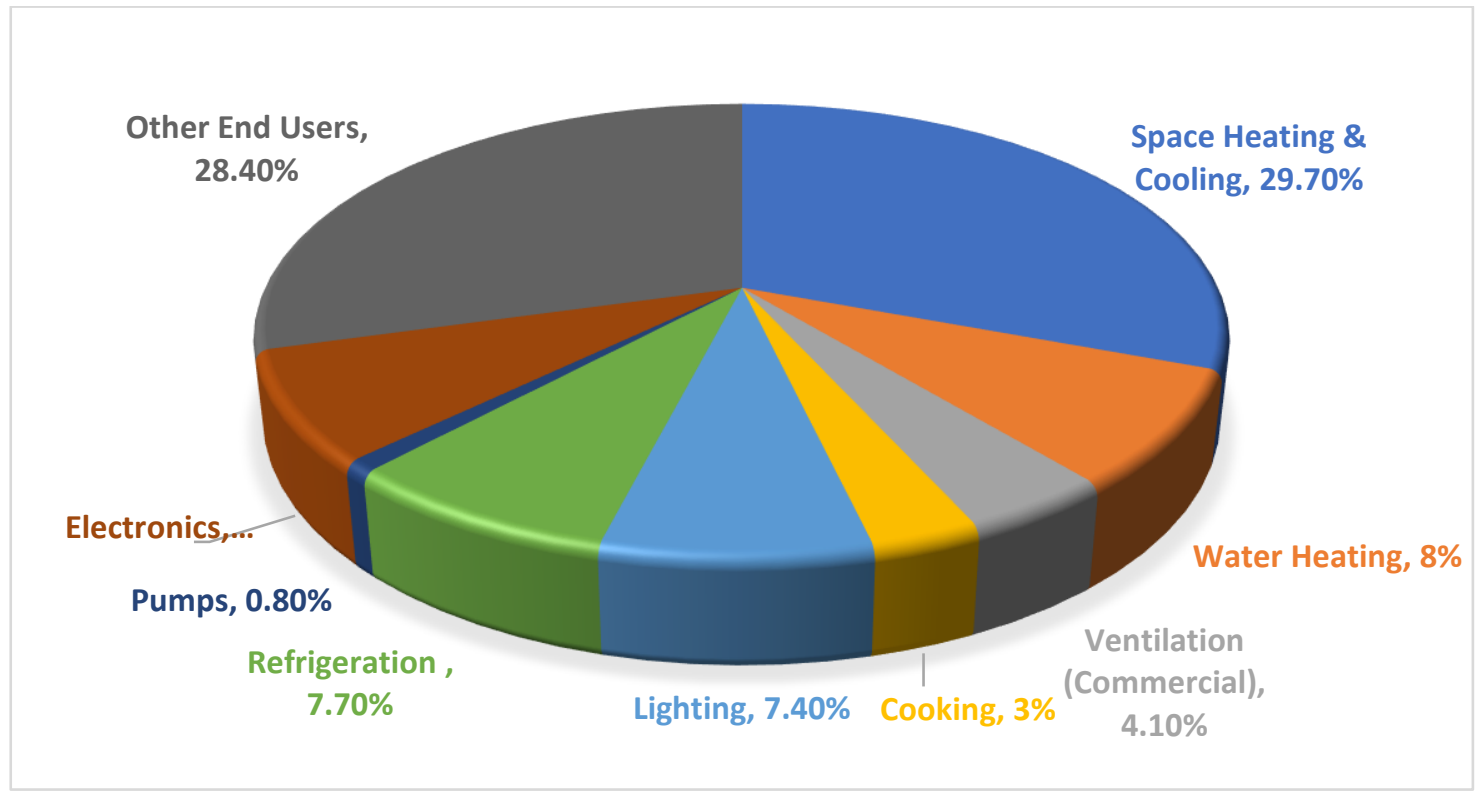

Figure 2.2: Breakdown of buildings energy consumption in the U.S. in 2016 [25]

Furthermore, consumption of electricity by the building has risen considerably from $25 \%$ in the 1950 s to $75 \%$ of U.S. electricity consumption in 2016 and contributing even more to peak power demand. Figure 2.3 represents the total sales of electricity in buildings in 2016. Overall, the energy consumption in buildings signifies an annual national energy bill of more than $\$ 380$ billion, emphasizing the economic importance of research and progress towards technological advancement that can decrease energy consumption in a building. In this respect, highly topical analyses and interventions are related to energy savings while ensuring adequate comfort conditions. This is called the energy efficiency of buildings. It accomplishes two important sustainable development goals while reducing energy demand, namely, primary resources economy and reducing emissions to the environment [10]. 


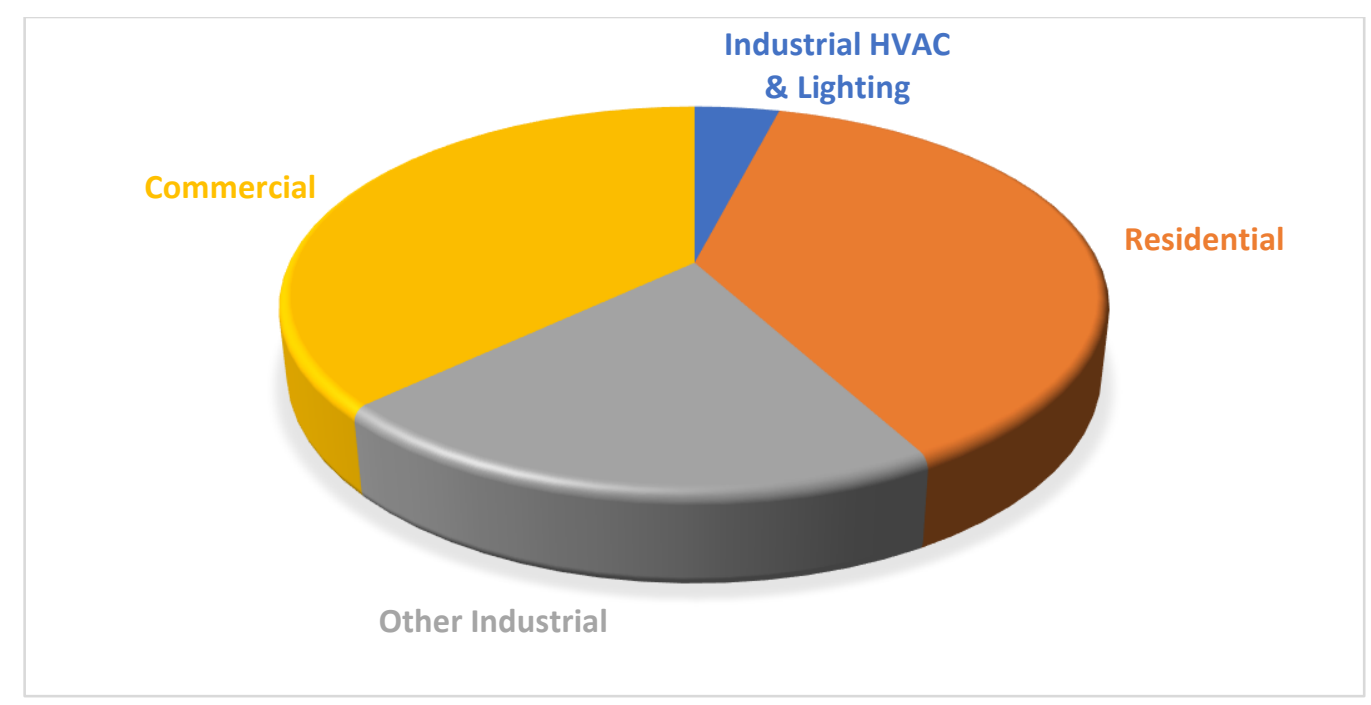

Figure 2.3: Total electricity sales for building in 2016 [25]

\subsection{History}

The evolution throughout history is essential to develop new technologies and strategies for improving energy efficiency in buildings. The progress can only be achieved by acknowledging the previous experiences and knowing the barriers encountered by predecessors. Without understanding the evolution of energy-efficient buildings, new concepts and solutions to reduce energy consumption in the building sector will be difficult to imagine.

Since ancient times, man has found ways of using and converting natural mechanisms to improve the living conditions, and among them are the houses and their construction techniques. Even if "energy efficiency" was not a common term as it is nowadays, before the 20th century, people have created and transferred from one generation to another the good practice codes. It is found that in $5500 \mathrm{BC}$, in the region of Carpathians, people used the solution of the houses built partially buried, obtaining in this way a more stable indoor temperature [26].

Benefits of the ground thermal properties were also used later in the houses of the Cappadocians, Essenian communities from the Middle East, and Native Americans. The evolution of those designs must be remarked in the Persians "badger" (wind tower), wherein dedicated routing the wind and ground energy were employed to assure indoor comfort. Romans also used the heating with burning gases that flowed through cavities in 
the floor or the walls. These elements with high thermal mass actively keep the indoor temperature comfortable for a more extended period. Windows covered with mica were also an active way to preserve a pleasant temperature of the inside air by trapping the solar radiation [26].

In the last decade of the 19th century, the scientific works in the building field implied studies of the thermal insulation effect in the heat transfer domain, formation, and transport of the moisture in the walls and multilayer configuration of windows. At this time, the preheating of the air at the service room located in the basement became a standard method. In this way, the ventilation process was being initialized by the convective circulation of the air towards the top floors [26].

At the end of the 1950s, the seasonal energy storage system was one of the most critical topics in buildings. One of these projects was materialized in Germany in 1984 as the first long-term thermal energy storage. The 1960s came with the enthusiasm of processing thermal load data by a computer that became an advantageous method in evaluating the energy performance of the buildings. Later, the researchers developed the degree day methods, Bin-method, and modified bin-method. The oil crisis from 1973 determined the amplification of the interest in building energy efficiency. People became more preoccupied with the airtightness of buildings, super-insulation and heat recovery in ventilation systems, the use of triple pane windows, and passive technologies that mainly were oriented to the use of thermal energy from the sun [26].

The intelligent building concept had started emerging in 1980 when several buildings gradually integrated the control of various equipment and systems. Initially, the automated systems implemented in facilities were dedicated separately to each machine, and later their complexity was capable of controlling multiple systems [26].

\subsection{Energy Management in Buildings}

\subsubsection{Energy Efficiency Index (EEI)}

Abu Bakar et al. presented a review on the EEI, which has been used as an indicator for tracking the energy consumption performance in the building. The authors discussed the difficulty in accurately measuring the energy system of the building since there exist many factors which influence the consumption of energy of the building, such as the condition 
of weather, materials used in the building insulation, HVAC system, occupancy, and activities carried around the building. Some of the energy estimating methods considered were the forecasting method, Computer-aided analysis, Degree-day method, and Bin method. Further, various case studies are also presented, which discuss the research of the EEI for building. The authors conclude that being in favor of EEI is an essential indicator for measuring the energy performance in the building. It offers numerous models of algorithms to provide solutions to the complex energy system [27].

Aapo Huovila et al. introduce a paper that studies existing energy efficiency indicators and develops a new indicator for energy efficiency in building energy efficiency, encompassing both occupancy and space efficiency. The authors conclude that the SEC (specific energy consumption) is a useful indicator for comparing technical solutions in the building design phase; EIU (Energy intensity of consumption) is illustrative when space efficiency is considered. When the space of the building is fixed, EIO (energy intensity of occupancy) is a good indicator of space efficiency and occupancy. Still, it does not include the size of a building. SECu,s (specific energy consumption adjusted for occupancy and space efficiency) takes both aspects into account but is challenging to calculate in an actual building due to difficulty gathering accurate real-time occupancy. However, when more sensors are installed, and the internet of things can make the flow of information more accessible, this indicator can be of good use, which will offer savings in energy and emissions [28].

\subsubsection{Energy Efficiency Study in Buildings}

Eiman Graiz and Wael al Azhari expound on using energy-efficient glass in an office building to reduce the heating, lighting, and cooling demands in their paper [29]. They use Ecotect software to analyze the solar incidence, sun path, and the worst and best orientation of the building. The authors used three types of glasses to study the impact on the four different office buildings. Then, daylighting was simulated three times for each office using the Ecotech software on the $21 \mathrm{st}$ of June at 1:30 pm. Hence, the authors suggested a set of guidelines for employing the energy-efficient glass in Amman city, characterized by the Mediterranean climate as Orientation: Between $125^{\circ}$ and $235^{\circ}$ from the north and optimum orientation is $180^{\circ}$ from the north, Annual Incident Solar Radiation must be between a 
maximum of $4,400 \mathrm{kWh} / \mathrm{m}^{2}$ and a minimum of $1,700 \mathrm{kWh} / \mathrm{m}^{2}$. The glass should be selected with Low-E, U-Value less than $1.5 \mathrm{Wm}^{2} / \mathrm{k}$, SHGC, and Shading coefficient (SC) less than 0.2. The authors claimed that the energy savings can be attained to $50 \%$ by installing energy-efficient glass.

Aynur Ucar and Figen Balo presented a paper in 2010 discussing the determination of the energy savings and the optimum thickness of insulation in the four different insulated exterior walls. The author considered four cities from the four climate zones of Turkey for the analysis. The external wall considered had $2 \mathrm{~cm}$ inner plaster $(\mathrm{k}=0.698 \mathrm{~W} / \mathrm{m} \mathrm{K}), 3 \mathrm{~cm}$ for external plaster $(\mathrm{k}=0.872 \mathrm{~W} / \mathrm{m} \mathrm{K}), 20 \mathrm{~cm}$ of horizontal hollow brick and insulation material. For the study, expanded polystyrene, extruded polystyrene, and rock wool were selected as insulation materials. Further, the authors used two economic indicators, $\mathrm{P}_{1}$ (lifecycle cost of a purchase option) and $\mathrm{P}_{2}$ (alternative), to calculate net energy cost savings. From the results, for energy cost savings over a lifetime of 10 years, the energy cost savings are directly proportional to the fuel cost, the material used for insulation, and climate conditions. The energy cost savings varied from $4.2 \$ / \mathrm{m}^{2}$ to $9.5 \$ / \mathrm{m}^{2}$ depending upon the insulating material and city. The greatest value of the optimum insulation thickness was found using Liquefied Petroleum Gas (LPG) as a source of energy and lowest when natural gas as a source of energy [30].

Siyuan Wu et al. presented a review of Ground Source Heat Pump (GSHP) systems with heat pipes for energy efficiency in buildings. Initially, the authors introduce the fundamental principles and operating processes of GSHP and heat pumps. The authors then discussed the research carried out in the design and transformation of the ground heat exchanger. The authors reported the works performed by Sarbu et al. [5] for improving the structure of ground heat exchangers and developed a new type of Groundwater Heat Pump (GWHP) system. They also reported the contribution of Ozgener and Hepbasli [6] for adding a solar collector in the ground-coupled loop for enhancing the depletion of thermal heat of the ground instigated by employing a single Ground-Coupled Heat Pump (GCHP) system in cold areas for a considerable time. The authors concluded that current experimental results and simulation have shown potential energy-saving [31]. 
Youssef Bichiou and Moncef Krarti presented a comprehensive energy simulation platform that could select the envelope features of the building and HVAC system design and operation setting optimally, minimizing the life cycle costs. The authors considered three optimization algorithms in the simulation platforms: Particle Swarm, Genetic, and Sequential search algorithms. Various shapes of building considered for the simulation environment were rectangle, trapezoid, L-shape, U-shape, T-shape, Cross shape, and Hshape. The simulation environment was used to design single-family homes in five US locations: Chicago, IL; Boulder, CO; San Francisco, CA; Phoenix, AZ; and Miami, FL. It was observed that the sequential algorithm was found best for all cities except San Francisco, CA, for which particle swarm optimization was determined to be the best, considering the HVAC system only optimization. Moreover, for complete optimization with no budget constraints, it was realized that the genetic algorithm was best for Chicago, Phoenix, and San Francisco, whereas Sequential search for Miami and Particle Swarm optimization for the boulder. Further, the authors also claimed that the optimal selection can cut life cycle costs by $10-25 \%$ depending on the kind of home and the climatic condition [32].

Mengmeng Cai et al. discussed the energy savings and reduction in peak loads in buildings by adjusting HVAC set points. The authors were interested in thermostatic control for demand response, among other coordination of rooftop units, fan control since it requires no additional hardware and easy implementation. The authors collected raw data by setpoint adjustment by an increment of $1^{\circ} \mathrm{F}$ through $5^{\circ} \mathrm{F}$ from the Base Case of $70^{\circ} \mathrm{F}$ between $12 \mathrm{pm}$ to $3 \mathrm{pm}$ from mid-April to mid-October. They plotted those data against the average outdoor temperature obtained during the same time duration. Whenever the average outdoor temperature fell above the threshold value but not too extreme, the potential demand reduction and daily energy savings were constant. Also, from the study, the authors claimed that the trend of outdoor temperature profile influences the energy savings and peak load reduction potential of a building before and during the Demand Response (DR) period. Also, the authors claimed that an average of $1.6 \%$ of daily energy savings and $5.2 \%$ of average peak reduction can be achieved with a $5^{\circ} \mathrm{F}$ increase in set point during the DR period [33]. 
BA Thornton et al. developed a technical support document targeting medium office buildings to save 50\% energy. The authors presented two energy-saving packages where the primary package includes radiant heating and cooling with dedicated outdoor air systems (DOAS), and it could save 50\% of energy savings. On the other hand, the secondary energy-saving package depends on a more traditional high-performance VAV system. It does not attain 50\% of energy savings in all 16 climatic locations used to analyze the project. A prototype building model that meets the Standard 90.1-2004 requirements based on the DOE medium office benchmark building was also developed. Energy simulation with EnergyPlus 3.0 was used to determine the potential savings in energy by the package measures. Using the prevailing energy codes and standards, eight climatic zones and 16 city locations were used where the prototype building was simulated to determine the energy savings. It was found that the primary energy saving package provided a national-weighted average energy savings of $56.1 \%$ over the Standard 90.12004 for 16 climate settings. The secondary energy-saving package, only different from the first package in HVAC, the VAV system, demonstrated a weighted average savings potential of $46.3 \%$. Further, to evaluate the cost-effectiveness of the savings in energy, a cost estimate for each package of energy measures was provided. It was found that the primary package has an average payback of 7.6 years, whereas the secondary package has an average payback of 4.6 years [34].

Sara Nikoofard et al. discussed the household energy requirement for heating and cooling requirements due to external shading. The authors considered a two-story detached house for the "test case house" that was initially modeled and simulated without using any external shadings to develop a "Base Case" requirement of energy. The weather data files used in the simulation were from the Canadian Weather year for Energy Calculation files. From the simulation, it was observed that the shading occurred due to a neighboring house on the south side resulted in the most significant increase in the requirement of heating energy. Further, the shading caused by the home located on the west side reduced the most cooling load. Moreover, it was also observed that cooling energy requirement reduces if the neighboring house is located on the west or east side than the south side. On the other hand, heating energy requirement escalates more if the adjacent house is situated on the south side. Also, the authors claimed that in high-density neighborhoods with densely 
situated larger homes on all three sides, the requirement of heating energy escalates due to shading by as much as $10 \%$. In contrast, the cooling energy requirement reduces $90 \%$ compared to an unshaded house [35].

Junjie Liu et al. presented a paper in 2010 that discussed energy recovery ventilator efficiency for transferring heat and moisture from the exhaust air into the fresh outdoor air to save energy in residential buildings. The authors used EnergyPlus software for simulating the performance of the Energy Recovery Ventilator (ERV). In winter, the design indoor air parameters were considered to be $20^{\circ} \mathrm{C}$ temperature with $2^{\circ} \mathrm{C}$ margin of error $60 \%$ relative humidity $(\mathrm{RH})$ with $10 \%$ margin of error. Further, the air-conditioning system considered was floor radiant heating plus ERV. For comparison, another system with the same air-conditioning system with equivalent air infiltration was considered. The operating period of ERV was from 8:00 am to 6:00 pm every day from October to March. Then, the authors calculated the energy savings by ERV in five representative cities with the same indoor condition but different outdoor conditions, and it was observed that the higher the difference between outdoor and indoor temperature, the higher saving was achieved. Moreover, the energy savings analysis was also calculated for different fan power of ERV for 50, 100, and $150 \mathrm{~W}$ assuming the air exchange rate with fresh air being 0.5 per hour. Hence, the authors concluded that to enhance energy performance savings, a reasonable new air exchange rate, more power, efficient fans, more efficient enthalpy exchange material, and proper operation period according to local climate should be selected [36].

The U.S. DOE assessed energy technologies and research opportunities. The assessment encompassed the energy use by the residential and commercial buildings in 2014. Various operating characteristics of building such as building envelope, ventilation, and air quality, space conditioning, thermal storage, lightings, heat exchangers, and moisture removal system are discussed thoroughly in the report. The report suggested the use of energyefficient equipment for reducing the load on demand. Moreover, it also discussed various system-level opportunities for saving energy such as improved control system, energy harvesting to power wireless sensors and controls, control algorithm to optimize building system performance automatically, components, and techniques that allow building devices to share waste heat [12]. 
Samar Jaber and Salman Ajib discussed the optimal orientation, size of windows, and thickness of thermal insulation from an economic, environmental, and energetic perspective for residential buildings located in the Mediterranean region. TRNSYS simulation software was used to simulate the annual load of the building. Further, the authors calculated the heating and cooling demand at different west, east, north, and south orientations and found the total energy required throughout the year for each direction to be $14,001 \mathrm{kWh}, 13,833 \mathrm{kWh}, 13,761 \mathrm{kWh}$, and 13,565 kWh, respectively. Hence, it was concluded that a passive façade facing south is best for energy savings. Further, it was found that the optimum window size was $20 \%$ and $10 \%$ of the total façade area from the West and North façade, respectively. Using appropriate shading devices, the new energy consumption was reduced by $5.06 \%$ in winter and $8.61 \%$ in the summer season. Furthermore, three scenarios were studied for thermal insulation by varying the insulation thickness in the ceiling and wall. Hence, it was concluded that the specific energy consumption could be reduced by $25.31 \%$ by installing proper windows with shading devices and insulating walls and ceiling by $0.13 \mathrm{~m}$ and $0.2 \mathrm{~m}$, respectively [37].

Danielle Griego et al. developed detailed simulation and optimization procedures for studying numerous energy efficiency measures for assessing an optimum set of recommendations for a typical home in Salamanca, Mexico. The data were based on building construction material, building utility data for two years, appliance information, occupancy schedules, appliances, and thermal comfort levels. A detailed building energy optimization tool developed through National Renewable Energy Laboratory (NREL), BEOptE+, was selected to estimate the annual energy saving from numerous combinations of thermal comfort and energy-efficient measures. For calculating the Predicted Mean Vote (PMV) for each hour of the year, the authors used Fanger Comfort Model. The scale for the PMV model was based on seven-point from -3 to +3 , and values corresponding between -1 and +1 were considered to be an acceptable level of thermal comfort. Hence, the authors recommend reducing plug loads, maintaining R-1.4 $\mathrm{m}^{2} \mathrm{~K} / \mathrm{W}$ roof assembly, $\mathrm{R}-0.35 \mathrm{~m}^{2} \mathrm{~K} / \mathrm{W}$ truck-branch Domestic Hot Water (DHW) pipe distribution, an electric stove, low-flow showerheads and sinks, and 100\% Compact Fluorescent Light (CFL) bulbs. The authors claimed that $7 \%$ annual energy savings can be achieved in unconditioned homes and 35\% in conditioned homes [38]. 


\subsection{Study of BEMS}

Majid Jamil and Sonam Mittal presented a paper with a review of building energy management systems. The authors emphasized that building an energy management system acts as a bridge between the electric grid and the consumer side to realize the demand response and make the dream of an intelligent grid visible. Further, various BEMS platforms monitor and control energy in residential or commercial buildings such as BEMOSS, EcoStructure Building Expert, and Cisco Energy Wise Suit. Additionally, the author also described the benefit of BEMS, such as minimization of energy waste, ecofriendly, provides DR solutions for renewable energy installation, reduces cost, and enhances comfort. Hence, the authors concluded that energy management in a building can be performed economically and efficiently using available BEMS technologies [39].

Phil Jones Mei describes BEMS as the computer-based control system that monitors and controls the electrical and mechanical aspects such as heating, cooling, ventilation, power systems, and lightings. Further, the author discussed the core function of BEMS as the controlling of boilers, pumps, heating systems, and locally containing the mixture of heat for achieving the required temperature of a room. BEMS controls the chiller and another cooling system in an air-conditioning system that distributes the air throughout the building. The author also claimed that installing BEMS energy savings of 10-20\% can be achieved than stand-alone controllers. The author, however, emphasized the importance of scheduled maintenance of the BEMS system and keeping its setting up to date to match the user comfort and realize more energy savings. Further, the author discussed the advancement of technology in the BEMS sector. The operator can access the interface through handheld devices locally instead of using the central supervisory control system. The author also suggested including the entire life-cycle costing calculation based on discounted cash flow while performing financial analysis [40].

Khairy Syed and Hossam A. Gabbar discussed the Building Energy Management System in their paper published in 2018. The authors also examined the control system, integration, and interfacing of BEMS units. Numerous benefits of the BEMS system were also delineated, including but not limited to enabling users to analyze, collate and transform the data into meaningful information, allowing them to monitor the consumption of energy and determine the waste. The authors further discussed the BEMS architecture and several 
energy monitoring systems such as direct, indirect, and hybrid monitoring systems. The author also highlighted various electrical networks and infrastructure required for the BEMS system. The authors mainly emphasized various energy-saving opportunities such as heating or cooling the zoned areas only when needed, ensuring the building operates according to the occupancy-time schedule, use of BEMS optimizers, Frost protection system, demand programming, enthalpy control, optimization of the performance of airhandling systems, etc. The authors also introduced the concept of smart homes and energy management systems in smart homes [41].

Chien-Nan Chen et al. presented a paper in the $20163^{\text {rd }}$ International Conference on Green Technology and Sustainable Development discussing designing and implementing a Building Energy Management System. The report highlights the utilization of a considerable amount of infographic and data visualization design elements in conjunction with interactive and dynamic charts that help users gain insights into critical building performance data. The developed design has general power and demand measurement, Time of Use (TOU) metrological management, and a power quality monitoring system. In addition to these, other service functions such as comparison of electricity consumption/charges in various cycles, two/three-step power charge tentative calculation, time division electricity analysis, analysis of minimum power charge contract capacity, etc., also developed in the BEMS platform. The authors planned to launch this system to aid the Kaohsiung city government's ineffective management of electricity consumption [42].

D. Mariano-Hernandez et al. presented a paper regarding the review of strategies for building energy management systems. The authors mainly described four methods: Model predictive control, demand-side management, optimization, and fault detection and diagnosis. The authors have grouped these strategies as an area of active building energy management systems. The authors reviewed the building techniques and subsystems for each type of strategy. Furthermore, the authors also evaluate the software used to validate the methodology. The authors concluded that most of the studies only focused on decreasing the HVAC system's energy consumption, leaving alone the other subsystems of the building, which might significantly contribute to energy consumption depending upon the building type. Moreover, the authors demonstrated that more research was necessary 
on some specific fields such as energy prediction models for different subsystems, methods encompassing the behavior of the occupants based on real-time data that can be applied to both residential and non-residential buildings, and management of demand considering the growth of electric vehicles [43].

Natasa Djuric et al. presented a paper using the BEMS data and optimization tool to estimate the heating system performance. The authors considered a building with a total area of $13,700 \mathrm{~m}^{2}$, three floors, and a basement. The authors collected data through an onsite survey, BEMS, and additional measurements, including indoor air temperature in four offices, outdoor air temperature, ultrasound flow meter, and energy consumption by hot water using thermocouples. The authors developed a model using the heat balance equation, which incorporated heat balance for substations and zones. The results showed that the faults could cause both decreases and increase in the achieved air temperature indoor and the consumption of energy. The effects of defects are recognized to be under the influence of how and when they appear. Specifically, the BEMS strategy affects the consequences of the disconnected outdoor air temperature. The energy consumption and indoor temperature are influenced by the erroneous measurement of outdoor air temperature. The authors further claimed that the fault in the schedule could appear due to both a few levels in the BEMS maintenance services and an error in the scheduled program [44].

\subsection{Study of Control Aspects of BEMS}

Pacific Northwest National Laboratory (PNNL) published a report that discussed the training guide for retuning the building. The authors highlighted the re-tuning of the building based on occupancy scheduling, night and weekend temperature setback, and cycling of supply fans during unoccupied hours. The authors claimed that if the control aspects of the building are controlled adequately during the unoccupied mode, it can significantly reduce costs in commercial buildings. The authors mainly focused on shutting down the systems whenever possible or when it is not essential and stopping to start the procedure for an occasional night-time user or weekend user. The authors collected data in a commercial building to verify the controls aspects of the building during unoccupied hours and find that there is no proper night setback, no proper weekend setback, and cycling 
of the supply fan frequently. The authors also provided some measures to follow to control the control aspects of the building better. For example, it is suggested to reset the dischargeair temperature setpoint by 5 to $10^{\circ} \mathrm{F}$ when the supply fan turns off or when the facility goes unoccupied. The authors also claimed that with proper setback control, the difference between the baseload to the peak load can be a minimum of $30 \%$ but can be as high as $80 \%$. These savings were also illustrated through charts for better understanding [45].

Neelam Verma and Anjali Jain presented a paper that discussed controlling the lighting automatically in an optimized way in a Hotel building to achieve energy efficiency. The authors described various categories for lighting control, such as occupancy-based control, schedule-based control, and daylight-based control. Further, the daylight-based control can also be strategized into dimming or daylighting switching control. The authors used DesignBuilder software for simulation for the energy consumption of the building. The simulation was carried out for three different scenarios, first with general lighting and HVAC on, second with general lighting with daylight dimming control and HVAC, and third with general lighting with daylight switching control and HVAC. From the study, the authors claimed that automatic lighting control with dimming can reduce the total consumption of energy by $37 \%$ and consumption of lighting energy by $55 \%$. Hence, the authors concluded that dimming and switching control of lighting contribute to saving energy, but the latter have more savings at the expense of occupant's comfort [46].

Lawrence Berkeley National Laboratory (LBNL) published a report describing occupancybased energy management in buildings. The authors conducted field studies and modeling analyses of the structure based on occupancy through the building. The authors divided the projects into three parts: Feasibility and efficacy study, refine hardware and software tools, and link with other DOE programs, and finally, implantation and testing of the prototype. They used EnergyPlus software to model the building and its systems. Furthermore, they also deployed a sensor network in the building to collect the data from the building. The authors then compared the empirical data with the data obtained from the model in terms of power $(\mathrm{kW})$ and temperature. Further, they also worked on the development of a people dynamics model for building occupants. The authors concluded that each zone in the building could result in an HVAC energy consumption reduction of nearly $15 \%$ [47]. 
Guopeng Liu and Michael R. Brambley published a paper titled Occupancy Based Control Strategy for VAV Terminal Box Systems. This paper discussed using various technologies such as building occupancy sensors and sensor networks for controlling the terminal box. The authors used building occupancy sensors to count the occupancy for all the rooms and deliver the measured data to the signal processing station through the sensor network. Further, the building automation system determines a minimum airflow rate requirement based on the occupancy at each zone. The authors proposed this plan to control each terminal box for varying the airflow rate based on the necessity of each area. They aimed to minimize the fan power consumption and potential energy from simultaneous cooling and heating. The authors, however, di not implemented this design in any building to validate their research. The system architecture, control strategy, and available sensor technology were explained in this paper [48].

Dimas Ardiyanto et al. presented a paper discussing the energy savings in buildings through HVAC setpoint interventions based on occupancy. The authors considered occupant thermal comfort and energy savings as the two prominent aspects in controlling the HVAC operation in the building. The authors aimed to devise a method to save energy by adjusting HVAC setpoints based on comfort measured using Predicted Mean Vote (PMV) and occupancy information. The results showed that the HVAC electrical consumption decreased by $14 \%$ when the proposed HVAC setpoint adjustment method was employed. The simulated was also run considering no occupancy in the building and increment in HVAC setpoint at that period. This simulation found that the additional saving in HVAC energy of $8 \%$ could be achieved by taking the information about occupancy into account [49].

Kaushik Mandlem et al. discussed using Smart Thermostat-based BEMS for energy efficiency effectiveness in a residential building. The main factors that the authors considered were occupancy of the rooms, weather factor, the volume of the space, building envelope, and thermostat set point. Furthermore, the developed software is user-interactive. Hence, the user can change input according to their requirements. The developed software can simulate the energy consumption of the HVAC system for one year with a frequency of 30 minutes. This simulated data will help the author evaluate the economic feasibility of the intelligent thermostat-based BEMS, thus helping them decide. Moreover, the authors 
also performed a sensitivity analysis to know about the effect of each factor on energy consumption. Also, the model was validated against a typical household where the difference between the simulated and the actual energy consumed was 5 MMBtu with an error of $15 \%[50]$.

A report published by Iowa State University titled "Experimental and simulation study of demand-controlled ventilation" highlights the comparison of energy use and $\mathrm{CO}_{2}$ concentration for a multizone building utilizing three ventilation control strategies: occupancy-based DCV, constant ventilation, and $\mathrm{CO}_{2}$ based DCV. The authors compared the building's energy consumption using these three winter, summer, and transition seasons. The authors developed an IAQ to perform the study and used it in conjunction with EnergyPlus to simulate the building performance. They also conducted experiments at the Iowa Energy Center's Energy Resource Station to validate the IAQ model. The investigation found that in July, the cooling load in $\mathrm{CO}_{2}$-based DCV was 3\% more than in the constant control strategy and 7\% more than in Occupancy-based DCV. Also, it was found that in October, the cooling load in $\mathrm{CO}_{2}$-based DCV was $0.3 \%$ more than in the constant control strategy and $0.8 \%$ more than in Occupancy-based DCV. The authors concluded that the occupancy-based DCV required the least quantity of outside air complying with the ASHRAE ventilation standard [51].

\subsection{Potential of Proposed Research}

All the research mentioned above used some form of adjustment in controls to determine the savings in energy consumption of the building. Many research papers discussed the potential benefit and strategies of optimizing the BEMS. However, there is a gap in the literature in determining the effectiveness of the BEMS. With the rising trends in energy conservation among commercial buildings, BEMS is a common choice for potential conservation of energy. With attractive ROI, the companies tend to install BEMS to save their building energy consumption and leave less carbon footprint in the world. However, to achieve the actual potential savings from the BEMS, the operation characteristics of building and BEMS controls play an important role. Without appropriate fine-tuning of these controls, the BEMS will not run effectively. Hence, the organization would be missing on saving energy costs for their building. 
Currently, no literature has provided any tool to determine the effectiveness of the energy management system of the building based on varying BEMS controls. In this research work to resolve this problem, a simulation model was developed for determining the effectiveness of an energy management system for buildings with BEMS controls such as DCV, zonal control, temperature setback controls, and SATR. The developed model in this research is user-interactive; hence, the user can change the model's parameters to determine the effectiveness of BEMS of their building. Therefore, in this way, the potential for energy savings by using the appropriate BEMS controls was determined, and the current effectiveness of the BEMS was evaluated. This tool can also determine the peak ventilation air requirement for a building to meet the indoor air quality based on ASHRAE standard 62.1-2019 that could help in preliminary study for sizing ventilation components of a building. Furthermore, this research also helps in the reduction of GHG emissions by exploring the ineffectiveness of BEMS operation and quantifying the amount of GHG emissions reduced in terms of pounds of $\mathrm{CO}_{2}$ emissions saved per year.

With more BEMS control and building input parameters, this tool can act as a bridge between building owner/ energy managers and advanced building energy modeling tools available in the market.

\subsection{Conclusion}

This literature review explored the various techniques of energy management in the building. With the development of new technologies, the software, analytics, and hardware such as sensors required for BEMS are affordable even to small commercial buildings. Moreover, with much understanding of the building's operational characteristics, the savings that could be achieved through BEMS has escalated considerably. The tools and resources for modeling building energy performance have advanced significantly in recent years. Due to these developments, it has been possible to simulate building more precisely with varying control aspects of energy savings. Hence, this has led to a decrease in cost for optimizing the proper energy controls of the building and increased the potential energy savings of the building. 


\section{Research Methodology}

\subsection{Introduction}

The recent development in BEMS has allowed users to gain more transparency into the performance of energy-consuming equipment, develop advanced data-driven maintenance strategies for prolonging the lifespan for equipment, decrease site disruption, and enhance indoor environmental quality. These attributes of BEMS allow users to reduce the overall operating cost of the building by optimizing the consumption of energy. However, not all commercial buildings have an effective BEMS system. For instance, the start and stop times of the air handling unit may not be optimized according to the occupancy schedule. If the start time of the air handling unit is earlier than an optimal time for the start, then the energy is wasted for the circulation of the air in the building. Another example of ineffective BEMS, conditioning more outside air than required for a given space, can be considered. More energy is needed to bring the outside air to thermal comfort conditions. Hence, all these ineffective control aspects of BEMS hinder attaining the potential energy savings of the building. The current work on the simulation of control aspects of BEMS can be used to determine the effectiveness of the BEMS.

\subsection{Overview of Research Approach}

This work involves determining the effectiveness of the BEMS system by simulation of the control aspects of the BEMS. The simulation takes information about the types of rooms in the building, the dimension of the rooms, information about the building envelope and location, setpoint, and setback temperature at each room during the summer and winter months. The research workflow can be segmented into steps, as shown in the flow chart (Figure 3.1) and delineated in the following list.

Step-1: Select the building in terms of the number of zones and type of zones.

Step-2: Determine the operational characteristics of the building along with BEMS controls.

Step-3: Define charts for occupancy (i.e., Expected occupant percentage) based on the time of the day and day of the week for each type of zone. 
Step-4: Determine various HVAC energy consumption factors such as the dimension of individual zones, thermostat settings (i.e., setpoint and setback temperatures) for summer and winter months. Further, also choose the climatic region according to the location of the building among the given nine climatic regions of the U.S. Also, specify the type of building envelope and determine the sensible heat ratio for individual zones.

Step-5: Determine the expected number of occupants at each room based on the time of the day and day of the week for each type of zone based on Monte Carlo Simulation.

Step-6: Determine the new Air Change per Hour (ACH) and outside air requirement (cfm) for every 30-minute time interval for each zone. This calculation is based on the number of occupants and the area of the room.

Step-7: Calculate the HVAC energy consumption for every 30-minutes - for one year for each type of zone.

Step-8: Furthermore, calculate the total HVAC energy consumption of the building by the addition of energy consumption of individual rooms (Base Case).

Step-9: Furthermore, perform a similar calculation for the TEE case where all BEMS controls are enabled with improvement in building envelope to determine the annual energy consumption of the building.

Step-10: Compare the annual energy consumption of the building for the Base Case with the TEE Case to determine the percentage change in energy consumption. Based on the difference in energy consumption between the TEE Case and Base Case, assign a rating of BEMS effectiveness on a scale from 1-5, where 1 being poor condition and 5 being an excellent condition.

Step-11: Determine the annual reduction of GHG emissions by enhancing the effectiveness of BEMS. 


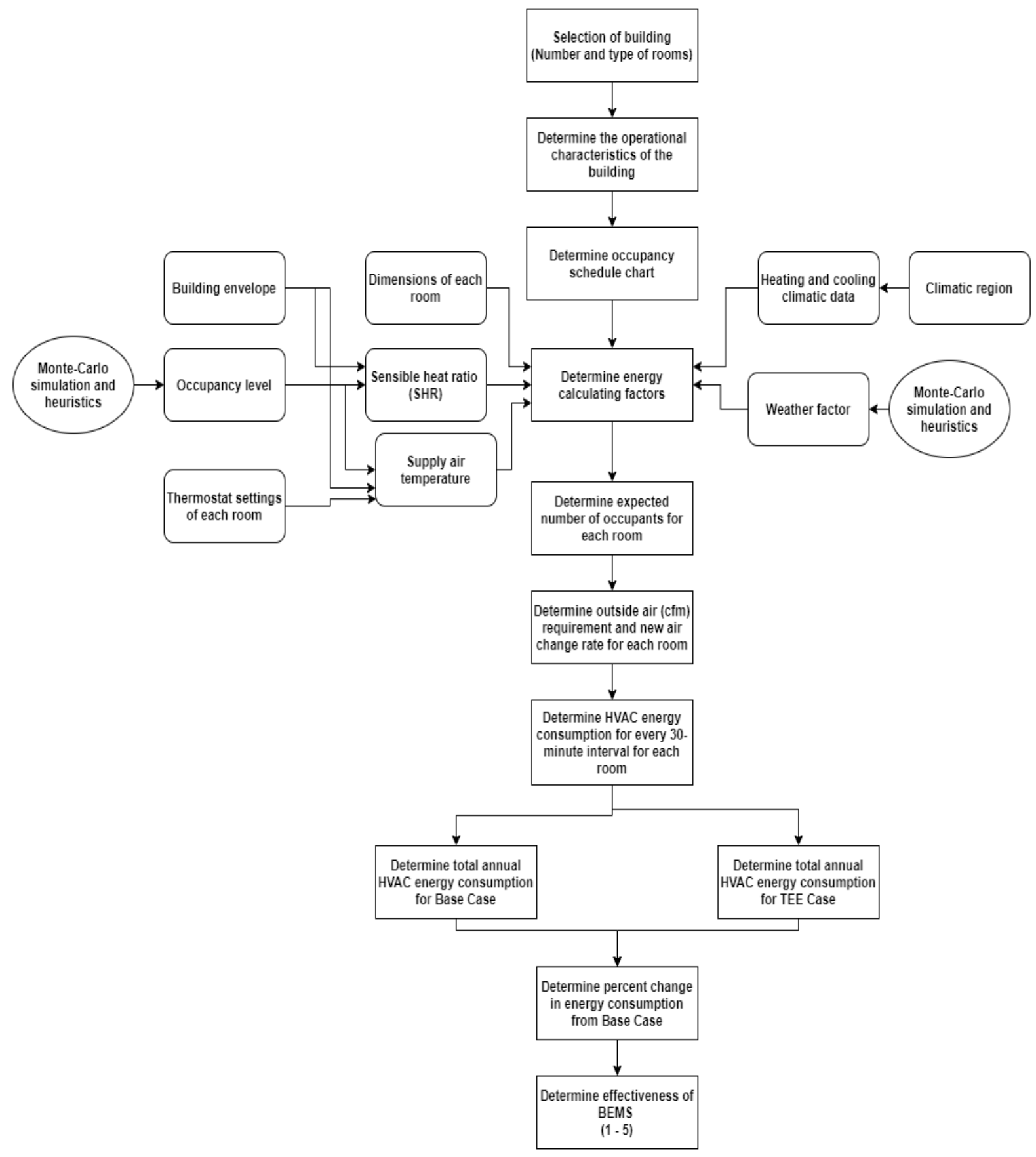

Figure 3.1: Steps for determining the effectiveness of BEMS

\subsection{Case Development}

Four BEMS operating parameters, namely, DCV, zonal controls, temperature setback controls, and SATR, are considered for this research study. Primarily, two cases, the Base Case and TEE Case, are developed to determine the BEMS system's effectiveness. The primary cases are discussed below: 
Base Case: This case is based on the building's user-defined BEMS controls and building envelope level. This case gives the energy required for space cooling and heating given the present condition of the building.

TEE Case: In this case, all four BEMS controls are input to the model, and the building envelope level is considered to be in good condition, i.e., no infiltration of air, double pane windows and doors, and good building envelope insulation. The energy required for space cooling and heating obtained from this case is used to calculate the effectiveness of BEMS of the building by comparing against the data obtained from the Base Case.

Additionally, other cases are also studied in this research in section 5.4, which deals with assessing the impact on the effectiveness of BEMS by adding individual BEMS controls into the simulation model that are not currently present in the building.

\subsection{Principle of Data Analysis}

The system requires some input from the user to calculate the HVAC energy consumption of the building with some BEMS controls. To be specific, the user has the option to input the total number of rooms in the building, type of individual rooms, the dimension of each room, thermostat setting for each room, geographical position according to climatic region, percentage of an outdoor air intake, BEMS controls, fuel type, and fuel cost. All these factors have been accounted as input data to the simulation. The proposed simulation is interactive, which allows its users to change the value of the variables. All these variables are defined in section 3.5. The simulation is performed in Microsoft Excel® based on the discrete event Monte Carlo Simulation (MCS) using the Visual Basic Application (VBA). A uniformly distributed random number will be generated in excel. To determine the expected number of occupants, heuristic rules will be applied for comparing the automatically generated random number and value from the occupancy chart.

\subsubsection{Monte Carlo Simulation (MCS)}

The MCS is a powerful tool for modeling data under uncertainty. Due to its outstanding capability of attaining a closer observance of reality, this tool is utilized to analyze complex statistical and mathematical problems [52]. It can obtain the estimation of the solution of complex multi-dimensional mathematical problems by generating random numbers. Thus, it is characterized as an approach of producing arbitrary numbers and comprehend the 
effect of risk and uncertainty of a particular system. Before the improvement of the computer in terms of computing capacity and affordability, as we have now, an arbitrary sampling number was used by skillful researchers. With the advancement of quicker

processors, MCS is exclusively used for thirty years to tackle complex problems in theoretical physics. As more temporary computers became more available, MCS strategies became increasingly attainable and valuable for the different fields. In a simulation process, the performance of a system can be studied by drawing numerous arbitrary samples and then investigating their behavior. In this proposed system, numerous factors simultaneously impact the outcome of the calculation. It is difficult to predict the exact outcome even though after having all the characteristics pre-defined. However, by employing MCS, numerous possible results can be generated, which guide us to select a better decision under uncertainty. Here, MCS is used to simulated desired parameters, i.e., total energy consumption at different time slots of a day, based on uniform distribution uncertainty and the weighted probability of occupancy. The outcomes are recorded, and the calculation is repeated for other days to obtain a cumulative result over several days.

\subsubsection{VBA for MCS}

VBA stands for Visual Basic for Applications, a programming language developed by Microsoft for Excel and other Microsoft Office programs such as PowerPoint and Word. It performs the coded instructions step by step, making it very fast. It is possible to build a user-defined function, automatic processes, and access Windows API (Application Programming Interfaces) using VBA. Access to the Microsoft Office software is required to use VBA in the proposed research, which may restrict its utility. However, Microsoft Office is generally accessible and runs effectively on regular work computers. Thus, the VBA was selected for our research work. Moreover, using VBA allows easy creation of a program with a graphical interface.

\subsection{Summary of Energy Calculation Factors}

All the energy calculation factors can be divided into two categories - major factors and minor factors. Major factors are those that directly impact energy accounting. Major factors are occupancy level and type of room. On the other hand, the minor factors are the ones 
that are present in all different scenarios, such as building envelope, level of thermostat, area of the room, geographical location.

\subsubsection{Occupancy}

In this proposed study, the most critical factor is Occupancy, as the heating or cooling of the amount of air depends upon the number of occupants present in a given space. For example, every person exhales some amount of $\mathrm{CO}_{2}$ in the area, which needs to be replaced by the outside air through a ventilation system to maintain the indoor air quality. The outside air needs to be conditioned (heated or cooled) according to the thermal comfort requirement. Hence, more people present in the room would require outside air to maintain the indoor air quality. Therefore, occupancy level plays a critical role in the consumption of energy for conditioning the outside air. The occupant's schedule is based on time and heuristic rules to detect the occupancy level in the room. Also, occupancy will vary based on the day of the week (i.e., weekday or weekend) and type of room.

To simulate the occupancy, VBA code containing the Microsoft Excel program will generate a random number every 30 minutes. The generated random number will be compared against the random number range data in the occupancy schedule chart as shown in Table 3.1 using a logic formula to determine the level of expected occupants at a given time of day, day of the week, and type of room. The total allowable occupants depend upon the type and area of the room according to ASHRAE 62.1-2019 standards.

For example, the occupancy schedule chart for determining the occupancy level for office space is shown in Table 3.1. If a random number generated by excel is 0.43 , the time of day is 8:17 am, and the day of the week is Wednesday, and then it is determined that the office space is expected to be $65 \%$ occupied. Therefore, $65 \%$ of total allowable occupants (rounded up to nearest integer) in the office space are expected to be present at the given time. Similarly, if it is a weekend, then for the same time and random number, $0 \%$ value is selected from Table 3.1. 
Table 3.1: Occupancy schedule chart for determining occupancy level for office space

\begin{tabular}{|c|c|c|c|c|c|}
\hline \multicolumn{6}{|c|}{ Office Space } \\
\hline \multirow{2}{*}{\multicolumn{2}{|c|}{ Time interval }} & \multirow{2}{*}{\multicolumn{2}{|c|}{ Random number range }} & \multicolumn{2}{|c|}{ Percentage of total allowable occupants } \\
\hline & & & & Weekdays & Weekends \\
\hline \multirow{2}{*}{$12: 00 \mathrm{AM}$} & \multirow{2}{*}{$8: 00 \mathrm{AM}$} & 0 & 0.99 & $0 \%$ & $0 \%$ \\
\hline & & 0.991 & 1 & $5 \%$ & $2 \%$ \\
\hline \multirow{2}{*}{ 8:01 AM } & \multirow{2}{*}{ 9:00 AM } & 0 & 0.75 & $65 \%$ & $0 \%$ \\
\hline & & 0.751 & 1 & $85 \%$ & $5 \%$ \\
\hline \multirow{2}{*}{ 9:01 AM } & \multirow{2}{*}{$10: 00 \mathrm{AM}$} & 0 & 0.8 & $70 \%$ & $0 \%$ \\
\hline & & 0.81 & 1 & $90 \%$ & $10 \%$ \\
\hline \multirow{2}{*}{ 10:01 AM } & \multirow{2}{*}{$12: 00 \mathrm{PM}$} & 0 & 0.98 & $90 \%$ & $0 \%$ \\
\hline & & 0.981 & 1 & $95 \%$ & $20 \%$ \\
\hline \multirow{2}{*}{ 12:01 PM } & \multirow{2}{*}{ 1:00 PM } & 0 & 0.3 & $55 \%$ & $5 \%$ \\
\hline & & 0.31 & 1 & $15 \%$ & $0 \%$ \\
\hline \multirow{2}{*}{ 1:01 PM } & \multirow{2}{*}{ 4:00 PM } & 0 & 0.98 & $90 \%$ & $0 \%$ \\
\hline & & 0.981 & 1 & $95 \%$ & $10 \%$ \\
\hline \multirow{2}{*}{ 4:01 PM } & \multirow{2}{*}{ 5:00 PM } & 0 & 0.8 & $70 \%$ & $0 \%$ \\
\hline & & 0.81 & 1 & $90 \%$ & $5 \%$ \\
\hline \multirow{2}{*}{ 5:01 PM } & \multirow{2}{*}{ 6:00 PM } & 0 & 0.75 & $65 \%$ & $0 \%$ \\
\hline & & 0.751 & 1 & $85 \%$ & $5 \%$ \\
\hline \multirow{2}{*}{ 6:01 PM } & \multirow{2}{*}{ 8:00 PM } & 0 & 0.35 & $35 \%$ & $5 \%$ \\
\hline & & 0.351 & 1 & $15 \%$ & $0 \%$ \\
\hline \multirow{2}{*}{ 8:01 PM } & \multirow{2}{*}{$12: 00 \mathrm{AM}$} & 0 & 0.99 & $0 \%$ & $0 \%$ \\
\hline & & 0.991 & 1 & $5 \%$ & $2 \%$ \\
\hline
\end{tabular}

Using the VBA programming makes the model flexible. The user can change the random number range and percentage of total allowable occupants relatively quickly in the predefined "Occupancy" excel worksheet if desired.

\subsubsection{Type of Room}

Another critical factor is the type of room. Inside a building structure, all enclosed spaces that people typically occupy should be persistently ventilated during involved hours with open-air, utilizing either natural or mechanical ventilation. The amount of outside air required for the ventilation is directly proportional to the energy consumed by the building. Hence, not to take excess air from outside than needed for the thermal comfort of the occupants, specific standards or guidelines must be followed. ASHRAE Standard 62.1 2019 has been a consensus standard for determining ventilation rates for acceptable IAQ for various rooms, given in Table 3.2. 
Table 3.2: ASHRAE Recommended Ventilation Rates and Typical Air Change Rates [53]

\begin{tabular}{|c|c|c|c|c|}
\hline Room Type & $\begin{array}{c}\text { People } \\
\text { Outdoor Air } \\
\text { Rate } \\
(\mathbf{c f m} / \mathbf{p e r s o n})\end{array}$ & $\begin{array}{c}\text { Area } \\
\text { Outdoor Air } \\
\text { Rate } \\
\left(\mathbf{c f m}_{\left.\mathbf{f} \mathbf{f t}^{2}\right)}\right.\end{array}$ & $\begin{array}{c}\text { Occupant } \\
\text { Density } \\
\left(\# / \mathbf{1 0 0 0} \mathbf{f t}^{\mathbf{2}}\right)\end{array}$ & $\begin{array}{c}\text { Air } \\
\text { Change } \\
\mathbf{p e r ~ H o u r ~} \\
(\mathbf{A C H})\end{array}$ \\
\hline Office Private Space & 5 & 0.06 & 5 & 4 \\
\hline Office Open Space & 5 & 0.06 & 20 & 4 \\
\hline Conference Room & 5 & 0.06 & 50 & 10 \\
\hline Meeting Room & 5 & 0.06 & 50 & 10 \\
\hline Lobby & 5 & 0.06 & 10 & 6 \\
\hline Breakroom & 5 & 0.12 & 50 & 7.5 \\
\hline Storage Room & 5 & 0.06 & 2 & 5 \\
\hline Reception & 5 & 0.06 & 30 & 6 \\
\hline Gymnasium & 20 & 0.18 & 7 & 5 \\
\hline Kitchen & 7.5 & 0.12 & 20 & 20 \\
\hline Cafeteria & 7.5 & 0.18 & 100 & 13.5 \\
\hline Printing Room & 5 & 0.06 & 4 & 17.5 \\
\hline Corridor & 0 & 0.06 & 0 & 11 \\
\hline Electrical Room & 0 & 0.06 & 0 & 7.5 \\
\hline Data Server Room & 0 & 0.06 & 0 & 17.5 \\
\hline Rest Room & 0 & 0 & 0 & 10 \\
\hline
\end{tabular}

\subsubsection{Number of Room}

The number of rooms depends on the building the user wants to examine in a simulation. HVAC energy consumption is directly related to the number of rooms. The more rooms in the building, the more energy is required to maintain thermal comfort in individual rooms. At the beginning of the simulation, the user has to define the number of rooms in the building. Without selecting the number of rooms, the program will not execute the next step.

\subsubsection{Area of Room}

To maintain the room temperature and thermal comfort conditions, the HVAC system requires delivering or removing heat from the room air. Therefore, the energy necessary to heat or cool down the air depends on the quantity of air present in the room; consequently, 
it depends on the size of the room. To determine the air required ( $\mathrm{cfm}$ ) for a given type of room, four factors are to be known, which are the number of occupants, the total area of the room, People Outdoor Air Rate (cfm/person), and Area Outdoor Air rate $\left(\mathrm{cfm} / \mathrm{ft}^{2}\right)$ for that specific type of room according to ASHRAE Standard 62.1 - 2019. Hence, the larger the area, the more outdoor air (cfm) must be conditioned, leading to increased energy consumption. The user has to provide the room's dimensions (area and height) in the simulation tool.

\subsubsection{Smart Thermostat}

The thermal comfort levels of people can differ from individual to individual, as one individual may desire a colder room while the other might desire a warmer room. In this work, it has been presumed that each room has a smart thermostat to warrant the thermal comfort of the occupants. The main objective of the smart thermostat is to regulate the temperature with the occupancy level and control the HVAC timer remotely using any internet-connected device to obtain a comfortable temperature. Another valuable aspect of a smart thermostat is that a setback temperature can also be set. During an unoccupied schedule, the thermostat setpoint level changes to a user-predefined setting, reducing HVAC units' energy consumption. For example, in office spaces during the night where there are no occupants, the setpoint level of the thermostat is changed to a user-predefined level. Hence, the HVAC system has to do less work to maintain the thermal conditions.

The user has to input the setpoint and setback level for the thermostat for the summer and winter months. According to the user input values, the simulation tool will maintain the thermal condition for the setpoint and setback levels by the pre-defined occupancy schedule.

\subsubsection{Weather}

Weather and climate conditions have a significant effect on overall energy consumption. The energy consumed by the HVAC system depends upon the outside temperature and humidity. Therefore, in this study, the weather has been considered as one of the main input factors.

The climate conditions of the U.S. vary with the location. The U.S. is divided into nine regions based on their climate, as shown in Figure 3.2. All these regions are considered to 
evaluate the energy consumption in this research work. The heating degree day (HDD) and cooling degree days (CDD) chart for each climate zone in the reference sheet is shown in Table 3.3. Degree days (DD) measure the difference between outside temperature and baseline temperature for a given period and can be used to predict the energy use for heating or cooling.

Figure 3.2 depicts the nine-climate zone of the U.S. User will be asked to select a climatic location they are located among the nine climatic zones.

Table 3.3: List of heating and cooling degree days for each climate zone

\begin{tabular}{|c|c|c|c|}
\hline S.No. & Location & HDD & CDD \\
\hline 1 & Pacific & 3,078 & 838 \\
\hline 2 & Mountain & 4,530 & 1,346 \\
\hline 3 & West North Central & 5,926 & 891 \\
\hline 4 & West South Central & 1,905 & 2,479 \\
\hline 5 & East North Central & 5,673 & 719 \\
\hline 6 & East South Central & 3,102 & 1,553 \\
\hline 7 & Middle Atlantic & 5,132 & 678 \\
\hline 8 & South Atlantic & 2,412 & 2,005 \\
\hline 9 & New England & 5,701 & 469 \\
\hline
\end{tabular}

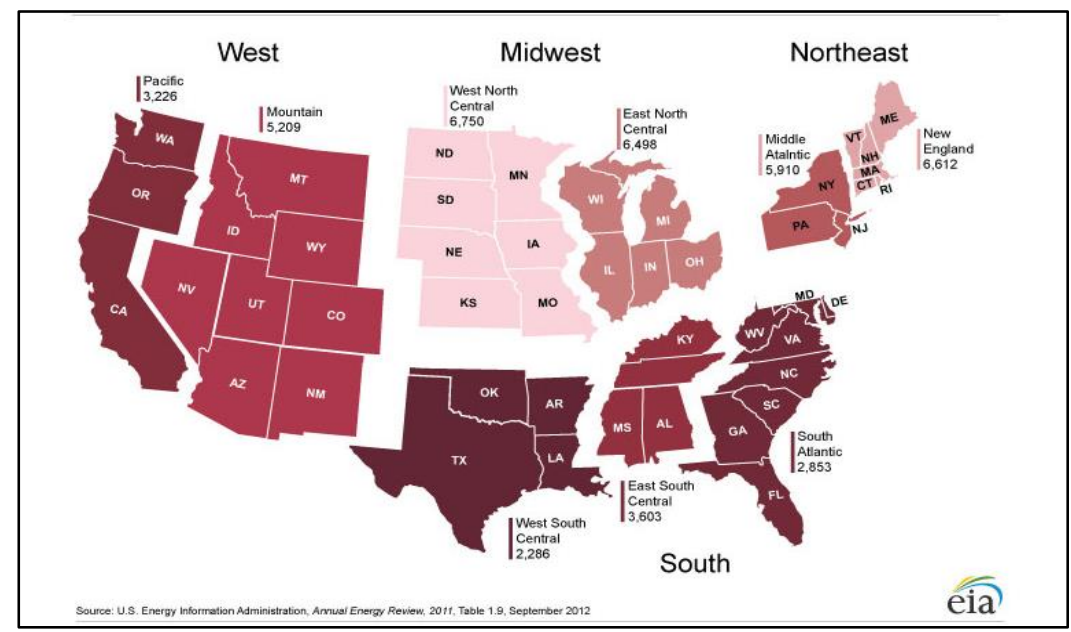

Figure 3.2: Census Regions [54]

To determine whether heating or cooling is required, it is necessary to know the cooling ratio. The cooling ratio can calculate from CDD dividing by CDD plus HDD. The example of the cooling ratio table from the reference is shown in Table 3.4. An automatically 
generated random number will be compared with this cooling ratio for a specific day at 30minute intervals to determine the energy consumption for heating or cooling during the energy calculation.

Table 3.4: Calculation of cooling ratio for the South Atlantic region

\begin{tabular}{|c|c|c|c|c|c|c|}
\hline Month & Name & Days & Cumulative & HDD & CDD & Cooling \\
\hline 1 & January & 31 & 0 & 569 & 29 & 0.05 \\
\hline 2 & February & 28 & 31 & 460 & 30 & 0.07 \\
\hline 3 & March & 31 & 59 & 322 & 53 & 0.15 \\
\hline 4 & April & 30 & 90 & 129 & 84 & 0.40 \\
\hline 5 & May & 31 & 120 & 39 & 189 & 0.83 \\
\hline 6 & June & 30 & 151 & 2 & 338 & 1.00 \\
\hline 7 & July & 31 & 181 & 1 & 412 & 1.00 \\
\hline 8 & August & 31 & 212 & 1 & 392 & 1.00 \\
\hline 9 & September & 30 & 243 & 11 & 264 & 0.96 \\
\hline 10 & October & 31 & 273 & 118 & 123 & 0.52 \\
\hline 11 & November & 30 & 304 & 315 & 47 & 0.13 \\
\hline 12 & December & 31 & 334 & 445 & 44 & 0.09 \\
\hline
\end{tabular}

In this study, only 18 states were selected for the simplicity of the simulation model. Two weather stations from each of the 18 states are included in this simulation model. The user is asked to select the "state" and "nearest weather station" from the available options. Based on the chosen state, two weather stations will be available to choose from, and based on the selected weather station, the elevation (ft.), heating dry bulb temperature (DBT), cooling DBT, and humidity ratio are determined from values referenced from the 2017 ASHRAE Handbook [55]. Here, for simplicity, 99.6\% value for heating DBT, $0.4 \%$ value for cooling DBT, and humidity ratio is selected, which means that the outdoor temperature of the location stays above $99.6 \%$ of all the hours in the year for heating DBT and the outdoor temperature and humidity ratio in a year for the location will exceed this design value about $0.4 \%$ of the time for cooling DBT and humidity ratio respectively. This temperature and humidity give us the peak condition for the calculation; hence, to determine the HVAC energy consumption for every 30 -minute interval, a weather factor is used. 
Weather is divided into three levels - level 1 as mild, level 2 as moderate, and level 3 as extreme weather conditions. The updated weather factor is counted every eight hours and is expected to be the same for the next eight hours. The year is split into twelve months to determine the weather factor, and the rules are shown in Table 3.5. Similar to occupancy level selection, based on the day and random number, the level of weather factor is determined. For example, during Jan $8^{\text {th }}$, i.e., Day 8 and random number 0.6 , the weather factor of 0.02 is selected. For same day 8 , if the random number is 0.88 , then the weather factor of 0.2 will be selected, and so on.

Table 3.5: Rules to determine weather factor

\begin{tabular}{|c|c|c|c|c|}
\hline \multicolumn{5}{|c|}{ Weather Factor } \\
\hline \multicolumn{2}{|c|}{ Days Interval } & \multicolumn{2}{|c|}{ Random number range } & \multirow{2}{*}{\begin{tabular}{|l|} 
WF \\
\\
0.02
\end{tabular}} \\
\hline \multirow{3}{*}{1} & \multirow{3}{*}{31} & 0 & 0.85 & \\
\hline & & 0.851 & 0.98 & 0.2 \\
\hline & & 0.99 & 1 & 1 \\
\hline \multirow{3}{*}{32} & \multirow{3}{*}{59} & 0 & 0.88 & 0.02 \\
\hline & & 0.881 & 0.98 & 0.2 \\
\hline & & 0.99 & 1 & 1 \\
\hline \multirow{3}{*}{60} & \multirow{3}{*}{90} & 0 & 0.95 & 0.02 \\
\hline & & 0.951 & 0.999 & 0.2 \\
\hline & & 0.9991 & 1 & 1 \\
\hline \multirow{3}{*}{91} & \multirow{3}{*}{120} & 0 & 0.99 & 0.02 \\
\hline & & 0.991 & 0.999 & 0.2 \\
\hline & & 0.9991 & 1 & 1 \\
\hline \multirow{3}{*}{121} & \multirow{3}{*}{151} & 0 & 0.99 & 0.005 \\
\hline & & 0.991 & 0.999 & 0.2 \\
\hline & & 0.9991 & 1 & 1 \\
\hline \multirow{3}{*}{152} & \multirow{3}{*}{181} & 0 & 0.85 & 0.02 \\
\hline & & 0.851 & 0.98 & 0.2 \\
\hline & & 0.99 & 1 & 1 \\
\hline \multirow{3}{*}{182} & \multirow{3}{*}{212} & 0 & 0.72 & 0.02 \\
\hline & & 0.721 & 0.98 & 0.2 \\
\hline & & 0.99 & 1 & 1 \\
\hline \multirow{3}{*}{213} & \multirow{3}{*}{243} & 0 & 0.75 & 0.02 \\
\hline & & 0.76 & 0.98 & 0.2 \\
\hline & & 0.99 & 1 & 1 \\
\hline \multirow{3}{*}{244} & \multirow{3}{*}{273} & 0 & 0.98 & 0.02 \\
\hline & & 0.981 & 0.999 & 0.2 \\
\hline & & 0.9991 & 1 & 1 \\
\hline \multirow{3}{*}{274} & \multirow{3}{*}{304} & 0 & 0.99 & 0.02 \\
\hline & & 0.991 & 0.999 & 0.2 \\
\hline & & 0.9991 & 1 & 1 \\
\hline \multirow{3}{*}{305} & \multirow{3}{*}{334} & 0 & 0.99 & 0.02 \\
\hline & & 0.991 & 0.999 & 0.2 \\
\hline & & 0.9991 & 1 & 1 \\
\hline \multirow{3}{*}{335} & \multirow{3}{*}{365} & 0 & 0.93 & 0.02 \\
\hline & & 0.931 & 0.99 & 0.2 \\
\hline & & 0.991 & 1 & 1 \\
\hline
\end{tabular}


Here, the weather factor of 0.02 is considered as level 1 (mild), 0.2 as level 2 (moderate), and 1 as level 3 (extreme). These random number range and the weather factor are chosen based on the energy consumption pattern of the building. By analyzing the electric and natural gas consumption pattern and energy-consuming equipment, the factors are determined. The energy consumption pattern from the simulation tool resembles the utility bill. Users can modify the random number range and the weather factor if desired by editing the "Reference" worksheet.

\subsubsection{Building Envelope (BE)}

Heat flows from the warmer area to the cooler area according to the law of thermodynamics. There are three methods for transfer for heat: conduction, convection, and radiation. The transfer of heat through solid walls, roofs, and windows is known as conduction. Similarly, heat transfer by the movement of liquid and gases (air) is known as convection. The transfer of heat by wave, such as sunlight, is referred to as radiation. Transferred heat through these methods can significantly affect the load factor of heating or cooling units. The energy requirement for conditioning the room at a comfortable temperature is increased when the conditioned air is mixed with the outside cold air and sunlight heat. To maintain proper oxygen $\left(\mathrm{O}_{2}\right), \mathrm{CO}_{2}$, and humidity levels at the building for providing comfort for occupants, the outdoor air needs to be controlled. However, the uncontrolled outside heat transfer through the building cracks, wall, roof, unintentional openings, window, door egress, entrance, infiltration, and indoor air leakage out of the building, known as exfiltration, may occur. All these processes for heat transfer depend on the physical structure of the building, generally known as Building Envelope. Hence, in calculating heating or cooling load, the building envelope is considered one of the critical parameters for determining the load factor.

Different types of BEMS controls are used for the simulation study. The impact of building envelope on energy savings for different BEMS controls levels is considered dynamic and is not studied in this research. The Building Envelope (BE) factors used in this research for various BEMS controls are shown in Table 3.6, obtained based on the trial-and-error method. These factors are adjusted such that the percentage of energy savings obtained by adding new BEMS control does not exceed what is expected from the works of literature. 
Hence, a different BE load factor is used for various BEMS controls used during the study, as shown in Table 3.6 below. For example, when the building has only control type A (zonal control and temperature setback control), the BE factor is estimated to be 0.1 during poor building envelope and 0 when it has a good building envelope. However, when the building has DCV control and control type A, the BE factor is assumed to be 0.04. This allows the simulation to increase the energy consumption while having a poor building envelope. Similarly, when the building envelope is improved, the BE factor of 0.03 is used. Furthermore, whenever the building has SATR control, a constant BE factor is used for both poor building envelope and good building envelope condition. The variation in energy consumption of different condition of building envelope is already accounted by the SAT factor discussed in next section 3.5.8.

Table 3.6: Rules to determine BE factor

\begin{tabular}{|c|c|c|}
\hline \multirow{2}{*}{ Type of BEMS control } & \multicolumn{2}{|c|}{ BE factor } \\
\cline { 2 - 3 } & $\begin{array}{c}\text { BE - Poor } \\
\text { (level 1) }\end{array}$ & $\begin{array}{c}\text { BE - Good } \\
\text { (level 2) }\end{array}$ \\
\hline $\begin{array}{c}\text { Control type A } \\
\text { (zonal control and temperature setback control) }\end{array}$ & 0.01 & 0 \\
\hline DCV and control type A & 0.04 & 0.03 \\
\hline SATR and control type A & 0.015 & 0.015 \\
\hline DCV, SATR and control type A & 0.03 & 0.03 \\
\hline
\end{tabular}

\subsubsection{Supply Air Temperature (SAT)}

The SAT from the heating or cooling unit depends upon the winter or summer season. The design upper and lower limit of the SAT during the winter and summer season relies on the HVAC system and user thermal comfort requirements. Generally, the SAT during the summer months is at $55^{\circ} \mathrm{F}$ at a minimum level. Similarly, during the winter months, at maximum level, the SAT from the heating unit is $120^{\circ} \mathrm{F}$.

In this research, the upper limit of SAT during winter has been considered $100^{\circ} \mathrm{F}$, and the lower limit of SAT during summer has been considered $55^{\circ} \mathrm{F}$. Moreover, the thermostat's 
setpoint temperature should not be less than $70^{\circ} \mathrm{F}$ during summer and greater than $75^{\circ} \mathrm{F}$ during the winter season. Depending upon the building envelope level and occupancy level, a rule is designed such that the supply air temperature varies depending upon the heating or cooling load inside the space.

During high occupancy levels, the occupants and the plug loads used in spaces generate a considerable amount of sensible load. Furthermore, occupants are also responsible for the increase in the latent load of the building due to the release of moisture from their bodies. Also, the infiltration of air into the building adds up to the increase in sensible and latent cooling loads. Hence, these two factors are considered directly related to the temperature of the supply air for space.

The following Table 3.7 shows the rule defined for a determination of load factor during summer months:

Table 3.7: Building Load factor during summer

\begin{tabular}{|c|c|c|}
\hline $\begin{array}{c}\text { Building } \\
\text { Envelope }\end{array}$ & $\begin{array}{c}\text { Occupancy level } \\
(\boldsymbol{\%})\end{array}$ & $\begin{array}{c}\text { Load Factor } \\
\text { (LF) }\end{array}$ \\
\hline \multirow{4}{*}{ Good } & 0 & 0.6 \\
\cline { 2 - 3 } & $1-25$ & 0.2 \\
\cline { 2 - 3 } & $26-75$ & 0.35 \\
\cline { 2 - 3 } & $76-100$ & 0.65 \\
\hline \multirow{4}{*}{ Poor } & 0 & 0.8 \\
\cline { 2 - 3 } & $1-25$ & 0.65 \\
\cline { 2 - 3 } & $26-75$ & 0.8 \\
\cline { 2 - 3 } & $76-100$ & 1 \\
\hline
\end{tabular}

Here, the supply temperature $\left(\mathrm{T}_{\mathrm{s}}\right)$ is calculated from the following equation:

$$
\mathrm{T}_{\mathrm{s}}=\mathrm{T}_{\mathrm{t}}-(\mathrm{LF} \times 15)
$$

Where,

$\mathrm{T}_{\mathrm{t}}=$ Thermostat set-temperature or setback temperature depending on occupied/ unoccupied state

LF = Load factor varies depending upon the level of occupancy 
For example, if there is no occupancy at the building and has a good building envelope, a load factor of 0.6 is assigned. On the other hand, if the building envelope is poor at no occupancy state, a load factor of 0.8 is assigned. The load factor is used in the equation above to determine the SAT. During the occupied state, the SAT is set to user-defined temperature.

During the winter months, the SAT from the heating unit is considered dependent upon the building envelope. Similar to the summer months, the occupancy level or plug loads are not significant factors for selecting the SAT. During high occupancy levels, the occupant and plug load generate heat in the space that decreases the load of the heating unit. However, for the poor building envelope, air infiltration contributes a considerable load to the room. The following Table 3.8 shows the rule defined for a selection of load factors during winter months:

Table 3.8: Building Load factor during winter months

\begin{tabular}{|c|c|c|}
\hline Building Envelope & $\begin{array}{c}\text { Occupancy level } \\
(\boldsymbol{\%})\end{array}$ & $\begin{array}{c}\text { Load Factor } \\
(\mathbf{L . F})\end{array}$ \\
\hline \multirow{2}{*}{ Good } & 0 & 0.4 \\
\cline { 2 - 3 } & $1-100$ & 0.6 \\
\hline \multirow{2}{*}{ Poor } & 0 & 0.8 \\
\cline { 2 - 3 } & $1-100$ & 1 \\
\hline
\end{tabular}

Here, the supply temperature $\left(T_{\mathrm{s}}\right)$ is calculated from the following equation:

$$
\mathrm{T}_{\mathrm{s}}=\mathrm{T}_{\mathrm{t}}+(\text { L.F } \times 25)
$$

For example, if a building has a good building envelope and is unoccupied, then a load factor of 0.4 is assigned. On the other hand, if the building has a poor building envelope and is occupied, then a load factor of 1 is set. Based on the equation given above, the SAT is determined.

\subsubsection{Sensible Heat Ratio (SHR)}

Sensible heat ratio (SHR) is the ratio between the total sensible heat load and the total heat load. The total heat load is the sum of the total sensible heat load and total latent heat load. The sensible heat ratio is assumed for various scenarios based on the building envelope and occupancy level. The infiltration of air into the building and the number of occupants 
in the space increases the latent cooling load of the room. Table 3.9 provides values for SHR for various scenarios of building envelope and occupancy level.

Table 3.9: SHR based on BE and occupancy level

\begin{tabular}{|c|c|c|}
\hline Building Envelope & $\begin{array}{c}\text { Occupancy level } \\
(\mathbf{\%})\end{array}$ & $\begin{array}{c}\text { Sensible Heat Ratio } \\
\text { (S.H.R) }\end{array}$ \\
\hline \multirow{4}{*}{ Good } & 0 & 0.9 \\
\cline { 2 - 3 } & $1-25$ & 0.85 \\
\cline { 2 - 3 } & $26-50$ & 0.8 \\
\cline { 2 - 3 } & $51-75$ & 0.75 \\
\cline { 2 - 3 } & $76-100$ & 0.7 \\
\hline \multirow{4}{*}{ Poor } & 0 & 0.7 \\
\cline { 2 - 3 } & $1-25$ & 0.65 \\
\cline { 2 - 3 } & $26-50$ & 0.6 \\
\cline { 2 - 3 } & $51-75$ & 0.55 \\
\cline { 2 - 3 } & $76-100$ & 0.5 \\
\hline
\end{tabular}

For instance, with a building with a good envelope and low occupancy (25\% - 50\%), the sensible heat ratio is considered to be 0.8 . This means that the sensible load contributes $80 \%$ of the load while the latent load contributes $20 \%$.

\subsection{Simulation Description}

This simulation aims to determine the effectiveness of BEMS by calculating the annual HVAC energy consumption with varying BEMS controls and building operating parameters. In this research, energy consumption has been shown for one year for the given building using VBA. The program developed here is very user-interactive, where the user can select various inputs to define the scenario appropriately. Additionally, the users can change the expected occupancy levels for a more precise simulation of the building under consideration.

\subsubsection{Users Inputs and Outputs}

The energy consumption simulation program has been divided into five sections: User manual, Inputs, Reference, Climatic data, and Occupancy. At first, the "User Manual" sheet of MS excel describes the complete process step by step to guide the users through the simulation process. Next, the "Inputs" sheet of the Microsoft Excel software asks a user to select several rooms in the building. Additionally, the user also must provide the type of 
rooms, a dimension of the room, setpoint and setback thermostat temperature for summer and winter months, location of the building (Climatic zone, State and City). The reference sheet contains information required for energy calculation based on the weather, Occupancy chart, ASHARE standard for people, and area outdoor air rate for various types of rooms and fuel types. Upon providing all the information on the input page, the program starts the calculation and shows the expected number of occupants and outdoor air $(\mathrm{cfm})$ requirements for each room. At the very end, the tool will ask for the source of energy for heating the building, the average cost of electricity $(\$ / \mathrm{kWh})$, and an average cost of natural gas (\$/MMBtu).

In the excel file, sheets are generated for each room with the associated expected number of occupancies for every 30 minutes. The number of occupancies is determined according to the occupancy schedule chart and a random number between 0 and 1 . With the help of the MCS and heuristic rules, the expected number of occupancies is determined based on the arbitrary occupancy level. The thermostat setting for each type of room is input by the user; hence there will be no random number generation. Now, the simulation will calculate the HVAC energy consumption at 30 minutes intervals for the building for 365 days. The energy consumption sheet is also generated for each room, respectively, where the heat load (sensible and latent during summer and only sensible during winter) is shown. Moreover, for electricity has an energy source for heating and cooling the building, the power $(\mathrm{kW})$ and energy consumption $(\mathrm{kWh})$ are also shown in the same excel sheet. However, for natural gas as a heating source, energy consumption (Btu) is shown during the winter months.

Finally, a total energy consumption sheet is generated where the total HVAC energy consumption for the building is calculated. Another sheet with a twelve-monthly summary of energy consumption is also generated. This gives us a baseline of energy consumption of the building according to the current condition.

Furthermore, for the second simulation run (TEE case), all the worksheets are cleared from the first simulation except for the twelve-month summary table of energy. For the second simulation, the user should select all the BEMS controls and improved building envelope, and the total energy consumption is determined as similar to the first simulation run. The 
energy consumption data between the TEE Case and Base Case is analyzed to evaluate the effectiveness of BEMS.

The simulation model does not have any input system to indicate the position of individual rooms based on the physical layout. The user can select the type of room from the dropdown menu of different types of rooms. Furthermore, the user also does not have the option to select between the placement of the room (interior versus exterior).

However, the user can select the building envelope level for each room. The building envelope level is divided into two levels: level 1 and level 2. Level 1 indicates poor insulation, has infiltration of air and single-pane windows, whereas level 2 means good insulation, no infiltration of air, and double pane windows. Since the model does not allow the user to input the rooms based on the physical layout and placement of the rooms (interior versus exterior), the user can change the level of the building envelope based on the physical layout and placement of the rooms. For example, suppose a room lies in exterior position and has poor wall insulation, degradation of weatherstripping at windows and doors, and single or double pane windows. In that case, the user can change the level of the building envelope to level 1. On the contrary, if the room lies in an interior position, there is no need to account for wall insulation, and hence, the user can set the building envelope level to level 2. Therefore, users can decide the level of the building envelope for each of the rooms based on the placement of the rooms and physical layout.

\subsubsection{Description of Energy Consumption Calculation}

In this study, user input values are taken into consideration for determining the building operating parameters. The user can also select the BEMS controls that are used in the building from the given option. Based on these inputs, the energy consumption of the building was calculated.

Initially, the supply air requirement of individual spaces is determined based on $\mathrm{ACH}$. Considering the proportionality change in air change per hour to the change in occupancy level, the new air change per hour is calculated for each room. Then, the required air volume $(\mathrm{cfm})$ is calculated based on the new air change per hour. Furthermore, the outdoor air required for the given level of occupancy is calculated for each room. The outside and return air percentages are determined based on the total volume of necessary supply air and 
outside fresh air. Moreover, the temperature and humidity ratio of the mixed air is calculated based on the percentage of outside and return air.

Based on the building envelope input by the user and the occupancy level, the sensible heat ratio (SHR) and the load factor for estimating the SAT are determined. Also, the sensible heating load or cooling load is determined based on the temperature difference between supply air and room temperature. Further, the latent heating or cooling load is determined by using the values of SHR and sensible heating or cooling load, respectively. Moreover, the humidity ratio is calculated for the supply air condition from the determined value of latent heating or cooling load.

Then, depending upon the summer or winter season, the energy required for heating or cooling the supply air is calculated. For example, during the summer season, the energy needed for both sensible cooling and dehumidification of air is calculated due to higher humidity in the air. For the winter season, the energy required for only sensible heating is calculated. Furthermore, the power needed for the HVAC unit to remove the heat load during the summer or add heat during the winter is calculated. The power is thus converted to the energy required by multiplying with the time unit. Hence, the total energy consumed by the HVAC system of the building is obtained.

Air-Change per Hour (ACH): At full occupancy, the value of $\mathrm{ACH}$ is used according to the given ASHRAE Standard 62.1 - 2019 for a particular type of room. But, during partload occupancy, the value of ACH is calculated proportionally to the level of occupancy. For example, at half occupancy, the rate of $\mathrm{ACH}$ is also halved. However, during no occupancy, the $\mathrm{ACH}$ is calculated based on dimensions of the room and area outdoor air rate.

$$
\mathrm{ACH}_{\text {new }}=\% \text { Occupancy } \mathrm{x} \mathrm{ACH}
$$

During no-occupancy:

$$
\mathrm{ACH}_{\text {new }}=\mathrm{A} \times \mathrm{R}_{\mathrm{a}} \times 60 / \mathrm{V}
$$

Where,
A
$=\quad$ Area of the space
$\mathrm{R}_{\mathrm{a}}$
$=\quad$ Area Outdoor Air Rate 


$$
\mathrm{V} \quad \text { Volume of the Room }
$$

Supply Air Requirement: Based on the $\mathrm{ACH}_{\text {new }}$, the required supply air (cfm) is determined.

$$
V_{T}=\sum_{i=1}^{n} \operatorname{Vix}\left(A C H_{n e w}\right) \mathrm{i} / 60
$$

Where,

$$
\begin{array}{lll}
\mathrm{V}_{\mathrm{T}} & = & \text { Total requirement of supply air, cfm } \\
\mathrm{Vi} & = & \text { Volume of zone } \mathrm{i}, \mathrm{ft}^{3} \\
\mathrm{n} & = & \text { Total number of zones }
\end{array}
$$

Outdoor Air Requirements: The outside air required for a specific type of space can be calculated as:

$$
\text { Vo } \quad \sum_{i=1}^{n} \mathrm{~N} \times \mathrm{Rp}+\mathrm{A} \times \mathrm{Ra}
$$

Where,

$$
\begin{array}{lll}
\mathrm{V}_{\mathrm{o}} & = & \text { Outside Air Required for all the zones }(\mathrm{cfm}) \\
\mathrm{N} & = & \text { Number of Occupants in zone } \mathrm{i} \\
\mathrm{R}_{\mathrm{p}} & = & \text { People Outdoor Air Rate for zone } \mathrm{i} \\
\mathrm{A} & = & \text { Area of the space of zone } \mathrm{i} \\
\mathrm{R}_{\mathrm{a}} & = & \text { Area Outdoor Air Rate for zone } \mathrm{i}
\end{array}
$$

The number of occupants cannot exceed the designed allowable number of people (\# of people/1000 $\mathrm{ft}^{2}$ ) in the given space according to the ASHRAE Standard 62.1 - 2019. For example, in "Breakrooms," the designed allowable number of people is $25 / 1000 \mathrm{ft}^{2}$. The people's outdoor air rate and area outdoor air rate are determined according to the ASHRAE Standard 62.1 - 2019 for the given type of room. The area of the space and number of occupants is taken as input from the user. 
Return Air Thermal Conditions: The thermal conditions (temperature and humidity ratio) of the return air are determined from two factors: temperature, humidity ratio of return air from each zone, and amount of air $(\mathrm{cfm})$ returned from each zone. The temperature of the return air can be calculated as follows:

$$
T_{r}=\sum_{i=1}^{n} T_{r i} \cdot\left(\frac{V_{r i}}{V_{R}}\right)
$$

$\mathrm{T}_{\mathrm{r}}=$ dry-bulb temperature of the mixed return air, $\left({ }^{\circ} \mathrm{F}\right)$

$\mathrm{T}_{\mathrm{ri}}=$ dry-bulb temperature of return air from zone $\mathrm{i},\left({ }^{\circ} \mathrm{F}\right)$

$\mathrm{V}_{\mathrm{Ri}}=$ Return air from zone $\mathrm{i},(\mathrm{cfm})$

$\mathrm{V}_{\mathrm{R}}=$ Total return air from all zones $(\mathrm{cfm})$

The humidity ratio of the return air can be calculated as:

$$
h_{r}=\sum_{i=1}^{n} h_{r i} \cdot\left(\frac{V_{r i}}{V_{R}}\right)
$$

Where,

$$
\begin{array}{lll}
\mathrm{h}_{\mathrm{r}} & =\quad \text { humidity ratio of return air } \\
\mathrm{h}_{\mathrm{ri}} & =\quad \text { humidity ratio of return air from zone } \mathrm{i}
\end{array}
$$

The humidity ratio depends upon the elevation, temperature, and relative humidity. The relative humidity of the air at room condition is assumed to be a constant value of $50 \%$. For deriving the equation for the indoor humidity ratio, five different sets of temperature $(65,70,75,80$, and 85) and ten different sets of elevation $(10,60,200,500$ 1,000, 3,000, $8,000,10,000,12,000$ and 14,500) were taken. The humidity ratio was determined for each combination of temperature and elevation using an online humidity ratio calculator [56]. A linear regression approach was used for the obtained data, and the following equation for the indoor humidity ratio was determined. The coefficient of determination for the fitted regression line is determined to be $96.82 \%$.

$$
\mathrm{h}_{\mathrm{r} 1}=-1.9958296 \times 10^{-2}+3.909277 \times 10^{-4} \times T_{r}+4.7285411 \times 10^{-7} \times h
$$

Where, 
$\mathrm{h}=\quad$ elevation in feet

Here, the humidity ratio of return air from zone 1 can be determined by substituting the return air temperature from zone 1 and the location's elevation.

Mixed Air Thermal Conditions: The outside air is mixed with the return air to reduce the energy consumption for conditioning the air while maintaining the IAQ guided by ASHRAE Standard 62.1 - 2019. The temperature of the mixed air can be calculated as follows:

$$
\mathrm{T}_{\mathrm{m}}=\mathrm{T}_{\mathrm{o}} \mathrm{x}\left(\mathrm{V}_{\mathrm{o}} / \mathrm{V}_{\mathrm{T}}\right)+\mathrm{T}_{\mathrm{r}} \mathrm{x}\left(\left(\mathrm{V}_{\mathrm{T}}-\mathrm{V}_{\mathrm{o}}\right) / \mathrm{V}_{\mathrm{T}}\right)
$$

Where,

$$
\begin{array}{ll}
\mathrm{T}_{\mathrm{m}} & =\text { dry-bulb temperature of mixed air } \\
\mathrm{T}_{\mathrm{o}} & =\text { dry-bulb temperature of outside air }
\end{array}
$$

Here, the dry-bulb temperature of outside air is determined according to the location selected by the user.

The humidity ratio of the mixed air can be calculated as:

$$
\mathrm{h}_{\mathrm{m}}=\mathrm{h}_{\mathrm{o}} \mathrm{x}\left(\mathrm{V}_{\mathrm{o}} / \mathrm{V}_{\mathrm{T}}\right)+\mathrm{h}_{\mathrm{r}} \mathrm{x}\left(\left(\mathrm{V}_{\mathrm{T}}-\mathrm{V}_{\mathrm{o}}\right) / \mathrm{V}_{\mathrm{T}}\right)
$$

Where,

$$
\begin{array}{lll}
\mathrm{h}_{\mathrm{m}} & = & \text { humidity ratio of mixed air } \\
\mathrm{h}_{\mathrm{o}} & = & \text { humidity ratio of outside air } \\
\mathrm{h}_{\mathrm{r}} & = & \text { humidity ratio of return air }
\end{array}
$$

Here, the humidity ratio of the outside air is determined according to the location selected by the user.

Humidity Ratio of Supply Air: The thermal conditions (temperate, humidity ratio) of supply air are required to determine energy consumed by the heating or cooling unit. The supply air temperature is estimated based on the level of occupancy, building envelope condition, and weather factor. The rule is designed to select SAT based on those two factors as given in Table 3.7 and Table 3.8.

Sensible load calculation: 
As an example, the sensible cooling load during summer months for zone 1 is calculated as:

$$
\mathrm{Q}_{\mathrm{sl}}=\left(\mathrm{V}_{\mathrm{T} 1} \times 60 / \mathrm{v}\right) \times \mathrm{c}_{\mathrm{p}} \times\left(\mathrm{T}_{\mathrm{r} 1}-\mathrm{T}_{\mathrm{s} 1}\right)
$$

Where,

$$
\begin{array}{lll}
\mathrm{V}_{\mathrm{T} 1} & = & \text { total supply air at zone } 1, \mathrm{cfm} \\
\mathrm{v} & = & \text { specific volume of air at standard condition, } 13.3 \mathrm{ft}^{3} / \mathrm{lb} \\
\mathrm{c}_{\mathrm{p}} & = & \text { specific heat of air at standard conditions, } 0.24 \mathrm{Btu} / \mathrm{lb}-{ }^{\circ} \mathrm{F} \\
\mathrm{T}_{\mathrm{s} 1}= & \text { dry-bulb temperature of supply air for zone } 1
\end{array}
$$

The sensible heating load during winter months for zone 1 is calculated as:

$$
\mathrm{Q}_{\mathrm{sl}}=\left(\mathrm{V}_{\mathrm{T} 1} \times 60 / \mathrm{v}\right) \times \mathrm{c}_{\mathrm{p}} \times\left(\mathrm{T}_{\mathrm{s} 1}-\mathrm{T}_{\mathrm{r} 1}\right)
$$

The total heating/ cooling load for zone 1 is calculated as:

$$
\mathrm{Q}_{\mathrm{T} 1}=\mathrm{Q}_{\mathrm{sl}} / \mathrm{SHR}
$$

Where,

$$
\begin{array}{lll}
\mathrm{Q}_{\mathrm{T} 1}= & \text { Total heating/ cooling load for zone } 1 \\
\mathrm{Q}_{\mathrm{sl}}= & \text { Total sensible load } \\
\mathrm{SHR}= & \text { sensible heat ratio }
\end{array}
$$

Similarly, the total sensible load and total heating/cooling load for all the zones in the building are calculated to determine the total heating/cooling load of the building. The sensible heat ratio is determined based on Table 3.9.

The humidity ratio of the supply air during summer months for zone 1 is calculated as:

$$
\mathrm{h}_{\mathrm{s} 1}=\mathrm{h}_{\mathrm{r} 1}-\left(\left(\mathrm{Q}_{\mathrm{T} 1}-\mathrm{Q}_{\mathrm{s} 1}\right) /\left(\mathrm{V}_{\mathrm{T} 1} \times \mathrm{C}\right)\right)
$$

Where,

$\mathrm{h}_{\mathrm{s} 1}=$ humidity ratio of air leaving the cooling unit for zone 1 (lbm moisture/lbm of dry air)

$\mathrm{h}_{\mathrm{r} 1}=$ humidity ratio of air in the zone 1 (lbm moisture/lbm of dry air) 


$$
\mathrm{C}=\text { conversion constant, } 4,840\left(\text { Btu-min } / \mathrm{hr}-\mathrm{ft}^{3}\right)
$$

The humidity ratio of the supply air during winter months for a zone is calculated as:

$$
\mathrm{h}_{\mathrm{sw} 1}=\left(\left(\mathrm{Q}_{\mathrm{T} 1}-\mathrm{Qs}_{\mathrm{l}}\right) /\left(\mathrm{V}_{\mathrm{T} 1} \times \mathrm{C}\right)\right)-\mathrm{h}_{\mathrm{r} 1}
$$

Similarly, the humidity ratio of the supply air for all the zones is calculated.

Load on Heating / Cooling Unit: The load on the heating or cooling unit is determined based on the heating or cooling degree days for a given climatic region selected by the user. For example, during the summer months, the cooling load for the cooling unit is calculated, whereas during the winter months heating load for the heating unit is calculated.

Cooling unit load: The cooling unit load is determined by calculating the sensible and latent cooling load for the cooling and dehumidification unit. For example, the sensible cooling unit load for zone 1 is calculated as:

$$
\mathrm{Q}_{\mathrm{sc} 1}=\left(\mathrm{V}_{\mathrm{T} 1} \times 60 / \mathrm{v}\right) \times \mathrm{c}_{\mathrm{p}} \times\left(\mathrm{T}_{\mathrm{m}}-\mathrm{T}_{\mathrm{s} 1}\right)
$$

Where,

$$
\begin{array}{ll}
\mathrm{Q}_{\mathrm{sc1}}= & \text { Sensible Cooling unit load for zone 1(Btu/hr) } \\
\mathrm{K} & =\text { conversion constant, } 60 \mathrm{~min} / \mathrm{hr}
\end{array}
$$

The latent cooling unit load for zone 1 is calculated as:

$$
\mathrm{Q}_{11}=\mathrm{V}_{\mathrm{T} 1} \times \mathrm{C} \times\left(\mathrm{h}_{\mathrm{m}}-\mathrm{h}_{\mathrm{s} 1}\right)
$$

Where,

$$
\mathrm{Q}_{11} \quad=\quad \text { Latent Cooling load for zone } 1(\mathrm{Btu} / \mathrm{hr})
$$

Similarly, the sensible and latent cooling unit loads for all the zones are determined accordingly.

Heating unit load: The heating unit load is determined by calculating the sensible heating unit load. For example, the sensible heating unit load for zone 1 is calculated as:

$$
\mathrm{Q}_{\mathrm{sh} 1}=\left(\mathrm{V}_{\mathrm{T} 1} \times 60 / \mathrm{v}\right) \times \mathrm{c}_{\mathrm{p}} \times\left(\mathrm{T}_{\mathrm{s} 1}-\mathrm{T}_{\mathrm{m}}\right)
$$

Where,

$$
\mathrm{Q}_{\text {sh1 }}=\text { Sensible heating load }(\mathrm{Btu} / \mathrm{hr})
$$


Similarly, the sensible heating load for all the zones is determined accordingly.

HVAC: The HVAC energy consumption for zone 1 can be calculated as:

During Summer Months,

$$
\mathrm{E}_{\mathrm{S} 1}=\left(\left(\mathrm{Q}_{\mathrm{C} 1} \times \mathrm{W} \times \mathrm{OH}\right) *(\mathrm{WF}+\mathrm{BE})\right) /(\mathrm{T} \times \mathrm{COP})
$$

Where,

$\mathrm{E}_{\mathrm{S} 1}=\quad \mathrm{HVAC}$ energy consumption during summer for zone $1(\mathrm{kWh})$

$\mathrm{Q}_{\mathrm{C} 1}=$ Total cooling load for zone 1 (sensible cooling load for zone $1\left(\mathrm{Q}_{\mathrm{sc} 1}\right)$ + latent cooling load for zone $\left.\left(\mathrm{Q}_{11}\right)\right)$

$\mathrm{W}=$ Tons to Kilowatt conversion constant, $3.516 \mathrm{~kW} / \mathrm{ton}$
$\mathrm{OH}=$ Operating hours, 0.5 for 30 minutes interval
$\mathrm{T}=$ Tons to Btu/hr conversion constant, 12,000 Btu/hr-ton
$\mathrm{COP}=$ Coefficient of Performance
$\mathrm{WF}=$ Weather Factor
$\mathrm{BE}=$ Building envelope fator

Here, the total cooling load is determined from the above calculation in "Cooling unit load." COP of the HVAC unit is input by the user. Similarly, the total energy consumption during summer is calculated by summation of cooling energy consumption from all the zones in the building.

During Winter Months,

$$
\begin{array}{r}
\mathrm{E}_{\mathrm{W} 1}=\left(\left(\mathrm{Q}_{\mathrm{sh} 1} \times \mathrm{OH}\right) *(\mathrm{WF}+\mathrm{BE})\right) /\left(\mathrm{Eff}_{\mathrm{e}} \times 3,412 \mathrm{Btu} / \mathrm{kWh}\right) \\
\text { Note: For electric heating system } \\
\mathrm{E}_{\mathrm{W} 1=} \quad\left(\left(\mathrm{Q}_{\mathrm{sh} 1} \times \mathrm{OH}\right) *(\mathrm{WF}+\mathrm{BE})\right) / \mathrm{Eff}_{\mathrm{g}} \quad \text { Note: For Gas Heating system }
\end{array}
$$

Where,

$$
\begin{aligned}
& \mathrm{E}_{\mathrm{W} 1}=\quad \text { heating unit energy consumption during winter for zone } 1(\mathrm{kWh}) \\
& \mathrm{Q}_{\mathrm{sh} 1}=\quad \text { Sensible heating unit load }
\end{aligned}
$$




$$
\begin{aligned}
& \text { Eff }_{\mathrm{e}}=\quad \text { System efficiency of electrical heating system } \\
& \text { Eff }_{\mathrm{g}}=\quad \text { System efficiency of gas heating system }
\end{aligned}
$$

Similarly, the heating energy consumption for all the zones is calculated by summation of heating energy consumption from all the zones in the building.

Hence, the total annual energy consumed by the HVAC system is determined by the summation of the energy consumed during the summer months and winter months.

$$
T E=\sum_{i=1}^{n}\left(E_{s i}+E_{w i}\right)
$$

Where,

\section{$\mathrm{TE}=$ Total energy consumed by the HVAC system}

\subsubsection{Rating for Effectiveness of BEMS}

For determining the effectiveness of BEMS, two types of energy sources are considered in this simulation tool, i.e., electricity and natural gas. To normalize both kinds of energy sources for comparison, they are converted to their respective cost. The average cost of electricity $(\$ / \mathrm{kWh})$ is used that is calculated by dividing the total electricity cost in a year by total electricity $(\mathrm{kWh})$ consumption. This electricity cost includes all the expenses included in the electric bill, such as demand charge, customer charge, and taxes. Similarly, the average natural gas cost $(\$ / M M B t u)$ is used for determining the cost of natural gas. Moreover, the total cost for electricity and natural gas is determined for each month, and the percentage of electricity and the natural gas cost is calculated for respective months.

Furthermore, a continuous scale of 1 to 5 is used to determine the effectiveness of BEMS, where a rating of 1 represents poor, and 5 represents excellent energy management system, respectively. The rating of BEMS starts with 1, and the remaining 4 scores are assigned to the electrical and natural gas energy based on the percentage of their energy cost for each month.

For instance, during January, the electricity consumption is $3,500 \mathrm{kWh}$, and natural gas consumption is $55 \mathrm{MMBtu}$, as obtained from the simulation tool for the user-defined case. The average cost of electricity is $\$ 0.1011 / \mathrm{kWh}$, and natural gas is $\$ 9.52 / \mathrm{MMBtu}$. The 
electricity cost is $\$ 353.85$ (i.e., $3,500 \mathrm{kWh} \times \mathbf{x} \$ 0.1011$ ) and the natural gas cost is $\$ 523.6$ (i.e., 55 MMBtu x $\$ 9.52 /$ MMBtu). The total cost of energy consumption for January is $\$ 877.45$. (i.e., $\$ 353.85+\$ 523.6$ ). Moreover, the percentage of electricity cost is $40.33 \%$ (i.e., $\$ 353.85$ / $\$ 877.45 \times 100$ ) and natural gas is $59.67 \%$. Then, out of 4 , the total scale for electricity is 1.6132 (i.e., $40.33 \%$ x 4), and for natural gas is 2.3868 .

Furthermore, once the energy consumption data for the Base Case and TEE case has been determined, the percentage difference of the TEE case from the Base Case is calculated for both electricity and natural gas. Moreover, the total scale assigned for electricity and natural gas is multiplied with the remaining percentage value than what was obtained from the TEE case and Base Case difference for electricity and natural gas.

For instance, if the electricity consumption obtained from TEE case is 1,078 $\mathrm{kWh}$ and natural gas is $15 \mathrm{MMBtu}$, then the percentage difference of TEE case from Base Case for electricity consumption is $69.2 \%$ (i.e. $(3,500 \mathrm{kWh}-1,078 \mathrm{kWh}) \times 100 / 3,500 \mathrm{kWh})$ and for natural gas is $72.72 \%$ (i.e. (55 MMBtu - 15 MMBtu) x 100 / 55 MMBtu). The effectiveness of BEMS is obtained by multiplying the remaining percentage of the difference with the assigned scale for electricity and natural gas.

$$
\text { (i.e., } 1+(100 \%-69.2 \%) \times 1.6132+(100 \%-72.72 \%) \times 2.3868)=2.15
$$

Hence, an effectiveness rating of 2.15 out of 5 is obtained for the building for January. Similarly, the effectiveness rating for all other months is calculated as well.

Here, if the difference of energy consumption between the Base Case and TEE Case is 0\% (i.e., building has all the BEMS controls and good building envelope), then the rating of the effectiveness of BEMS would be 5 .

(i.e., $1+(100 \%-0 \%) \times 1.6132+(100 \%-0 \%) \times 2.3868)=5$

The overall effectiveness of the BEMS is determined in similar way by taking tenergy consumption data. A rating Table 3.10 is given below for guiding users regarding the meaning of the rating value. 
Table 3.10: User Guidance for representation of rating value

\begin{tabular}{|c|c|}
\hline Range of rating value & Effectiveness of BEMS \\
\hline $1-2$ & Poor \\
\hline $2-2.75$ & Not Good \\
\hline $2.75-3.5$ & Not Satisfactory \\
\hline $3.5-4$ & Satisfactory \\
\hline $4-4.75$ & Good \\
\hline $4.75-5$ & Excellent \\
\hline
\end{tabular}

*the range of rating starts from the left-hand side value

Table 3.11: Example of determination of the effectiveness of BEMS

\begin{tabular}{|c|c|c|c|c|c|c|c|}
\hline \multirow{2}{*}{ Month } & \multicolumn{2}{|c|}{ kWh } & \multicolumn{2}{c|}{ MMBtu } & \multicolumn{2}{c|}{ Percentage difference from Base Case } & \multirow{2}{*}{$\begin{array}{c}\text { Effectiveness of } \\
\text { BEMS (1-5) }\end{array}$} \\
\cline { 2 - 7 } & Base Case & TEE Case & Base Case & TEE Case & kWh usage & MMBtu usage & 2.09 \\
\hline January & 4,167 & 1,303 & 56.98 & 14.1 & $69 \%$ & $76 \%$ & 2.85 \\
\hline February & 3,558 & 2,044 & 49.56 & 19.19 & $43 \%$ & $62 \%$ & 2.09 \\
\hline March & 2,531 & 773 & 34.49 & 8.86 & $70 \%$ & $81 \%$ & 1.87 \\
\hline April & 1,875 & 479 & 24.48 & 4.88 & $75 \%$ & $0 \%$ & 1.6 \\
\hline May & 1,205 & 186 & 0 & 0 & $85 \%$ & $0 \%$ & 3.16 \\
\hline June & 5,102 & 2,758 & 0 & 0 & $46 \%$ & $0 \%$ & 2.4 \\
\hline July & 7,689 & 2,763 & 0 & 0 & $65 \%$ & $0 \%$ & 3 \\
\hline August & 6,527 & 3,278 & 0 & 0 & $50 \%$ & $0 \%$ & 1.64 \\
\hline September & 3,992 & 640 & 0 & 0 & $84 \%$ & $0 \%$ & 2.12 \\
\hline October & 2,291 & 663 & 0 & 0 & $72 \%$ & $80 \%$ & 1.89 \\
\hline November & 1,921 & 496 & 26.17 & 5.34 & $75 \%$ & $68 \%$ & 2.48 \\
\hline December & 3,014 & 1,305 & 41.17 & 13.3 & $57 \%$ & $72 \%$ & 2.39 \\
\hline Total & 43,872 & 16,688 & 233 & 66 & $62 \%$ & & \\
\hline
\end{tabular}

\subsubsection{Reduction of GHG Emissions for Site Energy and Source Energy}

Source energy is the total primary energy consumption (i.e., Site energy) plus all distribution and production losses. In contrast, site energy is the combination of primary and secondary energy purchased directly for use at the building. Each fuel source is multiplied by a Site-to-Source conversion factor to obtain delivery and production losses. 
Table 3.12: Source-Site ratios for various energy types [57]

\begin{tabular}{ccc} 
Energy Type & U.S. Ratio & Canadian Ratio \\
\hline Electricity (Grid Purchase) & 2.80 & 1.96 \\
Electricity (Onsite Solar or Wind - regardless of REC ownership) & 1.00 & 1.00 \\
Natural Gas & 1.05 & 1.01 \\
Fuel Oil (No. 1,2,4,5,6, Diesel, Kerosene) & 1.01 & 1.01 \\
Propane \& Liquid Propane & 1.01 & 1.04 \\
Steam & 1.20 & 1.33 \\
Hot Water & 1.20 & 1.33 \\
Chilled Water & 0.91 & 0.57 \\
Wood & 1.00 & 1.00 \\
Coal/Coke & 1.00 & 1.00 \\
Other & 1.00 & 1.00
\end{tabular}

The basic fuels used to generate heat and electricity, such as natural gas, coal, and fuel oil, are the primary energy sources. The energy product formed from raw fuel, such as heat (acquired from a district steam system) and electricity, is referred to as secondary energy sources (purchased from the grid).

In this research, the reduction of $\mathrm{CO}_{2}$ emission was calculated based on annual energy savings by adding BEMS controls and/or improvement in the building envelope. The site energy usage obtained from the first simulation (i.e., Base Case) and second simulation (i.e., TEE Case) and reduction of energy between the two cases are converted to source energy by multiplying with 2.8 for electrical energy source and 1.05 for natural gas. Furthermore, the reduction of $\mathrm{CO}_{2}$ emission was calculated by multiplying the $\mathrm{CO}_{2}$ emission rate of $2.19 \mathrm{lbs} / \mathrm{kWh}$ for electrical energy and $113 \mathrm{lbs} / \mathrm{MMBtu}$ of natural gas for both site and source energy. Finally, the total reduction of $\mathrm{CO}_{2}$ emission was obtained by summing the each of energy source for site energy and source energy.

\subsubsection{Verification of the Simulation Tool}

Three different methods were used for the verification of the data obtained from the simulation tool. For the first method, the utility bill of the building is analyzed. Based on the estimation of energy consumption of the auxiliary unit, the energy required for space heating and cooling for every month is estimated. This estimated value is compared against the data obtained from the simulation tool. 
Furthermore, the energy required for space heating and cooling is also calculated based on the DD method. Based on the capacity of HVAC units, HDD, and CDD, the energy required for heating and cooling the building is determined monthly. Thus, obtained data is also used to compare the data obtained from the simulation tool.

Finally, the building is modeled using a DOE's software: eQuest. eQuest is an energy modeling software that allows users to model the building and run a simulation to evaluate energy consumption impacts under various design conditions. The user-defined parameters and BEMS controls are used for modeling the building. This software is used as a verification tool for comparing the annual HVAC energy consumption obtained from the software against the developed simulation tool. In this way, if similar data is obtained from verification methods, it can be concluded that the methodology used in the simulation tool is working as intended.

\subsection{Conclusion}

The proposed method is a simulation model designed in MS Excel with multiple tabs for different functions such as guiding users about simulation procedure, the input of userdefined building parameters, and storage of data for calculation. Once the user inputs the data into the model, the underlying calculations are executed based on an algorithm developed through VBA. The results include determination of ventilation requirement for individual spaces to maintain IAQ, HVAC energy consumption, and effectiveness of BEMS. Further, the obtained results are also verified using three different methods of verification. Hence, overall, this tool was designed for users to understand the effectiveness of their BEMS. 


\section{Simulation Tool Development}

\subsection{Simulation Excel Input Tabs Details}

This excel-based effectiveness of energy management system determination of buildings contains five worksheets named User Manual, Reference, Inputs, Occupancy, and Climatic Data.

\subsection{1 "User Manual" Worksheet}

The "User Manual" worksheet briefly describes the factors considered for the simulation, the simulation procedure, assumptions, and limitations of this simulation tool. This manual aims to guide the user to run the simulation step by step and describe the required methods to get the correct simulation results. Figure 4.1 shows the screenshot of the user manual of the excel file.

In the first section, various factors considered for the simulation are listed: occupancy, room characteristics, thermostat settings, weather factor, BEMS controls, and building envelope factor.

In the second section of the manual, the procedure for running the simulation is described in detail. The first step is to clear the past data if there is any. This can be achieved by using the "Clear" button in the sheet "User Manual." Once the past information is cleared, the user can start the simulation by clicking the "Start Simulation" button.

In the third section, the assumption made for the development of the simulation model is described. Finally, in the last section, the limitation of the simulation model are discussed. The user is advised to go through all the assumptions and limitations of the model better to understand the performance capability of the simulation tool. 


\section{User Manual}

This simulation model provides effectivness of an energy management system of a building considering the energy consumption by HVAC system

Factors to be considered

1 Occupancy: "Occupied" or "Unoccupied" \& expected occpancy level during occupied hours

2 Room Characterisitcs: Dimensions of the room and type of room

3 Thermostat Settings: Setpoint and Setback temperature during summer and winter

4 Weather factor: 1 or 2 or 3 indicating Good or Mild or Harsh weather conditions

5 BEMS controls: 1 through 10 indicating combination of various BEMS controls

6 Building Envelope factor: 1 or 2 indicating Poor or Good insulation in the respective room

Building Envelope include insulation of the rooms, infiltration of air, window shading, type of windows and fenestration

Procedure: The simulation excel file contains five sheets titled "User Manual", "Reference", "Occupancy", "Climatic Data" and "Inputs". Do not delelte these sheets.

1 Start the simulation by deleting the past data. Hit "Clear" button

2 Start the simulation by clicking the "Start Simulation" button.

3 This prompts the user to enter the number of room

4 Select the BEMS controls that the building has from the given option, if the building does not have DCV system then user is asked to enter percentage of outside air intake into the building.

5 Then the model redirects to the input page displaying a color coded table for user to input building parameters.

$\begin{array}{lll}6 & \text { Select the type of rooms, and building envelope from the list in their particular cell. }\end{array}$

\begin{tabular}{l|l}
7 & Enter the area and height of room and thermostat settings of each room
\end{tabular}

8 The feasiblity of generating effective energy efficiency by BEMS controls can be check by clicking the "Check Feasibility" button

9 Then proceed to STEP 1 , Step 2, STEP 3, STEP 4 and STEP 5.

10 In Step 1, Enter the region number, state number and nearest weather station number of your location from the given option list. Also enter the design supply air temperature during summer and winter months.

11 In step 3, enter the type of energy source used for heating i.e., Natural gas / Electricity

12 After clicking step 4, the annual energy consumption of the building is displayed.

13 Then, the user is taken back to the user manual page. Click the clear button. This clear the existing records except for the summary of energy consumption data of the building.

14 Repeat the step from step 3 to step 13. Remember to select "All" during selection of bems controls and set the building envelope to level 2.

15 Then click step 5 and enter the average cost of electricity $(\$ / \mathrm{kWh})$ and natural gas $(\$ / \mathrm{MMBtu})$.

16 Finally, the effectiveness of the energy management system is displayed between a continuous scale of 1- 5.

\begin{tabular}{|c|l|}
\hline \multicolumn{2}{|l|}{ Assumptions } \\
\hline 1 & The time interval for the simulation has been considered 30 minutes. So, it will not be able to detect determine the ventilation requirement or energy consumption between 0-30 minute interval. \\
\hline 2 & The temperature of the return air is assumed to be same as that of room temperature. \\
\hline 3 & The loss of energy for the return air is negleded and the misture of outside air and return air is considered as an ideal mixture. \\
\hline 4 & The weather factor are updated only after 8 hours. \\
\hline 5 & The values in occupancy chart are assumed to be same for similar types of rooms \\
\hline 6 & Relative humidity for thermal comfort condition is assumed to be at 50 percent. \\
\hline 7 & A natural disaster is ignored in this simulation. \\
\hline \multicolumn{3}{|l}{} \\
\hline 1 & The model uses many input boxes, none of them take any character (alphabet/words) or 0 or anything out of the range. \\
\hline 2 & The model is capacble of handling only 16 different types of rooms / spaces. \\
\hline 3 & The model is designed to handle any number of rooms but considering the time it takes on normal computers it is advised to limit under 20 rooms. \\
\hline 4 & The simulation time varies anywhere between 35 minutes to 45 minutes for ten rooms and increases by about 3-5 minutes for every addition of room. \\
\hline 5 & The excel program may not respond when the simulation is running, however, it responds once the simulation is finished. \\
\hline 6 & The simulation model only has two states from each climatic region and two weather station from each state. \\
\hline 7 & Only electricity and natural gas are accounted as sources of energy. \\
\hline 8 & The season factor is generated for Zone 1 and will remain contant for all the other zones for particular hours. \\
\hline 9 & There are various BEMS controls, but only zoning control, temperature setback cotnrol, DCV system and SATR control are considered. \\
\hline 10 & Only dehumidification of air is accounted for energy calculation and not the humdification process for simplicity in calculations. \\
\hline 11 & The feasibility of DCV system depends on various factors according to ASHRAE 62.1-2019 standard but only area and occupant density of a room is considered. \\
\hline
\end{tabular}

\section{Figure 4.1: "User Manual” worksheet}




\subsection{2 "Occupancy" Worksheet}

This worksheet includes all the different types of rooms where occupancy can impact air supply. For example, this worksheet has an occupancy chart for Gymnasium, Meeting room, Break room, Office private space, Printing Room, Kitchen, and storage room. The occupancy level, i.e., percentage of total allowable occupants as shown in Figure 4.2, is considered during the calculation of ventilation requirements based on DCV controls. The occupancy profile is different for different rooms and is based on the occupancy pattern for the community center building at Huntington.

It is recommended that users update the room occupancy level to match their building occupancy pattern. As shown in Figure 4.2, a random number range is considered, and a certain percentage of occupancy is expected during specific time intervals during weekdays and weekends. The determination of occupancy level from the occupancy schedule chart is also described in 3.5.1 above. As an example, an occupancy chart of "Gymnasium" is shown in Figure 4.2. The occupancy chart of all the rooms used for this simulation is shown in Appendix Table A3 and Table A4.

\begin{tabular}{|c|c|c|c|c|c|}
\hline \multicolumn{6}{|c|}{ Gymnasium } \\
\hline \multirow{2}{*}{\multicolumn{2}{|c|}{ Time Interval }} & \multirow{2}{*}{\multicolumn{2}{|c|}{ Random number range }} & Weekdays & Weekends \\
\hline & & & & Percentage of Total & Percentage of Total \\
\hline \multirow{2}{*}{$12: 00 \mathrm{AM}$} & \multirow{2}{*}{ 8:00 AM } & 0 & 0.99 & $0 \%$ & $0 \%$ \\
\hline & & 0.991 & 1 & $5 \%$ & $2 \%$ \\
\hline \multirow{2}{*}{ 8:01 AM } & \multirow{2}{*}{ 9:00 AM } & 0 & 0.75 & $80 \%$ & $0 \%$ \\
\hline & & 0.751 & 1 & $25 \%$ & $5 \%$ \\
\hline \multirow{2}{*}{ 9:01 AM } & \multirow{2}{*}{ 10:00 AM } & 0 & 0.8 & $80 \%$ & $0 \%$ \\
\hline & & 0.81 & 1 & $30 \%$ & $10 \%$ \\
\hline \multirow{2}{*}{ 10:01 AM } & \multirow{2}{*}{ 12:00 PM } & 0 & 0.98 & $20 \%$ & $0 \%$ \\
\hline & & 0.981 & 1 & $75 \%$ & $20 \%$ \\
\hline \multirow{2}{*}{ 12:01 PM } & \multirow{2}{*}{ 1:00 PM } & 0 & 0.3 & $55 \%$ & $5 \%$ \\
\hline & & 0.31 & 1 & $15 \%$ & $0 \%$ \\
\hline \multirow{2}{*}{ 1:01 PM } & \multirow{2}{*}{ 4:00 PM } & 0 & 0.98 & $60 \%$ & $0 \%$ \\
\hline & & 0.981 & 1 & $95 \%$ & $10 \%$ \\
\hline \multirow{2}{*}{ 4:01 PM } & \multirow{2}{*}{ 5:00 PM } & 0 & 0.8 & $40 \%$ & $0 \%$ \\
\hline & & 0.81 & 1 & $90 \%$ & $5 \%$ \\
\hline \multirow{2}{*}{ 5:01 PM } & \multirow{2}{*}{ 6:00 PM } & 0 & 0.75 & $0 \%$ & $0 \%$ \\
\hline & & 0.751 & 1 & $35 \%$ & $5 \%$ \\
\hline \multirow{2}{*}{ 6:01 PM } & \multirow{2}{*}{ 8:00 PM } & 0 & 0.35 & $35 \%$ & $5 \%$ \\
\hline & & 0.351 & 1 & $0 \%$ & $0 \%$ \\
\hline \multirow{2}{*}{ 8:01 PM } & \multirow{2}{*}{ 12:00 AM } & 0 & 0.99 & $0 \%$ & $0 \%$ \\
\hline & & 0.991 & 1 & $5 \%$ & $2 \%$ \\
\hline
\end{tabular}

Figure 4.2: Occupancy Chart 


\subsection{3 "Reference" Worksheet}

The objective of the "Reference" worksheet is to save all the required information to run the simulation. It contains data such as people's outdoor air rate (cfm/person), area outdoor air rate $\left(\mathrm{cfm} / \mathrm{ft}^{2}\right)$, Occupant density $\left(\# / 1000 \mathrm{ft}^{2}\right)$, and $\mathrm{ACH}$ for 16 different types of rooms as discussed in section 3.5.2. For simplification, the U.S. is divided into nine regions based on other climatic conditions. Furthermore, this worksheet also has information regarding HDD and CDD for nine areas. There are also data on probability charts of weather factors, building operating hours, and heating and cooling equipment efficiency.

Moreover, the SAT input by the user for summer and winter are also stored in this worksheet. This user-driven simulation allows users to change all these numbers according to their requirements. All the information from the "Reference" sheet is provided in Appendix Table A1 and Table A2.

\subsection{4 "Climatic Data" Worksheet}

This worksheet contains information regarding climatic data for nine regions. For simplification, only two states from each region and only two weather stations from each state are considered for the simulation. For each of the weather stations, further data such as elevation $(\mathrm{ft})$, heating DBT $\left({ }^{\circ} \mathrm{F}\right)$, cooling DBT $\left({ }^{\circ} \mathrm{F}\right)$, and humidity ratio (grains of moisture/grains of dry air) is provided in the sheet. The data are used from the 2017 ASHRAE handbook [55]. For heating DBT, 99.6\% value from the design table is used, which means that the outdoor temperature of the location stays above $99.6 \%$ of all the hours in the year, based on a 30-year average.

Similarly, for cooling DBT, a $0.4 \%$ value from the design table is used, which means that the outdoor temperature in a year for the location will exceed this design value about $0.4 \%$ of the time. Likewise, the humidity ratio during dehumidification is considered at $0.4 \%$ of the design table value. The worksheet "Climatic Data" is shown in Figure 4.3. 


\begin{tabular}{|c|c|c|c|c|c|c|c|c|c|c|}
\hline & Climatic Region & & State & & Weather Station & Elevation (ft) & $\begin{array}{c}\text { Heating DBT (oF) } \\
(99.6 \%)\end{array}$ & $\begin{array}{c}\text { Cooling DBT (oF) } \\
(0.4 \%)\end{array}$ & $\begin{array}{c}\text { HR (g/lbs) } \\
(0.4 \%)\end{array}$ & HR $(g / g)$ \\
\hline \multirow{4}{*}{1} & \multirow{4}{*}{ Pacific } & 1 & WA & 1 & Olympia Regional & 188 & 20.4 & 87.3 & 82.7 & 0.0118 \\
\hline & & & & 2 & Fairchild AFB & 2,461 & 5.2 & 91.8 & 81.7 & 0.0117 \\
\hline & & 2 & $\mathrm{CA}$ & 3 & Southern California Logistics & 2,885 & 27.6 & 100.7 & 101.2 & 0.0145 \\
\hline & & & & 4 & Monterey Regional & 165 & 36.6 & 78.7 & 76.1 & 0.0109 \\
\hline \multirow{4}{*}{2} & \multirow{4}{*}{ Mountain } & 3 & MT & 5 & Missoula Intl & 3,192 & -3.5 & 93.1 & 81.8 & 0.0117 \\
\hline & & & & 6 & Bert Mooney AP & 5,506 & -17.3 & 87.9 & 77.8 & 0.0111 \\
\hline & & 4 & $\mathrm{AZ}$ & 7 & Luke AFB & 1,085 & 34.8 & 110.9 & 125.6 & 0.0179 \\
\hline & & & & 8 & Window Rock AP & 6,739 & 0.1 & 89.8 & 92.2 & 0.0132 \\
\hline \multirow{4}{*}{3} & \multirow{4}{*}{ West North Central } & 5 & ND & 99 & Hector Intl & 900 & -18.7 & 90 & 123.7 & 0.0177 \\
\hline & & & & 10 & Minot Intl & 1,665 & -18.1 & 90.5 & 118.4 & 0.0169 \\
\hline & & 6 & KS & 11 & Lawrence Municipal & 832 & 3.4 & 99.2 & 141.4 & 0.0202 \\
\hline & & & & 12 & Mcconnell AFB & 1,371 & 8.3 & 100.2 & 137.4 & 0.0196 \\
\hline \multirow{4}{*}{4} & \multirow{4}{*}{ West South Central } & 7 & $\mathrm{AR}$ & 13 & Texarkana regional & 361 & 23.8 & 99.3 & 139.5 & 0.0199 \\
\hline & & & & 14 & Bentonville Municipal & 1,296 & 10.1 & 96.6 & 130.1 & 0.0186 \\
\hline & & 8 & $\mathrm{TX}$ & 15 & Victoria regional & 115 & 31.4 & 97.9 & 78.7 & 0.0112 \\
\hline & & & & 16 & San angelo regional & 1,916 & 22.2 & 101.7 & 125.7 & 0.0180 \\
\hline \multirow{4}{*}{5} & \multirow{4}{*}{ East North Central } & 9 & WI & 17 & Sheboygan & 577 & -1.8 & 83 & 136.3 & 0.0195 \\
\hline & & & & 18 & Appleton Intl & 917 & -6 & 88.4 & 136.7 & 0.0195 \\
\hline & & 10 & $\mathrm{OH}$ & 19 & JMCOX dayton Intl & 1,000 & 2.3 & 90.3 & 128.8 & 0.0184 \\
\hline & & & & 20 & Toledo Express AP & 669 & 1.5 & 91.2 & 129.7 & 0.0185 \\
\hline \multirow{4}{*}{6} & \multirow{4}{*}{ East South Central } & 11 & KY & 21 & Henderson City-County AP & 387 & 8.8 & 93.4 & 135.1 & 0.0193 \\
\hline & & & & 22 & Cincinnati Northern Ky Intl & 869 & 5.9 & 91.6 & 133.8 & 0.0191 \\
\hline & & 12 & $\mathrm{AL}$ & 23 & Montgomery regional & 202 & 24.3 & 96.8 & 139.9 & 0.0200 \\
\hline & & & & 24 & Birmingham Shuttlesworth Intl & 615 & 20.8 & 95.6 & 138.7 & 0.0198 \\
\hline \multirow{4}{*}{7} & \multirow{4}{*}{ Middle Atlantic } & 13 & NY & 25 & Plattsburgh Intl & 234 & -8.7 & 86.6 & 71.2 & 0.0102 \\
\hline & & & & 26 & Elmira Corning regional & 955 & -0.1 & 89.6 & 120.3 & 0.0172 \\
\hline & & 14 & $\mathrm{PA}$ & 27 & Erie Intl & 730 & 6.1 & 86.7 & 125 & 0.0179 \\
\hline & & & & 28 & Washington County AP & 1,185 & 2.7 & 88.3 & 122.5 & 0.0175 \\
\hline \multirow{4}{*}{8} & \multirow{4}{*}{ South Atlantic } & 15 & WV & 29 & Mid-Ohio Valley Regional & 831 & 8.6 & 90.6 & 130 & 0.0186 \\
\hline & & & & 30 & Yeager AP & 910 & 10.7 & 91.2 & 130.8 & 0.0187 \\
\hline & & 16 & FL & 31 & Orlando Intl & 90 & 38.3 & 93.8 & 144.6 & 0.0207 \\
\hline & & & & 32 & Jacksonville Intl & 26 & 29.5 & 94.5 & 142.7 & 0.0204 \\
\hline \multirow{4}{*}{9} & \multirow{4}{*}{ New England } & 17 & $\mathrm{ME}$ & 33 & Brunswick NAS & 70 & -2.2 & 86.2 & 112.1 & 0.0160 \\
\hline & & & & 34 & Sanford seacost regional & 244 & -6.1 & 89.7 & 117.9 & 0.0168 \\
\hline & & 18 & $\mathrm{CT}$ & 35 & Hartford-brainard AP & 19 & 8.2 & 90.9 & 125.7 & 0.0180 \\
\hline & & & & 36 & Waterbury-oxford AP & 726 & 3.2 & 87.6 & 125.4 & 0.0179 \\
\hline
\end{tabular}

Figure 4.3: Climatic Data from 2017 ASHRAE Handbook [55] 


\subsection{5 "Inputs" Worksheet}

Once the information is provided on the "User Manual" worksheet, the model directs the user to the sheet "Inputs." The user must select all the rooms from the given list and level for the building envelope from the drop-down menu for each room. The model explains to the user to decide on what level of building envelope to select. Further, the user must enter the room's dimensions (area and height), thermostat settings for setpoint, and setback temperature for summer and winter. The screenshot of the sheet "Inputs" is shown in Figure 4.4 .

Furthermore, the feasibility, infeasibility, or unnecessary BEMS controls for generating energy efficiency can also be checked from the "Inputs" worksheet. Based on the data input by the user, the feasibility of generating effective energy efficiency by BEMS controls can be studied by clicking the "Check Feasibility" button on the "Inputs" sheet. The feasibility is determined mainly based on the size, type of rooms in the building, the building envelope's nature, and air infiltration. Suppose the building has more than $500 \mathrm{sq}$. $\mathrm{ft}$ area, recommended occupant density of greater than 25 per $100 \mathrm{sq}$. $\mathrm{ft}$ according to ASHRAE 62.1-2019 standards, and good building envelope characteristics. In that case, it is considered feasible for generating effective energy efficiency. However, even after having met the room characteristics in terms of size and occupant density, if the building envelope is poor, it has infiltration of air, then it is considered infeasible for generating effective energy efficiency. Moreover, if the room sizes of the building are small, i.e., less than 500 sq. ft. and have good building envelope characteristics, it is considered unnecessary for generating effective energy efficiency. 


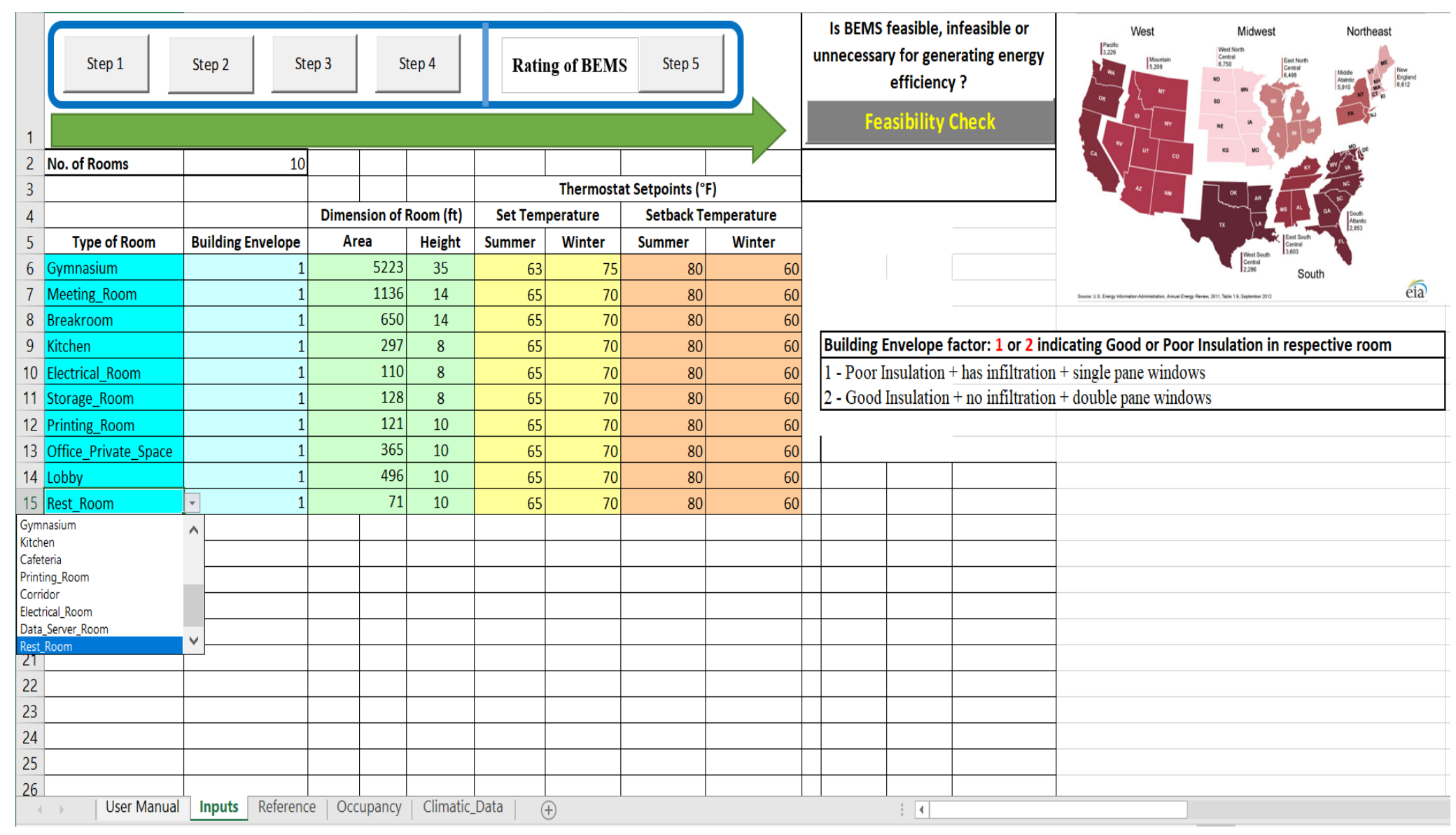

Figure 4.4: "Inputs" worksheet 


\subsection{Developing Excel VBA Code}

The simulation was developed using Excel-based VBA code with a graphical interface. "User Manual" and "Inputs" worksheets contain several pop-up message boxes and buttons to complete the simulation, which is generated with VBA code. First, the simulation "Start Simulation" button is required to click, after which the model will ask the user to enter the number of rooms in the building. The entered value is used for generating a table in the input page with an equivalent number of rows.

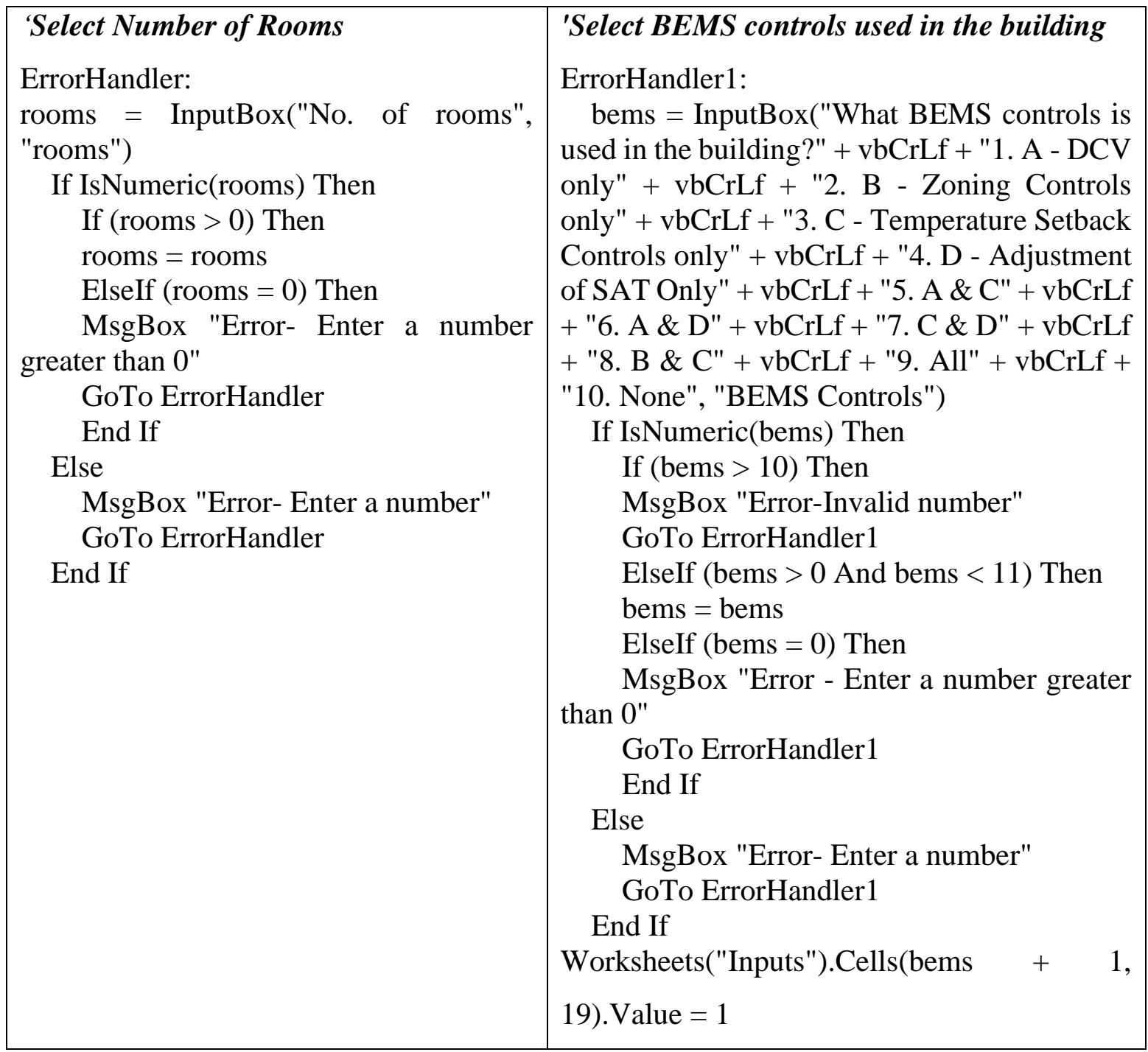

Further, a pop-up message box asks the user to select the BEMS controls used in the building generated by the VBA code above. Additionally, suppose there is no DCV in the building. In that case, the user is asked to enter an approximate percentage of outside air intake into the building, which is generated by the VBA code below: 


\section{'Percentage of Outside Air intake into the building}

If bems $=2$ Or bems $=3$ Or bems $=4$ Or bems $=7$ Or bems $=8$ Or bems $=10$ Then

$\mathrm{OA}=\operatorname{InputBox}("$ What is the approximate percentage of outside air intake on a scale from 0-100?", "Outside Air")

Worksheets("Inputs").Cells(13, 19).Value = OA

End If

Furthermore, the user has to input building parameters such as type of room, building dimensions, building envelope level, and thermostat setting of each room in the "Inputs" worksheet in a color-coded table. The user can then check the feasibility of generating effective energy efficiency by the BEMS controls. The following code will run to display the decision of either "Feasible," "Infeasible," or "Unnecessary":

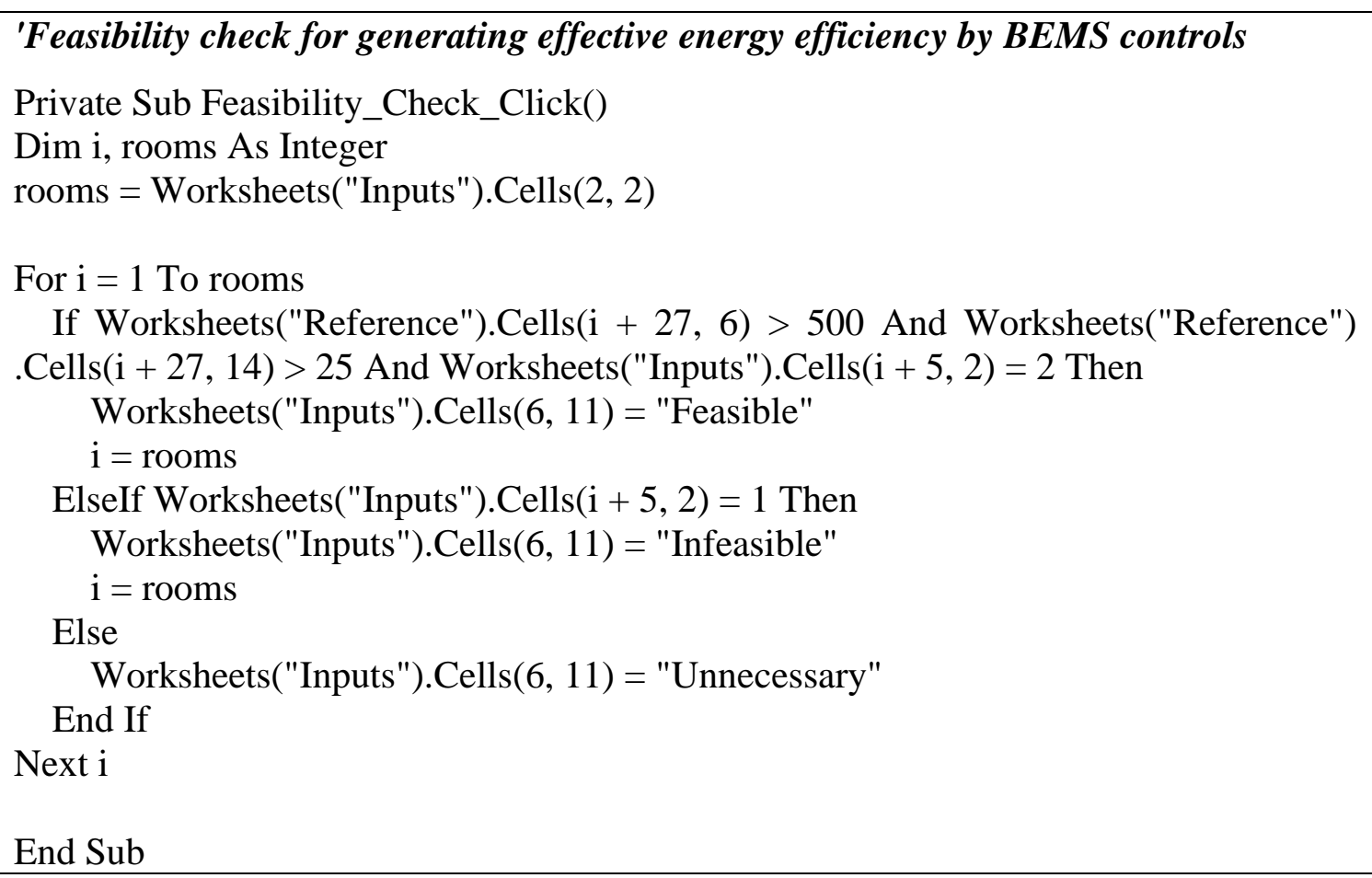

Next, the user has to click five buttons sequentially in order of "Step 1", Step 2", "Step 3", "Step 4", and "Step 5". The worksheet for each room will be automatically generated by clicking the "Step 1" button. Users will be asked regarding the climatic region, location, and nearest weather station after clicking the "Step 1" button. For example, the following code is executed to the climatic region and location of the user:

\section{Private Sub Ventilation_Click()}

Dim r, v, z, Q_s, Q_t, e As Double

Dim rooms, region, state, ws As Variant 


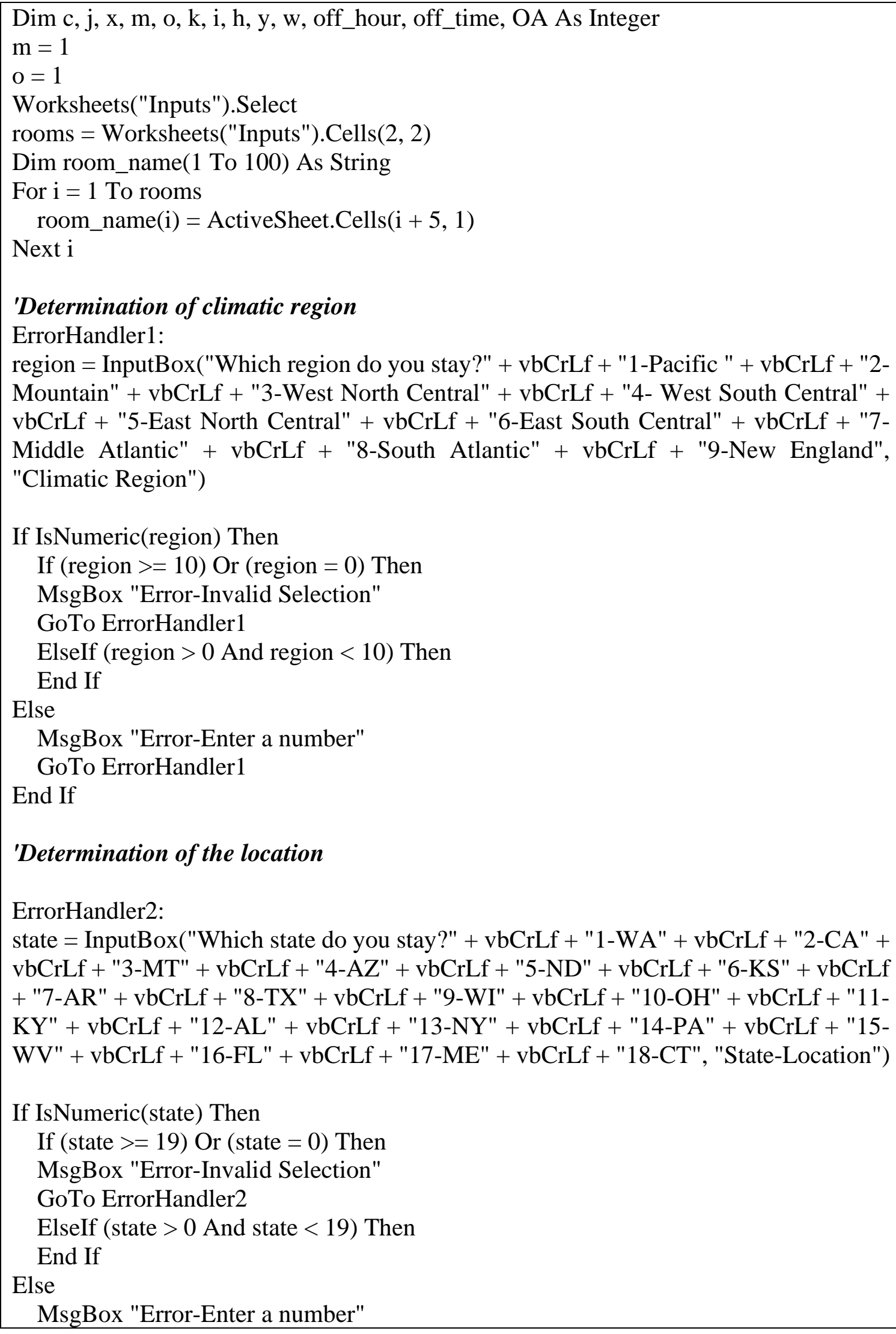

\section{'Determination of climatic region}

ErrorHandler1:

region = InputBox ("Which region do you stay?" + vbCrLf + "1-Pacific " + vbCrLf + "2Mountain" + vbCrLf + "3-West North Central" + vbCrLf + "4- West South Central" + vbCrLf + "5-East North Central" + vbCrLf + "6-East South Central" + vbCrLf + "7Middle Atlantic" + vbCrLf + "8-South Atlantic" + vbCrLf + "9-New England", "Climatic Region")

If IsNumeric(region) Then

If (region $>=10$ ) Or (region $=0$ ) Then

MsgBox "Error-Invalid Selection"

GoTo ErrorHandler1

ElseIf (region > 0 And region < 10) Then

End If

Else

MsgBox "Error-Enter a number"

GoTo ErrorHandler1

End If

\section{'Determination of the location}

ErrorHandler2:

state = InputBox("Which state do you stay?" + vbCrLf + "1-WA" + vbCrLf + "2-CA" + vbCrLf + "3-MT" + vbCrLf + "4-AZ" + vbCrLf + "5-ND" + vbCrLf + "6-KS" + vbCrLf + "7-AR" + vbCrLf + "8-TX" + vbCrLf + "9-WI" + vbCrLf + "10-OH" + vbCrLf + "11$\mathrm{KY}^{\prime}$ + vbCrLf + "12-AL" + vbCrLf + "13-NY" + vbCrLf + "14-PA" + vbCrLf + "15$\mathrm{WV}$ + vbCrLf + "16-FL" + vbCrLf + "17-ME" + vbCrLf + "18-CT", "State-Location")

If IsNumeric(state) Then

If (state $>=19)$ Or $($ state $=0)$ Then

MsgBox "Error-Invalid Selection"

GoTo ErrorHandler2

ElseIf (state $>0$ And state < 19) Then

End If

Else

MsgBox "Error-Enter a number" 


GoTo ErrorHandler2
End If
Worksheets("Climatic_Data").Cells(3, 16).Formula = "=VLOOKUP(" \& region \&
",Climatic_Data!\$A3:\$J \$38,2,FALSE)"
Worksheets("Climatic_Data").Cells(4, 16).Formula = "=VLOOKUP(" \& state \&
",Climatic_Data!\$C\$3:\$J\$38,2,FALSE)"

Moreover, the expected number of people for a different room type is calculated based on the occupancy chart and random number generated by excel. Here, only 16 different types of rooms are considered for determining occupancy. Depending upon the user requirement, the occupancy chart on the "Occupancy" Worksheet should be updated, and the code should also be updated. The following code is used to calculate an expected number of occupants for every 30 -minute interval:

\section{'Expected number of Occupants}

If Worksheets("Inputs").Cells(k + 5, 1).Value = "Gymnasium" Then

ActiveSheet.Cells $(2,4) \cdot$.Formula $=$ "=ROUNDUP((Reference!\$E\$" \& $\mathrm{k}+27 \&$ $") *(\operatorname{INDEX}(\mathrm{IF}(\mathrm{OR}(\mathrm{MOD}(\mathrm{A} 2,7)=6, \mathrm{MOD}(\mathrm{A} 2,7)=0)$, Occupancy! $\$ \mathrm{G} \$ 5: \$ G \$ 24$, Occupan cy!\$F\$5:\$F \$24),IF(C2<=INDEX(Occupancy!\$E\$5:\$E\$24,MATCH(B2,Occupancy!\$ B \$5:\$B \$24,1)),MATCH(B2,Occupancy!\$B \$5:\$B \$24,1), MATCH(B2,Occupancy!\$B $\$ 5: \$ B \$ 24,1)+1)))), 0) "$

ElseIf Worksheets("Inputs").Cells $(\mathrm{k}+5,1)$.Value = "Meeting_Room" Then

ActiveSheet.Cells(2, 4).Formula $=$ "=ROUNDUP((Reference!\$E\$" \& $\mathrm{k}+27 \&$ $") *(\operatorname{INDEX}(\mathrm{IF}(\mathrm{OR}(\mathrm{MOD}(\mathrm{A} 2,7)=6, \mathrm{MOD}(\mathrm{A} 2,7)=0)$, Occupancy! $\$ \mathrm{G} \$ 30: \$ G \$ 49$, Occupa ncy!\$F\$30:\$F\$4),IF(C2<=INDEX(Occupancy!\$E\$30:\$E\$49,MATCH(B2,Occupanc $y$ ! \$B \$30:\$B \$49,1)), MATCH(B2,Occupancy!\$B \$30:\$B \$49,1), MATCH(B2,Occupanc $\mathrm{y}(\$ \mathrm{~B} \$ 30: \$ \mathrm{~B} \$ 49,1)+1)))), 0) "$

ElseIf Worksheets("Inputs").Cells( $\mathrm{k}+5,1) \cdot$ Value = "Breakroom" Or

Worksheets("Inputs").Cells $(\mathrm{k}+5,1)$.Value $=$ "Cafeteria" Then

ActiveSheet.Cells $(2,4) \cdot$.Formula $=$ "=ROUNDUP((Reference!\$E\$" \& $\mathrm{k}+27 \&$ $") *(\operatorname{INDEX}(\mathrm{IF}(\mathrm{OR}(\mathrm{MOD}(\mathrm{A} 2,7)=6, \mathrm{MOD}(\mathrm{A} 2,7)=0)$, Occupancy! $\mathrm{G} \$ 55: \$ G \$ 74, \mathrm{Occupa}$ ncy!\$F\$55:\$F \$74),IF(C2<=INDEX(Occupancy!\$E\$55:\$E\$74,MATCH(B2,Occupanc $\mathrm{y} ! \$ \mathrm{~B} \$ 55: \$ \mathrm{~B} \$ 74,1)), \mathrm{MATCH}(\mathrm{B} 2$, Occupancy! $\$ \mathrm{~B} \$ 55: \$ \mathrm{~B} \$ 74,1)$, MATCH(B2,Occupanc $\mathrm{y}(\$ \mathrm{~B} \$ 55: \$ \mathrm{~B} \$(4,1)+1)))), 0) "$

ElseIf Worksheets("Inputs").Cells(k + 5, 1).Value = "Office_Private_Space" Or _ Worksheets("Inputs").Cells $(\mathrm{k}+5,1)$.Value = "Office_Open_Space" Then 
ActiveSheet.Cells(2, 4).Formula $=$ "=ROUNDUP((Reference!\$E\$" \& $\mathrm{k}+27 \&$ ")*(INDEX $(\operatorname{IF}(\mathrm{OR}(\mathrm{MOD}(\mathrm{A} 2,7)=6, \operatorname{MOD}(\mathrm{A} 2,7)=0)$, Occupancy! $\mathrm{G} \$ 80$ :\$G\$99,Occupa ncy!\$F\$80:\$F\$99),IF(C2<=INDEX(Occupancy!\$E\$80:\$E\$99,MATCH(B2,Occupanc y!\$B \$80:\$B \$99,1)),MATCH(B2,Occupancy!\$B \$80:\$B \$99, 1), MATCH(B2,Occupanc $\mathrm{y}$ !\$B $\$ 80: \$ B \$ 99,1)+1)))), 0) "$

ElseIf Worksheets("Inputs").Cells(k + 5, 1).Value = "Printing_Room" Then

ActiveSheet.Cells(2, 4).Formula $=$ "=ROUNDUP((Reference!\$E\$" \& k $+27 \&$ ")*(INDEX $(\operatorname{IF}(\mathrm{OR}(\mathrm{MOD}(\mathrm{A} 2,7)=6, \mathrm{MOD}(\mathrm{A} 2,7)=0), \mathrm{Occupancy}$ ! $\$$ G 105:\$G \$124, Occu pancy!\$F 105:\$F\$124),IF(C2<=INDEX(Occupancy!\$E\$105:\$E\$124,MATCH(B2,Oc cupancy!\$B \$105:\$B \$124,1)),MATCH(B2,Occupancy!\$B \$105:\$B \$124,1), MATCH(B 2,Occupancy!\$B \$105:\$B \$124,1)+1)))),0)"

ElseIf Worksheets("Inputs").Cells(k + 5, 1).Value = "Kitchen" Then

ActiveSheet.Cells(2, 4).Formula $=$ "=ROUNDUP((Reference!\$E\$" \& k + $27 \&$ ")*(INDEX $(\operatorname{IF}(\mathrm{OR}(\mathrm{MOD}(\mathrm{A} 2,7)=6, \operatorname{MOD}(\mathrm{A} 2,7)=0)$, Occupancy! $\$$ G 130 :\$G \$149, Occu pancy!\$F\$130:\$F\$149),IF(C2<=INDEX(Occupancy!\$E\$130:\$E\$149,MATCH(B2,Oc cupancy!\$B \$130:\$B \$149,1)),MATCH(B2,Occupancy!\$B \$130:\$B \$149,1), MATCH(B 2,Occupancy!\$B \$130:\$B \$149,1)+1)))),0)"

ElseIf Worksheets("Inputs").Cells(k + 5, 1).Value = "Storage_Room" Then

ActiveSheet.Cells(2, 4).Formula = "=ROUNDUP((Reference!\$E\$" \& k + $27 \&$ ")*(INDEX $(\operatorname{IF}(\mathrm{OR}(\mathrm{MOD}(\mathrm{A} 2,7)=6, \mathrm{MOD}(\mathrm{A} 2,7)=0), \mathrm{Occupancy}$ ! $\$$ G155:\$G\$174, Occu pancy!\$F 155:\$F\$174),IF(C2<=INDEX(Occupancy!\$E\$155:\$E\$174,MATCH(B2,Oc cupancy! \$B \$155:\$B \$174,1)),MATCH(B2,Occupancy!\$B \$155:\$B \$174,1), MATCH(B 2,Occupancy!\$B \$155:\$B \$174,1)+1)))),0)"

ElseIf Worksheets("Inputs").Cells(k + 5, 1).Value = "Lobby" Or

Worksheets("Inputs").Cells $(\mathrm{k}+5,1)$.Value = "Reception" Then

ActiveSheet.Cells(2, 4).Formula = "=ROUNDUP((Reference!\$E\$" \& k + $27 \&$ ")*(INDEX $(\operatorname{IF}(\mathrm{OR}(\mathrm{MOD}(\mathrm{A} 2,7)=6, \mathrm{MOD}(\mathrm{A} 2,7)=0), \mathrm{Occupancy}$ ! $\$$ G180:\$G \$199, Occu pancy!\$F 180:\$F\$199),IF(C2<=INDEX(Occupancy!\$E\$180:\$E\$199,MATCH(B2,Oc cupancy!\$B \$180:\$B \$199,1)),MATCH(B2,Occupancy!\$B \$180:\$B \$199, 1), MATCH(B 2,Occupancy!\$B \$180:\$B \$199,1)+1)))),0)"

Else

ActiveSheet.Cells(2, 4).Value $=0$

End If 
Here, the expected number of occupants in spaces such as a corridor, electrical room, data server room, and a rest room is not determined since the ventilation provided in those rooms is not based on occupants' number.

Furthermore, the required number of air changes, outdoor air (cfm), and total supply air $(\mathrm{cfm})$ is determined based on the following code. Here, the parameters are calculated differently depending upon the type of room, and user-selected BEMS controls used in the building. For example, for the restroom, the air is always exhausted outside, for electrical and data server room it is always ventilated without any concern of occupancy state, the corridor is ventilated based on time of day (building operating hours), no DCV strategy, DCV but based on occupancy or $\mathrm{CO}_{2}$ strategy.

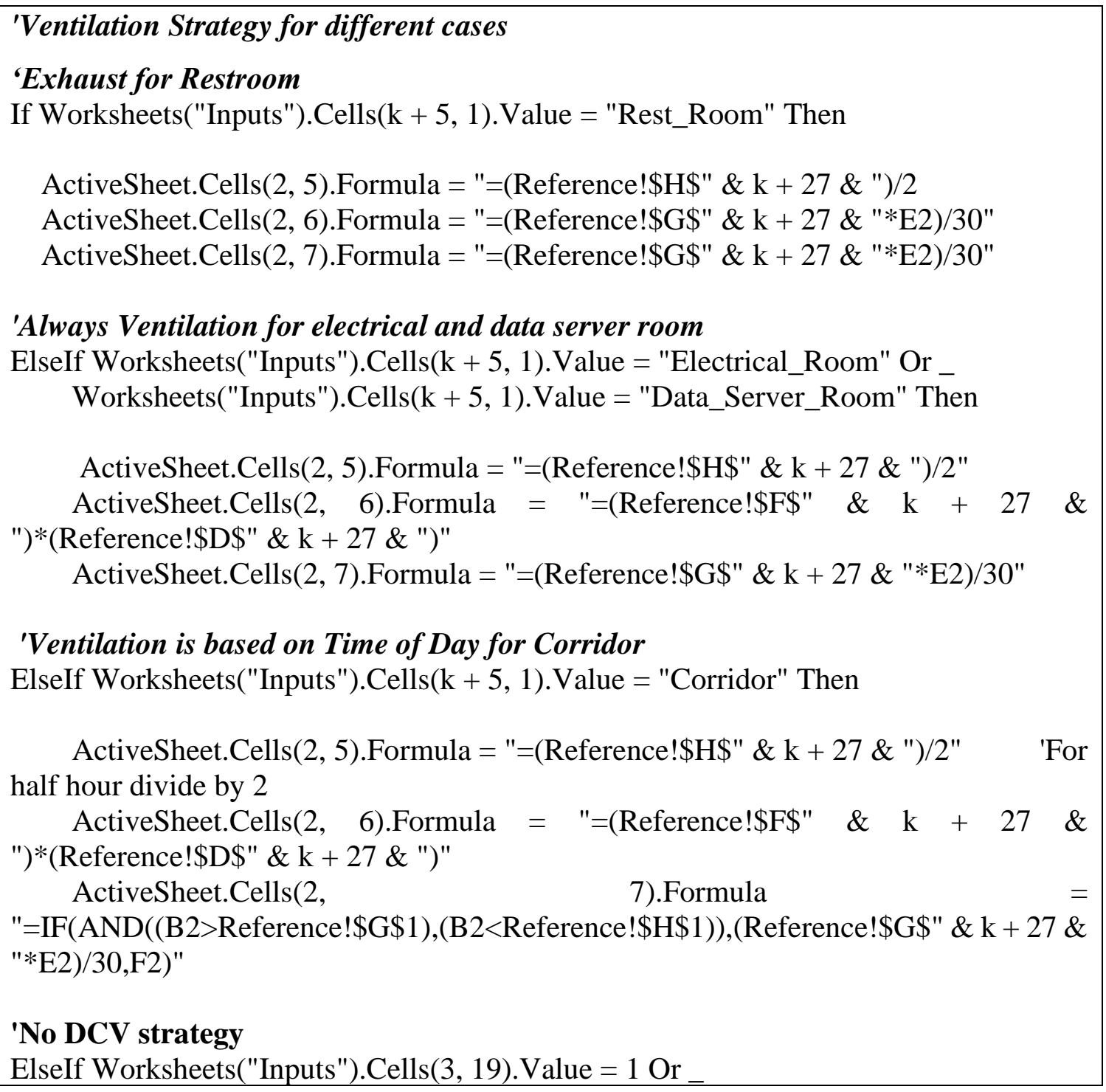



Worksheets("Inputs").Cells(4, 19).Value = 1 Or _ Worksheets("Inputs").Cells $(5,19)$.Value $=1$ Or Worksheets("Inputs").Cells $(8,19)$.Value $=1$ Or Worksheets("Inputs").Cells $(9,19)$.Value $=1$ Or _ Worksheets("Inputs").Cells(11, 19).Value = 1 Then

ActiveSheet.Cells $(2,5)$. Formula $="=($ Reference! $\$ H \$ " \& \mathrm{k}+27 \&$ " $) / 2 "$ ActiveSheet.Cells(2, 7).Formula = "=(Reference!\$G\$" \& k + $27 \&$ \& E2)/30" ActiveSheet.Cells $(2,6)$. Formula = "=Inputs!\$S\$13*G2/100"

\section{'Has DCV but is based on occupancy sensor}

ElseIf Worksheets("Inputs").Cells(k + 16, 21).Value < 500 Or_

Worksheets("Inputs").Cells(k + 16, 29).Value < 25 And

Worksheets("Inputs").Cells(2, 19).Value = 1 Or

Worksheets("Inputs").Cells(6, 19).Value = 1 Or _

Worksheets("Inputs").Cells(7, 19).Value $=1$ Or

Worksheets("Inputs").Cells(10, 19).Value = 1 Then

ActiveSheet.Cells(2, 5).Formula $="=$ ROUNDUP(IF(D2=0,((Reference! \$F $\$ " \& \mathrm{k}$ $+27 \&$ "*Reference!\$D\$" \& k + $27 \&$ \&60)/(Reference!\$G\$" \& k + $27 \&$ "))/2,(Reference!\$H\$" \& k + $27 \&$ ")/2),2)"

ActiveSheet.Cells(2, 6).Formula $="=\mathrm{D} 2 *($ Reference!\$C\$" \& $\mathrm{k}+27 \&$ ")+(Reference!\$F\$" \& k + $27 \&$ ")*(Reference!\$D\$" \& k + $27 \&$ ")"

ActiveSheet.Cells(2, 7).Formula = "=(Reference!\$G\$" \& k + $27 \&$ \&*E2)/30"

\section{'Has DCV and is based on $\mathrm{CO}_{2}$ level strategy}

ElseIf Worksheets("Inputs").Cells(k + 16, 21).Value > 500 And _

Worksheets("Inputs").Cells(k + 16, 29).Value > 25 And

Worksheets("Inputs").Cells(2, 19).Value $=1$ Or

Worksheets("Inputs").Cells $(6,19)$.Value $=1$ Or _

Worksheets("Inputs").Cells(7, 19).Value = 1 Or _

Worksheets("Inputs").Cells(10, 19).Value = 1 Then

ActiveSheet.Cells(2, 5).Formula $="=$ ROUNDUP(IF(D2=0, $(($ Reference!\$F\$" \& k + $27 \&$ "*Reference!\$D\$" \& $\mathrm{k}+27 \&$ \&60)/(Reference!\$G\$" \& k + $27 \&$ "))/2,((D2/Reference!\$E\$" \& k + $27 \&$ ")*Reference!\$H\$" \& k + 27 \& ")/2),2)"

ActiveSheet.Cells(2, 6).Formula $="=\mathrm{D} 2 *($ Reference!\$C\$" \& $\mathrm{k}+27 \&$ ")+(Reference!\$F\$" \& k + $27 \&$ ")*(Reference!\$D\$" \& k + $27 \&$ ")"

ActiveSheet.Cells(2, 7).Formula = "=ROUNDUP(IF(((Reference!\$G\$" \& k + 27 \& "*E2)/30)<F2,F2,(Reference!\$G\$" \& k + $27 \&$ \&*E2)/30),2)"

End If

Next, the user is required to click "Step 2" which generates the "Mixed Air" worksheet.

Depending upon the temperature setback controls in the zone, the temperature of total 
return air is calculated. The following code is run to get the temperature and humidity ratio of total return air:

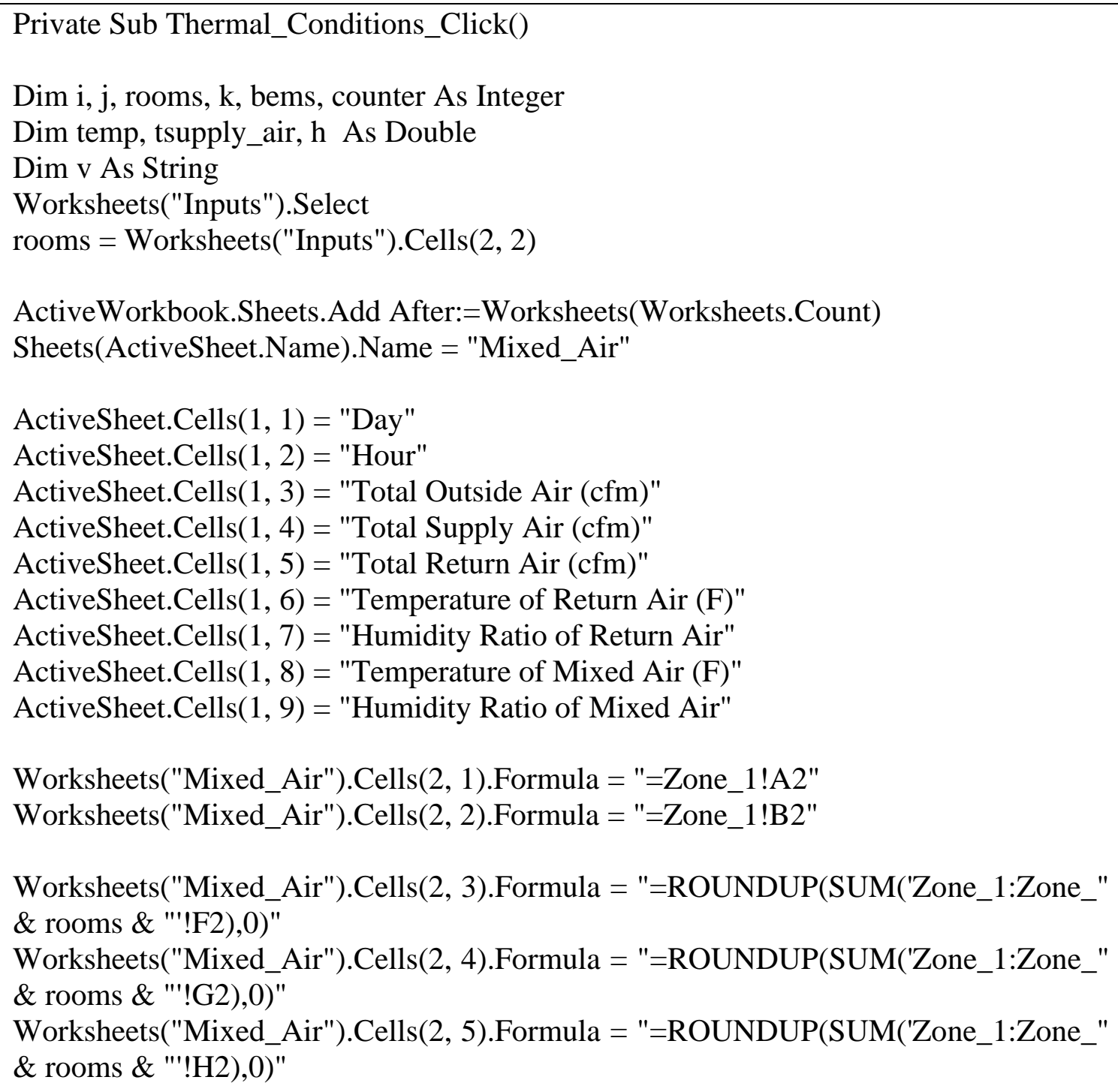

\section{'Humidity ratio of Return Air}

Worksheets("Mixed_Air").Cells(2, 7).Formula = "=ROUNDUP(SUM('Zone_1:Zone_" \& rooms \& "'!N2)/E2,4)"

\section{'Temperature of Return Air : No temperature Setback Controls}

If Worksheets("Inputs").Cells(2, 19). Value = 1 Or

Worksheets("Inputs").Cells(3, 19).Value = 1 Or _

Worksheets("Inputs").Cells(5, 19).Value = 1 Or

Worksheets("Inputs").Cells( 7, 19).Value = 1 Or _

Worksheets("Inputs").Cells(11, 19).Value = 1 Then 


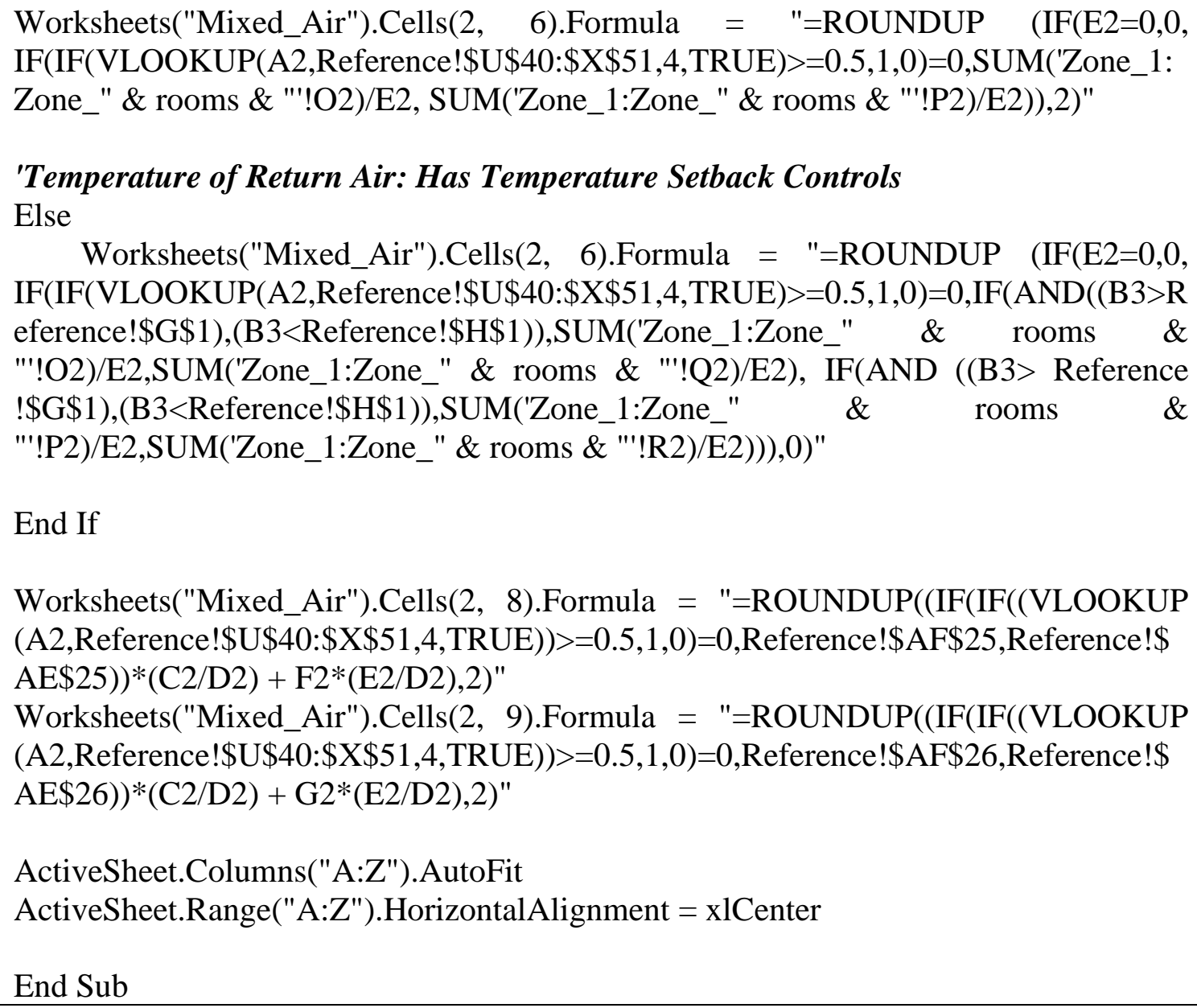

Furthermore, the VBA code embedded in button "Step 3" will generate worksheets such as "Energy_Zone_1", "Energy_Zone_2", and so on depending upon the number of rooms input by the user. The code for "Step 3" is designed to calculate the energy required for space heating or cooling for individual rooms in terms of sensible heat load (Btu/hr), latent heat load $(\mathrm{Btu} / \mathrm{hr})$, power $(\mathrm{kW})$, and energy consumption $(\mathrm{kWh})$ during summer where cooling is required. During winter, depending upon the energy source for heating, the energy is calculated. For example, for natural gas as a heating energy source, power $(\mathrm{kW})$ and energy consumption $(\mathrm{kWh})$ are not calculated. The sensible load (Btu/hr) is divided by the efficiency factor of the heating unit to get the input energy. The simulation model can only handle one energy source for heating, i.e., electric or natural gas. But, the building understudy for the thesis has both kinds of heating sources. Natural gas is used for heating the gymnasium, and electricity is used for heating other building spaces. Hence, a code is 
written below to consider the only gymnasium heated by natural gas and is marked by $(*)$ sign. The following code is used for determining the required energy:

\section{'Determination of Energy required for space heating or cooling}

Private Sub Energy_Step_Click()

Dim $\mathrm{i}, \mathrm{j}$, rooms As Integer

Dim region As Variant

Dim v As String

Worksheets("Reference").Activate

For $\mathrm{i}=1$ To 12

ActiveSheet.Range("V" \& i + 39).Formula = "=HLOOKUP(Climatic_Data !\$P\$3,\$R9 :\$AA $\$ 21, "$ \& i 1 \& ",FALSE)"

ActiveSheet.Range("W" \& i + 39).Formula = "=HLOOKUP(Climatic_Data!\$P\$3, \$R \$24:\$AA \$36," \& i + 1 \& ",FALSE)"

Next i

\section{'During Summer}

'Sensible heat load (Btu/hr)

Worksheets("Energy_Zone_" \& j).Cells(3, 5).Formula = "=ROUND ((IF(D3=0,0,IF(AND((B3>Reference!\$G\$1), (B3<Reference!\$H \$1)), 1.08*C3*(Mixed _Air!H2-'Zone_" \& j \& "'!J2),1.08*C3*(Mixed_Air!H2-'Zone_" \& j \& "'!J2))))* ((INDEX(Reference!\$G\$62:\$G\$97,IF(M3<=INDEX(Reference!\$F\$62:\$F\$97,MATC H(A3,Reference! \$C \$62:\$C \$97,1)),MATCH(A3,Reference! $\$$ C $\$ 62: \$ C \$ 79,1), \operatorname{IF}(\mathrm{M} 3<=\mathrm{I}$ NDEX(Reference!\$F\$62:\$F\$97,MATCH(A3,Reference!\$C $62: \$ C \$ 97,1)+1), M A T C H$ (A3,Reference!\$C\$62:\$C \$97,1)+1,MATCH(A3,Reference!\$C \$62:\$C\$97,1)+2))))+IF( Inputs!\$B \$" \& j 5 \& "=1,Reference!\$AE\$43,Reference!\$AE\$44)),0)"

\section{'Latent heat load (Btu/hr)}

Worksheets("Energy_Zone_" \& j).Cells(3, 6).Formula = "=ROUND $((\mathrm{IF}(\mathrm{D} 3=0,0,4770 * \mathrm{C} 3 *($ Reference!\$AE\$26-'Zone_" $\quad \& \quad \mathrm{j} \quad \& \quad$ "'!L2)) $) *((\mathrm{INDEX}$ (Reference!\$G\$62:\$G\$97,IF(M3<=INDEX(Reference!\$F\$62:\$F\$97,MATCH(A3,Ref erence!\$C\$62:\$C \$97,1)),MATCH(A3,Reference!\$C \$62:\$C \$79,1), IF(M3<=INDEX(R eference!\$F\$62:\$F\$97,MATCH(A3,Reference!\$C \$62:\$C \$97,1)+1),MATCH(A3,Refe rence!\$C $\$ 62: \$ C \$ 97,1)+1, \operatorname{MATCH}(\mathrm{A} 3$, Reference!\$C $\$ 62: \$ C \$ 97,1)+2))))+\mathrm{IF}($ Inputs!\$ B \$" \& j + 5 \& "=1,Reference!\$AE\$43,Reference!\$AE\$44)),0)"

"Total heat load (Btu/hr)

Worksheets("Energy_Zone_" \& j).Cells(3, 7).Formula = "=E3+F3"

'Determination of Power (kW) 


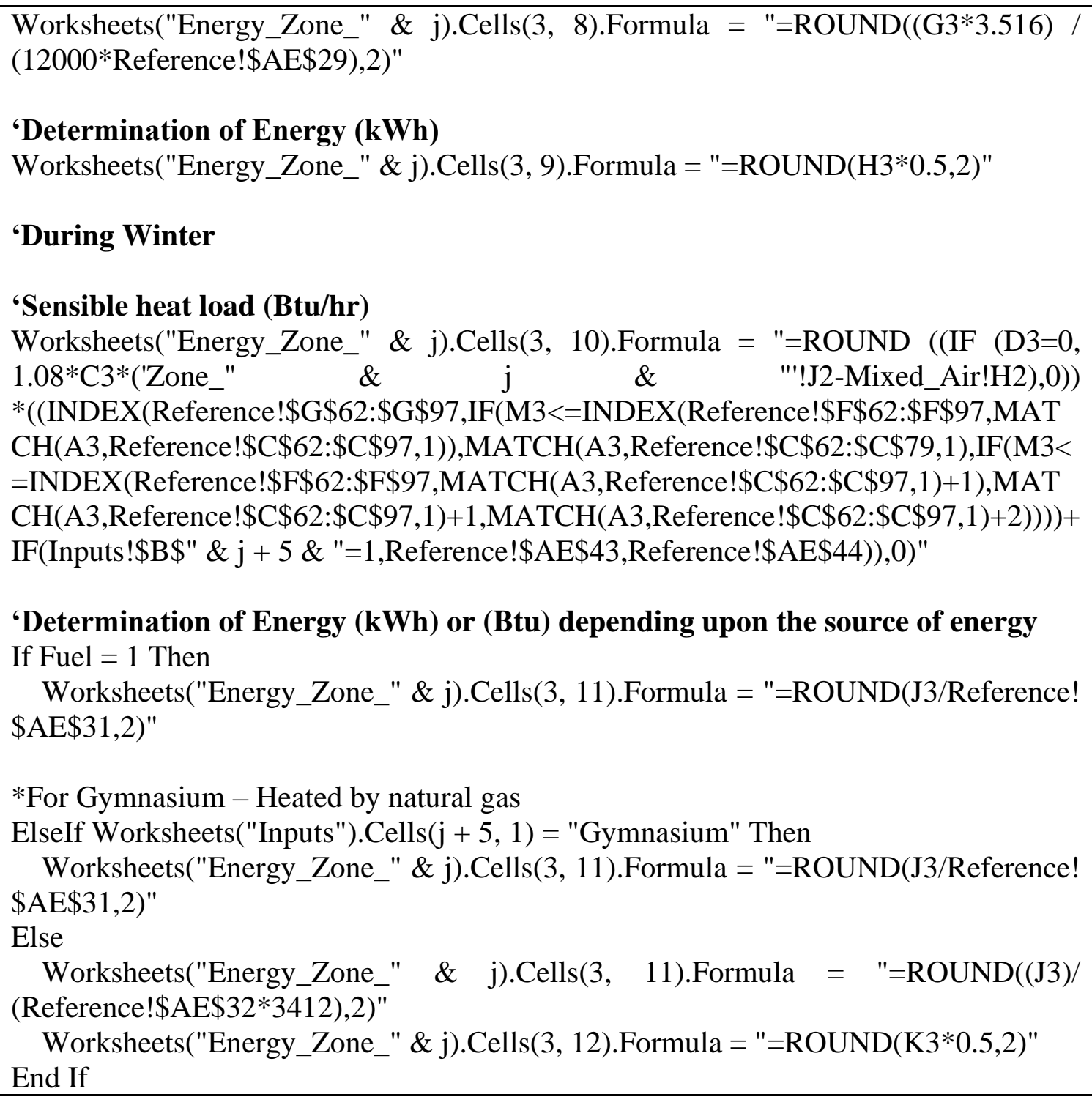

The fourth button, "Step 4," is designed to determine the summation of energy required for space heating and cooling from all the rooms. After clicking this button, a new worksheet, "Total Energy Consumption," will be generated. Once the summation is completed, a message box will pop up that displays the total annual electric energy $(\mathrm{kWh})$ and natural gas $(\mathrm{Btu})$ required for space heating and cooling the building. The following code will run to determine the total annual energy consumption in terms of $\mathrm{kWh}$ and Btu:

\section{'Determination of total annual energy consumption in terms of $k$ Wh and Btu}

Private Sub Total_Energy_Click()

For $\mathrm{i}=1$ To rooms

ActiveSheet.Cells $(2, \mathrm{i}+\mathrm{s})=$ "Zone_" \& i 


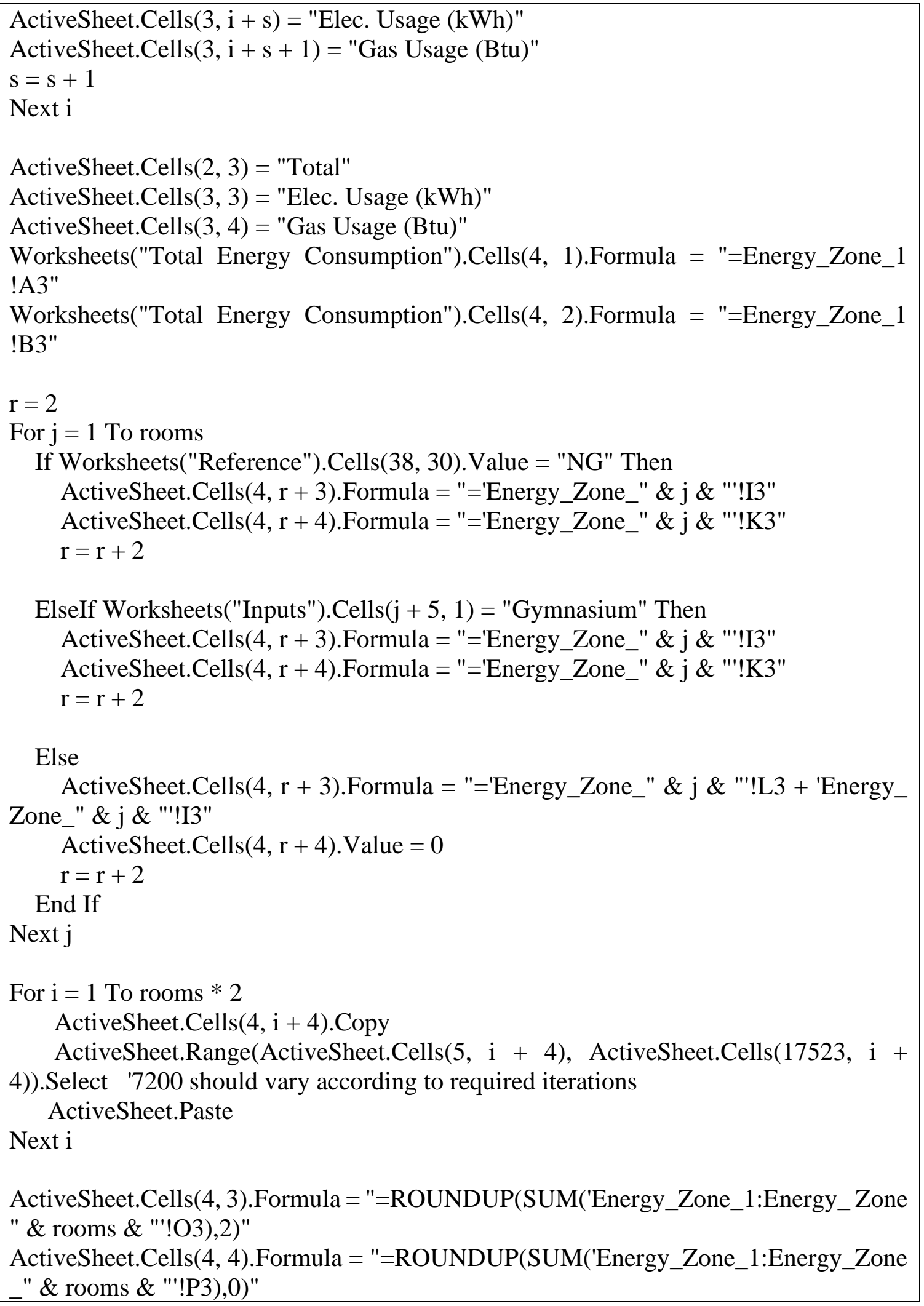


Furthermore, the building's electric and natural gas energy consumption every month is also determined automatically after clicking the "Step 4" button. For example, the following code is executed for the determination of monthly energy consumption for the heating system:

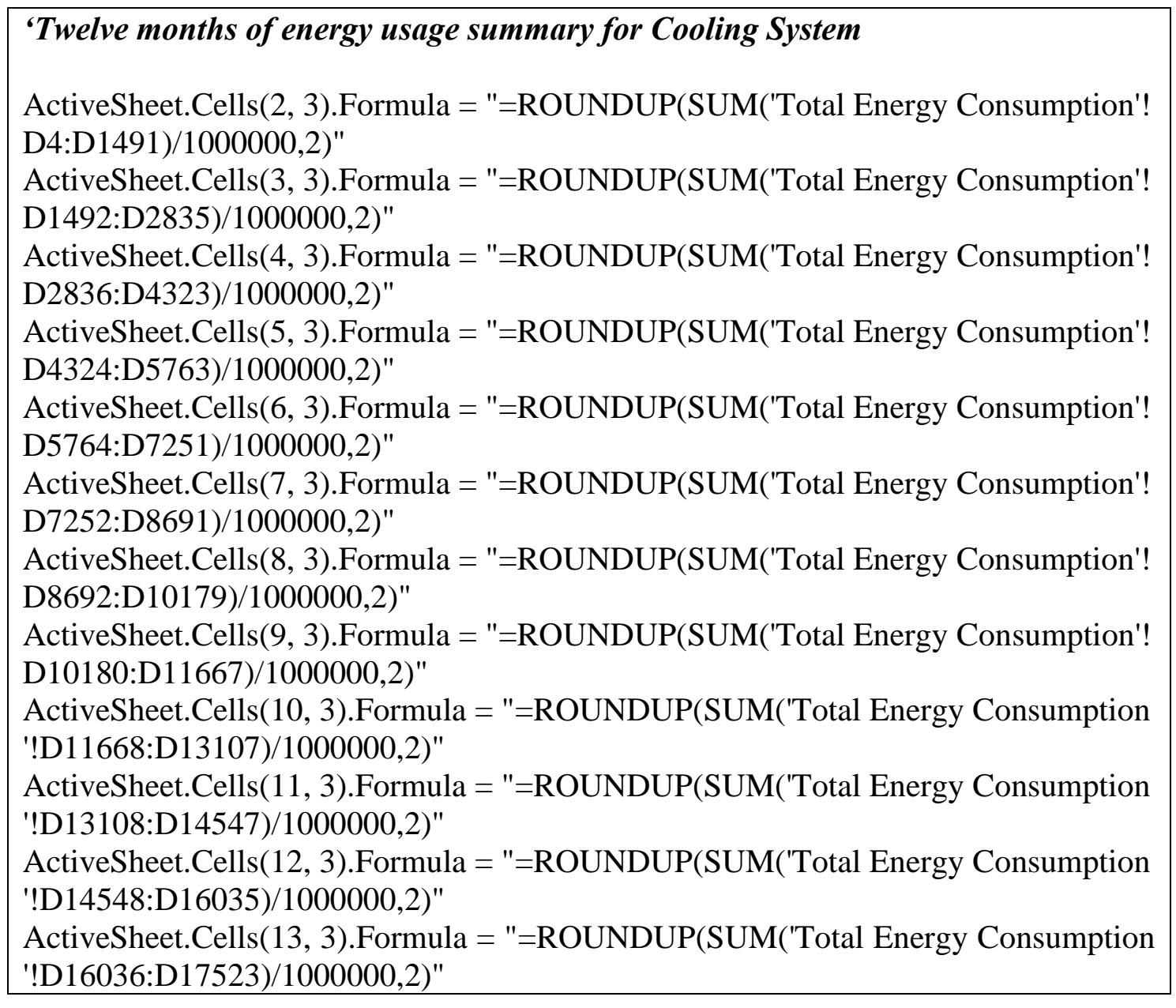

Finally, the fifth button, "Step 5," is designed to determine the rating of BEMS. The rating is determined on a monthly and annual basis. The following code is executed after clicking the button "Step 5": 


\section{'Determination of Rating of BEMS}

Private Sub rating_Click()

Dim e, $n$ As Double

ActiveWorkbook.Sheets.Add After:=Worksheets(Worksheets.Count)

Sheets(ActiveSheet.Name).Name = "Rating_of_BEMS"

ActiveSheet.Range("A1:Z20000").Borders.LineStyle = xlContinuous

e = InputBox $(" W h a t$ is Average cost of electricity $(\$ / \mathrm{kWh})$ ?", "Average electricity cost")

$\mathrm{n}=$ InputBox ("What is Average cost of natural gas (\$/mcf)?", "Average natural gas cost")

ActiveSheet.Cells $(3,1) \cdot$ Formula $=$ "=Summary_Energy_1!A2"

ActiveSheet.Cells $(3,2)$.Formula $=$ "=Summary_Energy_1!H2"

ActiveSheet.Cells $(3,3)$.Formula = "=Summary_Energy_2!H2"

ActiveSheet.Cells $(3,4)$.Formula = "=Summary_Energy_1!I2"

ActiveSheet.Cells $(3,5)$.Formula $="=$ Summary_Energy_2!I2"

ActiveSheet.Cells $(3,6)$. Formula $="=\operatorname{ROUNDUP}((\mathrm{B} 3-\mathrm{C} 3) / \mathrm{B} 3,2) "$

ActiveSheet.Cells(3, 7).Formula $="=\operatorname{ROUNDUP}(\mathrm{IF}(\mathrm{D} 3=0,0,(\mathrm{D} 3-\mathrm{E} 3) / \mathrm{D} 3), 2) "$

ActiveSheet.Cells(3, 8).Formula = "=1 + ROUNDUP $\left(\left((1-\mathrm{F} 3)^{*}((("\right.\right.$ \& e \& $" * \mathrm{~B} 3) /("$ \& e \& "*B3+" \& n \& "*D3))*4))+((1-G3)*(((" \& n \& "*D3)/(" \& e \& "*B3+" \& n \& "*D3))*4)),2)"

ActiveSheet.Cells $(15,2) \cdot$.Formula $="=\operatorname{ROUNDUP}(\operatorname{SUM}(\mathrm{B} 3: \mathrm{B} 14), 0) "$

ActiveSheet.Cells(15, 3).Formula $="=\operatorname{ROUNDUP}(\operatorname{SUM}(\mathrm{C} 3: \mathrm{C} 14), 0) "$

ActiveSheet.Cells(15, 4).Formula $="=\operatorname{ROUNDUP(SUM(D3:D14),0)"~}$

ActiveSheet.Cells(15, 5).Formula = "=ROUNDUP(SUM(E3:E14),0)"

ActiveSheet.Columns("A:Z").AutoFit

ActiveSheet.Range("A:Z").HorizontalAlignment = xlCenter

'Determination of Greenhouse gas emissions (lbs/yr)

ActiveWorkbook.Sheets.Add After:=Worksheets(Worksheets.Count)

Sheets(ActiveSheet.Name).Name = "Greenhouse gas Emissions"

ActiveSheet.Range("A1:Z20000").Borders.LineStyle = xlContinuous

ActiveSheet.Cells(3, 2).Formula = "=Rating_of_BEMS!B15"

ActiveSheet.Cells $(3,3)$.Formula $=$ "=Rating_of_BEMS!C15"

ActiveSheet.Cells $(4,2)$. Formula $=$ "=Rating_of_BEMS!D15"

ActiveSheet.Cells $(4,3)$. Formula = "=Rating_of_BEMS!E15"

'Conversion from Site energy to Source energy for electricity and natural gas

ActiveSheet.Cells $(3,4)$.Formula $=$ "=ROUNDUP(B3*2.8,0)"

ActiveSheet.Cells $(3,5)$.Formula $="=\operatorname{ROUNDUP}(\mathrm{C} 3 * 1.05,0) "$ 


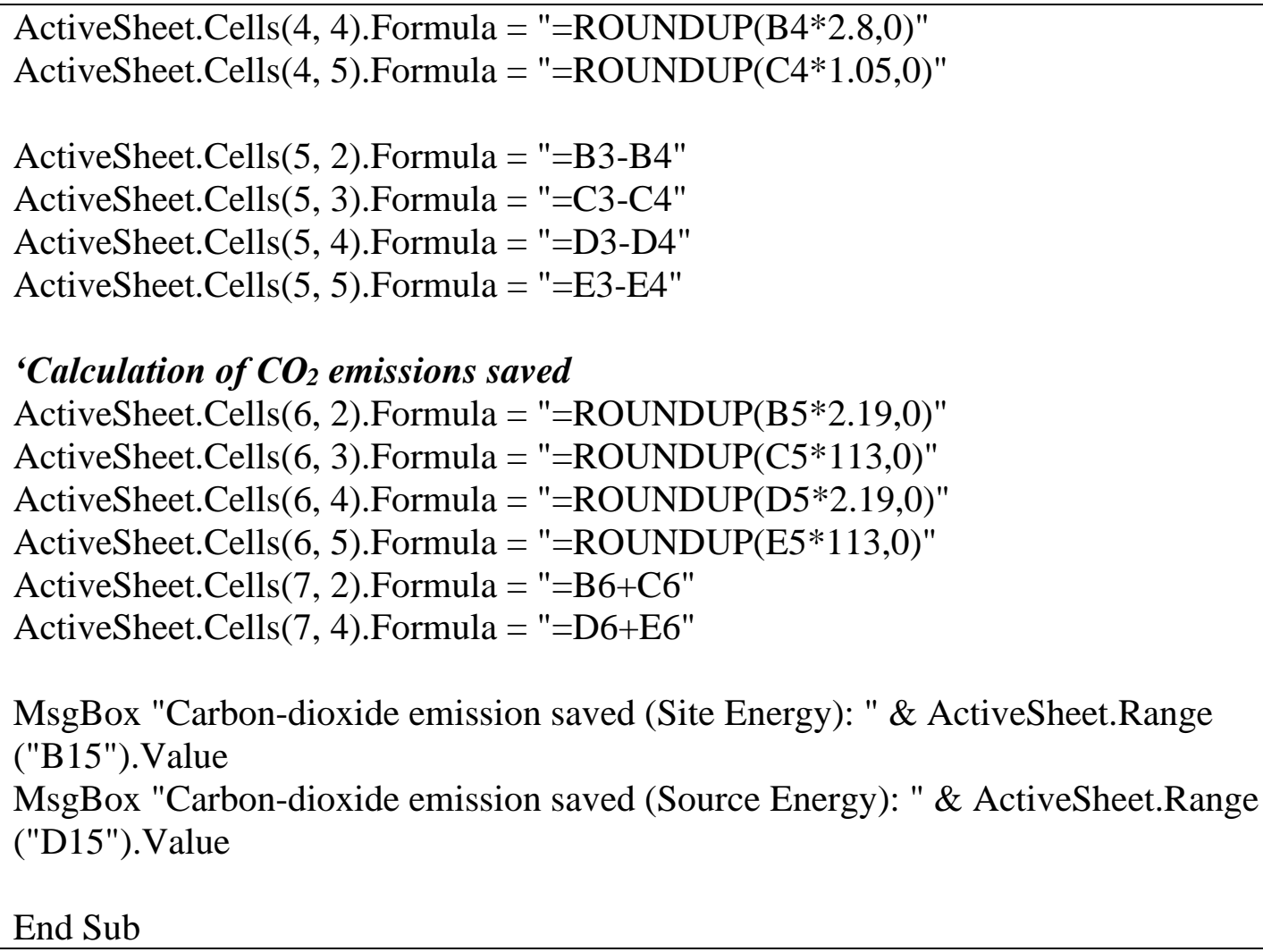

All the given VBA codes above are not the complete codes that run during the simulation. The above-given codes only represent the main formulas that are used for the calculation during the simulation run. Including all the codes will make the document size substantial. Hence, only the main formulas are included as an example of the codes developed for the research study.

\subsection{Conclusion}

The simulation tool is designed to handle any number of rooms; however, the constraint would be the time required for the simulation run, available BEMS controls, and building parameters to input in the model. Only four BEMS controls are considered in this study, and limited building parameters can be input into the model. Furthermore, multiple tests were performed to determine the time required for a various number of rooms, and it was found that the total time needed to simulate three rooms was 15-20 minutes, five rooms were 25-30 minutes, ten rooms were 35-45 minutes, and 15 rooms were 50-60 minutes. A default time of 10 minutes is included in above mentioned time duration for the input of the values from the user. The simulation was run on a computer with Intel Core i7-8550U 
CPU @ $1.80 \mathrm{GHz}$ (8 CPUs) and 8,192 MB RAM. The simulation would take less time if run on a computer with better computing capabilities.

Further, with advanced computing computers, the simulation tool can perform faster even with a more significant number of rooms. This simulation tool would be a helpful tool to get a quick estimate of the energy required for space heating and cooling of the building. Further, it would also help in understanding the requirement of outside air for maintaining the IAQ. Moreover, it can act as a bridge between building owner/energy managers and advanced energy modeling tools to benchmark the effectiveness of their BEMS. Since energy modeling of a building is cumbersome work and would require professional help to model the building in the software. By using this simulation tool, building owners can easily understand the energy required for space heating and cooling the building and the effectiveness of their BEMS. 


\section{Simulation System Execution and Results}

This chapter demonstrates the performance of the simulation tool based on actual building data. The user can determine an estimate for annual HVAC energy consumption for their building and the effectiveness of their energy management system. Furthermore, users also can determine the total supply of air and ventilation air required for the building at different times of the day based on occupancy to maintain the IAQ according to ASHRAE 62.12019 standard.

\subsection{Building Description}

For the demonstration of the simulation tool, a community center in Huntington, West Virginia, has been selected. The reason for choosing this community center is that it has multiple types of zones such as Gymnasium, Breakroom, Meeting Room, and Office spaces with different occupancy levels at different periods throughout the day. Hence, this building is considered an ideal building to determine the effectiveness of the energy management system. The floorplan of the community center is shown in Figure 5.1.

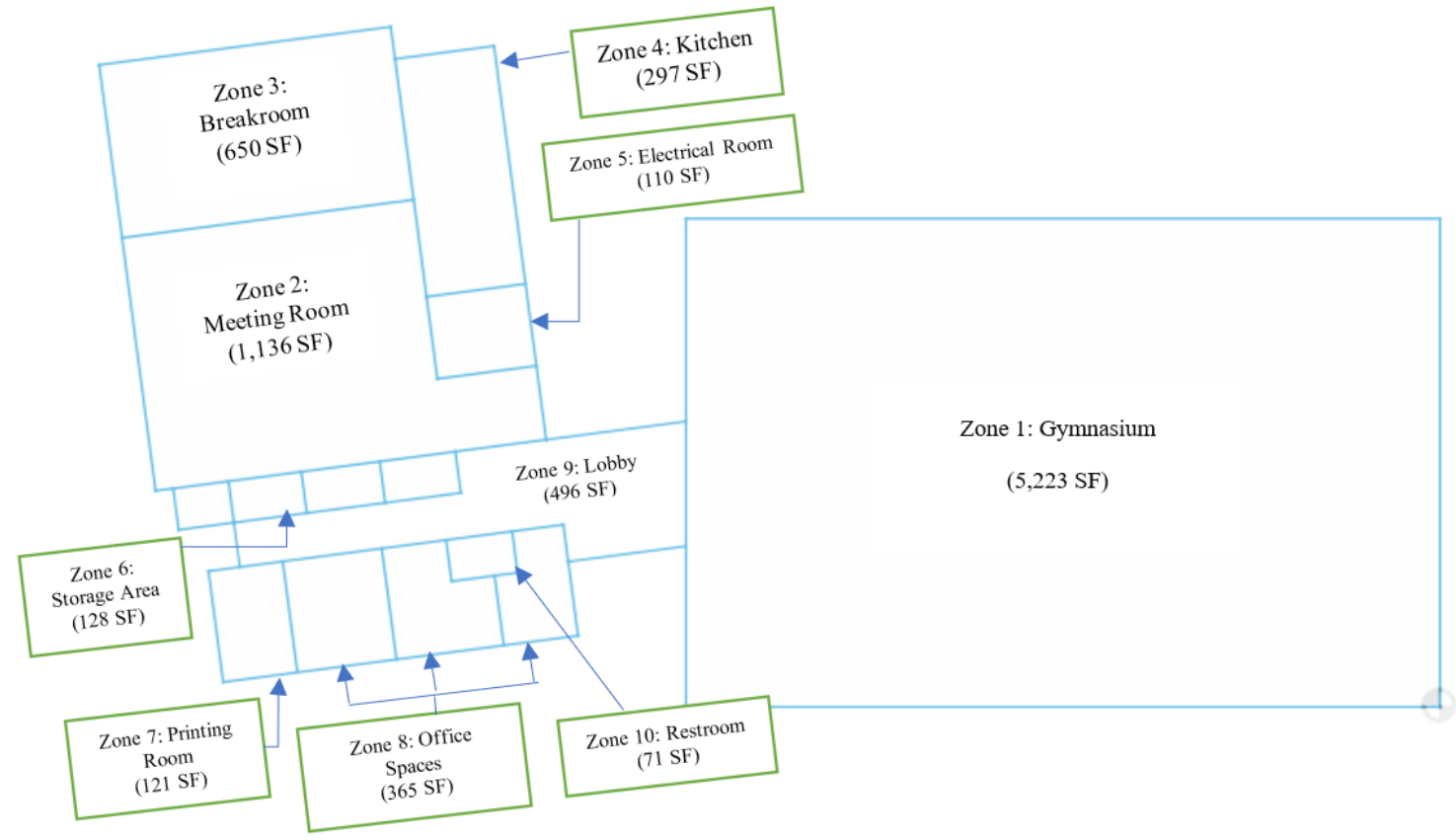

Figure 5.1: Floorplan of the community center

The community center is divided into two different buildings based on operational hours and the HVAC system used. The office building consists of a Meeting room, Breakroom, 
Kitchen, Lobby, Storage area, Printing area, Office spaces, Mechanical / Electrical room, and restroom. The other building of the community center is the Gymnasium. The office building opens from 7 am to 8 pm while the Gymnasium only opens from 7 am to $4 \mathrm{pm}$. The building does not open on weekends.

For cooling, the office building is served by a 2-ton capacity air conditioning unit. Two 5ton packaged air conditioning units serve the gymnasium. For heating, the office building is operated by the two packaged units with a capacity of $10 \mathrm{~kW}$ each. The gymnasium is served by three natural gas heating units, among which two of them are of capacity 0.1 $\mathrm{MMBtu} / \mathrm{hr}$, and the remaining is of capacity $0.2 \mathrm{MMBtu} / \mathrm{hr}$. The facility also has a natural gas water heater with a capacity of $0.034 \mathrm{MMBtu} / \mathrm{hr}$.

The ventilation requirement is different for each of the zones according to ASHRAE 62.12019 standards. According to the building personnel, it only has zoning and temperature setback controls which means that each zone except for the restroom has its thermostat to control the temperature of the spaces, and the temperature is setback during unoccupied hours and weekends.

During the visit to the building, it was found that the level of occupancy is low during the daytime, i.e., around 12-20 people, and high in the evening around 30-50 people. The office building has an 8-inch concrete block wall, whereas the gymnasium building has 3.5-inch insulation on a steel wall. Moreover, it was also found that the windows and doors were single panes both at the office building and gymnasium. Further, a lot of air infiltration was determined at the gymnasium building and office building through doors and windows. Hence, the overall building envelope insulation is considered to be poor.

Currently, none of the spaces has the demand control ventilation strategy. The thermostat is setback during unoccupied hours, and hence less energy is consumed during those periods. However, the spaces are ventilated using a constant air volume approach. The occupancy pattern varies in spaces such as Gymnasium, Meeting room, and Breakroom. The area's size is greater than 500 sq. $\mathrm{ft}$ and the occupant's density is also greater than 25 people/ 1,000 sq. ft. Hence, these three spaces are considered ideal for DCV strategy using $\mathrm{CO}_{2}$ sensors. 
Furthermore, other spaces in the building such as kitchen, office space, storage area, printing room, the lobby can also use demand-controlled ventilation but using the occupancy sensor approach or occupancy scheduling approach. If these spaces are expected to be occupied then, an energy management system can be programmed that enables these spaces to be ventilated according to recommended ACH by ASHRAE. These spaces can just be ventilated during unoccupied hours according to the area outdoor air requirement specified by ASHRAE 62.1-2019 standard. The electrical room should always be ventilated to avoid dust accumulation in the control panel and remove the heat generated inside the room due to the electrical system. Moreover, the air in the restroom should be exhausted, and ventilation should constantly be provided according to recommended $\mathrm{ACH}$ by ASHRAE to maintain the air quality inside the restroom.

Considering all the current operating characteristics of the building, the annual energy required for the HVAC system of the building is determined by using the simulation tool. Thus, obtained HVAC energy is compared against the annual energy bills of the building. Furthermore, from the given capacity of the HVAC unit, the annual energy consumption is determined based on the degree days method and compared against the data obtained from the simulation tool. In addition, the building is also modeled using eQuest software, and the energy required for space heating and cooling is determined and compared against the energy obtained from simulation.

Finally, with improvement in the building envelope and other BEMS controls, the effectiveness of the current energy management system is determined.

\subsection{Simulation Demonstration with Community Center Building}

The simulation is performed in two runs. For the first run (Base Case), the current operating characteristics of the building with current BEMS controls are input into the model. Once twelve-month energy data is obtained for the Base Case, the worksheets corresponding to the Base Case are deleted except for the "Summary_Energy_1" worksheet by clicking the "Clear" button in the "User Manual" worksheet. Further, a second simulation run is performed for the TEE Case. Here, all the BEMS controls are considered, along with improvement in the building envelope. The simulation is performed in similar order from "Step 1" to "Step 4". Once the twelve-month energy data is obtained for the TEE Case in 
the "Summary_Energy_2" worksheet, the "Step 5" button is clicked that gives us the effectiveness of BEMS by comparing data from the "Summary_Energy_1" worksheet and "Summary_Energy_2" worksheet. The following section described the individual cases in more detail.

\subsubsection{Simulation with User-Defined / Base Case}

As an example, the step-by-step simulation for the community center building is described in this section. First, the user has to provide the total number of rooms in the building by clicking the "Start Simulation" button to begin the simulation. Further, the user is asked to select the BEMS controls used in the building. If the building does not have a DCV system, the user is asked to input the approximate percentage of outdoor air intake inside the building for ventilation, as shown in Figure 5.2. After that, the "Inputs" worksheet will be activated, where a color-coded table is generated with the same number of rows as the number of rooms entered by the user. The user can select the type of rooms and level of building envelope from the drop-down menu, as shown in Figure 5.3. The instruction for choosing the building envelope is provided in the "Input" worksheet. The user has to manually input the thermostat setting, area, and height of the individual room.
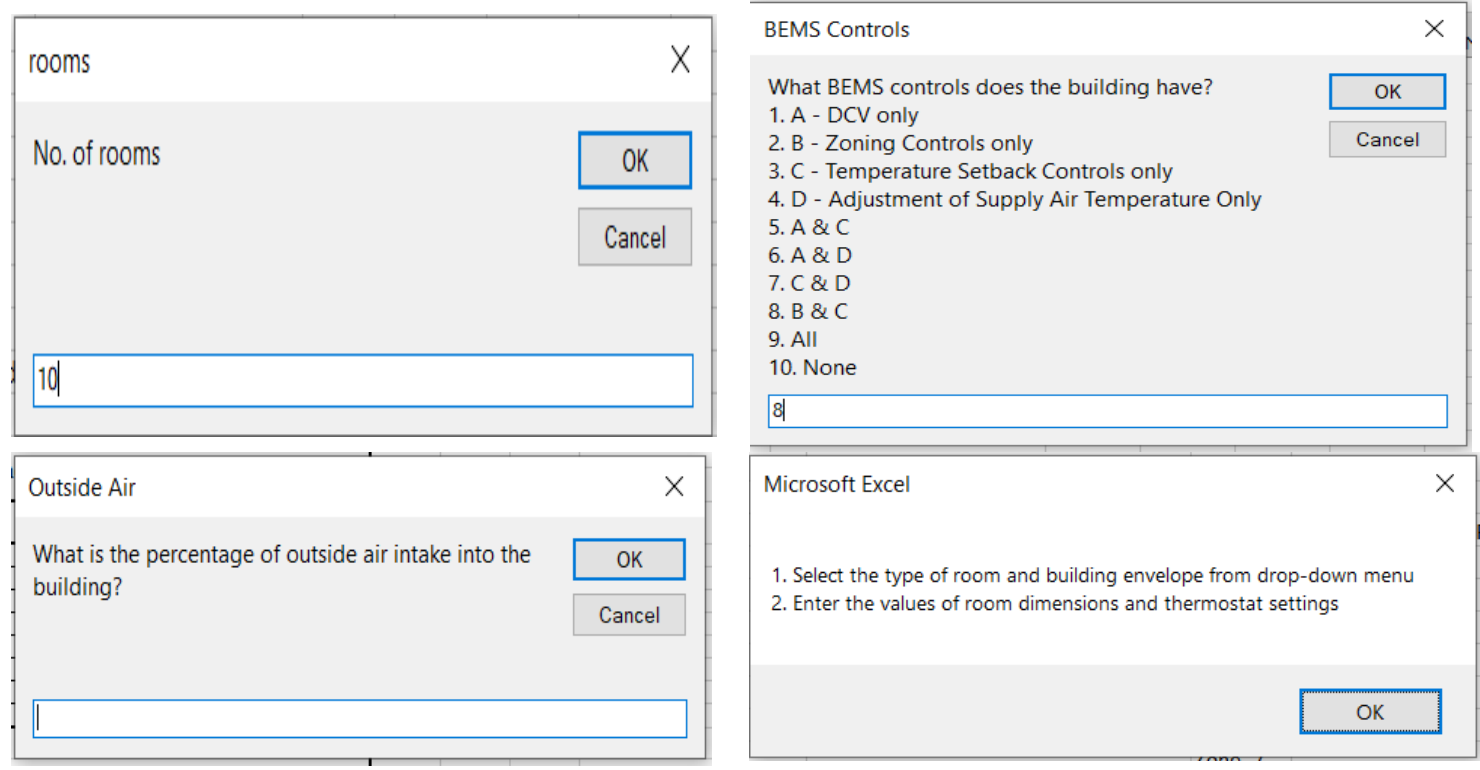

Figure 5.2: Input boxes for a user to provide general building information 


\begin{tabular}{|c|c|c|c|c|c|c|c|c|c|}
\hline 2 & No. of Rooms & & 10 & & & & & & \\
\hline 3 & & & & & & \multicolumn{4}{|c|}{ Thermostat Setpoints $\left({ }^{\circ} \mathrm{F}\right)$} \\
\hline 4 & & & & \multicolumn{2}{|c|}{ Dimension of Room (ft) } & \multicolumn{2}{|c|}{ Set Temperature } & \multicolumn{2}{|c|}{ Setback Temperature } \\
\hline 5 & Type of Room & \multicolumn{2}{|r|}{ Building Envelope } & Area & Height & Summer & Winter & Summer & Winter \\
\hline 6 & Gymnasium & & 1 & 5223 & 35 & 63 & 75 & 80 & 60 \\
\hline 7 & Meeting_Room & & 1 & 1136 & 14 & 65 & 70 & 80 & 60 \\
\hline 8 & Breakroom & & 1 & 650 & 14 & 65 & 70 & 80 & 60 \\
\hline 9 & Kitchen & & 1 & 297 & 8 & 65 & 70 & 80 & 60 \\
\hline 10 & Electrical_Room & & 1 & 110 & 8 & 65 & 70 & 80 & 60 \\
\hline 11 & Storage_Room & & 1 & 128 & 8 & 65 & 70 & 80 & 60 \\
\hline 12 & Printing_Room & & 1 & 121 & 10 & 65 & 70 & 80 & 60 \\
\hline 13 & Office_Private_Space & & 1 & 365 & 10 & 65 & 70 & 80 & 60 \\
\hline 14 & Lobby & & 1 & 496 & 10 & 65 & 70 & 80 & 60 \\
\hline 15 & Rest_Room & iv & 1 & 71 & 10 & 65 & 70 & 80 & 60 \\
\hline & $\wedge$ & & & & & & & \\
\hline \multicolumn{2}{|c|}{ Kitchen } & & & & & & & & \\
\hline \multicolumn{2}{|c|}{$\begin{array}{l}\text { Cafeteria } \\
\text { Printing_Room }\end{array}$} & & & & & & & & \\
\hline \multicolumn{2}{|c|}{$\begin{array}{l}\text { Corridor } \\
\text { Electrical_Room }\end{array}$} & & & & & & & & \\
\hline \multirow{2}{*}{\multicolumn{2}{|c|}{ Data_Server_Room }} & & & & & & & & \\
\hline & & $\checkmark$ & & & & & & & \\
\hline
\end{tabular}

Figure 5.3: Color-coded table for a user to input building data

Then, after populating the color-coded table in the "Input" worksheet, the user can check the feasibility of generating effective energy efficiency of the building by clicking the "Feasibility Check" button, as shown in Figure 5.4. Here, since the building envelope of all the rooms is set to " 1 " due to poor insulation, as shown in Figure 5.1, it is considered infeasible for generating effective energy efficiency with BEMS controls. There are various criteria for the building to be feasible, infeasible, or unnecessary for generating effective energy efficiency discussed in earlier section 4.1.5.

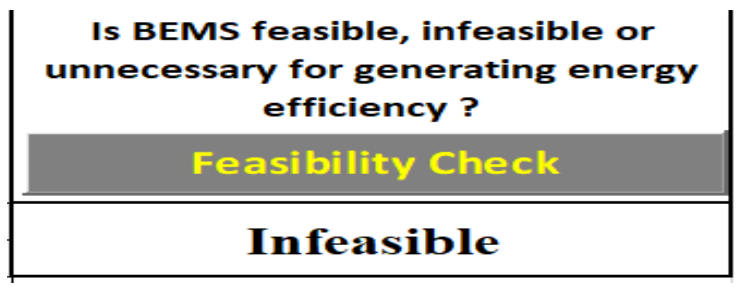

Figure 5.4: Feasibility check for generating effective energy efficiency

Further, the user needs to proceed with "Step 1". After clicking "Step 1", pop-up boxes appear that asks the user to input the climatic region, location, and nearest weather station, as shown in Figure 5.5. Then, ten new sheets are generated that are named "Zone_1" through "Zone_10". Here, for each of the zone, various parameters such as expected number of occupants, number of air changes, outdoor air $(\mathrm{cfm})$, total supply air $(\mathrm{cfm})$, 
return air $(\mathrm{cfm})$, seasonal factor, SAT $\left({ }^{\circ} \mathrm{F}\right)$, and humidity ratio of supply and return air is determined as shown in Table 5.1. Table 5.1 is the data from only a single zone; nine other similar worksheets are generated for nine remaining rooms.

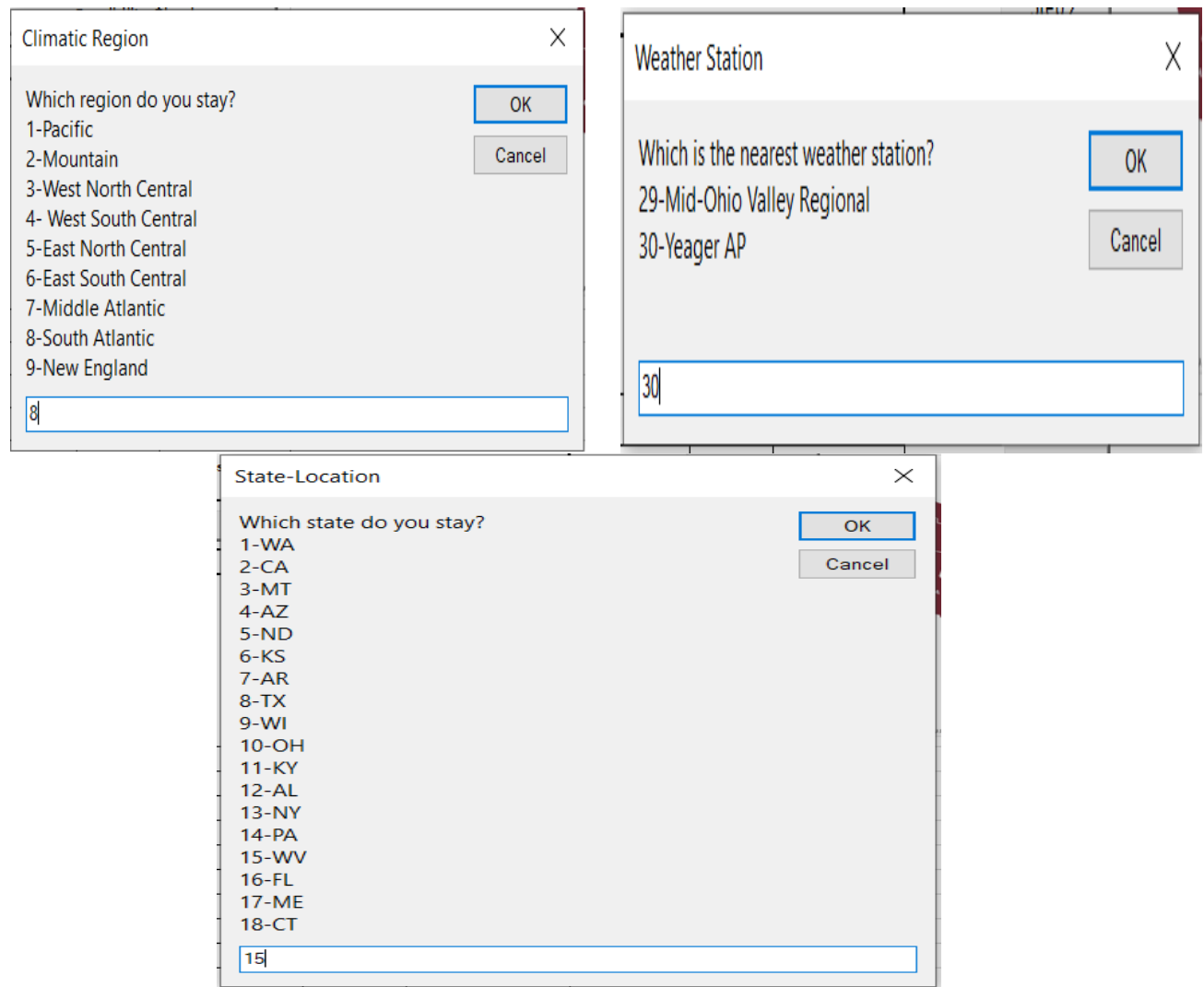

Figure 5.5: Input boxes for the user to provide information about their location

Furthermore, the user needs to click "Step 2," after which a new sheet named "Mixed Air" is generated. This sheet determines the total outside air ( $\mathrm{cfm})$, total supply air $(\mathrm{cfm})$, total return air $(\mathrm{cfm})$ required for the building. In addition, other parameters such as temperature and humidity of return and mixed air are also determined, as shown in Table 5.2.

Then, the user needs to click "Step 3," after which a message box is pops-up, as shown in Figure 5.6. The energy source for heating the building is asked. The user needs to select the option between natural gas and electricity for heating the building. Here, the building is heated with HVAC units with electric energy except for the gymnasium. The gymnasium is heated with natural gas. Therefore, modifications are made in the code to account for natural gas as the heating source for the gymnasium and electricity for the other zones of the building. 
Table 5.1: Worksheet of Supply Air Characteristics for the Base Case

\begin{tabular}{|c|c|c|c|c|c|c|c|c|c|c|c|}
\hline Day & Hour & $\begin{array}{l}\text { Occupancy } \\
\text { Random }\end{array}$ & $\begin{array}{c}\text { Expected } \\
\text { Occupants (\#) }\end{array}$ & $\begin{array}{c}\text { No. of Air Changes } \\
\text { (per } 30 \text { mins) }\end{array}$ & $\begin{array}{c}\text { Outdoor Air } \\
\text { (cfm) }\end{array}$ & \begin{tabular}{|c|} 
Total Supply \\
Air (cfm)
\end{tabular} & $\begin{array}{c}\text { Return Air } \\
\text { (cfm) }\end{array}$ & $\begin{array}{c}\text { Season } \\
\text { Random }\end{array}$ & $\begin{array}{c}\text { Supply Air } \\
\text { Temperature (F) }\end{array}$ & $\begin{array}{c}\text { Humidity Ratio } \\
\text { of Supply Air }\end{array}$ & $\begin{array}{c}\text { Humidity Ratio of } \\
\text { Return Air }\end{array}$ \\
\hline 1 & 12:00 AM & 0.93 & 0 & 2.5 & 1,219 & 12,187 & 10,968 & 0.46 & 100 & 0.0018 & 0.012 \\
\hline 1 & $12: 30 \mathrm{AM}$ & 0.91 & 0 & 2.5 & 1,219 & 12,187 & 10,968 & 0.46 & 100 & 0.0018 & 0.012 \\
\hline 1 & 1:00 AM & 0.17 & 0 & 2.5 & 1,219 & 12,187 & 10,968 & 0.46 & 100 & 0.0018 & 0.012 \\
\hline 1 & 1:30 AM & 0.5 & 0 & 2.5 & 1,219 & 12,187 & 10,968 & 0.46 & 100 & 0.0018 & 0.012 \\
\hline 1 & 2:00 AM & 0.38 & 0 & 2.5 & 1,219 & 12,187 & 10,968 & 0.46 & 100 & 0.0018 & 0.012 \\
\hline 1 & 2:30 AM & 0.6 & 0 & 2.5 & 1,219 & 12,187 & 10,968 & 0.46 & 100 & 0.0018 & 0.012 \\
\hline 1 & 3:00 AM & 0.04 & 0 & 2.5 & 1,219 & 12,187 & 10,968 & 0.46 & 100 & 0.0018 & 0.012 \\
\hline 1 & 3:30 AM & 0.35 & 0 & 2.5 & 1,219 & 12,187 & 10,968 & 0.46 & 100 & 0.0018 & 0.012 \\
\hline 1 & 4:00 AM & 0.73 & 0 & 2.5 & 1,219 & 12,187 & 10,968 & 0.46 & 100 & 0.0018 & 0.012 \\
\hline 1 & 4:30 AM & 0.08 & 0 & 2.5 & 1,219 & 12,187 & 10,968 & 0.46 & 100 & 0.0018 & 0.012 \\
\hline 1 & 5:00 AM & 0.24 & 0 & 2.5 & 1,219 & 12,187 & 10,968 & 0.46 & 100 & 0.0018 & 0.012 \\
\hline 1 & 5:30 AM & 0.07 & 0 & 2.5 & 1,219 & 12,187 & 10,968 & 0.46 & 100 & 0.0018 & 0.012 \\
\hline 1 & 6:00 AM & 0.84 & 0 & 2.5 & 1,219 & 12,187 & 10,968 & 0.46 & 100 & 0.0018 & 0.012 \\
\hline 1 & 6:30 AM & 0.2 & 0 & 2.5 & 1,219 & 12,187 & 10,968 & 0.46 & 100 & 0.0018 & 0.012 \\
\hline 1 & 7:00 AM & 0.77 & 0 & 2.5 & 1,219 & 12,187 & 10,968 & 0.46 & 100 & 0.0018 & 0.012 \\
\hline 1 & 7:30 AM & 0.98 & 0 & 2.5 & 1,219 & 12,187 & 10,968 & 0.46 & 100 & 0.0018 & 0.012 \\
\hline 1 & 8:00 AM & 0.8 & 0 & 2.5 & 1,219 & 12,187 & 10,968 & 0.48 & 100 & 0.0018 & 0.012 \\
\hline 1 & 8:30 AM & 0.68 & 30 & 2.5 & 1,219 & 12,187 & 10,968 & 0.48 & 100 & 0.0009 & 0.010 \\
\hline 1 & 9:00 AM & 0.28 & 30 & 2.5 & 1,219 & 12,187 & 10,968 & 0.48 & 100 & 0.0009 & 0.010 \\
\hline
\end{tabular}

Table 5.2: Worksheet of Mixed Air Characteristics for the Base Case

\begin{tabular}{|c|c|c|c|c|c|c|c|c|}
\hline Day & Hour & $\begin{array}{c}\text { Total Outside Air } \\
(\mathbf{c f m})\end{array}$ & $\begin{array}{c}\text { Total Supply Air } \\
\text { (cfm) }\end{array}$ & $\begin{array}{c}\text { Total Return Air } \\
\text { (cfm) }\end{array}$ & $\begin{array}{c}\text { Temperature of } \\
\text { Return Air (F) }\end{array}$ & $\begin{array}{c}\text { Humidity Ratio of } \\
\text { Return Air }\end{array}$ & $\begin{array}{c}\text { Temperature of } \\
\text { Mixed Air (F) }\end{array}$ & $\begin{array}{c}\text { Humidity Ratio of } \\
\text { Mixed Air }\end{array}$ \\
\hline 1 & $12: 00 \mathrm{AM}$ & 1,925 & 17,803 & 15,878 & 60 & 0.0118 & 54.67 & 0.02 \\
\hline 1 & $12: 30 \mathrm{AM}$ & 1,925 & 17,803 & 15,878 & 60 & 0.0118 & 54.67 & 0.02 \\
\hline 1 & 1:00 AM & 1,925 & 17,803 & 15,878 & 60 & 0.0117 & 54.67 & 0.02 \\
\hline 1 & $1: 30 \mathrm{AM}$ & 1,925 & 17,803 & 15,878 & 60 & 0.0118 & 54.67 & 0.02 \\
\hline 1 & 2:00 AM & 1,925 & 17,803 & 15,878 & 60 & 0.0118 & 54.67 & 0.02 \\
\hline 1 & 2:30 AM & 1,925 & 17,803 & 15,878 & 60 & 0.0118 & 54.67 & 0.02 \\
\hline 1 & 3:00 AM & 1,925 & 17,803 & 15,878 & 60 & 0.0118 & 54.67 & 0.02 \\
\hline 1 & 3:30 AM & 1,925 & 17,803 & 15,878 & 60 & 0.0118 & 54.67 & 0.02 \\
\hline 1 & 4:00 AM & 1,925 & 17,803 & 15,878 & 60 & 0.0118 & 54.67 & 0.02 \\
\hline
\end{tabular}




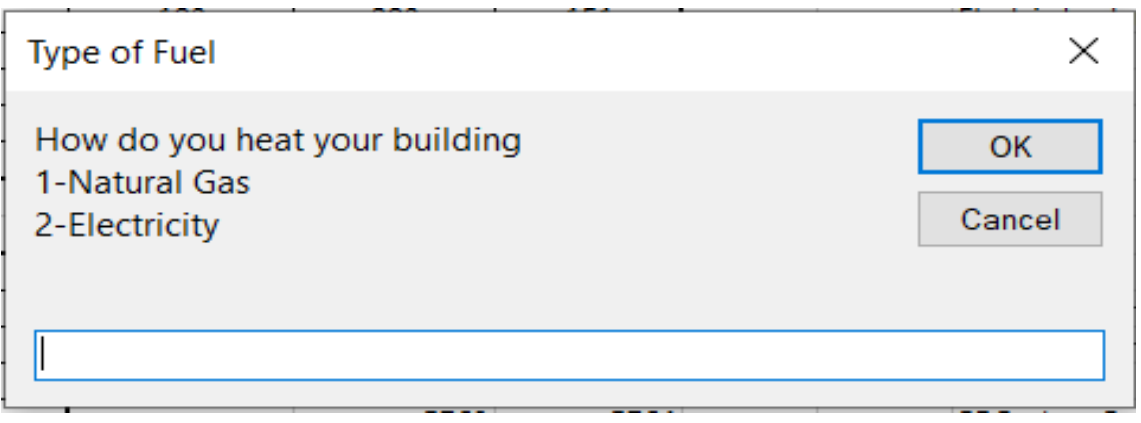

Figure 5.6: Input Box for the user to input the source of heating

Once the energy source for heating the building is selected, ten new sheets are generated with names as "Energy_Zone_1" through "Energy_Zone_10". Here, the energy required for space heating or cooling is determined for every 30-minute interval, as shown in Table 5.3. Table 5.3 is the data from only a single zone; nine other similar worksheets are generated for nine remaining rooms.

The next step is to click the "Step 4" button to generate the "Total Energy Consumption" worksheet. It will summarize the energy consumption required for space heating and cooling for each zone and the total building, as shown in Table 5.4. In addition, it will also summarize the total energy required for space heating and cooling for all twelve months, as shown in Table 5.5. 
Table 5.3: Worksheet of Energy Calculation for the Base Case

\begin{tabular}{|c|c|c|c|c|c|c|c|c|c|c|c|c|}
\hline \multirow[b]{2}{*}{ Date } & \multirow[b]{2}{*}{ Time } & \multirow[b]{2}{*}{$\begin{array}{c}\text { CFM } \\
\text { Requirement }\end{array}$} & \multirow[b]{2}{*}{$\begin{array}{c}\text { Cooling Month } \\
(\text { Yes }=1, \text { No }=0)\end{array}$} & \multicolumn{5}{|c|}{ During Summer } & \multicolumn{3}{|c|}{ During Winter } & \multirow[b]{2}{*}{$\begin{array}{l}\text { Seasonal } \\
\text { Factor }\end{array}$} \\
\hline & & & & $\begin{array}{c}\text { (Sensible heat load), } \\
\text { Btu/hr }\end{array}$ & $\begin{array}{c}\text { (Latent heat load), } \\
\text { Btu/hr }\end{array}$ & $\begin{array}{c}\text { (Total heat load), } \\
\text { Btu/hr }\end{array}$ & $\begin{array}{l}\text { Power, } \\
(\mathrm{kW})\end{array}$ & $\begin{array}{c}\text { Energy Usage, } \\
(\mathrm{kWh})\end{array}$ & $\begin{array}{c}\text { (Sensible heat load), } \\
\text { Btu/hr }\end{array}$ & Power,(kW) & \begin{tabular}{|c|} 
Energy Usage, \\
$(\mathbf{k W h})$
\end{tabular} & \\
\hline 1 & 12:00 AM & 2,272 & 0 & 0 & 0 & 0 & 0 & 0 & 2,225 & 0.69 & 0.35 & 0.46 \\
\hline 1 & 12:30 AM & 2,272 & 0 & 0 & 0 & 0 & 0 & 0 & 2,225 & 0.69 & 0.35 & 0.46 \\
\hline 1 & 1:00 AM & 2,272 & 0 & 0 & 0 & 0 & 0 & 0 & 2,225 & 0.69 & 0.35 & 0.46 \\
\hline 1 & 1:30 AM & 2,272 & 0 & 0 & 0 & 0 & 0 & 0 & 2,225 & 0.69 & 0.35 & 0.46 \\
\hline 1 & 2:00 AM & 2,272 & 0 & 0 & 0 & 0 & 0 & 0 & 2,225 & 0.69 & 0.35 & 0.46 \\
\hline 1 & 2:30 AM & 2,272 & 0 & 0 & 0 & 0 & 0 & 0 & 2,225 & 0.69 & 0.35 & 0.46 \\
\hline 1 & 3:00 AM & 2,272 & 0 & 0 & 0 & 0 & 0 & 0 & 2,225 & 0.69 & 0.35 & 0.46 \\
\hline 1 & 3:30 AM & 2,272 & 0 & 0 & 0 & 0 & 0 & 0 & 2,225 & 0.69 & 0.35 & 0.46 \\
\hline 1 & 4:00 AM & 2,272 & 0 & 0 & 0 & 0 & 0 & 0 & 2,225 & 0.69 & 0.35 & 0.46 \\
\hline 1 & 4:30 AM & 2,272 & 0 & 0 & 0 & 0 & 0 & 0 & 2,225 & 0.69 & 0.35 & 0.46 \\
\hline 1 & 5:00 AM & 2,272 & 0 & 0 & 0 & 0 & 0 & 0 & 2,225 & 0.69 & 0.35 & 0.46 \\
\hline 1 & 5:30 AM & 2,272 & 0 & 0 & 0 & 0 & 0 & 0 & 2,225 & 0.69 & 0.35 & 0.46 \\
\hline 1 & 6:00 AM & 2,272 & 0 & 0 & 0 & 0 & 0 & 0 & 2,225 & 0.69 & 0.35 & 0.46 \\
\hline 1 & 6:30 AM & 2,272 & 0 & 0 & 0 & 0 & 0 & 0 & 2,225 & 0.69 & 0.35 & 0.46 \\
\hline
\end{tabular}

Table 5.4:Worksheet of Summary of Energy Consumption for the Base Case

\begin{tabular}{|c|c|c|c|c|c|c|c|c|c|c|c|c|c|c|c|c|c|c|c|c|c|c|c|}
\hline \multirow[b]{3}{*}{ Day } & \multirow[b]{3}{*}{ Hour } & \multicolumn{22}{|c|}{ Energy Consumption } \\
\hline & & \multicolumn{2}{|c|}{ Zone_1 } & \multicolumn{2}{|c|}{ Zone_2 } & \multicolumn{2}{|c|}{ Zone_3 } & \multicolumn{2}{|c|}{ Zone_4 } & \multicolumn{2}{|c|}{ Zone_5 } & \multicolumn{2}{|c|}{ Zone_6 } & \multicolumn{2}{|c|}{ Zone_7 } & \multicolumn{2}{|c|}{ Zone_8 } & \multicolumn{2}{|c|}{ Zone_9 } & \multicolumn{2}{|c|}{ Zone_10 } & \multicolumn{2}{|c|}{ Total } \\
\hline & & $\begin{array}{l}\text { Elec. } \\
\text { Usage } \\
(\mathrm{kWh})\end{array}$ & $\begin{array}{c}\text { Gas } \\
\text { Usage } \\
\text { (Btu) }\end{array}$ & $\begin{array}{l}\text { Elec. } \\
\text { Usage } \\
(\mathbf{k W h})\end{array}$ & $\begin{array}{c}\text { Gas } \\
\text { Usage } \\
\text { (Btu) }\end{array}$ & $\begin{array}{l}\text { Elec. } \\
\text { Usage } \\
(\mathbf{k W h})\end{array}$ & $\begin{array}{l}\text { Gas } \\
\text { Usage } \\
\text { (Btu) }\end{array}$ & $\begin{array}{l}\text { Elec. } \\
\text { Usage } \\
(\mathbf{k W h})\end{array}$ & $\begin{array}{c}\text { Gas } \\
\text { Usage } \\
\text { (Btu) }\end{array}$ & $\begin{array}{l}\text { Elec. } \\
\text { Usage } \\
(\mathrm{kWh})\end{array}$ & $\begin{array}{l}\text { Gas } \\
\text { Usage } \\
\text { (Btu) }\end{array}$ & $\begin{array}{l}\text { Elec. } \\
\text { Usage } \\
(\mathbf{k W h})\end{array}$ & $\begin{array}{l}\text { Gas } \\
\text { Usage } \\
\text { (Btu) }\end{array}$ & $\begin{array}{l}\text { Elec. } \\
\text { Usage } \\
\text { (kWh) }\end{array}$ & $\begin{array}{c}\text { Gas } \\
\text { Usage } \\
\text { (Btu) }\end{array}$ & $\begin{array}{l}\text { Elec. } \\
\text { Usage } \\
(\mathrm{kWh})\end{array}$ & $\begin{array}{c}\text { Gas } \\
\text { Usage } \\
\text { (Btu) }\end{array}$ & $\begin{array}{l}\text { Elec. } \\
\text { Usage } \\
\text { (kWh) }\end{array}$ & $\begin{array}{c}\text { Gas } \\
\text { Usage } \\
\text { (Btu) }\end{array}$ & $\begin{array}{l}\text { Elec. } \\
\text { Usage } \\
\text { (kWh) }\end{array}$ & $\begin{array}{c}\text { Gas } \\
\text { Usage } \\
\text { (Btu) }\end{array}$ & $\begin{array}{l}\text { Elec. } \\
\text { Usage } \\
\text { (kWh) }\end{array}$ & $\begin{array}{c}\text { Gas Usage } \\
\text { (Btu) }\end{array}$ \\
\hline 1 & 12:00 AM & 0 & 14,039 & 0.35 & 0 & 0.15 & 0 & 0.18 & 0 & 0.03 & 0 & 0.02 & 0 & 0.07 & 0 & 0.05 & 0 & 0.01 & 0 & 0.02 & 0 & 0.88 & 14,039 \\
\hline 1 & $12: 30 \mathrm{AM}$ & 0 & 14,039 & 0.35 & 0 & 0.15 & 0 & 0.18 & 0 & 0.03 & 0 & 0.02 & 0 & 0.07 & 0 & 0.05 & 0 & 0.01 & 0 & 0.02 & 0 & 0.88 & 14,039 \\
\hline 1 & 1:00 AM & 0 & 14,039 & 0.35 & 0 & 0.15 & 0 & 0.18 & 0 & 0.03 & 0 & 0.02 & 0 & 0.07 & 0 & 0.05 & 0 & 0.01 & 0 & 0.02 & 0 & 0.88 & 14,039 \\
\hline 1 & $1: 30 \mathrm{AM}$ & 0 & 14,039 & 0.35 & 0 & 0.15 & 0 & 0.18 & 0 & 0.03 & 0 & 0.02 & 0 & 0.07 & 0 & 0.05 & 0 & 0.01 & 0 & 0.02 & 0 & 0.88 & 14,039 \\
\hline 1 & 2:00 AM & 0 & 14,039 & 0.35 & 0 & 0.15 & 0 & 0.18 & 0 & 0.03 & 0 & 0.02 & 0 & 0.07 & 0 & 0.05 & 0 & 0.01 & 0 & 0.02 & 0 & 0.88 & 14,039 \\
\hline 1 & 2:30 AM & 0 & 14,039 & 0.35 & 0 & 0.15 & 0 & 0.18 & 0 & 0.03 & 0 & 0.02 & 0 & 0.07 & 0 & 0.05 & 0 & 0.01 & 0 & 0.02 & 0 & 0.88 & 14,039 \\
\hline 1 & 3:00 AM & 0 & 14,039 & 0.35 & 0 & 0.15 & 0 & 0.18 & 0 & 0.03 & 0 & 0.02 & 0 & 0.07 & 0 & 0.05 & 0 & 0.01 & 0 & 0.02 & 0 & 0.88 & 14,039 \\
\hline 1 & 3:30 AM & 0 & 14,039 & 0.35 & 0 & 0.15 & 0 & 0.18 & 0 & 0.03 & 0 & 0.02 & 0 & 0.07 & 0 & 0.05 & 0 & 0.01 & 0 & 0.02 & 0 & 0.88 & 14,039 \\
\hline 1 & 4:00 $\mathrm{AM}$ & 0 & 14,039 & 0.35 & 0 & 0.15 & 0 & 0.18 & 0 & 0.03 & 0 & 0.02 & 0 & 0.07 & 0 & 0.05 & 0 & 0.01 & 0 & 0.02 & 0 & 0.88 & 14,039 \\
\hline 1 & 4:30 AM & 0 & 14,039 & 0.35 & 0 & 0.15 & 0 & 0.18 & 0 & 0.03 & 0 & 0.02 & 0 & 0.07 & 0 & 0.05 & 0 & 0.01 & 0 & 0.02 & 0 & 0.88 & 14,039 \\
\hline 1 & 5:00 AM & 0 & 14,039 & 0.35 & 0 & 0.15 & 0 & 0.18 & 0 & 0.03 & 0 & 0.02 & 0 & 0.07 & 0 & 0.05 & 0 & 0.01 & 0 & 0.02 & 0 & 0.88 & 14,039 \\
\hline 1 & $5: 30 \mathrm{AM}$ & 0 & 14,039 & 0.35 & 0 & 0.15 & 0 & 0.18 & 0 & 0.03 & 0 & 0.02 & 0 & 0.07 & 0 & 0.05 & 0 & 0.01 & 0 & 0.02 & 0 & 0.88 & 14,039 \\
\hline 1 & 6:00 AM & 0 & 14,039 & 0.35 & 0 & 0.15 & 0 & 0.18 & 0 & 0.03 & 0 & 0.02 & 0 & 0.07 & 0 & 0.05 & 0 & 0.01 & 0 & 0.02 & 0 & 0.88 & 14,039 \\
\hline 1 & 6:30 AM & 0 & 14,039 & 0.35 & 0 & 0.15 & 0 & 0.18 & 0 & 0.03 & 0 & 0.02 & 0 & 0.07 & 0 & 0.05 & 0 & 0.01 & 0 & 0.02 & 0 & 0.88 & 14,039 \\
\hline
\end{tabular}


Table 5.5: Monthly energy consumption for the Base Case

\begin{tabular}{|c|c|c|c|}
\hline \multirow{4}{*}{ Year } & Month & $\begin{array}{c}\text { Energy Usage, } \\
\text { (kWh) }\end{array}$ & $\begin{array}{c}\text { Natural Gas } \\
\text { Usage, } \\
\text { (MMBtu) }\end{array}$ \\
\hline \multirow{4}{*}{} & January & 3,360 & 64.71 \\
\cline { 2 - 4 } & February & 3,028 & 58.32 \\
\cline { 2 - 4 } & March & 2,254 & 43.29 \\
\cline { 2 - 4 } & April & 1,865 & 33.93 \\
\cline { 2 - 4 } & May & 3,559 & 0 \\
\cline { 2 - 4 } & June & 6,269 & 0 \\
\cline { 2 - 4 } & July & 7,850 & 0 \\
\cline { 2 - 4 } & August & 7,342 & 0 \\
\cline { 2 - 4 } & September & 4,205 & 0 \\
\cline { 2 - 4 } & October & 2,819 & 0 \\
\cline { 2 - 4 } & November & 1,892 & 36.27 \\
\cline { 2 - 4 } & December & 3,425 & 65.99 \\
\hline Total & - & $\mathbf{4 7 , 8 6 8}$ & $\mathbf{3 0 3}$ \\
\hline
\end{tabular}

\subsubsection{Simulation with all BEMS controls and Improved Building Envelope}

Once the simulation is performed for the Base Case, the user needs to click the "Clear" button to clear the worksheet for the Base Case. All the worksheets from the simulation for the Base Case are deleted except for the "Summary_Energy_1" worksheet. The data in the "Summary_Energy_1" worksheet is shown in Table 5.5.

Further, the user is asked about the BEMS controls in the building where the user enters the number for the "All" option given in the message box. The user does not need to input the number of rooms and type of room in this case. The input values for the number and type of rooms are saved from the first simulation and used for the second simulation. Then, the user needs to select the level 2 option of building envelope from the drop-down menu in the "Inputs" worksheet for all the rooms. This is considered the TEE case where all the BEMS control are included in the model and improvements in the building envelope.

The simulation process is repeated from "Step 1" to "Step 4," similar to the Base Case. The results obtained from the simulation are shown in Table 5.6 through Table 5.9.

Here, it can be observed that the requirement for outdoor air, total supply air, and return air during unoccupied hours is less than in the Base Case, as shown in Table 5.6. Also, the SAT is less than the Base Case. However, the temperature of return air is less in the TEE 
case because mostly the outdoor air is only circulated through the building to meet the ventilation requirement according to ASHRAE 62.1-2019.

Furthermore, it can be compared from Table 5.7 and Table 5.8 that the total cfm requirement and energy required for heating the space is considerably less for the TEE case than the Base Case. Moreover, energy summary Tables 5.9 show the energy requirement for heating each zone at every 30-minute interval. For example, the total electric energy required from 12:00 AM to 12:30 AM for heating the building was $0.14 \mathrm{kWh}$, and the total needed natural gas was 1,327 Btu for the TEE case. In contrast, for the Base Case, 0.88 $\mathrm{kWh}$ of electrical energy was required and 14,039 Btu of natural gas for the same period. Table 5.10 summarizes the total energy needed for space heating and cooling for all twelve months during the TEE case.

The simulation determined that the total annual electrical energy $(\mathrm{kWh})$ and natural gas (MMBtu) required for the Base Case was 47,868 kWh and $303 \mathrm{MMBtu}$, respectively. While, for the TEE case considering all the BEMS controls and improved building envelope insulation, the total annual electrical energy $(\mathrm{kWh})$ and natural gas (MMBtu) required is $21,034 \mathrm{kWh}$ and $115 \mathrm{MMBtu}$, respectively. The electrical energy consumption was reduced by approximately $56 \%$, and the natural gas consumption was reduced by about $62 \%$. 
Table 5.6: Worksheet of Supply Air Characteristics for the TEE Case

\begin{tabular}{|c|c|c|c|c|c|c|c|c|c|c|c|}
\hline Day & Hour & $\begin{array}{c}\text { Occupancy } \\
\text { Random }\end{array}$ & $\begin{array}{c}\text { Expected } \\
\text { Occupants (\#) }\end{array}$ & $\begin{array}{l}\text { No. of Air Changes } \\
\text { (per } 30 \text { mins) }\end{array}$ & $\begin{array}{l}\text { Outdoor Air } \\
\text { (cfm) }\end{array}$ & $\begin{array}{l}\text { Total Supply Air } \\
\text { (cfm) }\end{array}$ & $\begin{array}{l}\text { Return Air } \\
\text { (cfm) }\end{array}$ & $\begin{array}{c}\text { Season } \\
\text { Random }\end{array}$ & $\begin{array}{c}\text { Supply Air } \\
\text { Temperature (F) }\end{array}$ & \begin{tabular}{|c|} 
Humidity Ratio of \\
Supply Air
\end{tabular} & $\begin{array}{c}\text { Humidity Ratio of } \\
\text { Return Air }\end{array}$ \\
\hline 1 & 12:00 AM & 0.01 & $\overline{0}$ & 0.2 & 940 & 975 & 35 & $\begin{array}{l}0.67 \\
\end{array}$ & 70.5 & 0.0001 & 0.012 \\
\hline 1 & 12:30 AM & 0.56 & 0 & 0.2 & 940 & 975 & 35 & 0.67 & 70.5 & 0.0001 & 0.012 \\
\hline 1 & \begin{tabular}{|l|}
$1: 00 \mathrm{AM}$ \\
\end{tabular} & 0.48 & 0 & 0.2 & 940 & 975 & 35 & 0.67 & 70.5 & 0.0001 & 0.012 \\
\hline 1 & 1:30 AM & 0.43 & 0 & 0.2 & 940 & 975 & 35 & 0.67 & 70.5 & 0.0001 & 0.012 \\
\hline 1 & 2:00 AM & 0.1 & 0 & 0.2 & 940 & 975 & 35 & 0.67 & 70.5 & 0.0001 & 0.012 \\
\hline 1 & $2: 30 \mathrm{AM}$ & 0.42 & 0 & 0.2 & 940 & 975 & 35 & 0.67 & 70.5 & 0.0001 & 0.012 \\
\hline 1 & 3:00 AM & 0.69 & 0 & 0.2 & 940 & 975 & 35 & 0.67 & 70.5 & 0.0001 & 0.012 \\
\hline 1 & 3:30 AM & 0.67 & 0 & 0.2 & 940 & 975 & 35 & 0.67 & 70.5 & 0.0001 & 0.012 \\
\hline 1 & \begin{tabular}{|l|}
$4: 00 \mathrm{AM}$ \\
\end{tabular} & 0.05 & 0 & 0.2 & 940 & 975 & 35 & 0.67 & 70.5 & 0.0001 & 0.012 \\
\hline 1 & 4:30 AM & 0.87 & 0 & 0.2 & 940 & 975 & 35 & 0.67 & 70.5 & 0.0001 & 0.012 \\
\hline 1 & \begin{tabular}{|l|}
$5: 00 ~ A M$ \\
\end{tabular} & 0.73 & 0 & 0.2 & 940 & 975 & 35 & 0.67 & 70.5 & 0.0001 & 0.012 \\
\hline 1 & 5:30 AM & 0.55 & 0 & 0.2 & 940 & 975 & 35 & 0.67 & 70.5 & 0.0001 & 0.012 \\
\hline 1 & 6:00 AM & 0.58 & 0 & 0.2 & 940 & 975 & 35 & 0.67 & 70.5 & 0.0001 & 0.012 \\
\hline 1 & 6:30 AM & 0.99 & 0 & 0.2 & 940 & 975 & 35 & 0.67 & 70.5 & 0.0001 & 0.012 \\
\hline 1 & 7:00 AM & 0.46 & 0 & 0.2 & 940 & 975 & 35 & 0.67 & 70.5 & 0.0001 & 0.012 \\
\hline 1 & 7:30 AM & 0.37 & 0 & 0.2 & 940 & 975 & 35 & 0.67 & 70.5 & 0.0001 & 0.012 \\
\hline 1 & \begin{tabular}{|l|}
$8: 00 ~ A M$ \\
\end{tabular} & 0.39 & 0 & 0.2 & 940 & 975 & 35 & 0.04 & 70.5 & 0.0001 & 0.012 \\
\hline 1 & \begin{tabular}{|l|}
$8: 30 ~ A M$ \\
\end{tabular} & 0.13 & 30 & 2.5 & 12,187 & 12,187 & 0 & 0.04 & 89.5 & 0.0004 & 0.010 \\
\hline
\end{tabular}

Table 5.7: Worksheet of Mixed Air Characteristics for the TEE Case

\begin{tabular}{|c|c|c|c|c|c|c|c|c|}
\hline Day & Hour & $\begin{array}{c}\text { Total Outside Air } \\
\text { (cfm) }\end{array}$ & $\begin{array}{c}\text { Total Supply Air } \\
\text { (cfm) }\end{array}$ & $\begin{array}{c}\text { Total Return Air } \\
\text { (cfm) }\end{array}$ & $\begin{array}{l}\text { Temperature of } \\
\text { Return Air (F) }\end{array}$ & $\begin{array}{c}\text { Humidity Ratio } \\
\text { of Return Air }\end{array}$ & $\begin{array}{l}\text { Temperature of } \\
\text { Mixed Air (F) }\end{array}$ & $\begin{array}{c}\text { Humidity Ratio } \\
\text { of Mixed Air }\end{array}$ \\
\hline 1 & 12:00 AM & 1,338 & 1,531 & 194 & 60 & 0.0117 & 16.96 & 0.01 \\
\hline 1 & $12: 30 \mathrm{AM}$ & 1,338 & 1,531 & 194 & 60 & 0.0117 & 16.96 & 0.01 \\
\hline 1 & 1:00 AM & 1,338 & 1,531 & 194 & 60 & 0.0117 & 16.96 & 0.01 \\
\hline 1 & $1: 30$ AM & 1,338 & 1,531 & 194 & 60 & 0.0117 & 16.96 & 0.01 \\
\hline 1 & 2:00 AM & 1,338 & 1,531 & 194 & 60 & 0.0117 & 16.96 & 0.01 \\
\hline 1 & $2: 30$ AM & 1,338 & 1,531 & 194 & 60 & 0.0117 & 16.96 & 0.01 \\
\hline 1 & 3:00 AM & 1,338 & 1,531 & 194 & 60 & 0.0117 & 16.96 & 0.01 \\
\hline 1 & 3:30 AM & 1,338 & 1,531 & 194 & 60 & 0.0117 & 16.96 & 0.01 \\
\hline 1 & 4:00 AM & 1,338 & 1,531 & 194 & 60 & 0.0117 & 16.96 & 0.01 \\
\hline 1 & 4:30 AM & 1,338 & 1,531 & 194 & 60 & 0.0117 & 16.96 & 0.01 \\
\hline 1 & 5:00 AM & 1,338 & 1,531 & 194 & 60 & 0.0117 & 16.96 & 0.01 \\
\hline 1 & 5:30 AM & 1,338 & 1,531 & 194 & 60 & 0.0117 & 16.96 & 0.01 \\
\hline 1 & 6:00 AM & 1,608 & 1,801 & 194 & 60 & 0.0117 & 16.02 & 0.01 \\
\hline 1 & 6:30 AM & 1,338 & 1,531 & 194 & 60 & 0.0117 & 16.96 & 0.01 \\
\hline 1 & 7:00 AM & 1,338 & 1,531 & 194 & 60 & 0.0117 & 16.96 & 0.01 \\
\hline 1 & $7: 30$ AM & 1,338 & 1,531 & 194 & 60 & 0.0117 & 16.96 & 0.01 \\
\hline 1 & 8:00 AM & 1,338 & 1,531 & 194 & 71 & 0.0117 & 18.35 & 0.01 \\
\hline
\end{tabular}


Table 5.8: Worksheet of Energy Calculation for the TEE Case

\begin{tabular}{|c|c|c|c|c|c|c|c|c|c|c|c|c|}
\hline \multirow[b]{2}{*}{ Date } & \multirow[b]{2}{*}{ Time } & \multirow[b]{2}{*}{$\begin{array}{c}\text { CFM } \\
\text { Requirement }\end{array}$} & \multirow[b]{2}{*}{$\begin{array}{c}\text { Cooling Month } \\
(\text { Yes = 1, No = 0) }\end{array}$} & \multicolumn{5}{|c|}{ During Summer } & \multicolumn{3}{|c|}{ During Winter } & \multirow[b]{2}{*}{$\begin{array}{c}\text { Seasonal } \\
\text { Factor }\end{array}$} \\
\hline & & & & $\begin{array}{c}\text { (Sensible heat load), } \\
\text { Btu/hr }\end{array}$ & $\begin{array}{c}\text { (Latent heat load), } \\
\text { Btu/hr }\end{array}$ & $\begin{array}{c}\text { (Total heat load), } \\
\text { Btu/hr }\end{array}$ & $\begin{array}{c}\text { Power, } \\
(\mathrm{kW})\end{array}$ & $\begin{array}{c}\begin{array}{c}\text { Energy Usage, } \\
(\mathbf{k W h})\end{array} \\
\end{array}$ & $\begin{array}{c}\text { (Sensible heat load), } \\
\text { Btu/hr }\end{array}$ & $\begin{array}{c}\text { Power, } \\
(\mathrm{kW})\end{array}$ & $\begin{array}{c}\begin{array}{c}\text { Energy Usage, } \\
(\mathbf{k W h})\end{array} \\
\end{array}$ & \\
\hline 1 & 12:00 AM & 68 & 0 & 0 & 0 & 0 & 0 & 0 & 79 & 0.02 & 0.01 & 0.67 \\
\hline 1 & 12:30 AM & 68 & 0 & 0 & 0 & 0 & 0 & 0 & 79 & 0.02 & 0.01 & 0.67 \\
\hline 1 & 1:00 AM & 68 & 0 & 0 & 0 & 0 & 0 & 0 & 79 & 0.02 & 0.01 & 0.67 \\
\hline 1 & 1:30 AM & 68 & 0 & 0 & 0 & 0 & 0 & 0 & 79 & 0.02 & 0.01 & 0.67 \\
\hline 1 & 2:00 AM & 68 & 0 & 0 & 0 & 0 & 0 & 0 & 79 & 0.02 & 0.01 & 0.67 \\
\hline 1 & 2:30 AM & 68 & 0 & 0 & 0 & 0 & 0 & 0 & 79 & 0.02 & 0.01 & 0.67 \\
\hline 1 & 3:00 AM & 68 & 0 & 0 & 0 & 0 & 0 & 0 & 79 & 0.02 & 0.01 & 0.67 \\
\hline 1 & 3:30 AM & 68 & 0 & 0 & 0 & 0 & 0 & 0 & 79 & 0.02 & 0.01 & 0.67 \\
\hline 1 & 4:00 AM & 68 & 0 & 0 & 0 & 0 & 0 & 0 & 79 & 0.02 & 0.01 & 0.67 \\
\hline 1 & 4:30 AM & 68 & 0 & 0 & 0 & 0 & 0 & 0 & 79 & 0.02 & 0.01 & 0.67 \\
\hline 1 & 5:00 AM & 68 & 0 & 0 & 0 & 0 & 0 & 0 & 79 & 0.02 & 0.01 & 0.67 \\
\hline 1 & 5:30 AM & 68 & 0 & 0 & 0 & 0 & 0 & 0 & 79 & 0.02 & 0.01 & 0.67 \\
\hline 1 & 6:00 AM & 68 & 0 & 0 & 0 & 0 & 0 & 0 & 80 & 0.02 & 0.01 & 0.67 \\
\hline 1 & 6:30 AM & 68 & 0 & 0 & 0 & 0 & 0 & 0 & 79 & 0.02 & 0.01 & 0.67 \\
\hline 1 & 7:00 AM & 68 & 0 & 0 & 0 & 0 & 0 & 0 & 79 & 0.02 & 0.01 & 0.67 \\
\hline 1 & 7:30 AM & 68 & 0 & 0 & 0 & 0 & 0 & 0 & 79 & 0.02 & 0.01 & 0.67 \\
\hline 1 & 8:00 AM & 68 & 0 & 0 & 0 & 0 & 0 & 0 & 77 & 0.02 & 0.01 & 0.04 \\
\hline 1 & $8: 30 \mathrm{AM}$ & 68 & 0 & 0 & 0 & 0 & 0 & 0 & 81 & 0.02 & 0.01 & 0.04 \\
\hline 1 & 9:00 AM & 2,272 & 0 & 0 & 0 & 0 & 0 & 0 & 1,360 & 0.42 & 0.21 & 0.04 \\
\hline 1 & 9:30 AM & 2,272 & 0 & 0 & 0 & 0 & 0 & 0 & 983 & 0.3 & 0.15 & 0.04 \\
\hline
\end{tabular}

Table 5.9: Worksheet of Summary of Energy Consumption for the TEE Case

\begin{tabular}{|c|c|c|c|c|c|c|c|c|c|c|c|c|c|c|c|c|c|c|c|c|c|c|c|}
\hline \multirow[b]{3}{*}{ Day } & \multirow[b]{3}{*}{ Hour } & \multicolumn{22}{|c|}{ Energy Consumption } \\
\hline & & \multicolumn{2}{|c|}{ Zone_1 } & \multicolumn{2}{|c|}{ Zone_2 } & \multicolumn{2}{|c|}{ Zone_3 } & \multicolumn{2}{|c|}{ Zone_4 } & \multicolumn{2}{|c|}{ Zone_5 } & \multicolumn{2}{|c|}{ Zone_6 } & \multicolumn{2}{|c|}{ Zone_7 } & \multicolumn{2}{|c|}{ Zone_8 } & \multicolumn{2}{|c|}{ Zone_9 } & \multicolumn{2}{|c|}{ Zone_10 } & \multicolumn{2}{|c|}{ Total } \\
\hline & & $\begin{array}{l}\text { Elec. } \\
\text { Usage } \\
\text { (kWh) }\end{array}$ & $\begin{array}{c}\text { Gas } \\
\text { Usage } \\
\text { (Btu) }\end{array}$ & $\begin{array}{l}\text { Elec. } \\
\text { Usage } \\
\text { (kWh) }\end{array}$ & $\begin{array}{c}\text { Gas } \\
\text { Usage } \\
\text { (Btu) }\end{array}$ & $\begin{array}{c}\text { Elec. } \\
\text { Usage } \\
\text { (kWh) }\end{array}$ & $\begin{array}{c}\text { Gas } \\
\text { Usage } \\
\text { (Btu) }\end{array}$ & $\begin{array}{l}\text { Elec. } \\
\text { Usage } \\
(\mathbf{k W h})\end{array}$ & $\begin{array}{c}\text { Gas } \\
\text { Usage } \\
\text { (Btu) }\end{array}$ & $\begin{array}{l}\text { Elec. } \\
\text { Usage } \\
\text { (kWh) }\end{array}$ & $\begin{array}{c}\text { Gas } \\
\text { Usage } \\
\text { (Btu) }\end{array}$ & $\begin{array}{l}\text { Elec. } \\
\text { Usage } \\
\text { (kWh) }\end{array}$ & $\begin{array}{c}\text { Gas } \\
\text { Usage } \\
\text { (Btu) }\end{array}$ & $\begin{array}{l}\text { Elec. } \\
\text { Usage } \\
\text { (kWh) }\end{array}$ & $\begin{array}{l}\text { Gas } \\
\text { Usage } \\
\text { (Btu) }\end{array}$ & $\begin{array}{l}\text { Elec. } \\
\text { Usage } \\
(\mathbf{k W h})\end{array}$ & $\begin{array}{c}\text { Gas } \\
\text { Usage } \\
\text { (Btu) }\end{array}$ & $\begin{array}{l}\text { Elec. } \\
\text { Usage } \\
(\mathbf{k W h})\end{array}$ & $\begin{array}{c}\text { Gas } \\
\text { Usage } \\
\text { (Btu) }\end{array}$ & $\begin{array}{l}\text { Elec. } \\
\text { Usage } \\
\text { (kWh) }\end{array}$ & $\begin{array}{c}\text { Gas } \\
\text { Usage } \\
\text { (Btu) }\end{array}$ & $\begin{array}{l}\text { Elec. } \\
\text { Usage } \\
\text { (kWh) }\end{array}$ & $\begin{array}{c}\text { Gas } \\
\text { Usage } \\
\text { (Btu) }\end{array}$ \\
\hline 1 & 12:00 AM & 0 & 1,327 & 0.01 & 0 & 0.02 & 0 & 0.01 & 0 & 0.05 & 0 & 0 & 0 & 0 & 0 & 0.01 & 0 & 0.01 & 0 & 0.03 & 0 & 0.14 & 1,327 \\
\hline 1 & $12: 30 \mathrm{AM}$ & 0 & 1,327 & 0.01 & 0 & 0.02 & 0 & 0.01 & 0 & 0.05 & 0 & 0 & 0 & 0 & 0 & 0.01 & 0 & 0.01 & 0 & 0.03 & 0 & 0.14 & 1,327 \\
\hline 1 & 1:00 AM & 0 & 1,327 & 0.01 & 0 & 0.02 & 0 & 0.01 & 0 & 0.05 & 0 & 0 & 0 & 0 & 0 & 0.01 & 0 & 0.01 & 0 & 0.03 & 0 & 0.14 & 1,327 \\
\hline 1 & 1:30 AM & 0 & 1,327 & 0.01 & 0 & 0.02 & 0 & 0.01 & 0 & 0.05 & 0 & 0 & 0 & 0 & 0 & 0.01 & 0 & 0.01 & 0 & 0.03 & 0 & 0.14 & 1,327 \\
\hline 1 & 2:00 AM & 0 & 1,327 & 0.01 & 0 & 0.02 & 0 & 0.01 & 0 & 0.05 & 0 & 0 & 0 & 0 & 0 & 0.01 & 0 & 0.01 & 0 & 0.03 & 0 & 0.14 & 1,327 \\
\hline 1 & 2:30 AM & 0 & 1,327 & 0.01 & 0 & 0.02 & 0 & 0.01 & 0 & 0.05 & 0 & 0 & 0 & 0 & 0 & 0.01 & 0 & 0.01 & 0 & 0.03 & 0 & 0.14 & 1,327 \\
\hline 1 & 3:00 AM & 0 & 1,327 & 0.01 & 0 & 0.02 & 0 & 0.01 & 0 & 0.05 & 0 & 0 & 0 & 0 & 0 & 0.01 & 0 & 0.01 & 0 & 0.03 & 0 & 0.14 & 1,327 \\
\hline 1 & 3:30 AM & 0 & 1,327 & 0.01 & 0 & 0.02 & 0 & 0.01 & 0 & 0.05 & 0 & 0 & 0 & 0 & 0 & 0.01 & 0 & 0.01 & 0 & 0.03 & 0 & 0.14 & 1,327 \\
\hline 1 & 4:00 AM & 0 & 1,327 & 0.01 & 0 & 0.02 & 0 & 0.01 & 0 & 0.05 & 0 & 0 & 0 & 0 & 0 & 0.01 & 0 & 0.01 & 0 & 0.03 & 0 & 0.14 & 1,327 \\
\hline 1 & 4:30 AM & 0 & 1,327 & 0.01 & 0 & 0.02 & 0 & 0.01 & 0 & 0.05 & 0 & 0 & 0 & 0 & 0 & 0.01 & 0 & 0.01 & 0 & 0.03 & 0 & 0.14 & 1,327 \\
\hline 1 & 5:00 AM & 0 & 1,327 & 0.01 & 0 & 0.02 & 0 & 0.01 & 0 & 0.05 & 0 & 0 & 0 & 0 & 0 & 0.01 & 0 & 0.01 & 0 & 0.03 & 0 & 0.14 & 1,327 \\
\hline 1 & 5:30 AM & 0 & 1,327 & 0.01 & 0 & 0.02 & 0 & 0.01 & 0 & 0.05 & 0 & 0 & 0 & 0 & 0 & 0.01 & 0 & 0.01 & 0 & 0.03 & 0 & 0.14 & 1,327 \\
\hline 1 & 6:00 AM & 0 & 1,349 & 0.01 & 0 & 0.02 & 0 & 0.01 & 0 & 0.05 & 0 & 0 & 0 & 0 & 0 & 0.07 & 0 & 0.01 & 0 & 0.04 & 0 & 0.21 & 1,349 \\
\hline 1 & 6:30 AM & 0 & 1,327 & 0.01 & 0 & 0.02 & 0 & 0.01 & 0 & 0.05 & 0 & 0 & 0 & 0 & 0 & 0.01 & 0 & 0.01 & 0 & 0.03 & 0 & 0.14 & 1,327 \\
\hline
\end{tabular}


Table 5.10: Monthly energy consumption for TEE case

\begin{tabular}{|c|c|c|c|}
\hline Year & Month & $\begin{array}{c}\text { Energy Usage, } \\
\text { (kWh) }\end{array}$ & $\begin{array}{c}\text { Natural Gas Usage, } \\
\text { (MMBtu) }\end{array}$ \\
\hline \multirow{4}{*}{} & January & 1,410 & 23.88 \\
\cline { 2 - 4 } & February & 1,297 & 21 \\
\cline { 2 - 4 } & March & 1,063 & 17.19 \\
\cline { 2 - 4 } & April & 968 & 14.89 \\
\cline { 2 - 4 } & May & 1,546 & 0 \\
\cline { 2 - 4 } & June & 2,345 & 0 \\
\cline { 2 - 4 } & July & 3,562 & 0 \\
\cline { 2 - 4 } & August & 2,982 & 0 \\
\cline { 2 - 4 } & September & 1,853 & 0 \\
\cline { 2 - 4 } & October & 1,515 & 0 \\
\cline { 2 - 4 } & November & 964 & 15.65 \\
\cline { 2 - 4 } & December & 1,529 & 21.97 \\
\hline Total & - & $\mathbf{2 1 , 0 3 4}$ & $\mathbf{1 1 5}$ \\
\hline
\end{tabular}

\subsection{Effectiveness of energy management system of the community center}

After the second simulation, i.e., the TEE case is complete, the user needs to click the "Step 5 " button. By clicking this button, the model asks the user to input the average cost of electricity $(\$ / \mathrm{kWh})$ and natural gas $(\$ / M M B t u)$, as shown in Figure 5.7. Further, the model compares the twelve-month energy consumption data from the Base Case and the TEE case and provides the value for effectiveness of BEMS on a continuous scale of 1 to 5 .

Table 5.11 compares the difference in energy consumption for electricity $(\mathrm{kWh})$ and natural gas (MMBtu) monthly. Further, the effectiveness of BEMS is also determined every month.
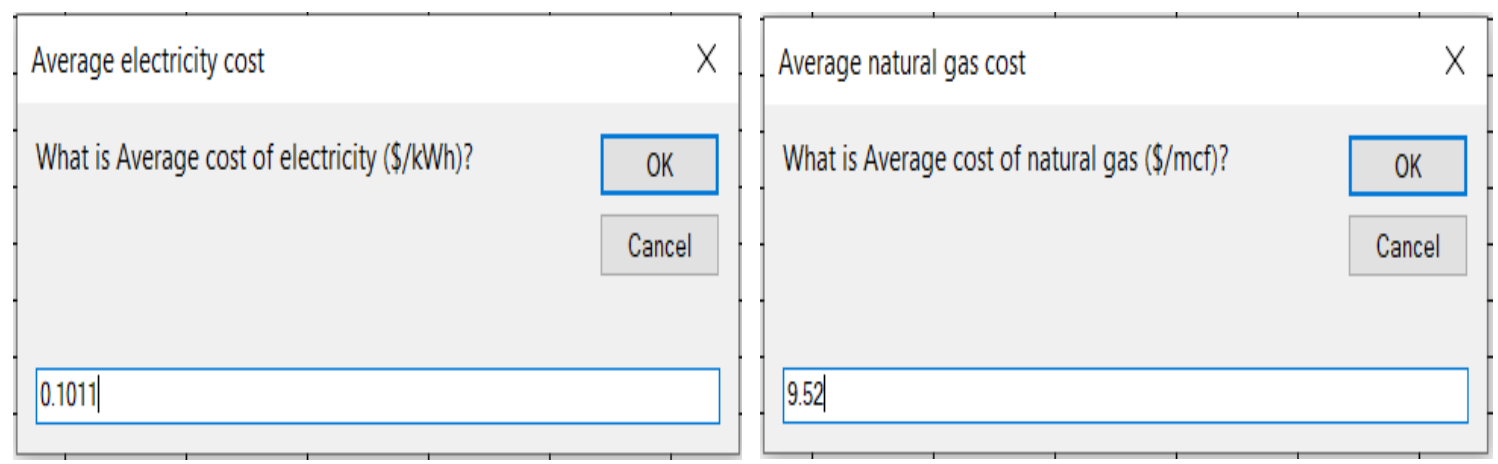

Figure 5.7: Input Boxes for the user to provide the average cost of energy 
Table 5.11: Comparison of energy consumption between Base Case and TEE case

\begin{tabular}{|c|c|c|c|c|c|c|c|c|}
\hline \multirow[t]{2}{*}{ Year } & \multirow[t]{2}{*}{ Month } & \multicolumn{2}{|c|}{$\begin{array}{c}\text { Energy Usage, } \\
\text { (kWh) }\end{array}$} & \multicolumn{2}{|c|}{$\begin{array}{c}\text { Natural Gas } \\
\text { Usage, } \\
\text { (MMBtu) } \\
\end{array}$} & \multicolumn{2}{|c|}{$\begin{array}{c}\text { Percentage } \\
\text { Reduction from } \\
\text { Base Case }\end{array}$} & \multirow{2}{*}{$\begin{array}{l}\text { Effectiveness } \\
\text { of BEMS } \\
(1-5)\end{array}$} \\
\hline & & $\begin{array}{l}\text { Base } \\
\text { Case }\end{array}$ & $\begin{array}{l}\text { TEE } \\
\text { Case }\end{array}$ & $\begin{array}{l}\text { Base } \\
\text { Case }\end{array}$ & $\begin{array}{l}\text { TEE } \\
\text { Case }\end{array}$ & kWh & MMBtu & \\
\hline \multirow{12}{*}{ สิิ } & January & 3,360 & 1,410 & 64.71 & 23.88 & $58 \%$ & $63 \%$ & 2.55 \\
\hline & February & 3,028 & 1,297 & 58.32 & 21 & $57 \%$ & $64 \%$ & 2.54 \\
\hline & March & 2,254 & 1,063 & 43.29 & 17.19 & $53 \%$ & $60 \%$ & 2.7 \\
\hline & April & 1,865 & 968 & 33.93 & 14.89 & $48 \%$ & $56 \%$ & 2.88 \\
\hline & May & 3,559 & 1,546 & 0 & 0 & $57 \%$ & $0 \%$ & 2.74 \\
\hline & June & 6,269 & 2,345 & 0 & 0 & $63 \%$ & $0 \%$ & 2.5 \\
\hline & July & 7,850 & 3,562 & 0 & 0 & $55 \%$ & $0 \%$ & 2.82 \\
\hline & August & 7,342 & 2,982 & 0 & 0 & $59 \%$ & $0 \%$ & 2.63 \\
\hline & September & 4,205 & 1,853 & 0 & 0 & $56 \%$ & $0 \%$ & 2.77 \\
\hline & October & 2,819 & 1,515 & 0 & 0 & $46 \%$ & $0 \%$ & 3.15 \\
\hline & November & 1,892 & 964 & 36.27 & 15.65 & $49 \%$ & $57 \%$ & 2.84 \\
\hline & December & 3,425 & 1,529 & 65.99 & 21.97 & $55 \%$ & $67 \%$ & 2.5 \\
\hline Total & - & 47,868 & 21,034 & 303 & 115 & $56 \%$ & $62 \%$ & 2.67 \\
\hline
\end{tabular}

Table 5.12: Summary of reduction of $\mathrm{CO}_{2}$ emission for TEE Case

\begin{tabular}{|c|c|c|c|c|}
\hline & \multicolumn{2}{|c|}{ Site energy } & \multicolumn{2}{c|}{ Source energy } \\
\hline Energy source & $\begin{array}{c}\text { Electricity } \\
\text { (kWh/yr) }\end{array}$ & $\begin{array}{c}\text { Natural gas } \\
\text { (MMBtu/yr) }\end{array}$ & $\begin{array}{c}\text { Electricity } \\
(\mathbf{k W h} / \mathbf{y r})\end{array}$ & $\begin{array}{c}\text { Natural gas } \\
(\mathbf{M M B t u} / \mathbf{y r})\end{array}$ \\
\hline Base Case energy usage & 47,868 & 303 & 134,030 & 318 \\
\hline TEE Case energy usage & 21,034 & 115 & 58,895 & 121 \\
\hline Annual energy savings & 26,834 & 188 & 75,135 & 197 \\
\hline $\begin{array}{c}\mathbf{C O}_{2} \text { emission saved based } \\
\text { on energy source (lbs/yr) }\end{array}$ & 58,766 & 21,244 & 164,546 & 22,306 \\
\hline $\begin{array}{c}\text { Total CO } \mathbf{C}_{\mathbf{2}} \text { emission saved } \\
\text { (lbs/yr) }\end{array}$ & \multicolumn{2}{|c|}{80,010} & \multicolumn{2}{c|}{186,852} \\
\hline
\end{tabular}

Table 5.12 shows the summary of the reduction of $\mathrm{CO}_{2}$ emission for the TEE Case. By upgrading the building to TEE Case from Base Case, the reduction of $\mathrm{CO}_{2}$ for site energy is $80,010 \mathrm{lbs} / \mathrm{yr}$, and for source, energy is $186,852 \mathrm{lbs} / \mathrm{yr}$. 


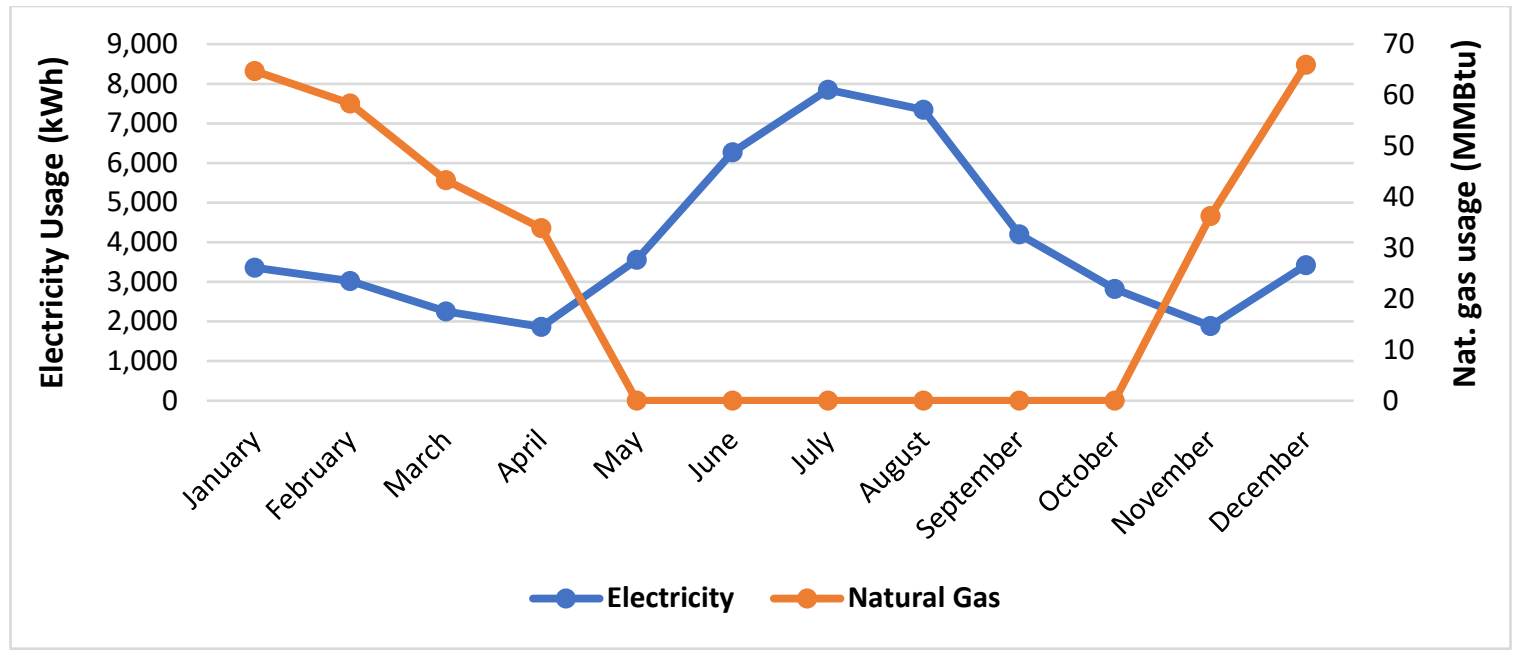

Figure 5.8: Energy consumption pattern for the Base Case

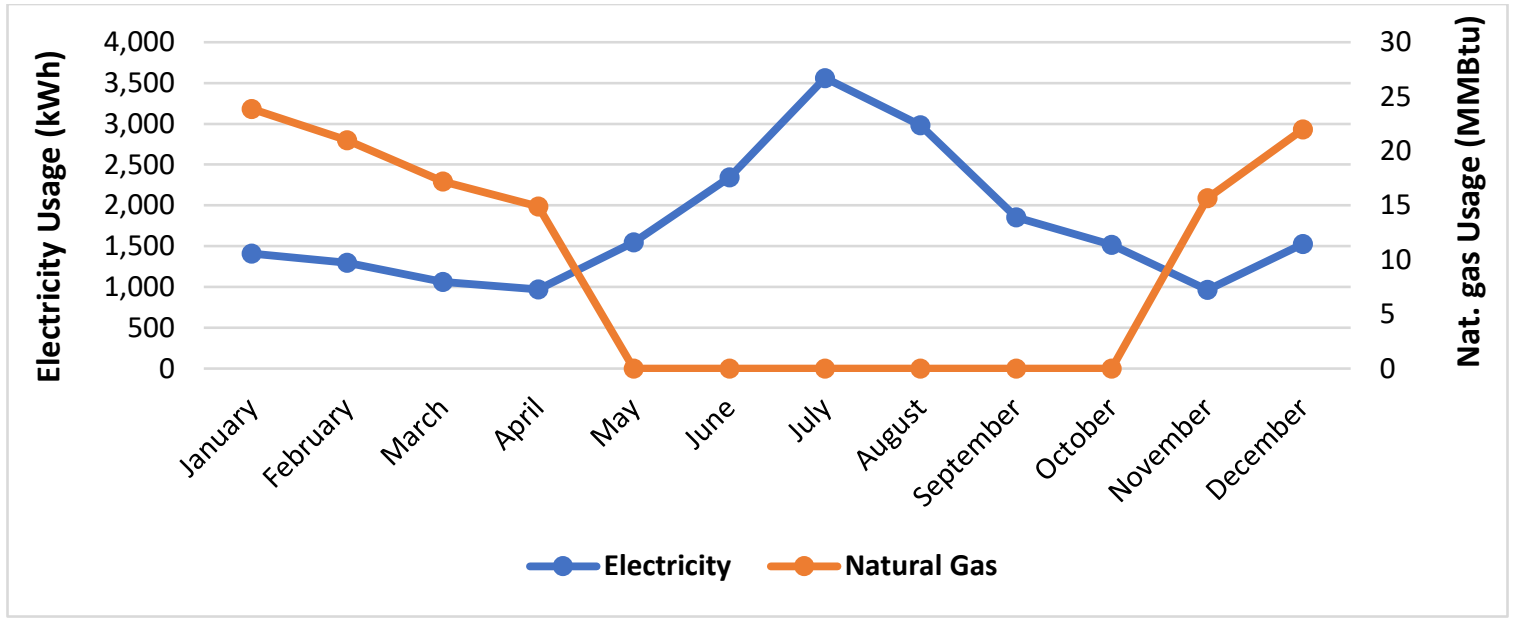

Figure 5.9: Energy consumption pattern for TEE Case

Figure 5.8 and Figure 5.9 show that the highest electricity demand for space cooling during July has reduced from $7,850 \mathrm{kWh}$ to $3,562 \mathrm{kWh}$. This reduces the energy cost of the building and reduces the overall demand cost for electricity. Further, the highest demand for natural gas during December of $66 \mathrm{MMBtu}$ declined to 23.88 MMBtu in January in the TEE case. Hence, by adding the BEMS controls, the overall need for space cooling and heating can be reduced. This reduces the cost associated with energy consumption and opens areas for downsizing the HVAC components while upgrading the system. Downsizing the HVAC equipment can further help to minimize the excess waste of energy. The following Figure 5.10. and Figure 5.11, shown below, compares the electric energy consumption and natural gas consumption for the Base Case and TEE case. 


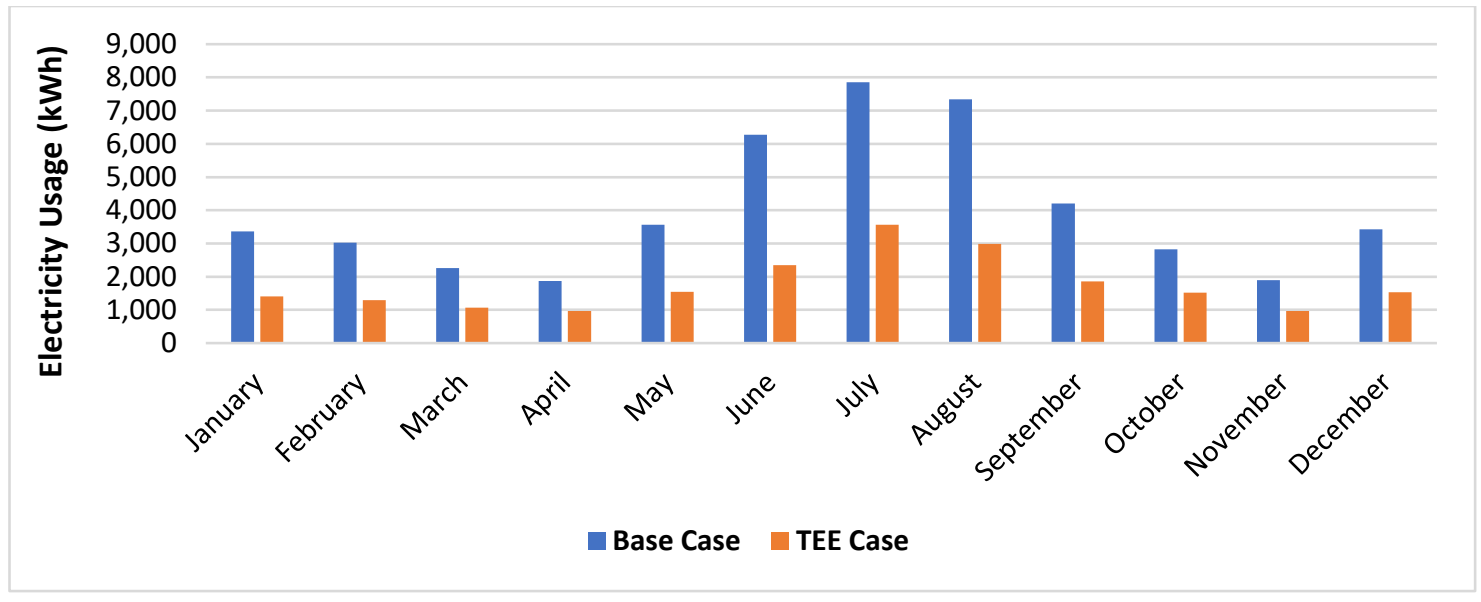

Figure 5.10: Comparison of electrical energy consumption between Base Case and TEE Case

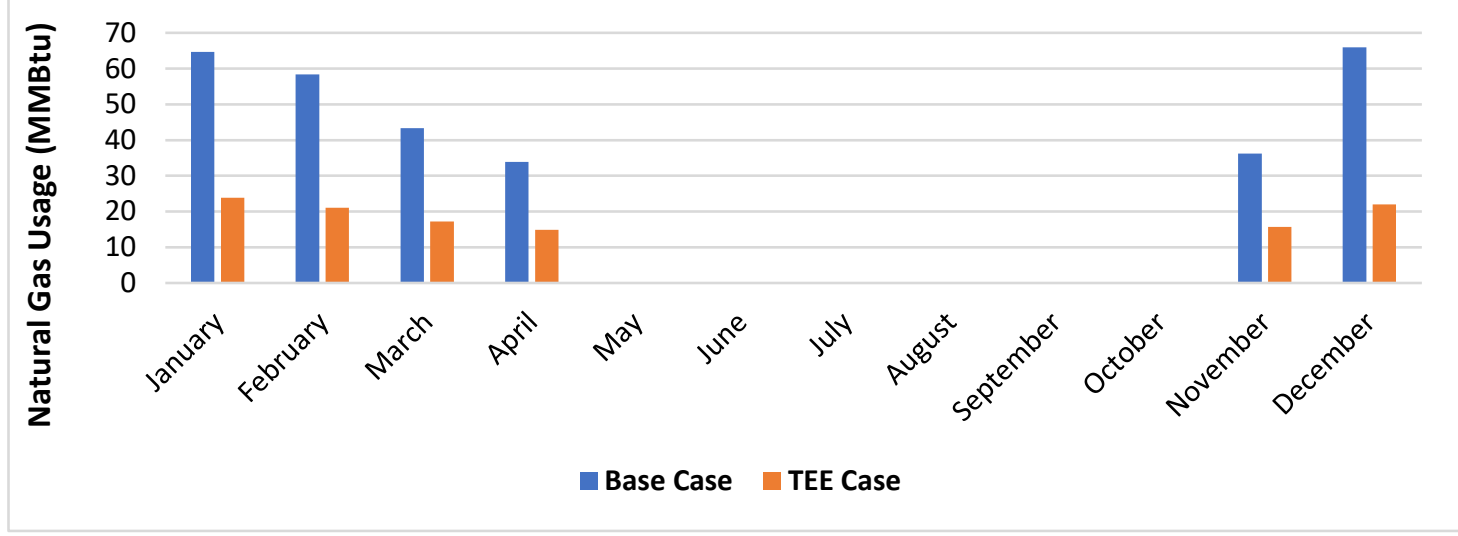

Figure 5.11: Comparison of natural gas consumption between Base Case and TEE Case

From Figure 5.12, it can be seen that the efficacy of BEMS ranges from 2.5 to 3.15. The overall usefulness of BEMS is determined to be 2.67, as shown in Table 5.11. According to the rating chart, as shown in Table 3.10, the effectiveness of BEMS is considered "Not Good'. 


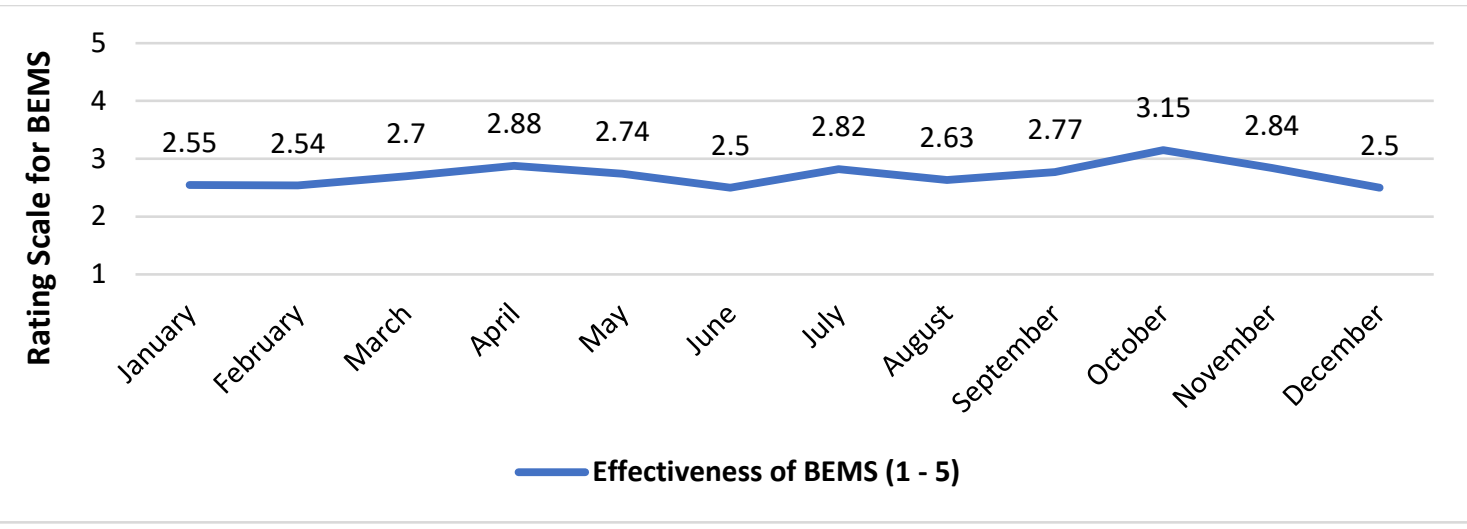

Figure 5.12: Effectiveness of BEMS for Base Case

\subsection{Verification of the Simulation Tool}

The performance of the simulation tool is verified using different approaches in this section, such as Utility Bill analysis, Degree day method calculation, and eQuest modeling and simulation of the building. These methods are further discussed below:

\subsubsection{Utility Bill Analysis}

The total energy consumption of the community center from the utility bill is shown in Table 5.13. The total electrical energy consumption is $90,474 \mathrm{kWh}$, and natural gas consumption is $404 \mathrm{MMBtu}$. The primary electrical energy-consuming equipment is the HVAC system and lighting, whereas the significant natural gas-consuming equipment is natural gas heaters and domestic water heater systems.

Table 5.13: Monthly energy consumption from utility bill

\begin{tabular}{|c|c|c|c|}
\hline Year & Month & $\begin{array}{c}\text { Energy Usage, } \\
(\mathbf{k W h})\end{array}$ & $\begin{array}{c}\text { Natural Gas Usage, } \\
\text { (MMBtu) }\end{array}$ \\
\hline \multirow{4}{*}{} & January & 5,882 & 66 \\
\cline { 2 - 4 } & February & 6,070 & 72 \\
\cline { 2 - 4 } & March & 4,753 & 63 \\
\cline { 2 - 4 } & April & 3,551 & 46 \\
\cline { 2 - 4 } & May & 5,072 & 31 \\
\cline { 2 - 4 } & June & 9,875 & 6 \\
\cline { 2 - 4 } & July & 11,751 & 6 \\
\cline { 2 - 4 } & August & 10,600 & 0 \\
\cline { 2 - 4 } & September & 11,760 & 27 \\
\cline { 2 - 4 } & October & 5,080 & 12 \\
\cline { 2 - 4 } & November & 5,400 & 35 \\
\cline { 2 - 4 } & December & 10,680 & 40 \\
\hline Total & - & $\mathbf{9 0 , 4 7 4}$ & $\mathbf{4 0 4}$ \\
\hline
\end{tabular}


An eQuest model for the building is developed that is shown later in section 5.4.3. An estimate of electrical energy consumption for different auxiliary units for a typical community center was obtained from the eQuest model. Further, the domestic water heater capacity of $0.035 \mathrm{MMBtu} / \mathrm{hr}$ was input to the model to estimate annual natural gas consumption by the hot water heating system for a typical community center building. The total electrical energy except for space heating and cooling and the natural gas consumption for the domestic hot water heating system obtained from the eQuest model is shown in Table 5.14.

Table 5.14: Estimate of energy consumption by auxiliary units of the building

\begin{tabular}{|c|c|c|c|}
\hline Year & Month & $\begin{array}{c}\text { Energy Usage, } \\
(\mathbf{k W h})\end{array}$ & $\begin{array}{c}\text { Natural Gas Usage, } \\
\text { (MMBtu) }\end{array}$ \\
\hline \multirow{12}{*}{ ণి } & January & 3,550 & 9.18 \\
\hline & February & 3,190 & 8.57 \\
\hline & March & 3,480 & 9.45 \\
\hline & April & 3,470 & 9.59 \\
\hline & May & 3,200 & 8.66 \\
\hline & June & 3,190 & 8.02 \\
\hline & July & 3,330 & 7.86 \\
\hline & August & 3,190 & 7.24 \\
\hline & September & 3,210 & 7.2 \\
\hline & October & 3,500 & 7.82 \\
\hline & November & 3,020 & 7.05 \\
\hline & December & 3,700 & 8.98 \\
\hline Total & - & 40,030 & 99.62 \\
\hline
\end{tabular}

By subtracting the electrical energy consumption and natural gas consumption from the data in Table 5.14, an estimate of electrical and natural gas energy required for space heating and cooling is obtained, as shown in Table 5.15.

The comparison in Table 5.16 shows that the total annual electrical energy consumption is $5 \%$ less, and natural gas consumption is $4 \%$ less in the Base Case than what is obtained from the utility bill analysis, respectively. However, for a month-to-month comparison, the data from two different approaches vary considerably in some of the months. This variation in data may be attributed to the auxiliary unit's difference in energy consumption pattern in the community center building than what is used by the eQuest software. This variation 
can be reduced by further detailed study of auxiliary unit capacity and energy consumption pattern and modeling it in eQuest software more precisely.

Table 5.15: Estimate of energy required for space heating and cooling

\begin{tabular}{|c|c|c|c|}
\hline Year & Month & $\begin{array}{c}\text { Energy Usage, } \\
(\mathbf{k W h})\end{array}$ & $\begin{array}{c}\text { Natural Gas Usage, } \\
(\mathbf{M M B t u})\end{array}$ \\
\hline \multirow{4}{*}{} & January & 2,332 & 56.82 \\
\cline { 2 - 4 } & February & 2,880 & 63.43 \\
\cline { 2 - 4 } & March & 1,273 & 53.55 \\
\cline { 2 - 4 }$\underset{\mathrm{N}}{ }$ & April & 81 & 36.41 \\
\cline { 2 - 4 } & May & 1,872 & 22.34 \\
\cline { 2 - 4 } & June & 6,685 & 0 \\
\cline { 2 - 4 } & July & 8,421 & 0 \\
\cline { 2 - 4 } & August & 7,410 & 0 \\
\cline { 2 - 4 } & September & 8,550 & 19.8 \\
\cline { 2 - 4 } & October & 1,580 & 4.18 \\
\cline { 2 - 4 } & November & 2,380 & 27.95 \\
\cline { 2 - 4 } & December & 6,980 & 31.02 \\
\hline Total & - & $\mathbf{5 0 , 4 4 4}$ & $\mathbf{3 1 6}$ \\
\hline
\end{tabular}

Table 5.16: Comparison of energy consumption between Base Case and Utility case

\begin{tabular}{|c|c|c|c|c|c|c|c|}
\hline \multirow{4}{*}{ Year } & \multirow{2}{*}{ Month } & \multicolumn{2}{|c|}{$\begin{array}{c}\text { Energy Usage, } \\
\text { (kWh) }\end{array}$} & \multicolumn{2}{c|}{$\begin{array}{c}\text { Natural Gas } \\
\text { Usage, } \\
\text { (MMBtu) }\end{array}$} & \multicolumn{2}{c|}{$\begin{array}{c}\text { Percentage } \\
\text { Reduction from } \\
\text { Utility Case }\end{array}$} \\
\cline { 3 - 8 } & & $\begin{array}{c}\text { Base } \\
\text { Case }\end{array}$ & $\begin{array}{c}\text { Utility } \\
\text { Case }\end{array}$ & $\begin{array}{c}\text { Base } \\
\text { Case }\end{array}$ & $\begin{array}{c}\text { Utility } \\
\text { Case }\end{array}$ & kWh & MMBtu \\
\hline \multirow{5}{*}{} & January & 3,360 & 2,332 & 64.71 & 56.82 & $-44 \%$ & $-14 \%$ \\
\cline { 2 - 8 } & February & 3,028 & 2,880 & 58.32 & 63.43 & $-5 \%$ & $8 \%$ \\
\cline { 2 - 8 } & March & 2,254 & 1,273 & 43.29 & 53.55 & $-77 \%$ & $19 \%$ \\
\cline { 2 - 8 } & April & 1,865 & 81 & 33.93 & 36.41 & $-2202 \%$ & $7 \%$ \\
\cline { 2 - 8 } & May & 3,559 & 1,872 & 0 & 22.34 & $-90 \%$ & $100 \%$ \\
\cline { 2 - 8 } & June & 6,269 & 6,685 & 0 & 0 & $6 \%$ & $0 \%$ \\
\cline { 2 - 8 } & July & 7,850 & 8,421 & 0 & 0 & $7 \%$ & $0 \%$ \\
\cline { 2 - 8 } & August & 7,342 & 7,410 & 0 & 0 & $1 \%$ & $0 \%$ \\
\cline { 2 - 8 } & September & 4,205 & 8,550 & 0 & 19.8 & $51 \%$ & $100 \%$ \\
\cline { 2 - 8 } & October & 2,819 & 1,580 & 0 & 4.18 & $-78 \%$ & $100 \%$ \\
\cline { 2 - 8 } & November & 1,892 & 2,380 & 36.27 & 27.95 & $21 \%$ & $-30 \%$ \\
\cline { 2 - 8 } & December & 3,425 & 6,980 & 65.99 & 31.02 & $51 \%$ & $-113 \%$ \\
\hline Total & - & $\mathbf{4 7 , 8 6 8}$ & $\mathbf{5 0 , 4 4 4}$ & $\mathbf{3 0 3}$ & $\mathbf{3 1 6}$ & $\mathbf{5 \%}$ & $\mathbf{4 \%}$ \\
\hline
\end{tabular}

Figure 5.13 and Figure 5.14 show the graphical representation of variation in electrical energy consumption and natural gas consumption between the Base Case and Utility case. 


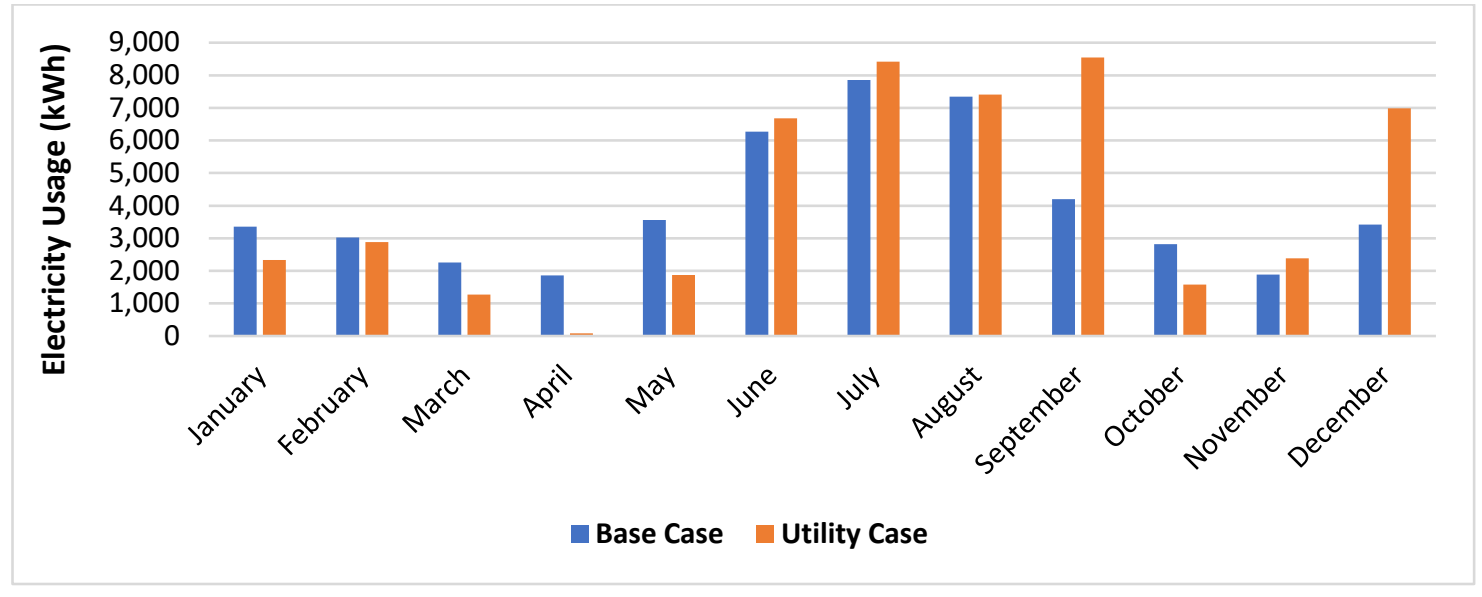

Figure 5.13: Comparison of electrical energy consumption between Base Case and Utility Case

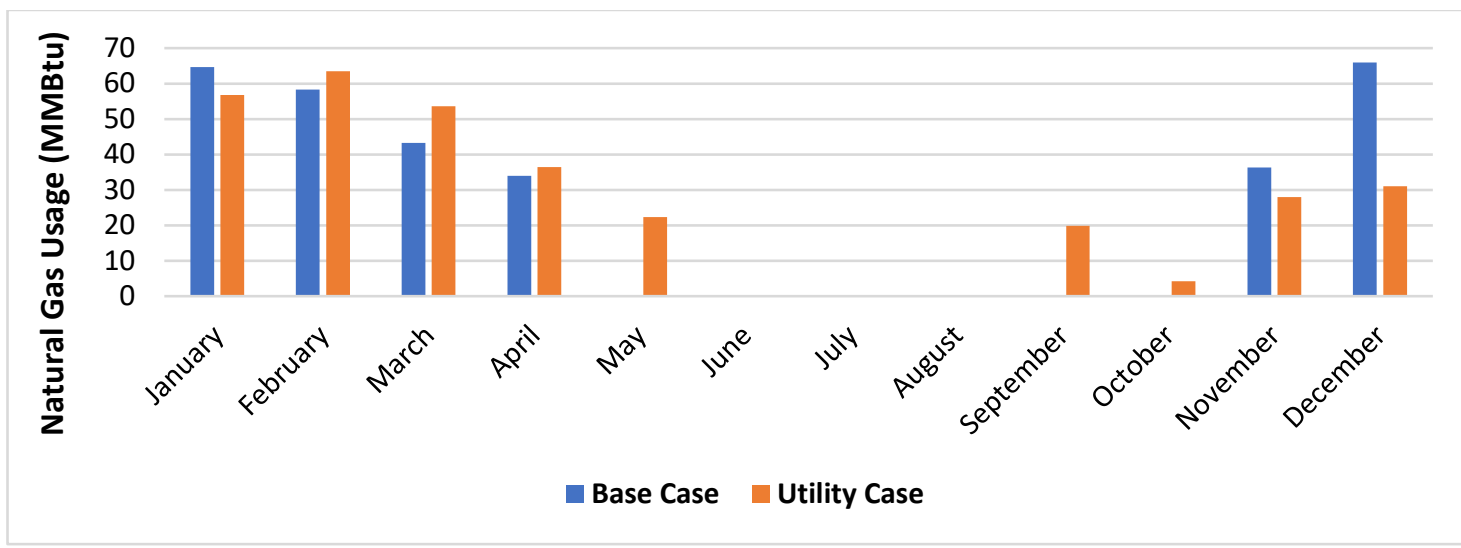

Figure 5.14: Comparison of natural gas consumption between Base Case and Utility Case

\subsubsection{Degree Day Method}

This verification method uses the degree day approach to estimate energy consumption for space cooling and heating the building monthly. Since Huntington city lies in the South Atlantic climatic region, the HDD and CDD data for the same area was used for the calculation. The HDD and CDD data used for the analysis is shown in Table 3.3 in an earlier section. The calculation used for estimation of the energy for space cooling and heating is given below:

\section{During Winter:}


An estimate of natural gas consumption for a month can be calculated by using the equation below:

Energy Input $\quad=($ R x L.F. $x$ HDD x 24) $/(\mathrm{Tr}-\mathrm{To}) \times$ Eff.

Where,

$$
\begin{array}{ll}
\mathrm{R} & =\text { Rated Capacity of Natural Gas heaters, }(0.4 \mathrm{MMBtu} / \mathrm{hr}) \\
\text { L.F. } & =\text { Load Factor, } 40 \% \text { (estimated) } \\
\text { HDD } & =\text { Heating Degree Days, }{ }^{\circ} \mathrm{F} \text { x days } / \text { month } \\
\operatorname{Tr} & =\text { Average Room Temperature, } 75^{\circ} \mathrm{F} \\
\text { To } & \quad=\text { Average Outdoor Temperature, } 34^{\circ} \mathrm{F}[58] \\
\text { Eff. } &
\end{array}
$$

For example, the estimation of natural gas energy used for heating during January month (first entry in Table 5.16) is determined as,

Energy Input $\quad=(0.4 \times 0.4 \times 569 \times 24) /(75-34) \times 0.85$

$$
=62.70 \mathrm{MMBtu} / \text { month }
$$

Similarly, the natural gas consumption for other months, November, December, February, March, and April, is calculated based on the Heating Degree days for each month. The obtained data are shown in Table 5.16.

The electrical energy used for heating is also calculated as:

Energy Input $\quad=($ R x L.F. $x$ HDD x 24) $/(\mathrm{Tr}-\mathrm{To}) \times$ Eff.

Where,

$$
\begin{array}{ll}
\mathrm{R} & =\text { Rated Capacity of electrical heating units, }(20 \mathrm{~kW}) \\
\text { L.F. } & =\text { Load Factor, } 70 \% \text { (estimated) } \\
\mathrm{HDD} & =\text { Heating Degree Days, }{ }^{\circ} \mathrm{F} \text { x days } / \text { month } \\
\mathrm{Tr} & =\text { Average Room Temperature, } 75^{\circ} \mathrm{F} \\
\text { To } & =\text { Average Outdoor Temperature, } 34^{\circ} \mathrm{F}[58]
\end{array}
$$


Eff. = Efficiency of electrical heating system, $98 \%$ (estimated)

For example, the estimation of electrical energy used for heating for January month (first entry in Table 5.16) is determined as,

Energy Input $\quad=(20 \times 0.7 \times 569 \times 24) /(75-34) \times 0.98$

$$
=4,758 \mathrm{kWh} / \text { month }
$$

\section{During Summer:}

The energy consumed for cooling the building spaces during summer is calculated as,

Energy Input $\quad=($ R x L.F. $\times$ CDD $\times 24 \mathrm{hrs} /$ day $) /($ To $-\mathrm{Tr}) \times 3412 \mathrm{Btu} / \mathrm{kWh} \times \mathrm{COP}$

Where,

$\begin{array}{ll}\mathrm{R} & =\text { Rated Capacity of cooling units, }(144,000 \mathrm{Btu} / \mathrm{hr}) \\ \mathrm{CDD} & =\text { Cooling Degree Days, }{ }^{\circ} \mathrm{F} \text { days/ month } \\ \mathrm{Tr} & =\text { Average Room Temperature, } 70^{\circ} \mathrm{F} \\ \mathrm{To} & =\text { Mean Outdoor Temperature, } 81^{\circ} \mathrm{F}[58] \\ \mathrm{COP} & =\text { Coefficient of Performance, } 3.1 \text { estimated }\end{array}$

For example, for the month of May (fifth entry in Table 5.16), the energy required for cooling the building spaces is determined as,

Energy Input $\quad=(144,000 \times 0.7 \times 189 \times 24) /(81-70) \times 3412 \mathrm{Btu} / \mathrm{kWh} \times 3.1$ $=3,930 \mathrm{kWh} / \mathrm{month}$

Hence, the results obtained by calculating the energy required for space heating and cooling using the degree days method are summarized in Table 5.17.

From the comparison as shown in Table 5.18, it is observed that the total annual electrical energy consumption is $12 \%$ less, and natural gas consumption is $23 \%$ more in the Base Case than what is obtained from the DD approach, respectively. However, based on the month-to-month comparison, the data from two different methods vary considerably for some of the months. This variation may be attributed to inaccurate estimation in load factor and efficiencies of the heating and cooling system. This variation can be reduced by accurate measurement of current (amperage) data of the HVAC rooftop units for several months and getting an accurate idea of the load factor of the units during different months 
and climatic changes. Further, the study of heating units can also be done to better estimate load factors under other weather conditions to understand load factors during various months better.

Table 5.17: Energy required for space cooling and heating obtained from DD method

\begin{tabular}{|c|c|c|c|}
\hline Year & Month & $\begin{array}{c}\text { Energy Usage, } \\
\text { (kWh) }\end{array}$ & $\begin{array}{c}\text { Natural Gas Usage, } \\
\text { (MMBtu) }\end{array}$ \\
\hline \multirow{7}{*}{} & January & 4,758 & 62.70 \\
\cline { 2 - 4 } & February & 3,847 & 50.69 \\
\cline { 2 - 4 } & March & 2,693 & 35.48 \\
\cline { 2 - 4 } & April & 1,079 & 14.21 \\
\cline { 2 - 4 } & May & 3,930 & 0 \\
\cline { 2 - 4 } & June & 7,028 & 0 \\
\cline { 2 - 4 } & July & 8,567 & 0 \\
\cline { 2 - 4 } & August & 8,151 & 0 \\
\cline { 2 - 4 } & September & 5,489 & 0 \\
\cline { 2 - 4 } & October & 2,557 & 0 \\
\cline { 2 - 4 } & November & 2,634 & 34.71 \\
\cline { 2 - 4 } & December & 3,721 & 49.03 \\
\hline Total & - & $\mathbf{5 4 , 4 5 4}$ & $\mathbf{2 4 7}$ \\
\hline
\end{tabular}

Table 5.18: Comparison of energy consumption between the Base Case and DD method

\begin{tabular}{|c|c|c|c|c|c|c|c|}
\hline \multirow[t]{2}{*}{ Year } & \multirow[t]{2}{*}{ Month } & \multicolumn{2}{|c|}{$\begin{array}{c}\text { Energy Usage, } \\
\text { (kWh) }\end{array}$} & \multicolumn{2}{|c|}{$\begin{array}{c}\text { Natural Gas } \\
\text { Usage, } \\
\text { (MMBtu) }\end{array}$} & \multicolumn{2}{|c|}{$\begin{array}{c}\text { Percentage } \\
\text { Reduction from } \\
\text { DD method }\end{array}$} \\
\hline & & $\begin{array}{l}\text { Base } \\
\text { Case }\end{array}$ & $\begin{array}{c}\text { DD } \\
\text { method }\end{array}$ & $\begin{array}{l}\text { Base } \\
\text { Case }\end{array}$ & $\begin{array}{c}\text { DD } \\
\text { method }\end{array}$ & kWh & MMBtu \\
\hline \multirow{12}{*}{ ๙ิ઼ิ } & January & 3,360 & 4,758 & 64.71 & 62.70 & $29 \%$ & $-3 \%$ \\
\hline & February & 3,028 & 3,847 & 58.32 & 50.69 & $21 \%$ & $-15 \%$ \\
\hline & March & 2,254 & 2,693 & 43.29 & 35.48 & $16 \%$ & $-22 \%$ \\
\hline & April & 1,865 & 1,079 & 33.93 & 14.21 & $-73 \%$ & $-139 \%$ \\
\hline & May & 3,559 & 3,930 & 0 & 0 & $9 \%$ & $0 \%$ \\
\hline & June & 6,269 & 7,028 & 0 & 0 & $11 \%$ & $0 \%$ \\
\hline & July & 7,850 & 8,567 & 0 & 0 & $8 \%$ & $0 \%$ \\
\hline & August & 7,342 & 8,151 & 0 & 0 & $10 \%$ & $0 \%$ \\
\hline & September & 4,205 & 5,489 & 0 & 0 & $23 \%$ & $0 \%$ \\
\hline & October & 2,819 & 2,557 & 0 & 0 & $-10 \%$ & $0 \%$ \\
\hline & November & 1,892 & 2,634 & 36.27 & 34.71 & $28 \%$ & $-4 \%$ \\
\hline & December & 3,425 & 3,721 & 65.99 & 49.03 & $8 \%$ & $-35 \%$ \\
\hline Total & - & 47,868 & 54,454 & 303 & 247 & $12 \%$ & $-23 \%$ \\
\hline
\end{tabular}


Figure 5.15 and Figure 5.16 show the graphical representation of variation in electrical energy consumption and natural gas consumption between the Base Case and the DD approach.

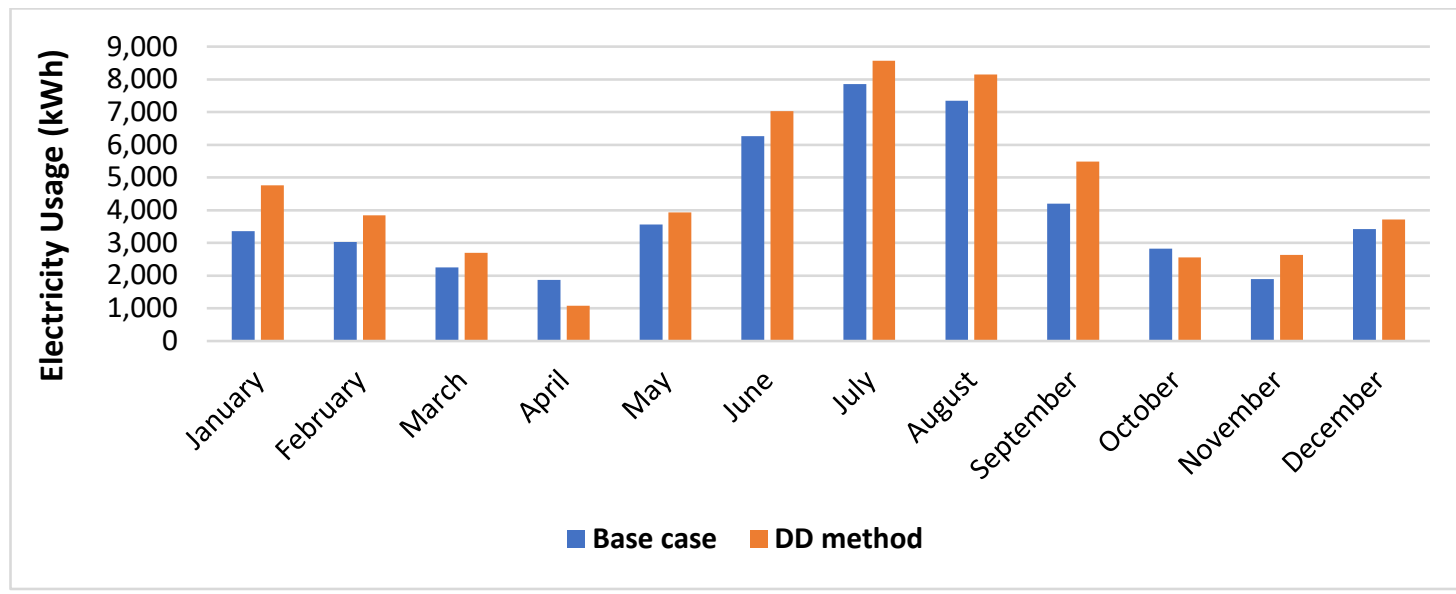

Figure 5.15: Comparison of electrical energy consumption between the Base Case and DD approach

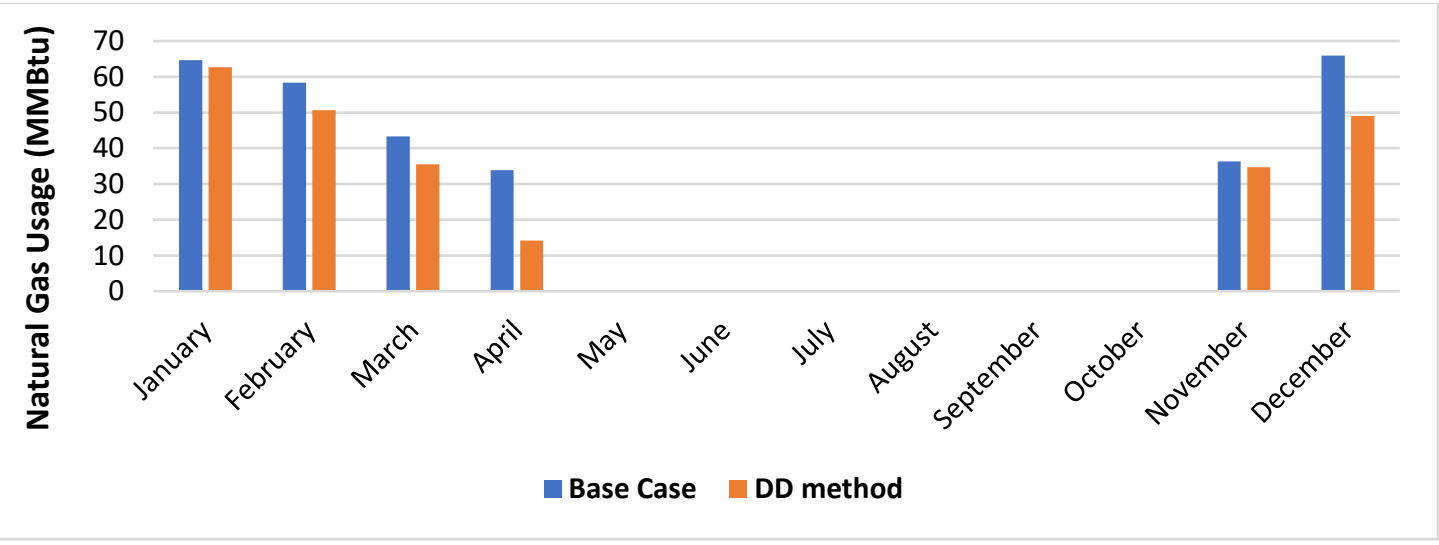

Figure 5.16: Comparison of natural gas consumption between the Base Case and DD approach

\subsection{3 eQuest modeling and simulation of the community center}

This approach uses the DOE's software eQuest for modeling and simulation of the community center. The method used for the modeling and simulation is further described below:

Initially, general information regarding the type of building is input into the model, as shown in Figure 5.17. Additionally, a project navigator screen displays a new building shell, HVAC system, and domestic hot water system, as shown in Figure 5.18. 


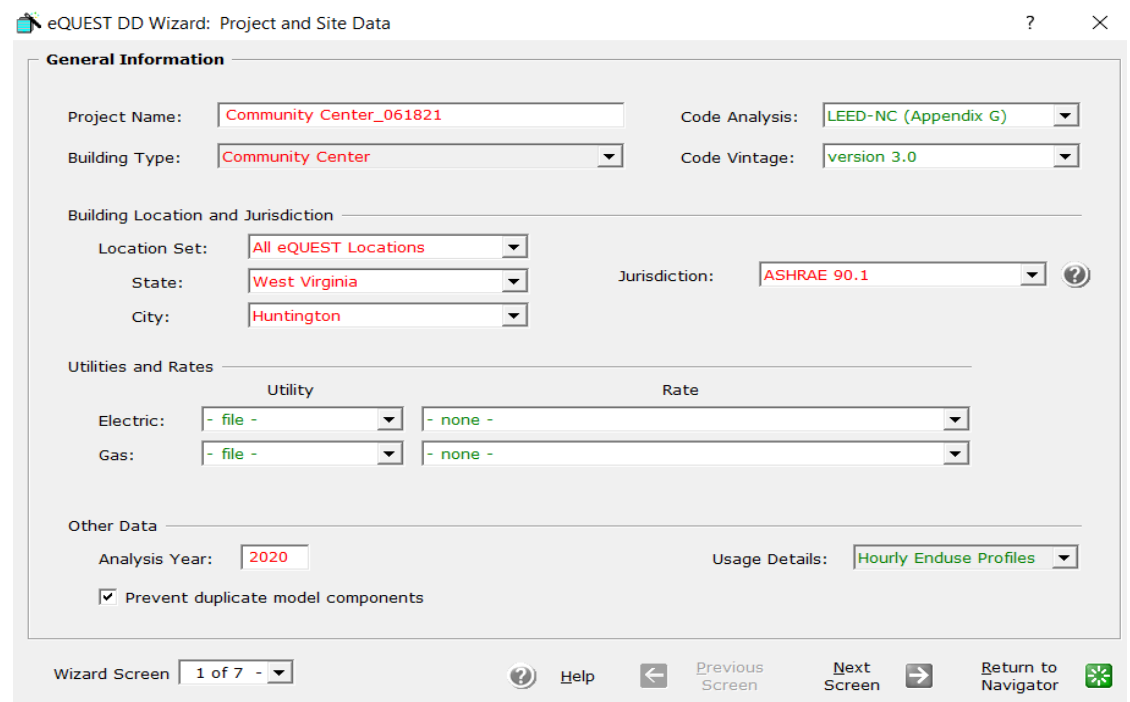

Figure 5.17: Project Site Data

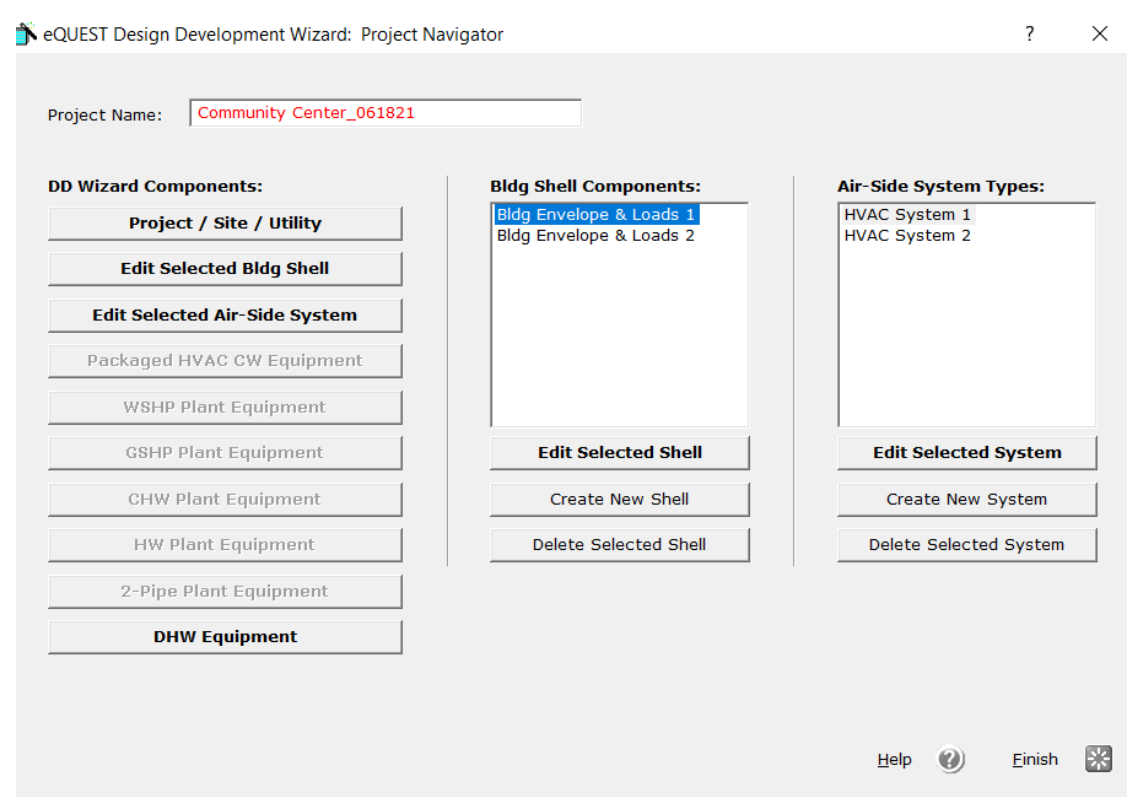

Figure 5.18: Project Navigator

Moreover, the footprint of the building is designed using AutoCAD software and used for generating footprint in eQuest software for office and gymnasium buildings, as shown in Figure 5.19. The building shell components such as insulation details, window, and door types are also selected, as shown in Figure 5.20. 

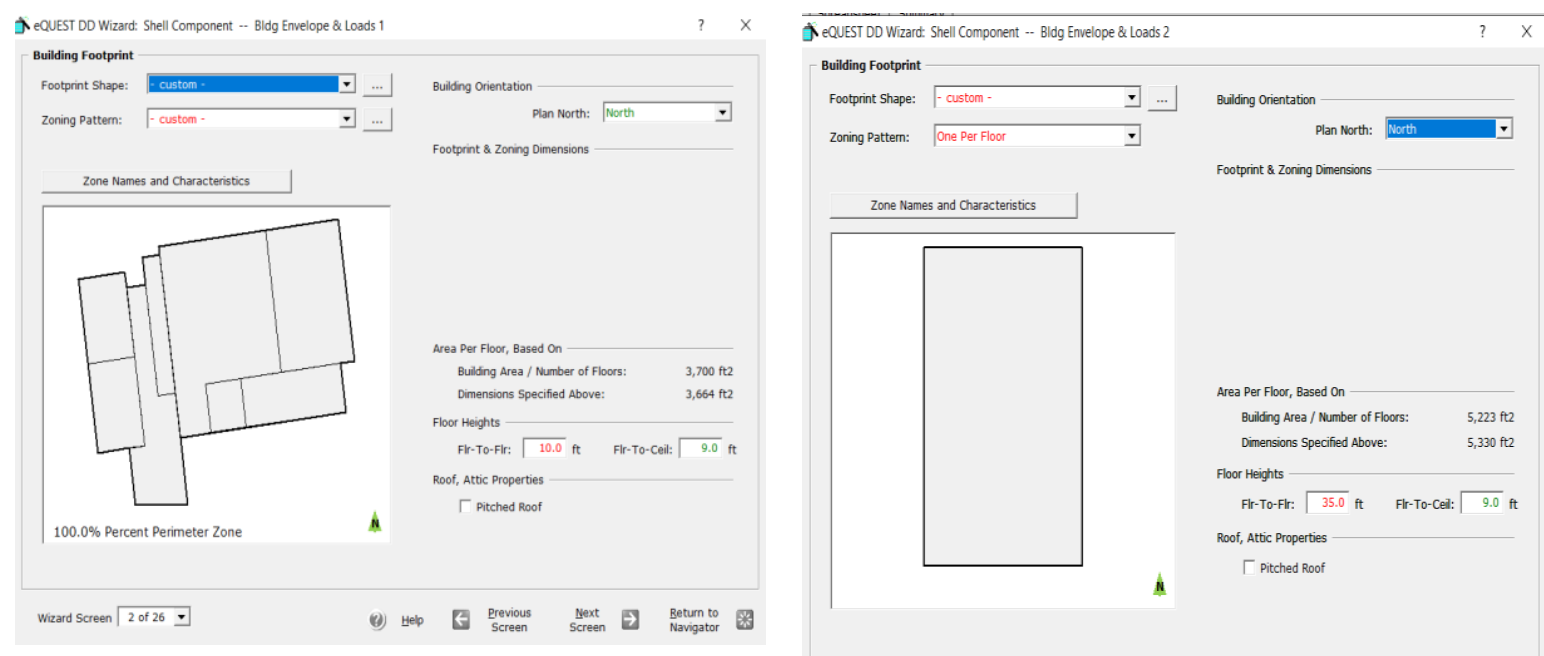

Figure 5.19: Building footprint for an office building (left) and gymnasium (right)
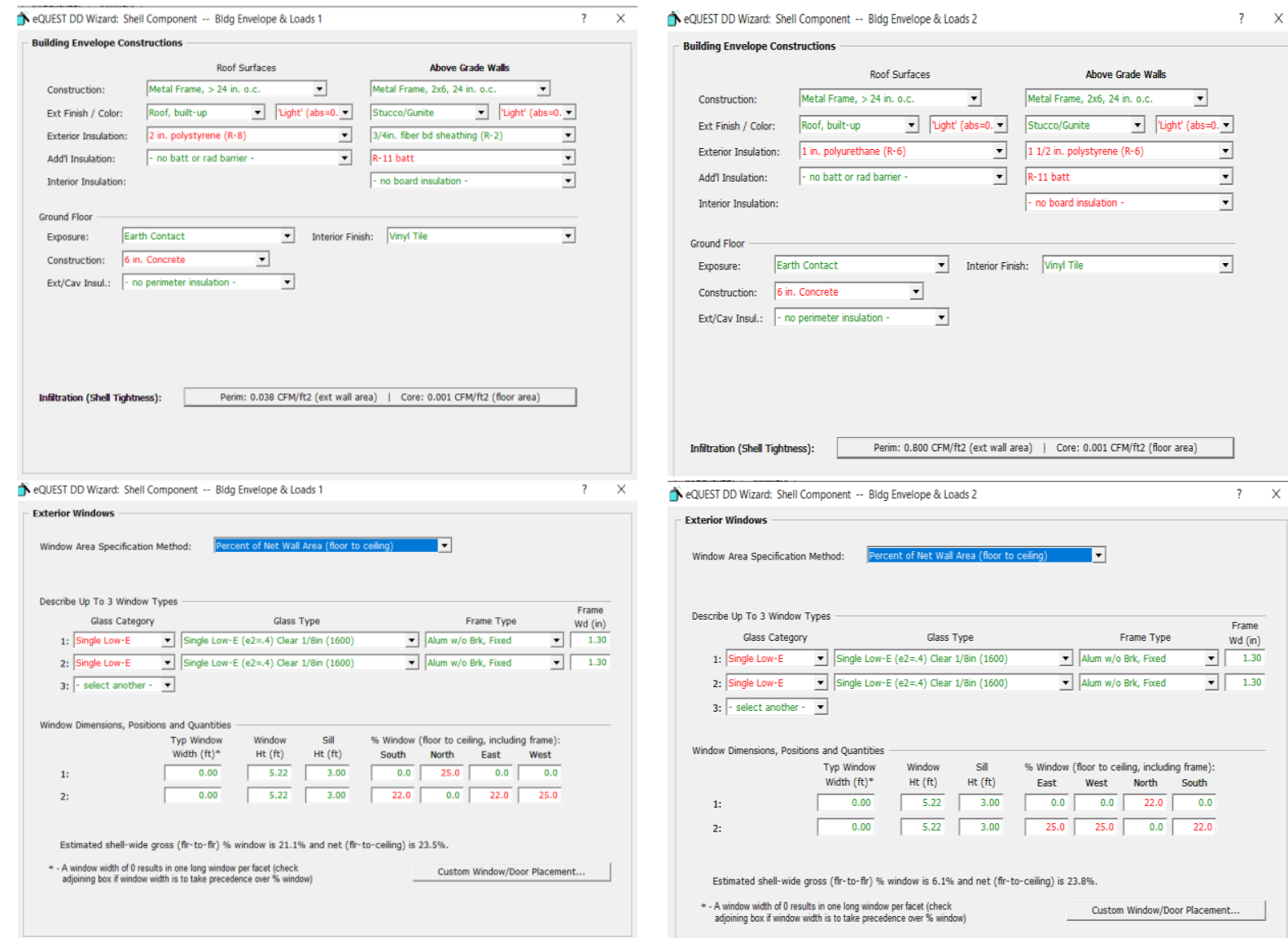

Exterior Windows

Window Area Specification Method: Percent of Net Wall Area (foor to celing) _.

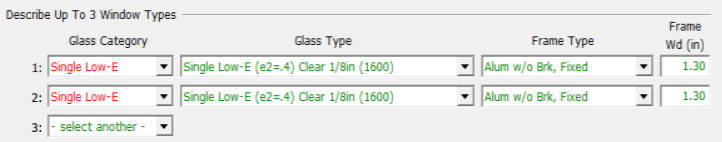

Window Dimensions, Positions and Quantities

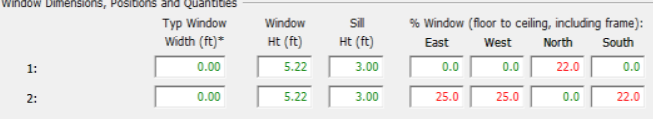

Estimated shell-wide gross (fir-to-fir) \% window is $6.1 \%$ and net (fir-to-ceiling) is $23.8 \%$.

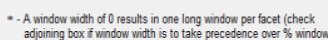

Custam WindowiDoor Placement...

Figure 5.20: Building shell components for an office building (left) and gymnasium (right) 

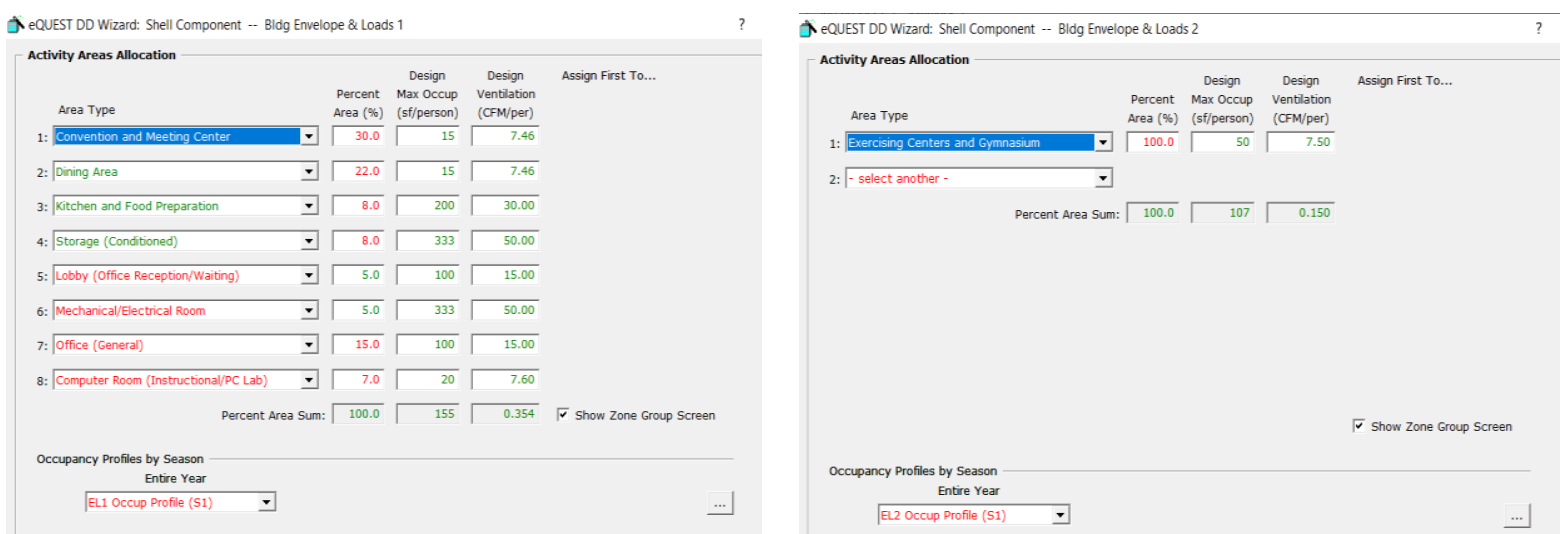

Figure 5.21: Activity area allocation for an office building (left) and gymnasium (right)
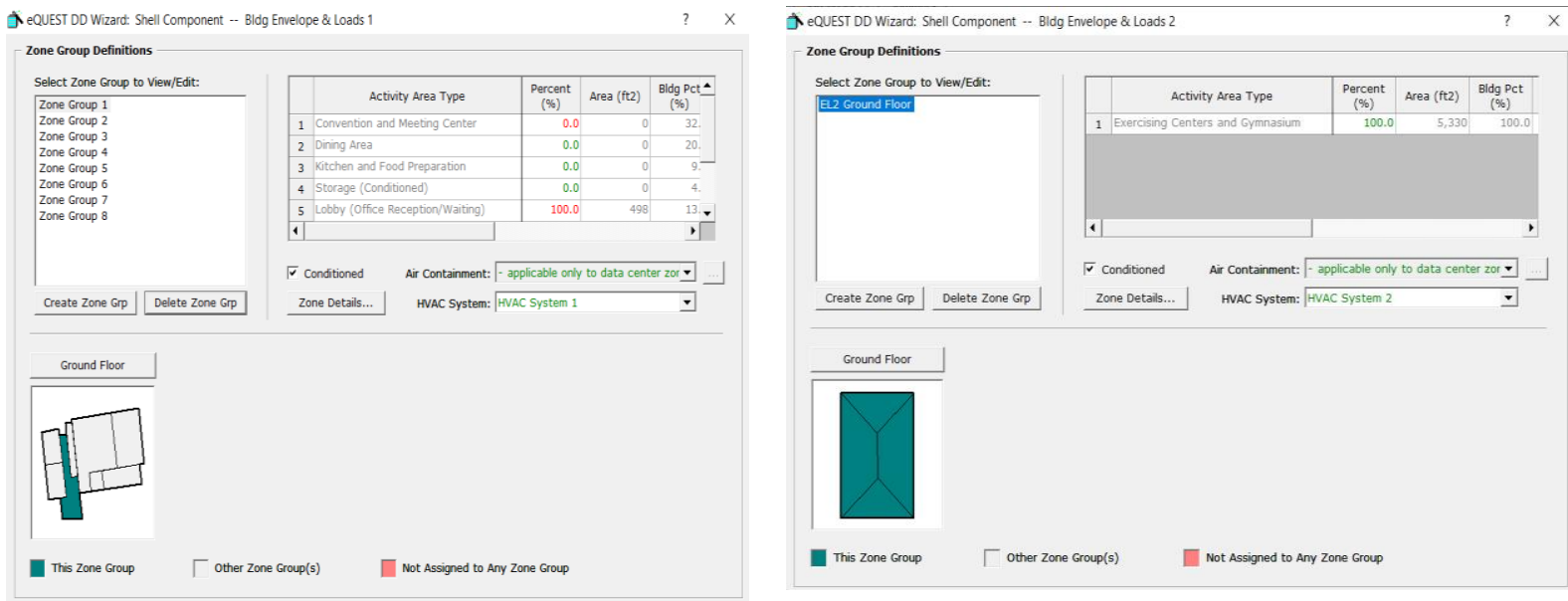

Figure 5.22: Zoning of the office building (left) and gymnasium (right)

The activity area and zoning controls are also assigned to both the buildings, as shown in Figure 5.21 and Figure 5.22, respectively. The HVAC system is selected for both the buildings and cooling and heating specifications according to the data collected during the visit to the community center. Furthermore, the thermostat setback and setpoint temperatures and the design room and SAT are also inputted to the model as shown in Figure 5.23 and Figure 5.24. 

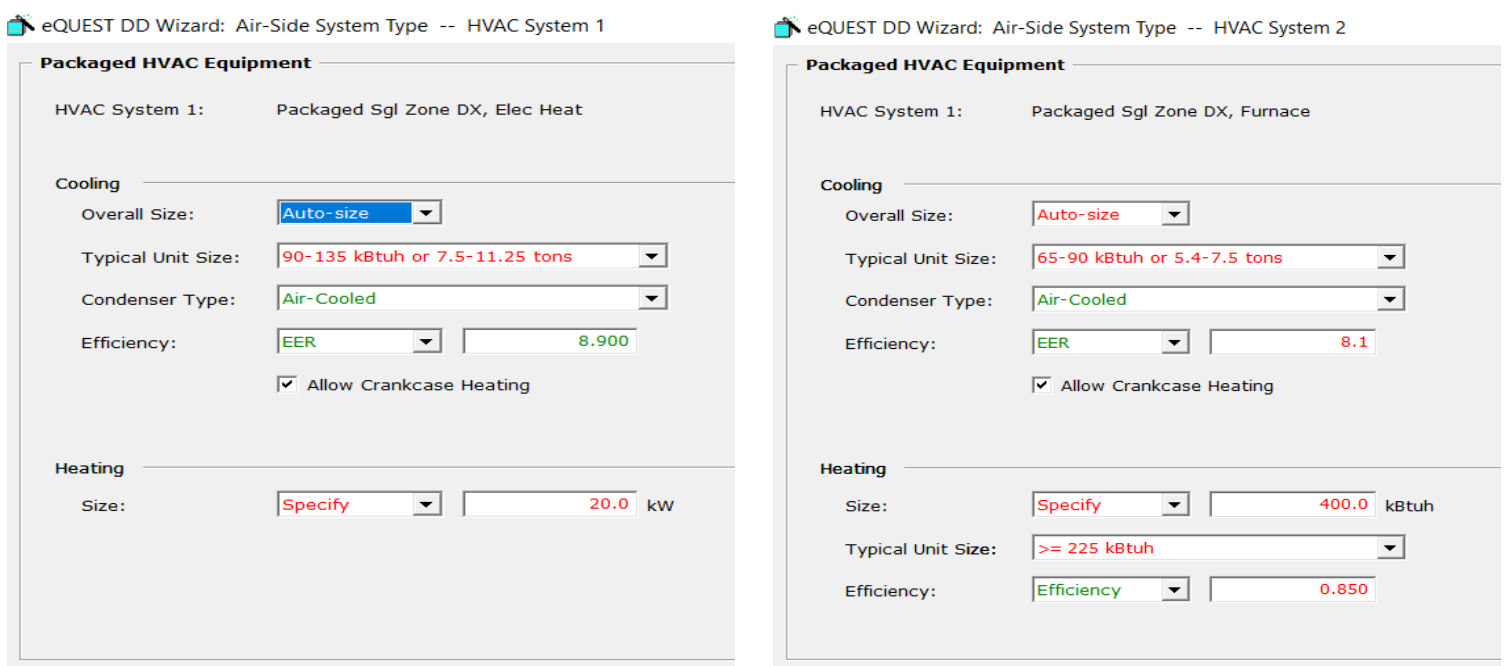

Figure 5.23: HVAC system for an office building (left) and gymnasium (right)
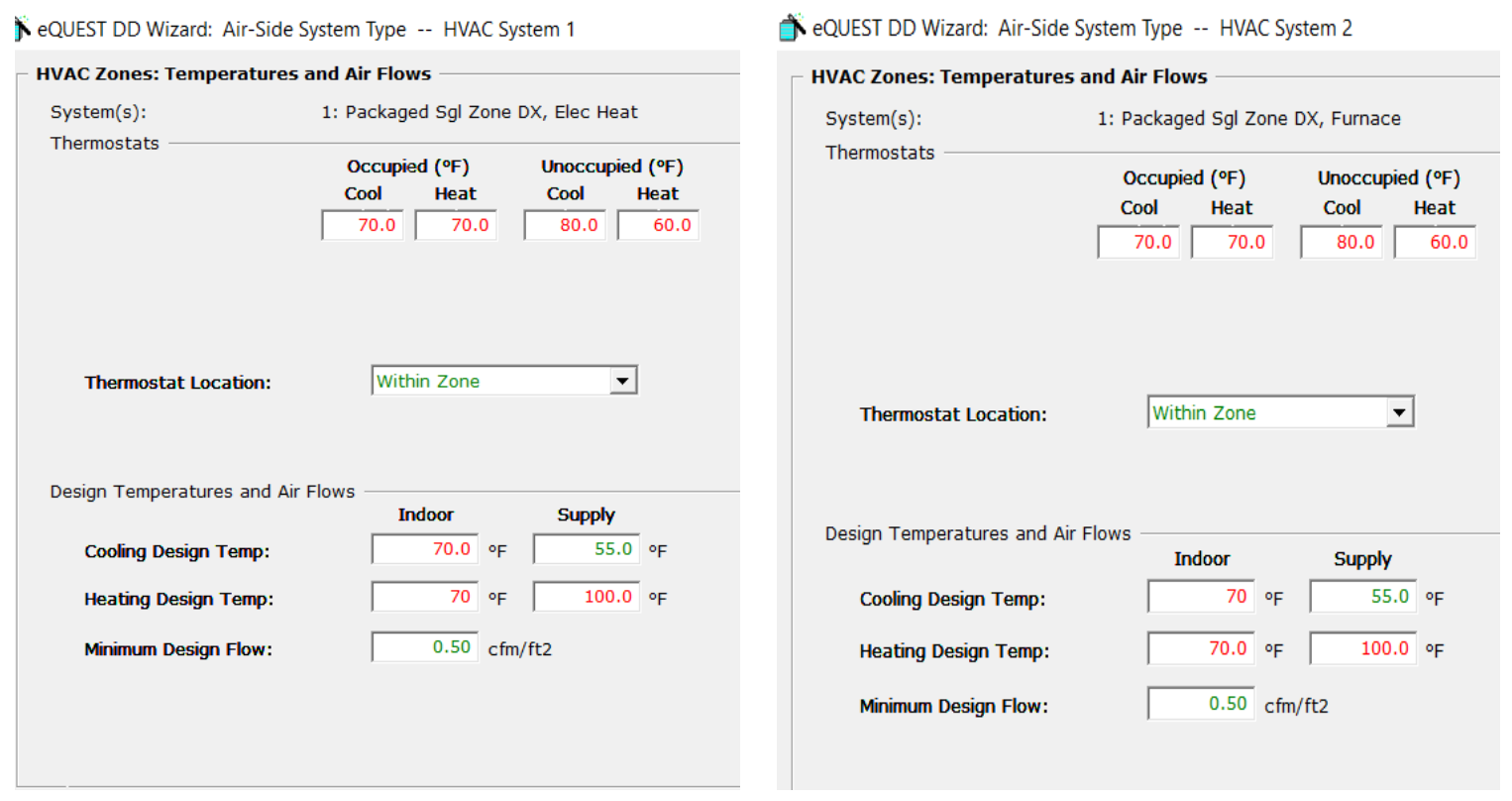

Figure 5.24: Temperature control setting for an office building (left) and gymnasium (right)

The hot water system was also inputted into the model, as shown in Figure 5.25. The capacity of the water heater was $0.035 \mathrm{MMBtu} / \mathrm{hr}$ that was input into the model. After input of all the parameters, the eQuest model was developed, as shown in Appendix Figure A1. 


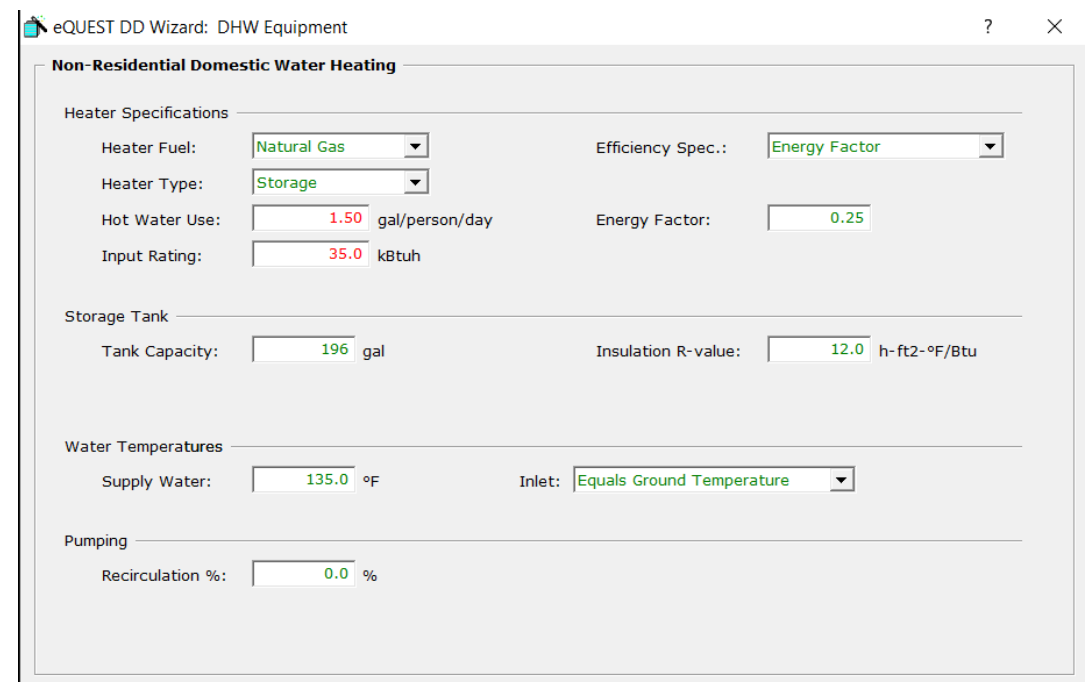

Figure 5.25: Hot water heating system

\section{Simulation Results}

The developed model is simulated for a year that gave the annual energy consumption of the building. As shown in Figure 5.26, the energy consumption in various areas such as area lighting, water heating, ventilation fans, space heating, space cooling, and so on can be determined by analyzing the stacked bar chart.

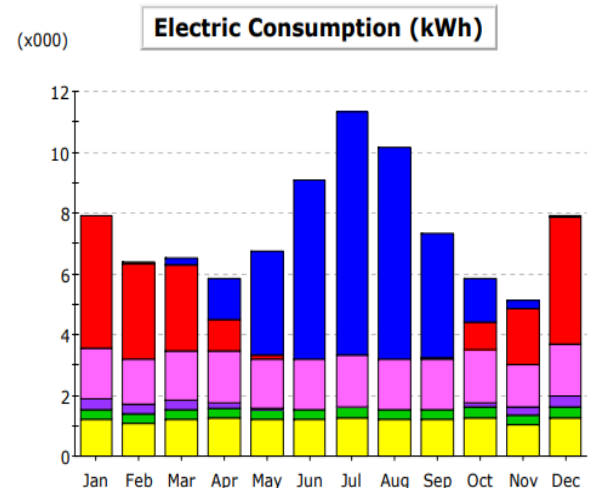

Jan Feb Mar Apr May Jun Jul Aug Sep Oct Nov Dec

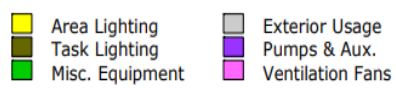

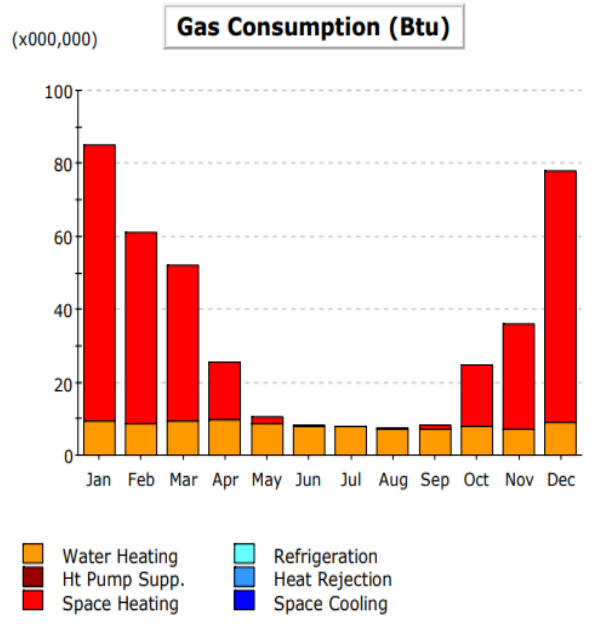

x000,000)

Space Cooling

\section{Figure 5.26: Energy consumption in community center obtained using eQuest}

Table 5.19 provides us the monthly consumption of energy for various areas. The total energy required for space cooling, space heating, and total annual electrical energy consumption and gas consumption is also shown in Table 5.19. The total annual electrical energy consumption obtained from the utility bill is $90,474 \mathrm{kWh}$, and natural gas 
consumption is 404 MMBtu. The total annual electrical energy consumption from the eQuest software is $90,170 \mathrm{kWh}$, and natural gas is 404.51 MMBtu. The yearly electrical energy obtained from the software is $0.33 \%$ less, and the natural gas is $0.1 \%$ more than the data obtained from the utility bill.

Table 5.19: Breakdown of energy consumption in community center using eQuest

\begin{tabular}{|c|c|c|c|c|c|c|c|c|c|c|c|c|c|}
\hline & Jan & Feb & Mar & Apr & May & Jun & Jul & Aug & Sep & Oct & Nov & Dec & Total \\
\hline Space Cool & 0.02 & 0.03 & 0.25 & 1.35 & 3.42 & 5.90 & 8.01 & 6.96 & 4.07 & 1.40 & 0.27 & 0.04 & 31.70 \\
\hline \multicolumn{14}{|l|}{ Refriaeration } \\
\hline Space Heat & 4.33 & 3.16 & 2.79 & 1.04 & 0.10 & 0.01 & - & 0.01 & 0.04 & 0.93 & 1.85 & 4.16 & 18.44 \\
\hline HP Supp. & - & - & - & - & - & - & - & - & $=$ & - & - & - & - \\
\hline Hot Water & - & - & - & - & - & - & - & - & - & - & - & - & - \\
\hline Vent. Fans & 1.65 & 1.49 & 1.66 & 1.73 & 1.65 & 1.66 & 1.73 & 1.65 & 1.66 & 1.73 & 1.42 & 1.73 & 19.75 \\
\hline Pumps \& Aux. & 0.37 & 0.31 & 0.29 & 0.14 & 0.02 & - & - & 0.01 & 0.02 & 0.17 & 0.27 & 0.37 & 1.97 \\
\hline Ext. Usage & - & - & - & - & - & - & - & - & - & - & - & - & - \\
\hline Misc. Equip. & 0.32 & 0.29 & 0.32 & 0.34 & 0.32 & 0.32 & 0.34 & 0.32 & 0.32 & 0.34 & 0.28 & 0.34 & 3.86 \\
\hline Task Lights & - & - & - & - & - & - & - & - & - & - & - & - & - \\
\hline Area Lights & 1.21 & 1.10 & 1.21 & 1.26 & 1.21 & 1.21 & 1.26 & 1.21 & 1.21 & 1.26 & 1.05 & 1.26 & 14.45 \\
\hline Total & 7.91 & 6.38 & 6.52 & 5.86 & 6.72 & 9.10 & 11.34 & 10.16 & 7.31 & 5.82 & 5.14 & 7.90 & 90.17 \\
\hline
\end{tabular}

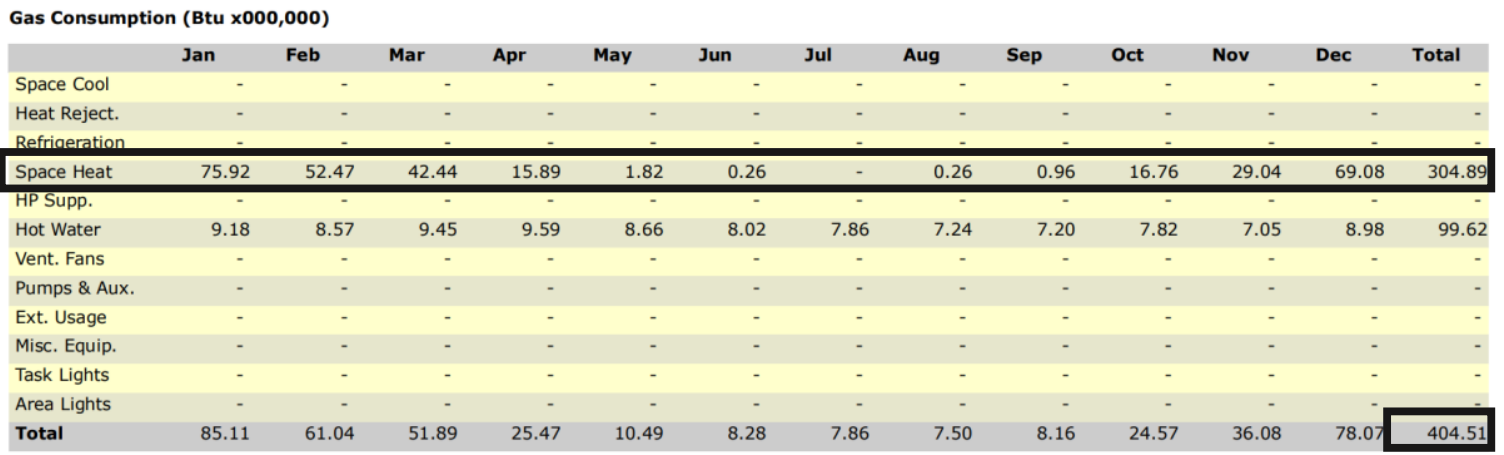

Table 5.20: Energy required for space cooling and heating obtained from eQuest

\begin{tabular}{|c|c|c|c|}
\hline Year & Month & $\begin{array}{c}\text { Energy Usage, } \\
(\mathbf{k W h})\end{array}$ & $\begin{array}{c}\text { Natural Gas Usage, } \\
\text { (MMBtu) }\end{array}$ \\
\hline \multirow{4}{*}{} & January & 4,350 & 75.92 \\
\cline { 2 - 4 } & February & 3,190 & 52.47 \\
\cline { 2 - 4 } & March & 4,140 & 42.44 \\
\cline { 2 - 4 } & April & 2,390 & 15.89 \\
\cline { 2 - 4 } & May & 3,520 & 1.82 \\
\cline { 2 - 4 } & June & 5,910 & 0.26 \\
\cline { 2 - 4 } & July & 8,010 & 0 \\
\cline { 2 - 4 } & August & 6,970 & 0.26 \\
\cline { 2 - 4 } & September & 4,110 & 0.96 \\
\cline { 2 - 4 } & October & 2,330 & 16.76 \\
\cline { 2 - 4 } & November & 2,120 & 29.04 \\
\cline { 2 - 4 } & December & 4,200 & 69.08 \\
\hline Total & - & $\mathbf{5 1 , 2 4 0}$ & $\mathbf{3 0 5}$ \\
\hline
\end{tabular}


The energy required for space cooling and heating is summarized in Table 5.20. From the comparison as shown in Table 5.21, it is observed that the total annual electrical energy consumption is $7 \%$ less, and natural gas consumption is $1 \%$ less in the Base Case than what is obtained from the eQuest software.

Table 5.21: Comparison of energy consumption between Base Case and eQuest method

\begin{tabular}{|c|c|c|c|c|c|c|c|}
\hline \multirow[t]{2}{*}{ Year } & \multirow[t]{2}{*}{ Month } & \multicolumn{2}{|c|}{$\begin{array}{c}\text { Energy Usage, } \\
\quad(\text { kWh })\end{array}$} & \multicolumn{2}{|c|}{$\begin{array}{c}\text { Natural Gas } \\
\text { Usage, } \\
\text { (MMBtu) }\end{array}$} & \multicolumn{2}{|c|}{$\begin{array}{c}\text { Percentage } \\
\text { Reduction from } \\
\text { eQuest method }\end{array}$} \\
\hline & & $\begin{array}{l}\text { Base } \\
\text { Case } \\
\end{array}$ & eQuest & $\begin{array}{l}\text { Base } \\
\text { Case } \\
\end{array}$ & eQuest & kWh & MMBtu \\
\hline \multirow{12}{*}{ त्ञิ } & January & 3,360 & 4,350 & 64.71 & 75.92 & $23 \%$ & $15 \%$ \\
\hline & February & 3,028 & 3,190 & 58.32 & 52.47 & $5 \%$ & $-11 \%$ \\
\hline & March & 2,254 & 4,140 & 43.29 & 42.44 & $46 \%$ & $-2 \%$ \\
\hline & April & 1,865 & 2,390 & 33.93 & 15.89 & $22 \%$ & $-114 \%$ \\
\hline & May & 3,559 & 3,520 & 0 & 1.82 & $-1 \%$ & - \\
\hline & June & 6,269 & 5,910 & 0 & 0.26 & $-6 \%$ & - \\
\hline & July & 7,850 & 8,010 & 0 & 0 & $2 \%$ & $0 \%$ \\
\hline & August & 7,342 & 6,970 & 0 & 0.26 & $-5 \%$ & - \\
\hline & September & 4,205 & 4,110 & 0 & 0.96 & $-2 \%$ & - \\
\hline & October & 2,819 & 2,330 & 0 & 16.76 & $-21 \%$ & $100 \%$ \\
\hline & November & 1,892 & 2,120 & 36.27 & 29.04 & $11 \%$ & $-25 \%$ \\
\hline & December & 3,425 & 4,200 & 65.99 & 69.08 & $18 \%$ & $4 \%$ \\
\hline Total & - & 47,868 & 51,240 & 303 & 305 & $7 \%$ & $1 \%$ \\
\hline
\end{tabular}

The difference in the energy consumption in the Base Case is within $25 \%$ of the data obtained from eQuest software except for natural gas consumption in April and October and electrical energy consumption in March. From May to October, the ratio of CDD to HDD is greater than 0.5 in the South Atlantic region. Hence only cooling equipment is run in the simulation tool. Whereas in eQuest software, the heating is done even the HDD is considerably low. Therefore, the percentage variation is greater in those months.

Figure 5.27 and Figure 5.28 show the graphical representation of variation in electrical energy consumption and natural gas consumption between the Base Case and the eQuest approach. 


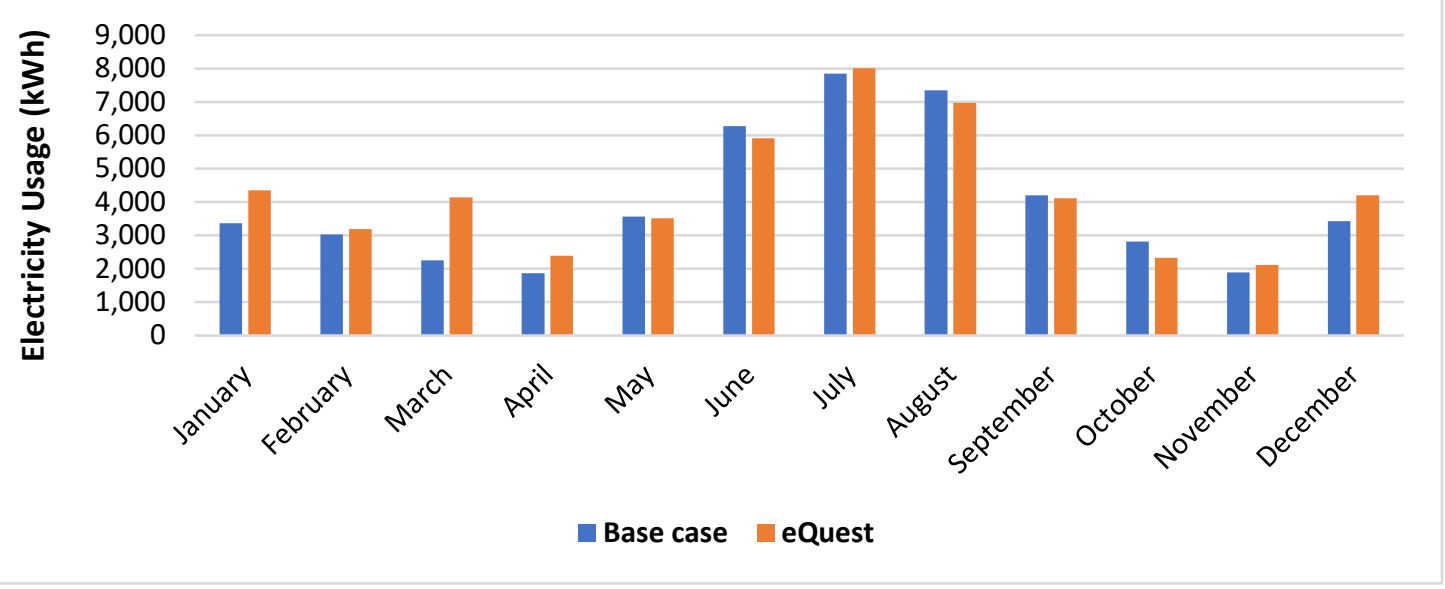

Figure 5.27: Comparison of electrical energy consumption between the Base Case and eQuest approach

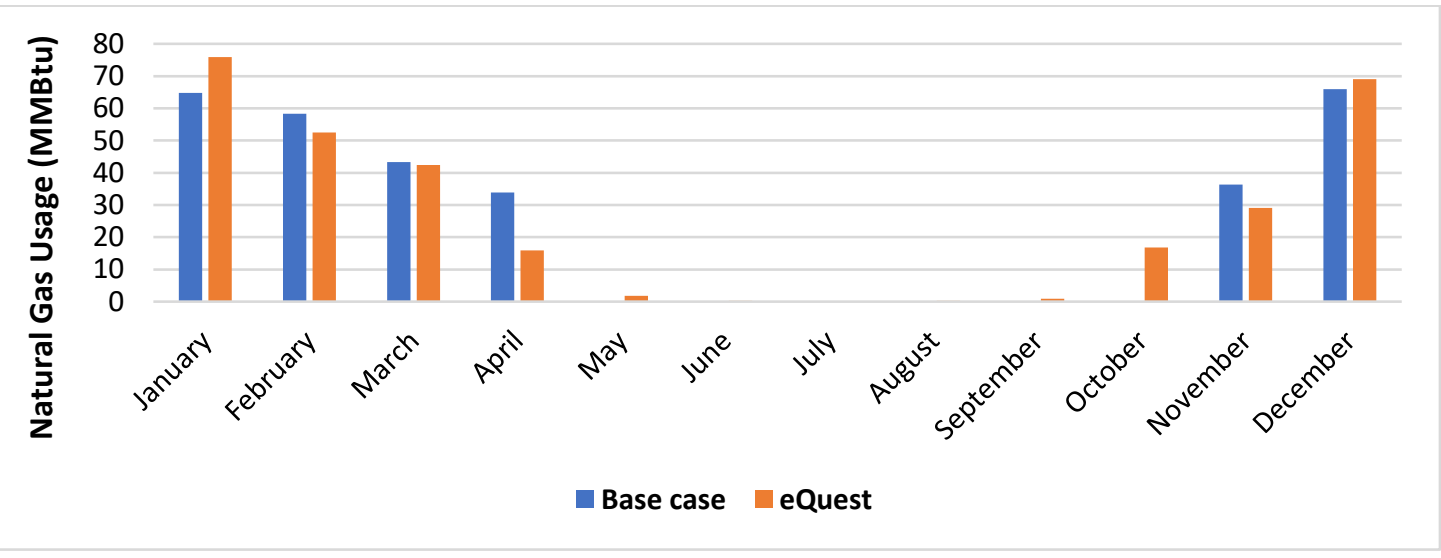

Figure 5.28: Comparison of natural gas consumption between the Base Case and eQuest approach

Table 5.22: Summary of energy consumption from various verification methods

\begin{tabular}{|c|c|c|c|c|}
\hline \multirow{2}{*}{ Methods } & \multirow{2}{*}{$\begin{array}{c}\text { Electric } \\
\text { energy usage }\end{array}$} & \multirow{2}{*}{$\begin{array}{c}\text { Natural } \\
\text { gas usage } \\
(\mathbf{k W H})\end{array}$} & $\begin{array}{c}\text { Percent difference of Base Case } \\
\text { from various methods }\end{array}$ \\
\cline { 4 - 5 } & 0 & 0 & $\mathbf{k W h}$ & $\mathbf{M M B t u}$ \\
\hline Base Case & 0 & 0 & - & - \\
\hline Utility analysis & 0 & 0 & $5 \%$ & $-23 \%$ \\
\hline DD Method & 0 & 0 & $7 \%$ & $1 \%$ \\
\hline eQuest Method & - & - & $\mathbf{8 \%}$ & $\mathbf{9 . 3 \%}$ \\
\hline Average error & - & & & \\
\hline
\end{tabular}

This estimation approach was used to estimate a range of energy consumption for space heating and cooling of the building. It can be seen from Table 5.22 given above that the natural gas consumption varies from $247 \mathrm{MMBtu}$ to $316 \mathrm{MMBtu}$, but the electric energy 
consumption only ranges from 50,444 to $54,454 \mathrm{kWh}$. It can see that the energy consumption obtained in the Base Case is within $10 \%$ for utility bill analysis and the eQuest method. For the DD method, the Base Case varies $12 \%$ from electrical energy consumption and $23 \%$ from natural gas consumption. The energy consumption obtained from the simulation for the Base Case can be considered a reasonable estimate based on the three verification approaches as the average error from the three approaches is within a $10 \%$ difference. Figure 5.29 shows the graphical representation of the comparison of energy consumption obtained from various methods.

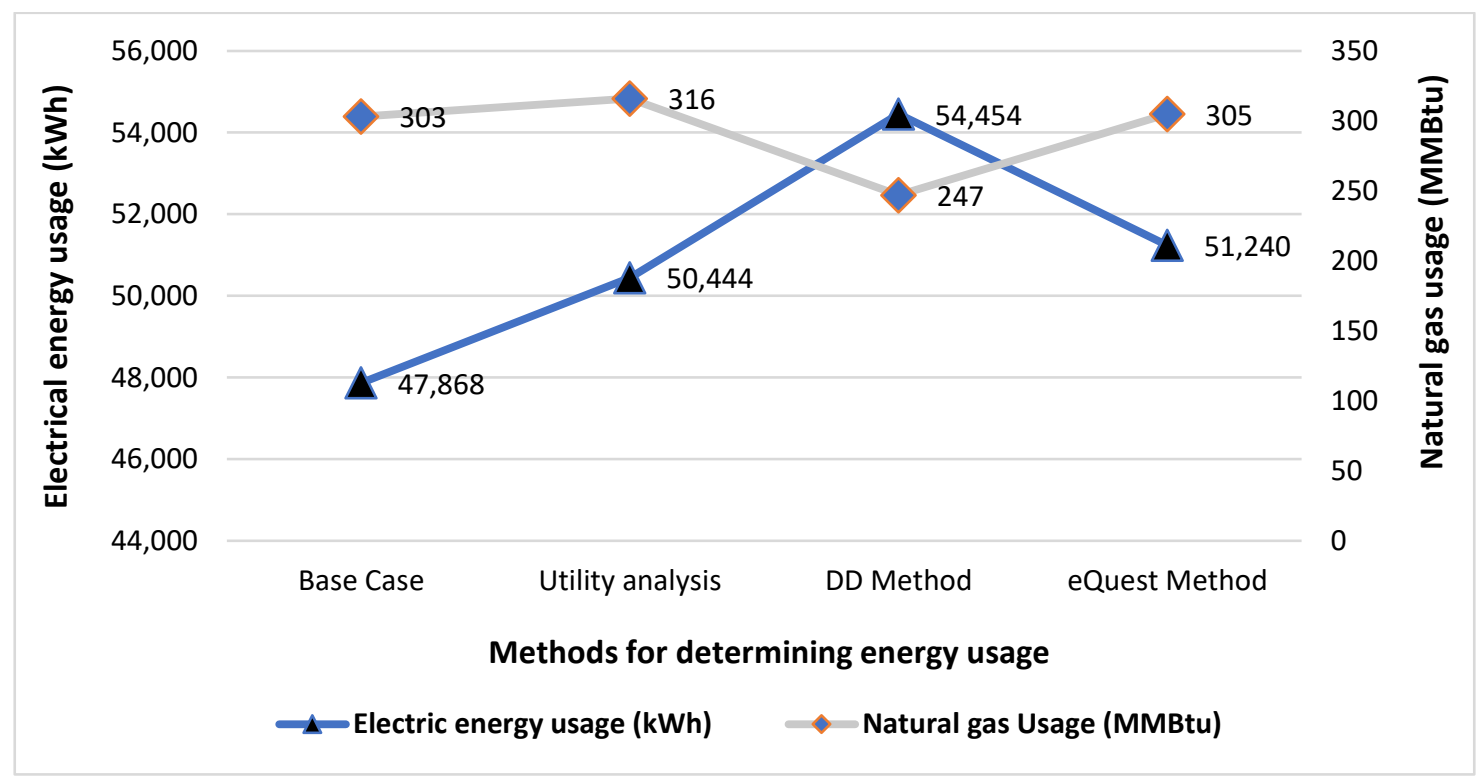

Figure 5.29: Comparison of energy consumption obtained from various methods

\subsection{BEMS with the addition of BEMS controls}

To study the effect of different levels of BEMS controls on the energy consumption and impact on effectiveness on the energy management system, simulation runs were performed. The simulation model was reset back to Base Case before performing simulation for each of the cases. The results from the simulation runs are shown and discussed in this section.

\subsubsection{Case I - With improvement in Building Envelope only}

In Case I, the building envelope of the building is only considered to be improved. The building, however, still has zoning controls and temperature setback controls as in the Base Case. The simulation process is similar to as described for the Base Case. The electrical 
energy consumption and natural gas consumption for this case obtained through simulation are shown in Table 5.23.

Table 5.23: Energy consumption for space heating and cooling for Case I

\begin{tabular}{|c|c|c|c|}
\hline Year & Month & $\begin{array}{c}\text { Energy Usage, } \\
(\mathbf{k W h})\end{array}$ & $\begin{array}{c}\text { Natural Gas Usage, } \\
\text { (MMBtu) }\end{array}$ \\
\hline \multirow{12}{*}{ ণి శి } & January & 2,748 & 52.62 \\
\hline & February & 2,476 & 47.4 \\
\hline & March & 1,646 & 31.2 \\
\hline & April & 1,266 & 22.62 \\
\hline & May & 2,574 & 0 \\
\hline & June & 5,359 & 0 \\
\hline & July & 6,907 & 0 \\
\hline & August & 6,398 & 0 \\
\hline & September & 3,301 & 0 \\
\hline & October & 1,914 & 0 \\
\hline & November & 1,284 & 24.18 \\
\hline & December & 2,814 & 53.9 \\
\hline Total & - & 38,687 & 232 \\
\hline
\end{tabular}

Table 5.24: Comparison of energy consumption between Base Case, TEE Case, and Case I

\begin{tabular}{|c|c|c|c|c|c|c|c|c|c|}
\hline \multirow{3}{*}{ Month } & \multicolumn{4}{|c|}{$\begin{array}{c}\text { Energy Usage, } \\
\text { (kWh) }\end{array}$} & \multicolumn{3}{c|}{$\begin{array}{c}\text { Natural Gas Usage, } \\
\text { (MMBtu) }\end{array}$} & $\begin{array}{c}\text { Percentage } \\
\text { Reduction of } \\
\text { TEE case from } \\
\text { Case I }\end{array}$ & $\begin{array}{c}\text { Rating } \\
\text { of } \\
\text { BEMS } \\
\end{array}$ \\
\cline { 2 - 13 } & $\begin{array}{c}\text { Base } \\
\text { Case }\end{array}$ & $\begin{array}{c}\text { TEE } \\
\text { Case }\end{array}$ & $\begin{array}{c}\text { Case } \\
\text { I }\end{array}$ & $\begin{array}{c}\text { Base } \\
\text { Case }\end{array}$ & $\begin{array}{c}\text { TEE } \\
\text { Case }\end{array}$ & $\begin{array}{c}\text { Case } \\
\text { I }\end{array}$ & kWh & MMBtu & \\
\hline January & 3,360 & 1,410 & 2,748 & 64.71 & 23.88 & 52.62 & $49 \%$ & $55 \%$ & 2.9 \\
\hline February & 3,028 & 1,297 & 2,476 & 58.32 & 21 & 47.4 & $48 \%$ & $56 \%$ & 2.89 \\
\hline March & 2,254 & 1,063 & 1,646 & 43.29 & 17.19 & 31.2 & $35 \%$ & $45 \%$ & 3.35 \\
\hline April & 1,865 & 968 & 1,266 & 33.93 & 14.89 & 22.62 & $24 \%$ & $34 \%$ & 3.8 \\
\hline May & 3,559 & 1,546 & 2,574 & 0 & 0 & 0 & $40 \%$ & $0 \%$ & 3.41 \\
\hline June & 6,269 & 2,345 & 5,359 & 0 & 0 & 0 & $56 \%$ & $0 \%$ & 2.76 \\
\hline July & 7,850 & 3,562 & 6,907 & 0 & 0 & 0 & $48 \%$ & $0 \%$ & 3.07 \\
\hline August & 7,342 & 2,982 & 6,398 & 0 & 0 & 0 & $53 \%$ & $0 \%$ & 2.87 \\
\hline September & 4,205 & 1,853 & 3,301 & 0 & 0 & 0 & $44 \%$ & $0 \%$ & 3.25 \\
\hline October & 2,819 & 1,515 & 1,914 & 0 & 0 & 0 & $21 \%$ & $0 \%$ & 4.17 \\
\hline November & 1,892 & 964 & 1,284 & 36.27 & 15.65 & 24.18 & $25 \%$ & $35 \%$ & 3.74 \\
\hline December & 3,425 & 1,529 & 2,814 & 65.99 & 21.97 & 53.9 & $46 \%$ & $59 \%$ & 2.83 \\
\hline Total & $\mathbf{4 7 , 8 6 8}$ & $\mathbf{2 1 , 0 3 4}$ & $\mathbf{3 8 , 6 8 7}$ & $\mathbf{3 0 3}$ & $\mathbf{1 1 5}$ & $\mathbf{2 3 2}$ & $\mathbf{4 6 \%}$ & $\mathbf{5 1 \%}$ & $\mathbf{3 . 1 1}$ \\
\hline
\end{tabular}


From Table 5.24, based on the annual energy consumption between Base Case and Case I, the electrical energy consumption decreased by approximately 19\%, and natural gas consumption decreased by $23 \%$. However, to reach the TEE case, the electrical energy should be further reduced by $46 \%$, and natural gas should be reduced by $51 \%$ from the Case I energy consumption data.

Table 5.25: Summary of reduction of $\mathrm{CO}_{2}$ emission for Case I

\begin{tabular}{|c|c|c|c|c|}
\hline & \multicolumn{2}{|c|}{ Site energy } & \multicolumn{2}{c|}{ Source energy } \\
\hline Energy source & $\begin{array}{c}\text { Electricity } \\
(\mathbf{k W h} / \mathbf{y r})\end{array}$ & $\begin{array}{c}\text { Natural gas } \\
(\mathbf{M M B t u} / \mathbf{y r})\end{array}$ & $\begin{array}{c}\text { Electricity } \\
(\mathbf{k W h} / \mathbf{y r})\end{array}$ & $\begin{array}{c}\text { Natural gas } \\
(\mathbf{M M B t u} / \mathbf{y r})\end{array}$ \\
\hline Base Case energy usage & 47,868 & 303 & 134,030 & 318 \\
\hline Case I energy usage & 38,687 & 232 & 108,324 & 244 \\
\hline Annual energy savings & 9,181 & 71 & 25,707 & 75 \\
\hline $\begin{array}{c}\mathbf{C O}_{2} \text { emission saved based } \\
\text { on energy source (lbs/yr) }\end{array}$ & 20,106 & 8,023 & 56,298 & 8,424 \\
\hline $\begin{array}{c}\text { Total CO2 emission saved } \\
\text { (lbs/yr) }\end{array}$ & \multicolumn{2}{|c|}{28,129} & \multicolumn{2}{c|}{64,722} \\
\hline
\end{tabular}

Table 5.25 shows the summary of the reduction of $\mathrm{CO}_{2}$ emission for Case I. It can be seen that by upgrading the building to Case I from Base Case, the reduction of $\mathrm{CO}_{2}$ is 28,129 $\mathrm{lbs} / \mathrm{yr}$ and $64,722 \mathrm{lbs} / \mathrm{yr}$ for site energy and source energy, respectively.

Figure 5.30 and Figure 5.31 below show the graphical illustration of the difference in energy consumption between the three cases.

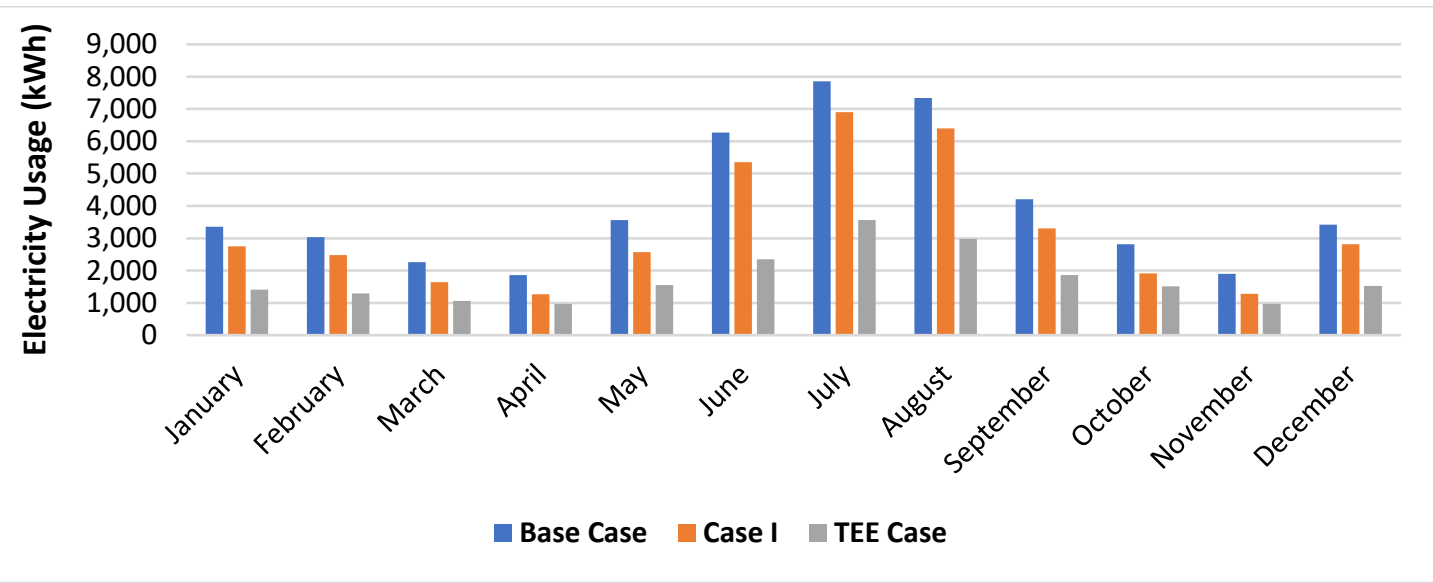

Figure 5.30: Comparison of electrical energy consumption between Base Case, Case I, and TEE Case 


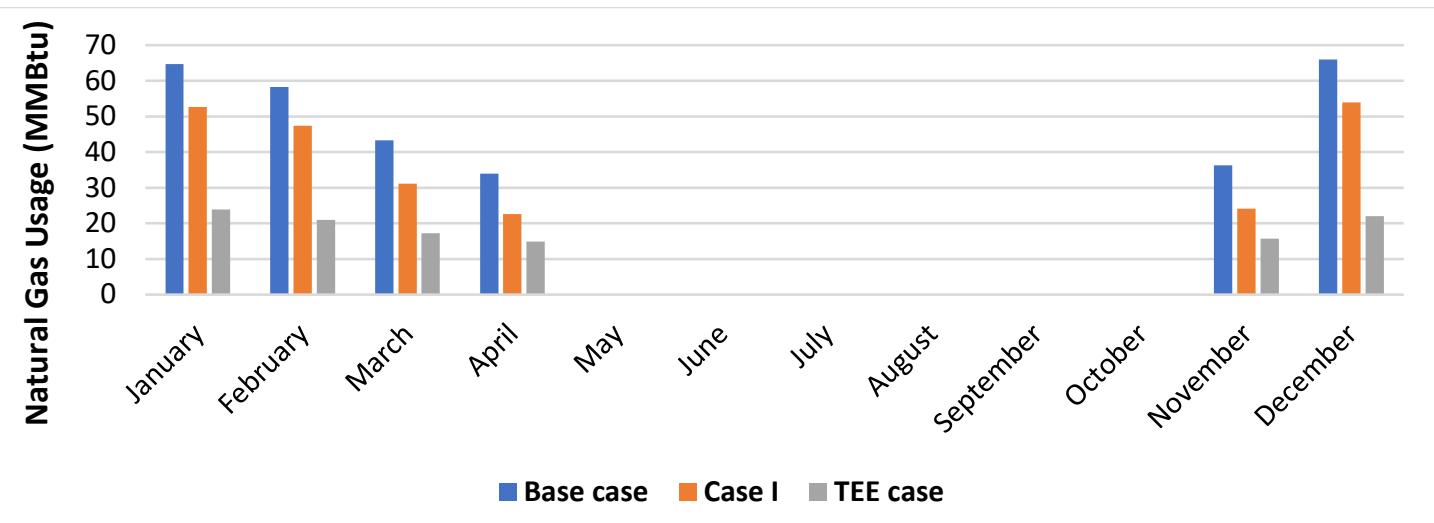

Figure 5.31: Comparison of natural gas consumption between Base Case, Case I, and TEE Case

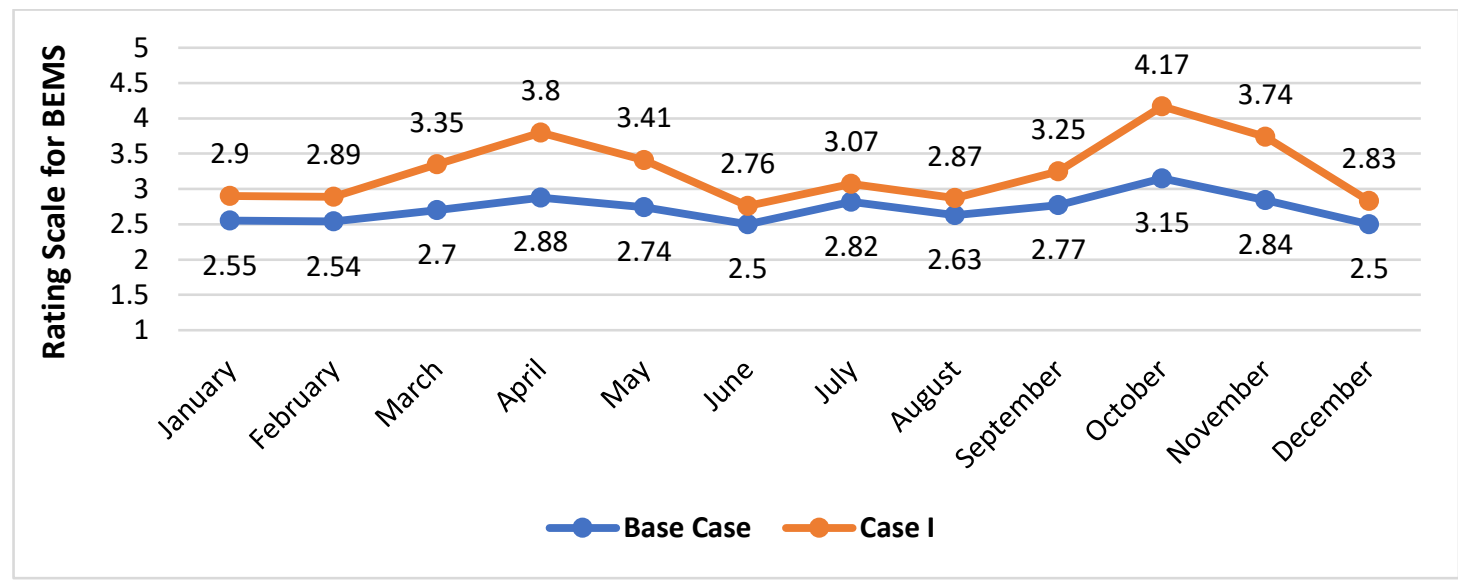

Figure 5.32: Change of effectiveness of BEMS from Base Case to Case I

From Figure 5.32, it can be seen that the efficacy of BEMS ranges from 2.76 to 4.17 for Case I. The overall efficacy of BEMS is determined to be 3.11, as shown in Table 5.24. According to the rating chart, as shown in Table 3.10, the effectiveness of BEMS is considered "Not Satisfactory".

From the pattern of the effectiveness of BEMS, it is observed that the effectiveness ratings are higher during March, April, May, September, October, and November. These months are off-peak months for the heating or cooling season. Here, December and January are peak months during winter, and June, July August are peak months during summer. Hence, it can be said that improving the insulation of the building envelope has less impact on peak months than in off-peak months. This can be explained by analyzing the heating and cooling units' load factor in peak and off-peak seasons. During on-peak season, the heating and cooling units are already running on a higher load factor; hence, it does not impact a 
poor building envelope. However, during the off-peak season, the heating or cooling units generally run at a low-load factor, but they tend to run at a higher load factor if the building envelope is poor. Hence, by improving the building envelope, we tend to see higher effectiveness of BEMS at off-peak months. The building envelope in this simulation model is changed from level 1 to level 2 for improvement.

\subsubsection{Case II - With the Addition of DCV}

The simulation model is reset back to the Base Case, i.e., the building is considered to have only the zoning controls and temperature setback controls with the poor building envelope. In Case II, DCV control is then added to the simulation. The electrical energy consumption and natural gas consumption for this case obtained through simulation are shown in Table 5.26 .

Table 5.26: Energy consumption for space heating and cooling for Case II

\begin{tabular}{|c|c|c|c|}
\hline Year & Month & $\begin{array}{c}\text { Energy Usage, } \\
(\mathbf{k W h})\end{array}$ & $\begin{array}{c}\text { Natural Gas Usage, } \\
\text { (MMBtu) }\end{array}$ \\
\hline \multirow{4}{*}{} & January & 2,334 & 45.91 \\
\cline { 2 - 4 } & February & 2,112 & 39.85 \\
\cline { 2 - 4 } & March & 1,819 & 34.51 \\
\cline { 2 - 4 } & April & 1,660 & 30.01 \\
\cline { 2 - 4 } & May & 2,343 & 0 \\
\cline { 2 - 4 } & June & 3,317 & 0 \\
\cline { 2 - 4 } & July & 4,889 & 0 \\
\cline { 2 - 4 } & August & 4,160 & 0 \\
\cline { 2 - 4 } & September & 2,681 & 0 \\
\cline { 2 - 4 } & October & 2,290 & 0 \\
\cline { 2 - 4 } & November & 1,681 & 32.06 \\
\cline { 2 - 4 } & December & 2,461 & 42.07 \\
\hline Total & - & $\mathbf{3 1 , 7 4 7}$ & $\mathbf{2 2 4}$ \\
\hline
\end{tabular}

From Table 5.27, based on the annual energy consumption between Base Case and Case II, the electrical energy consumption decreased by approximately $34 \%$, and natural gas consumption decreased by $26 \%$. However, to reach the TEE case, the electrical energy should be further reduced by $34 \%$, and natural gas should be reduced by $49 \%$ from the Case II energy consumption data. 
Table 5.27: Comparison of energy consumption between Base Case, TEE case, and Case II

\begin{tabular}{|c|c|c|c|c|c|c|c|c|c|}
\hline \multirow{3}{*}{ Month } & \multicolumn{4}{|c|}{$\begin{array}{c}\text { Energy Usage, (kWh) } \\
\end{array}$} & \multicolumn{3}{|c|}{$\begin{array}{c}\text { Natural Gas Usage, } \\
\text { (MMBtu) }\end{array}$} & $\begin{array}{c}\text { Percentage } \\
\text { Reduction of } \\
\text { TEE Case from } \\
\text { Case II }\end{array}$ & $\begin{array}{c}\text { Rating } \\
\text { of } \\
\text { BEMS } \\
\mathbf{( 1 - 5 )}\end{array}$ \\
\cline { 2 - 11 } & $\begin{array}{c}\text { Base } \\
\text { Case }\end{array}$ & $\begin{array}{c}\text { TEE } \\
\text { Case }\end{array}$ & $\begin{array}{c}\text { Case } \\
\text { II }\end{array}$ & $\begin{array}{c}\text { Base } \\
\text { Case }\end{array}$ & $\begin{array}{c}\text { TEE } \\
\text { Case }\end{array}$ & $\begin{array}{c}\text { Case } \\
\text { II }\end{array}$ & kWh & MMBtu & \\
\hline January & 3,360 & 1,410 & 2,334 & 64.71 & 23.88 & 45.91 & $40 \%$ & $48 \%$ & 3.2 \\
\hline February & 3,028 & 1,297 & 2,112 & 58.32 & 21 & 39.85 & $39 \%$ & $47 \%$ & 3.24 \\
\hline March & 2,254 & 1,063 & 1,819 & 43.29 & 17.19 & 34.51 & $42 \%$ & $50 \%$ & 3.12 \\
\hline April & 1,865 & 968 & 1,660 & 33.93 & 14.89 & 30.01 & $42 \%$ & $50 \%$ & 3.12 \\
\hline May & 3,559 & 1,546 & 2,343 & 0 & 0 & 0 & $34 \%$ & $0 \%$ & 3.64 \\
\hline June & 6,269 & 2,345 & 3,317 & 0 & 0 & 0 & $29 \%$ & $0 \%$ & 3.83 \\
\hline July & 7,850 & 3,562 & 4,889 & 0 & 0 & 0 & $27 \%$ & $0 \%$ & 3.92 \\
\hline August & 7,342 & 2,982 & 4,160 & 0 & 0 & 0 & $28 \%$ & $0 \%$ & 3.87 \\
\hline September & 4,205 & 1,853 & 2,681 & 0 & 0 & 0 & $31 \%$ & $0 \%$ & 3.77 \\
\hline October & 2,819 & 1,515 & 2,290 & 0 & 0 & 0 & $34 \%$ & $0 \%$ & 3.65 \\
\hline November & 1,892 & 964 & 1,681 & 36.27 & 15.65 & 32.06 & $43 \%$ & $51 \%$ & 3.08 \\
\hline December & 3,425 & 1,529 & 2,461 & 65.99 & 21.97 & 42.07 & $38 \%$ & $48 \%$ & 3.25 \\
\hline Total & $\mathbf{4 7 , 8 6 8}$ & $\mathbf{2 1 , 0 3 4}$ & $\mathbf{3 1 , 7 4 7}$ & $\mathbf{3 0 3}$ & $\mathbf{1 1 5}$ & $\mathbf{2 2 4}$ & $\mathbf{3 4 \%}$ & $\mathbf{4 9 \%}$ & $\mathbf{3 . 4 1}$ \\
\hline
\end{tabular}

Table 5.28: Summary of reduction of $\mathrm{CO}_{2}$ emission for Case II

\begin{tabular}{|c|c|c|c|c|}
\hline & \multicolumn{2}{|c|}{ Site energy } & \multicolumn{2}{c|}{ Source energy } \\
\hline Energy source & $\begin{array}{c}\text { Electricity } \\
\text { (kWh/yr) }\end{array}$ & $\begin{array}{c}\text { Natural gas } \\
\text { (MMBtu/yr) }\end{array}$ & $\begin{array}{c}\text { Electricity } \\
(\mathbf{k W h} / \mathbf{y r})\end{array}$ & $\begin{array}{c}\text { Natural gas } \\
(\mathbf{M M B t u} / \mathbf{y r})\end{array}$ \\
\hline Base Case energy usage & 47,868 & 303 & 134,030 & 318 \\
\hline TEE Case energy usage & 31,747 & 224 & 88,892 & 235 \\
\hline Annual energy savings & 16,121 & 79 & 45,139 & 83 \\
\hline $\begin{array}{c}\mathbf{C O}_{2} \text { emission saved based } \\
\text { on energy source (lbs/yr) }\end{array}$ & 35,305 & 8,927 & 98,854 & 9,373 \\
\hline $\begin{array}{c}\text { Total CO } \mathbf{C}_{\mathbf{2}} \text { emission saved } \\
\text { (lbs/yr) }\end{array}$ & \multicolumn{2}{|c|}{44,232} & \multicolumn{2}{c}{108,227} \\
\hline
\end{tabular}

Table 5.28 shows the summary of the reduction of $\mathrm{CO}_{2}$ emission for Case II. By upgrading the building to Case II from Base Case, the reduction of $\mathrm{CO}_{2}$ is 44,232 lbs/yr and 108,227 lbs/yr for site energy and source energy, respectively. Figure 5.33 and Figure 5.34 below show the graphical illustration of the difference in energy consumption between the three cases. 


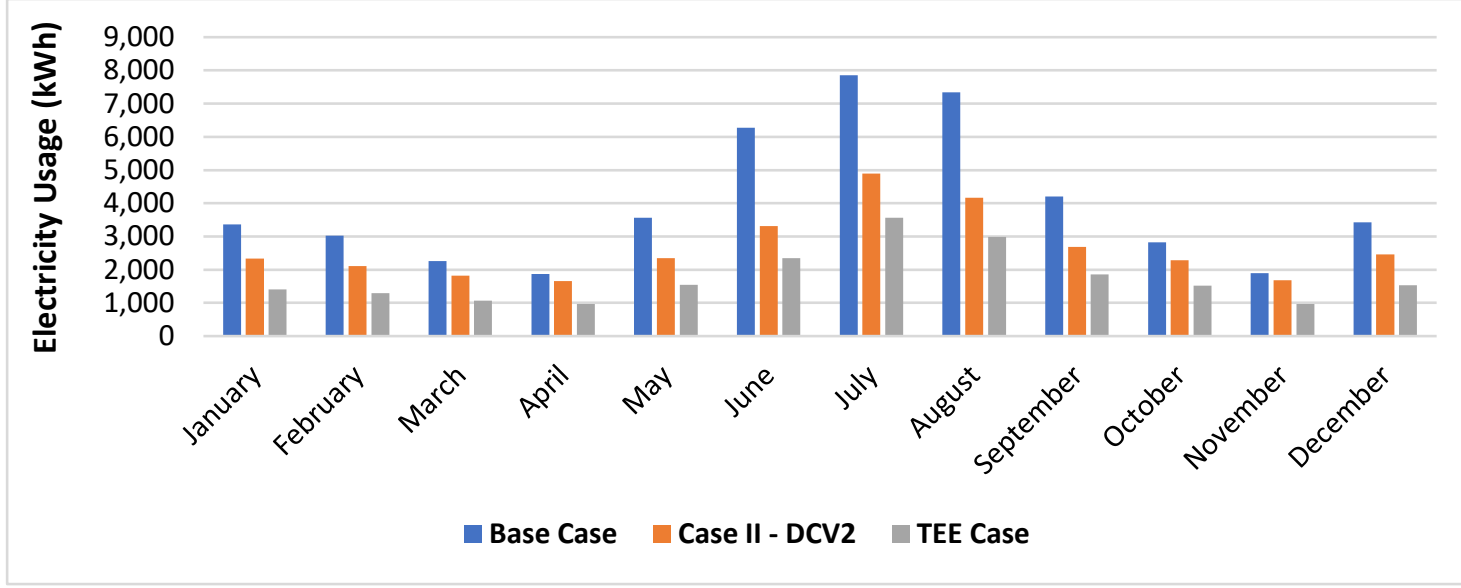

Figure 5.33: Comparison of electrical energy consumption between Base Case, Case II, and TEE Case

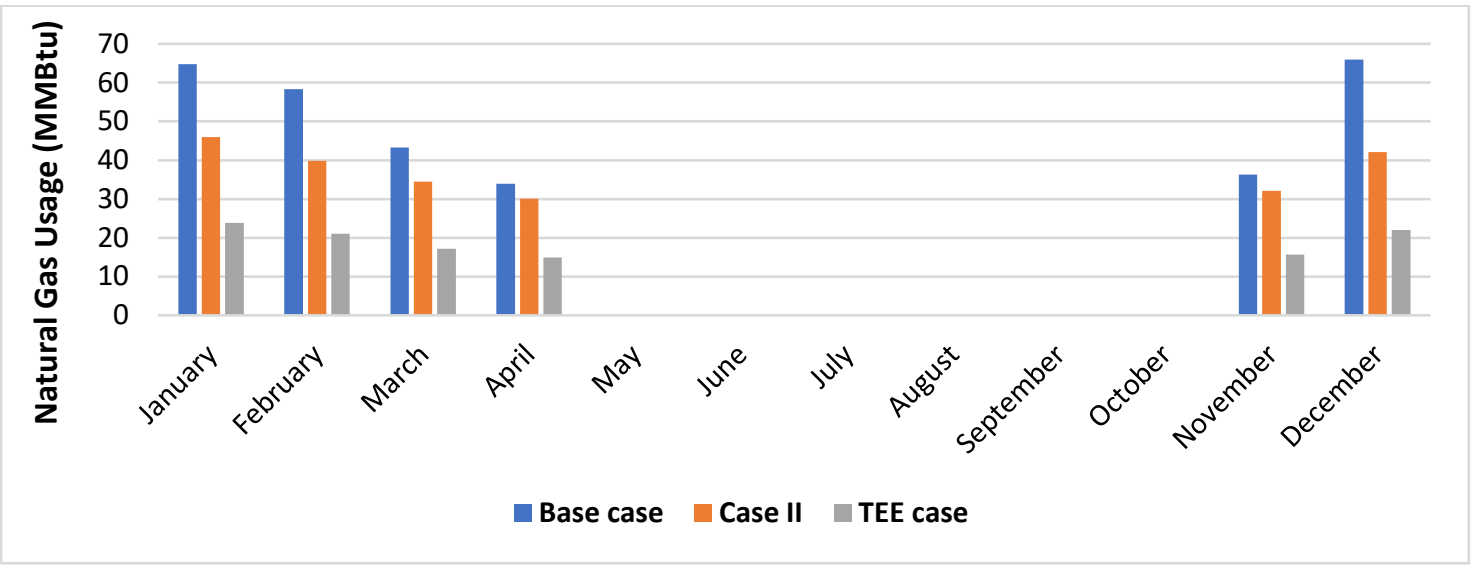

Figure 5.34: Comparison of natural gas consumption between the Base Case, Case II, and TEE Case

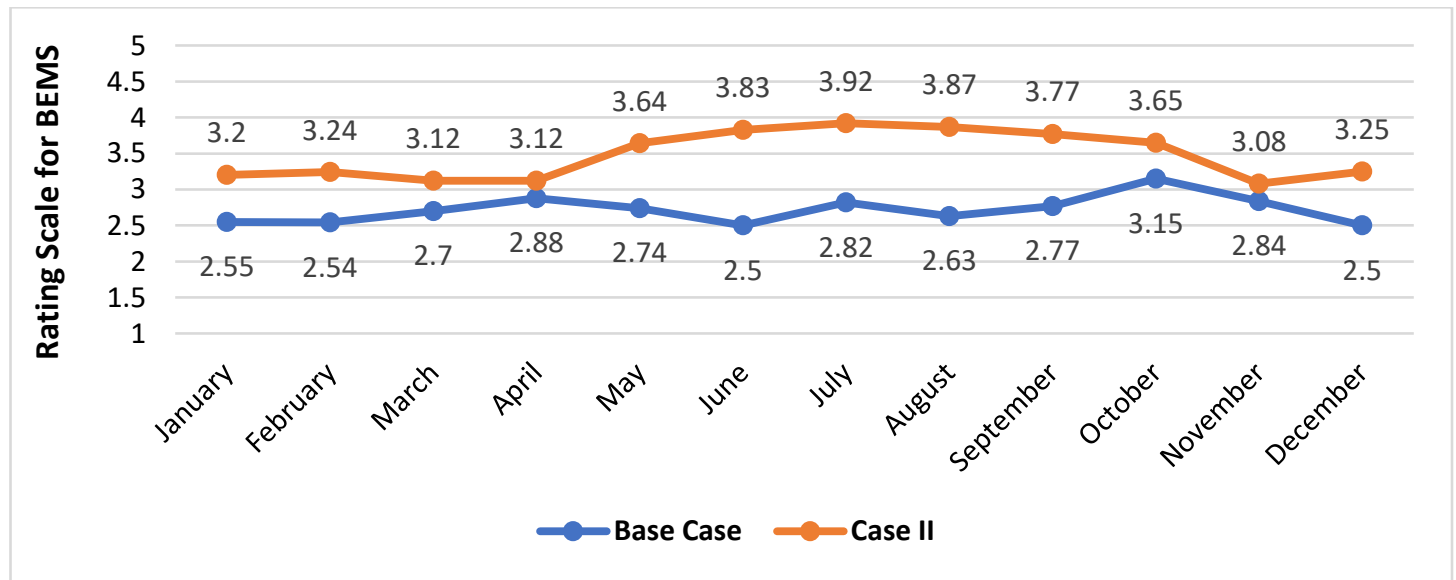

Figure 5.35: Change of effectiveness of BEMS from Base Case to Case II 
From Figure 5.35, it can be seen that the effectiveness of BEMS ranges from 2.5 to 3.92 for Case II. The overall efficacy of BEMS is determined to be 3.41, as shown in Table 5.27. According to the rating chart, as shown in Table 3.41, the effectiveness of BEMS is considered "Not Satisfactory".

From the pattern of the effectiveness of BEMS, it is observed that the effectiveness ratings are considerably higher during the summer months from May through September. In contrast, the effectiveness rating is not markedly higher in the remaining months. As discussed in an earlier section, the effectiveness rating of BEMS is associated with the cost of energy sources. For electricity, the cost also accounts for demand cost, but the cost is only related to natural gas consumption. During summer, both the gymnasium and office building are cooled using electricity as an energy source. Hence, if DCV is used, the amount of energy required for cooling the space reduces considerably. So, the cost of electricity during summer reduces significantly. During the winter months, the gymnasium is heated using natural gas, and the office spaces are heated using electric energy sources. Relative to the summer months, the cost is reduced less due to less natural gas and electricity consumption. Hence, the effectiveness of BEMS is higher during the summer months due to the addition of the DCV system.

\subsubsection{Case III - With DCV and Building Envelope improvement}

In Case III, along with the addition of DCV control, the building envelope is also improved. Likewise, as in earlier cases, the building also has zoning controls and temperature setback controls. The electrical energy consumption and natural gas use for this case obtained through simulation are shown in Table 5.29.

From Table 5.30, based on the annual energy consumption between Base Case and Case III, the electrical energy consumption decreased by approximately $42 \%$, and natural gas consumption decreased by $36 \%$. However, to reach the TEE case, the electrical energy should be reduced by $25 \%$, and natural gas should be reduced by $40 \%$ from the Case III energy consumption data. 
Table 5.29: Energy consumption for space heating and cooling for Case III

\begin{tabular}{|c|c|c|c|}
\hline Year & Month & $\begin{array}{c}\text { Energy Usage, } \\
\text { (kWh) }\end{array}$ & $\begin{array}{c}\text { Natural Gas Usage, } \\
\text { (MMBtu) }\end{array}$ \\
\hline \multirow{4}{*}{} & January & 2,067 & 40.45 \\
\cline { 2 - 4 } & February & 1,873 & 35 \\
\cline { 2 - 4 } & March & 1,558 & 29.31 \\
\cline { 2 - 4 } & April & 1,397 & 25.01 \\
\cline { 2 - 4 } & May & 1,953 & 0 \\
\cline { 2 - 4 } & June & 2,942 & 0 \\
\cline { 2 - 4 } & July & 4,500 & 0 \\
\cline { 2 - 4 } & August & 3,755 & 0 \\
\cline { 2 - 4 } & September & 2,301 & 0 \\
\cline { 2 - 4 } & October & 1,899 & 0 \\
\cline { 2 - 4 } & November & 1,416 & 26.72 \\
\cline { 2 - 4 } & December & 2,198 & 36.85 \\
\hline Total & - & $\mathbf{2 7 , 8 5 9}$ & $\mathbf{1 9 3}$ \\
\hline
\end{tabular}

Table 5.30: Comparison of energy consumption between Base Case, TEE Case, and Case III

\begin{tabular}{|c|c|c|c|c|c|c|c|c|c|}
\hline \multirow{3}{*}{ Month } & \multicolumn{4}{|c|}{$\begin{array}{c}\text { Energy Usage, (kWh) } \\
\end{array}$} & \multicolumn{3}{|c|}{$\begin{array}{c}\text { Natural Gas Usage, } \\
\text { (MMBtu) }\end{array}$} & $\begin{array}{c}\text { Percentage } \\
\text { Reduction of } \\
\text { TEE Case from } \\
\text { Case III }\end{array}$ & $\begin{array}{c}\text { Rating } \\
\text { of } \\
\text { BEMS } \\
(\mathbf{1}-\mathbf{5})\end{array}$ \\
\cline { 2 - 11 } & $\begin{array}{c}\text { Base } \\
\text { Case }\end{array}$ & $\begin{array}{c}\text { TEE } \\
\text { Case }\end{array}$ & $\begin{array}{c}\text { Case } \\
\text { III }\end{array}$ & $\begin{array}{c}\text { Base } \\
\text { Case }\end{array}$ & $\begin{array}{c}\text { TEE } \\
\text { Case }\end{array}$ & $\begin{array}{c}\text { Case } \\
\text { III }\end{array}$ & kWh & MMBtu & \\
\hline January & 3,360 & 1,410 & 2,067 & 64.71 & 23.88 & 40.45 & $32 \%$ & $41 \%$ & 3.5 \\
\hline February & 3,028 & 1,297 & 1,873 & 58.32 & 21 & 35 & $31 \%$ & $40 \%$ & 3.54 \\
\hline March & 2,254 & 1,063 & 1,558 & 43.29 & 17.19 & 29.31 & $32 \%$ & $41 \%$ & 3.49 \\
\hline April & 1,865 & 968 & 1,397 & 33.93 & 14.89 & 25.01 & $31 \%$ & $40 \%$ & 3.53 \\
\hline May & 3,559 & 1,546 & 1,953 & 0 & 0 & 0 & $21 \%$ & $0 \%$ & 4.17 \\
\hline June & 6,269 & 2,345 & 2,942 & 0 & 0 & 0 & $20 \%$ & $0 \%$ & 4.19 \\
\hline July & 7,850 & 3,562 & 4,500 & 0 & 0 & 0 & $21 \%$ & $0 \%$ & 4.17 \\
\hline August & 7,342 & 2,982 & 3,755 & 0 & 0 & 0 & $21 \%$ & $0 \%$ & 4.18 \\
\hline September & 4,205 & 1,853 & 2,301 & 0 & 0 & 0 & $19 \%$ & $0 \%$ & 4.23 \\
\hline October & 2,819 & 1,515 & 1,899 & 0 & 0 & 0 & $20 \%$ & $0 \%$ & 4.2 \\
\hline November & 1,892 & 964 & 1,416 & 36.27 & 15.65 & 26.72 & $32 \%$ & $41 \%$ & 3.48 \\
\hline December & 3,425 & 1,529 & 2,198 & 65.99 & 21.97 & 36.85 & $30 \%$ & $40 \%$ & 3.54 \\
\hline Total & $\mathbf{4 7 , 8 6 8}$ & $\mathbf{2 1 , 0 3 4}$ & $\mathbf{2 7 , 8 5 9}$ & $\mathbf{3 0 3}$ & $\mathbf{1 1 5}$ & $\mathbf{1 9 3}$ & $\mathbf{2 4 \%}$ & $\mathbf{4 1 \%}$ & $\mathbf{3 . 7 7}$ \\
\hline
\end{tabular}


Table 5.31: Summary of reduction of $\mathrm{CO}_{2}$ emission for Case III

\begin{tabular}{|c|c|c|c|c|}
\hline & \multicolumn{2}{|c|}{ Site energy } & \multicolumn{2}{c|}{ Source energy } \\
\hline Energy source & $\begin{array}{c}\text { Electricity } \\
(\mathbf{k W h} / \mathbf{y r})\end{array}$ & $\begin{array}{c}\text { Natural gas } \\
\text { (MMBtu/yr) }\end{array}$ & $\begin{array}{c}\text { Electricity } \\
(\mathbf{k W h} / \mathbf{y r})\end{array}$ & $\begin{array}{c}\text { Natural gas } \\
(\mathbf{M M B t u} / \mathbf{y r})\end{array}$ \\
\hline Base Case energy usage & 47,868 & 303 & 134,030 & 318 \\
\hline Case III energy usage & 27,859 & 193 & 78,005 & 203 \\
\hline Annual energy savings & 20,009 & 110 & 56,025 & 116 \\
\hline $\begin{array}{c}\mathbf{C O}_{2} \text { emission saved based } \\
\text { on energy source (lbs/yr) }\end{array}$ & 43,820 & 12,430 & 122,695 & 13,052 \\
\hline $\begin{array}{c}\text { Total CO2 emission saved } \\
\text { (lbs/yr) }\end{array}$ & \multicolumn{2}{|c|}{56,250} & \multicolumn{2}{c}{135,747} \\
\hline
\end{tabular}

Table 5.31 shows the summary of the reduction of $\mathrm{CO}_{2}$ emission for Case III. It can be seen that by upgrading the building to Case III from Base Case, the reduction of $\mathrm{CO}_{2}$ is $56,250 \mathrm{lbs} / \mathrm{yr}$ and $135,747 \mathrm{lbs} / \mathrm{yr}$ for site energy and source energy, respectively.

Figure 5.36 and Figure 5.37 below show the graphical illustration of the difference in energy consumption between the three cases.

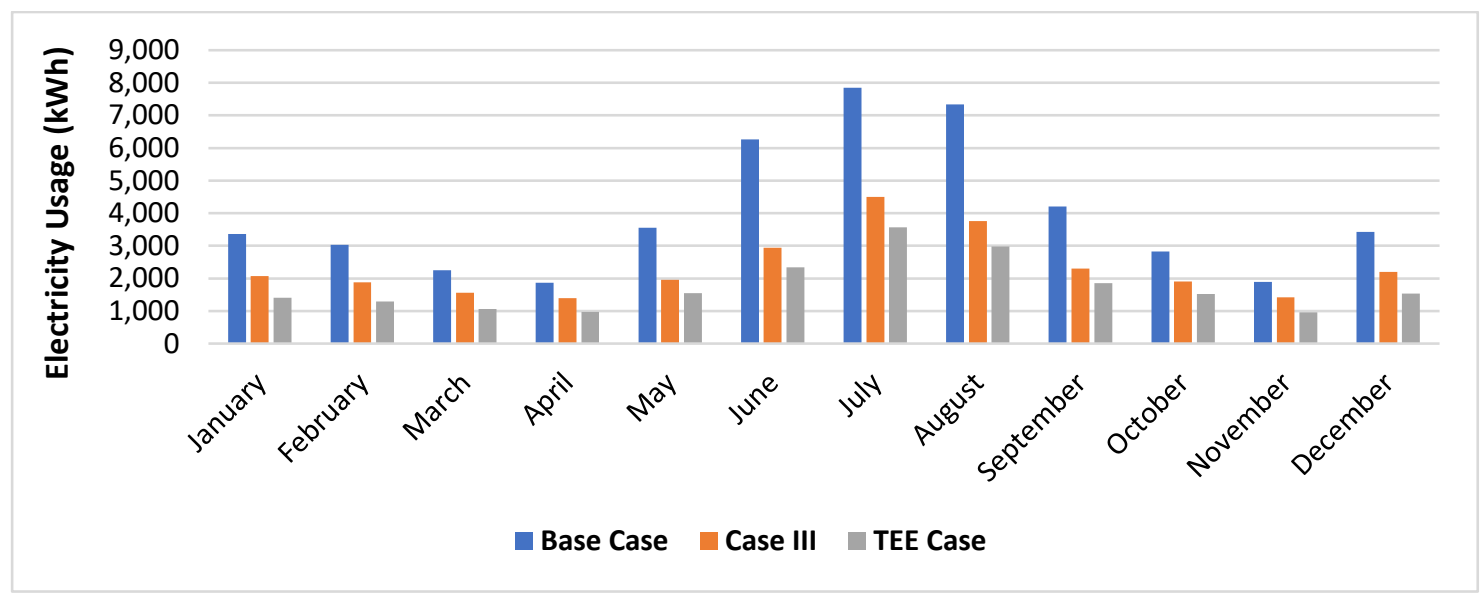

Figure 5.36: Comparison of electrical energy consumption between Base Case, Case III, and TEE Case

From Figure 5.38, it can be seen that the effectiveness of BEMS ranges from 3.5 to 4.23 for Case II. The overall efficacy of BEMS is determined to be 3.77, as shown in Table 5.30. According to the rating chart, as shown in Table 3.10, the effectiveness of BEMS is considered "Satisfactory". 


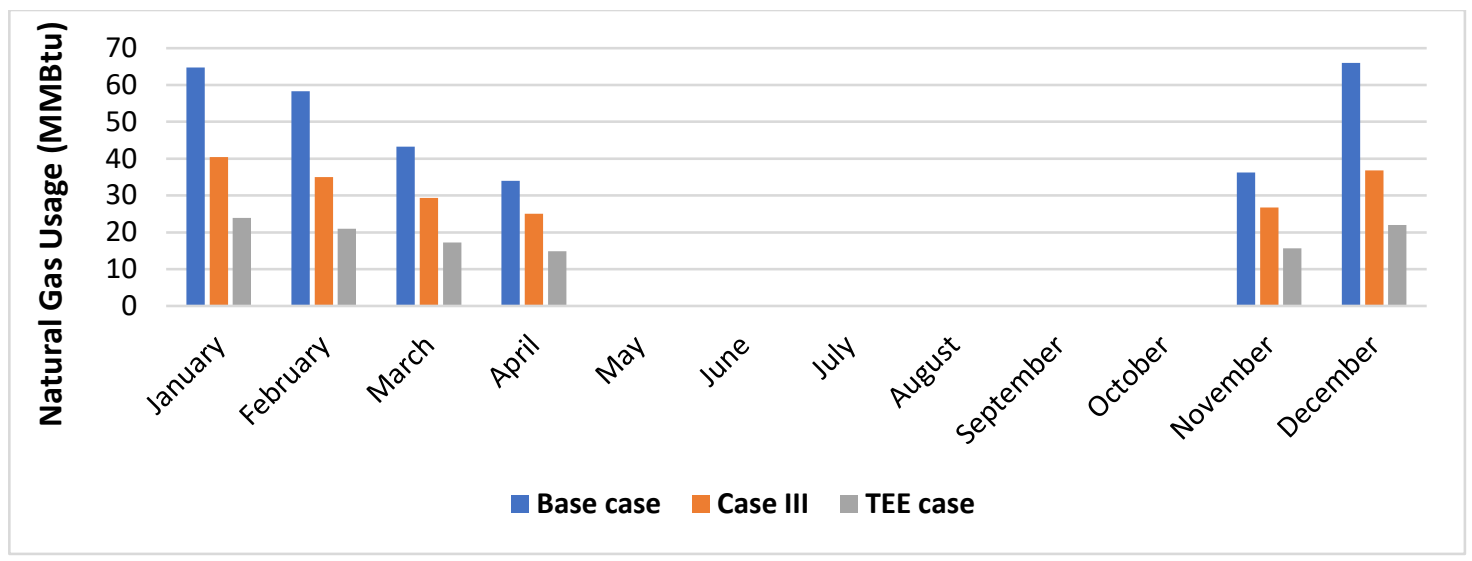

Figure 5.37: Comparison of natural gas consumption between Base Case, Case III, and TEE Case

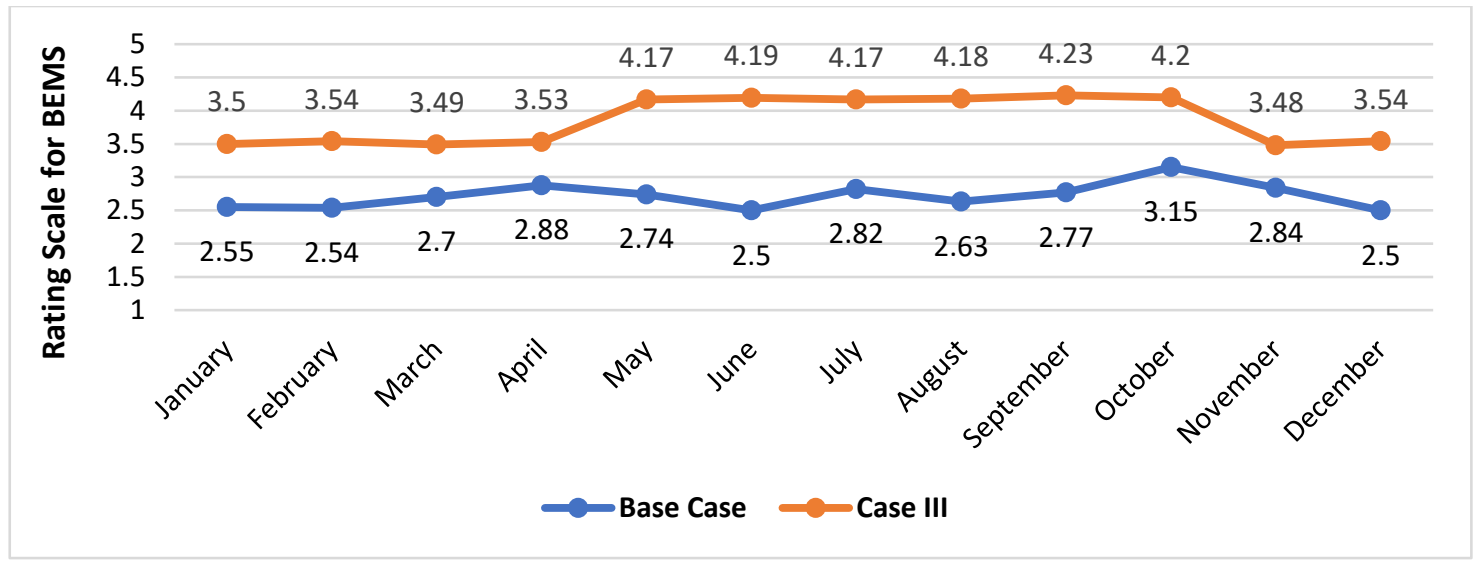

Figure 5.38: Change of effectiveness of BEMS from Base Case to Case III

The pattern of the effectiveness of BEMS obtained from Case III can be explained by using the logic from Case I and Case II effectiveness rating pattern. Due to the improvement of the building envelope, the rating increased during off-peak months. Due to DCV control, the effectiveness rating is higher during the summer months than winter months.

\subsubsection{Case IV - With the addition of SATR controls, only}

Case IV has SATR controls added that allows for varying the temperature of supply air to the spaces based on changing load condition of the room and building envelope condition. Here, the DCV system is not incorporated into the simulation model. However, the building has the zoning and temperature setback controls as in previous cases. The building envelope is considered poor for this simulation Case IV. The electrical energy consumption and natural gas use for this case obtained through simulation are shown in Table 5.32. 
Table 5.32: Energy consumption for space heating and cooling for Case IV

\begin{tabular}{|c|c|c|c|}
\hline Year & Month & $\begin{array}{c}\text { Energy Usage, } \\
\text { (kWh) }\end{array}$ & $\begin{array}{c}\text { Natural Gas Usage, } \\
\text { (MMBtu) }\end{array}$ \\
\hline \multirow{4}{*}{} & January & 2,332 & 44.61 \\
\cline { 2 - 4 } & February & 2,077 & 39.27 \\
\cline { 2 - 4 } & March & 1,628 & 30.73 \\
\cline { 2 - 4 } & April & 1,403 & 24.62 \\
\cline { 2 - 4 } & May & 3,341 & 0 \\
\cline { 2 - 4 } & June & 5,561 & 0 \\
\cline { 2 - 4 } & July & 6,972 & 0 \\
\cline { 2 - 4 } & August & 6,500 & 0 \\
\cline { 2 - 4 } & September & 3,861 & 0 \\
\cline { 2 - 4 } & October & 2,728 & 0 \\
\cline { 2 - 4 } & November & 1,406 & 26.45 \\
\cline { 2 - 4 } & December & 2,386 & 44.23 \\
\hline Total & - & $\mathbf{4 0 , 1 9 5}$ & $\mathbf{2 1 0}$ \\
\hline
\end{tabular}

Table 5.33: Comparison of energy consumption between Base Case, TEE case, and Case IV

\begin{tabular}{|c|c|c|c|c|c|c|c|c|c|}
\hline \multirow[t]{2}{*}{ Month } & \multicolumn{3}{|c|}{ Energy Usage, (kWh) } & \multicolumn{3}{|c|}{$\begin{array}{c}\text { Natural Gas Usage, } \\
\text { (MMBtu) }\end{array}$} & \multicolumn{2}{|c|}{$\begin{array}{c}\text { Percentage } \\
\text { Reduction of } \\
\text { TEE Case } \\
\text { from Case IV }\end{array}$} & \multirow{2}{*}{$\begin{array}{c}\text { Rating } \\
\text { of } \\
\text { BEMS } \\
(1-5)\end{array}$} \\
\hline & $\begin{array}{l}\text { Base } \\
\text { Case }\end{array}$ & $\begin{array}{l}\text { TEE } \\
\text { Case }\end{array}$ & $\begin{array}{l}\text { Case } \\
\text { IV }\end{array}$ & $\begin{array}{l}\text { Base } \\
\text { Case }\end{array}$ & $\begin{array}{l}\text { TEE } \\
\text { Case }\end{array}$ & \begin{tabular}{|c|} 
Case \\
IV
\end{tabular} & kWh & MMBtu & \\
\hline January & 3,360 & 1,410 & 2,332 & 64.71 & 23.88 & 44.61 & $40 \%$ & $46 \%$ & 3.25 \\
\hline February & 3,028 & 1,297 & 2,077 & 58.32 & 21 & 39.27 & $38 \%$ & $47 \%$ & 3.27 \\
\hline March & 2,254 & 1,063 & 1,628 & 43.29 & 17.19 & 30.73 & $35 \%$ & $44 \%$ & 3.38 \\
\hline April & 1,865 & 968 & 1,403 & 33.93 & 14.89 & 24.62 & $31 \%$ & $40 \%$ & 3.55 \\
\hline May & 3,559 & 1,546 & 3,341 & 0 & 0 & 0 & $54 \%$ & $0 \%$ & 2.86 \\
\hline June & 6,269 & 2,345 & 5,561 & 0 & 0 & 0 & $58 \%$ & $0 \%$ & 2.69 \\
\hline July & 7,850 & 3,562 & 6,972 & 0 & 0 & 0 & $49 \%$ & $0 \%$ & 3.05 \\
\hline August & 7,342 & 2,982 & 6,500 & 0 & 0 & 0 & $54 \%$ & $0 \%$ & 2.84 \\
\hline September & 4,205 & 1,853 & 3,861 & 0 & 0 & 0 & $52 \%$ & $0 \%$ & 2.92 \\
\hline October & 2,819 & 1,515 & 2,728 & 0 & 0 & 0 & $44 \%$ & $0 \%$ & 3.23 \\
\hline November & 1,892 & 964 & 1,406 & 36.27 & 15.65 & 26.45 & $31 \%$ & $41 \%$ & 3.51 \\
\hline December & 3,425 & 1,529 & 2,386 & 65.99 & 21.97 & 44.23 & $36 \%$ & $50 \%$ & 3.2 \\
\hline Total & 47,868 & 21,034 & 40,195 & 303 & 115 & 210 & $48 \%$ & $45 \%$ & 3.13 \\
\hline
\end{tabular}

From Table 5.33, based on the annual energy consumption between Base Case and Case IV, the electrical energy consumption decreased by approximately $16 \%$, and natural gas consumption decreased by $31 \%$. However, to reach the TEE case, the electrical energy 
should be further reduced by $48 \%$, and natural gas should be reduced by $45 \%$ from the Case IV energy consumption data.

Table 5.34: Summary of reduction of $\mathrm{CO}_{2}$ emission for Case IV

\begin{tabular}{|c|c|c|c|c|}
\hline & \multicolumn{2}{|c|}{ Site energy } & \multicolumn{2}{c|}{ Source energy } \\
\hline Energy source & $\begin{array}{c}\text { Electricity } \\
\text { (kWh/yr) }\end{array}$ & $\begin{array}{c}\text { Natural gas } \\
\text { (MMBtu/yr) }\end{array}$ & $\begin{array}{c}\text { Electricity } \\
\text { (kWh/yr) }\end{array}$ & $\begin{array}{c}\text { Natural gas } \\
\text { (MMBtu/yr) }\end{array}$ \\
\hline Base Case energy usage & 47,868 & 303 & 134,030 & 318 \\
\hline Case IV energy usage & 40,195 & 210 & 112,546 & 221 \\
\hline Annual energy savings & 7,673 & 93 & 21,484 & 98 \\
\hline $\begin{array}{c}\text { CO2 emission saved based } \\
\text { on energy source (lbs/yr) }\end{array}$ & 16,804 & 10,509 & 47,051 & 11,034 \\
\hline $\begin{array}{c}\text { Total CO2 emission saved } \\
\text { (lbs/yr) }\end{array}$ & \multicolumn{2}{|c|}{27,313} & \multicolumn{2}{c|}{58,085} \\
\hline
\end{tabular}

Table 5.34 shows the summary of the reduction of $\mathrm{CO}_{2}$ emission for Case IV. It can be seen that by upgrading the building to Case IV from Base Case, the reduction of $\mathrm{CO}_{2}$ is 27,313 lbs/yr and 58,085 lbs/yr for site energy and source energy, respectively.

Figure 5.39 and Figure 5.40 below show the graphical illustration of the difference in energy consumption between the three cases.

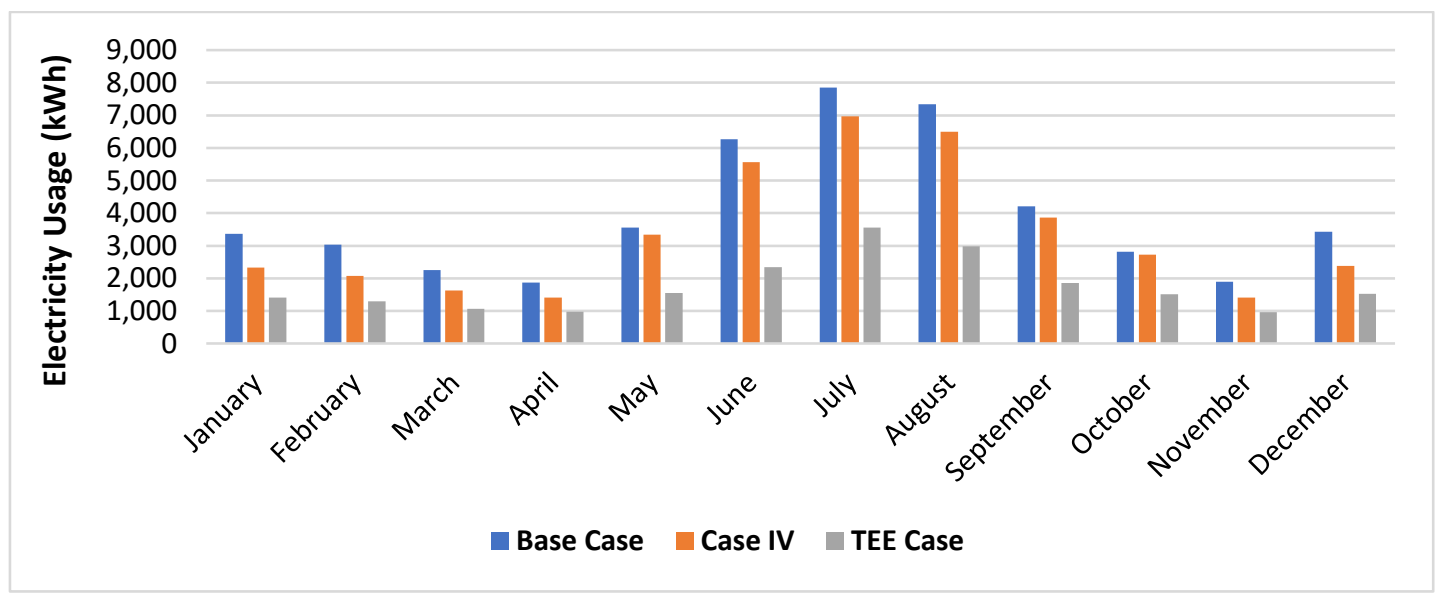

Figure 5.39: Comparison of electrical energy consumption between Base Case, Case IV, and TEE Case 


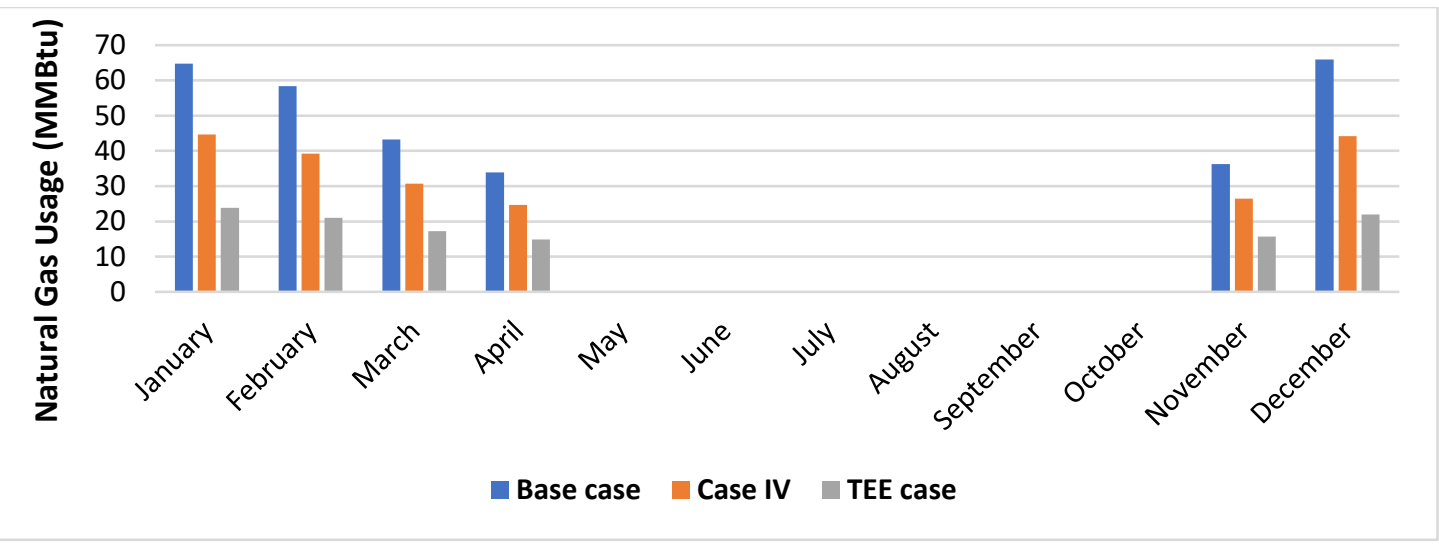

Figure 5.40: Comparison of natural gas consumption between Base Case, Case IV, and TEE Case

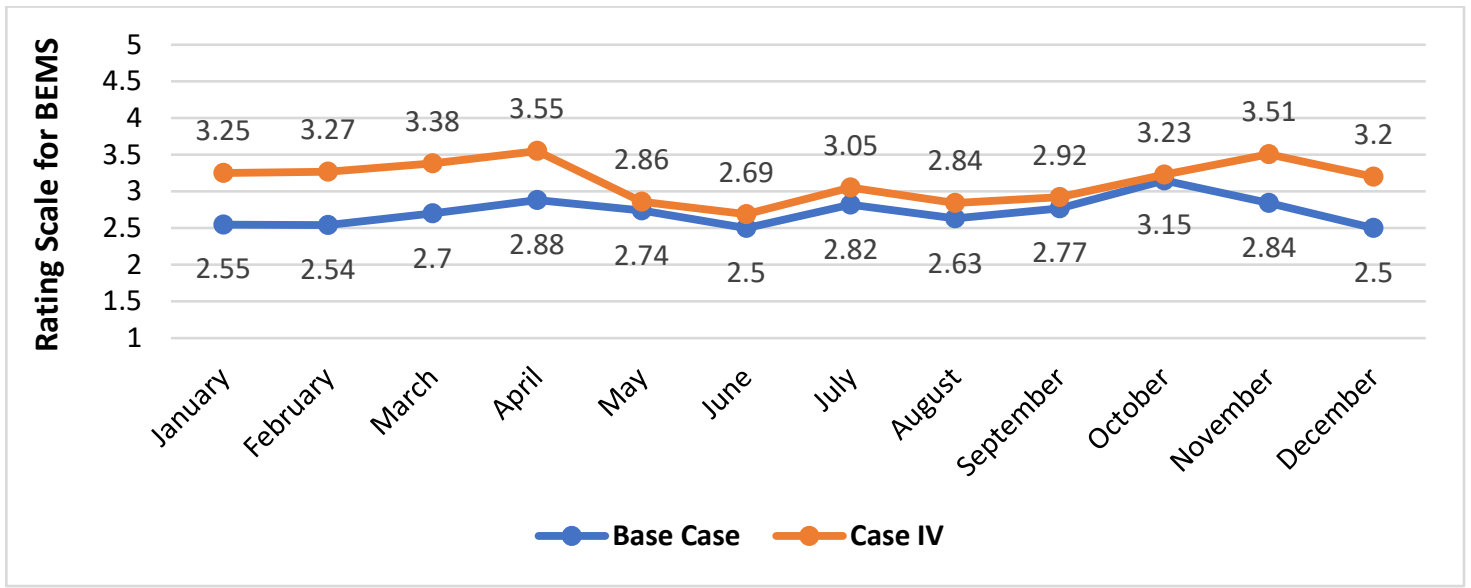

Figure 5.41: Change of effectiveness of BEMS from Base Case to Case IV

From Figure 5.41, it can be seen that the effectiveness of BEMS ranges from 2.69 to 3.55 for Case IV. The overall efficacy of BEMS is determined to be 3.13, as shown in Table 5.33. According to the rating chart, as shown in Table 3.10, the effectiveness of BEMS is considered "Not Satisfactory".

From the pattern of the effectiveness of BEMS in Case IV, as shown in Figure 5.39, it can be observed that the rating is increased during winter months than summer months from the Base Case with the addition of SATR control. The range of varying the SAT can explain this. The design SAT at the community center is $100^{\circ} \mathrm{F}$ during winter and $55^{\circ} \mathrm{F}$ during summer. The thermostat set temperature during winter is around $68-70{ }^{\circ} \mathrm{F}$ and $70-75^{\circ} \mathrm{F}$ during summer. Considering a $5^{\circ} \mathrm{F}$ difference in set temperature and SAT, the operating temperature range during summer is only $10-15^{\circ} \mathrm{F}$, but it extends to around $25^{\circ} \mathrm{F}$ during 
the winter months. Hence, there is more opportunity for energy saving during the winter months than during summer months by the addition of SATR control that is also seen in the effectiveness rating chart.

\subsubsection{Case V - With SATR and Building Envelope improvement}

Case V is similar to case IV, where SATR controls are added, but the building envelope is improved in this case. The electrical energy consumption and natural gas use for this case obtained through simulation are shown in Table 5.35.

Table 5.35: Energy consumption for space heating and cooling for Case V

\begin{tabular}{|c|c|c|c|}
\hline Year & Month & $\begin{array}{c}\text { Energy Usage, } \\
(\mathbf{k W h})\end{array}$ & $\begin{array}{c}\text { Natural Gas Usage, } \\
\text { (MMBtu) }\end{array}$ \\
\hline \multirow{4}{*}{} & January & 1,906 & 36.22 \\
\cline { 2 - 4 } & February & 1,691 & 31.65 \\
\cline { 2 - 4 } & March & 1,326 & 24.86 \\
\cline { 2 - 4 } & April & 1,152 & 19.91 \\
\cline { 2 - 4 } & May & 3,076 & 0 \\
\cline { 2 - 4 } & June & 5,139 & 0 \\
\cline { 2 - 4 } & July & 6,411 & 0 \\
\cline { 2 - 4 } & August & 5,991 & 0 \\
\cline { 2 - 4 } & September & 3,575 & 0 \\
\cline { 2 - 4 } & October & 2,514 & 0 \\
\cline { 2 - 4 } & November & 1,144 & 21.41 \\
\cline { 2 - 4 } & December & 1,954 & 35.72 \\
\hline Total & - & $\mathbf{3 5 , 8 7 9}$ & $\mathbf{1 7 0}$ \\
\hline
\end{tabular}

From Table 5.36, based on the annual energy consumption between Base Case and Case $\mathrm{V}$, the electrical energy consumption decreased by approximately $25 \%$, and natural gas consumption decreased by $44 \%$. However, to reach the TEE case, the electrical energy should be further reduced by $41 \%$, and natural gas should be reduced by $33 \%$ from the Case V energy consumption data. 
Table 5.36: Comparison of energy consumption between Base Case, TEE case, and Case V

\begin{tabular}{|c|c|c|c|c|c|c|c|c|c|}
\hline \multirow{3}{*}{ Month } & \multicolumn{4}{|c|}{$\begin{array}{c}\text { Energy Usage, (kWh) } \\
\end{array}$} & \multicolumn{3}{|c|}{$\begin{array}{c}\text { Natural Gas Usage, } \\
\text { (MMBtu) }\end{array}$} & $\begin{array}{c}\text { Percentage } \\
\text { Reduction of } \\
\text { TEE Case from } \\
\text { Case V }\end{array}$ & $\begin{array}{c}\text { Rating } \\
\text { of } \\
\text { BEMS } \\
(\mathbf{1}-\mathbf{5})\end{array}$ \\
\cline { 2 - 12 } & $\begin{array}{c}\text { Base } \\
\text { Case }\end{array}$ & $\begin{array}{c}\text { TEE } \\
\text { Case }\end{array}$ & $\begin{array}{c}\text { Case } \\
\text { V }\end{array}$ & $\begin{array}{c}\text { Base } \\
\text { Case }\end{array}$ & $\begin{array}{c}\text { TEE } \\
\text { Case }\end{array}$ & $\begin{array}{c}\text { Case } \\
\text { V }\end{array}$ & kWh & MMBtu & \\
\hline January & 3,360 & 1,410 & 1,906 & 64.71 & 23.88 & 36.22 & $26 \%$ & $34 \%$ & 3.76 \\
\hline February & 3,028 & 1,297 & 1,691 & 58.32 & 21 & 31.65 & $23 \%$ & $34 \%$ & 3.81 \\
\hline March & 2,254 & 1,063 & 1,326 & 43.29 & 17.19 & 24.86 & $20 \%$ & $31 \%$ & 3.93 \\
\hline April & 1,865 & 968 & 1,152 & 33.93 & 14.89 & 19.91 & $16 \%$ & $25 \%$ & 4.14 \\
\hline May & 3,559 & 1,546 & 3,076 & 0 & 0 & 0 & $50 \%$ & $0 \%$ & 3.02 \\
\hline June & 6,269 & 2,345 & 5,139 & 0 & 0 & 0 & $54 \%$ & $0 \%$ & 2.83 \\
\hline July & 7,850 & 3,562 & 6,411 & 0 & 0 & 0 & $44 \%$ & $0 \%$ & 3.23 \\
\hline August & 7,342 & 2,982 & 5,991 & 0 & 0 & 0 & $50 \%$ & $0 \%$ & 3 \\
\hline September & 4,205 & 1,853 & 3,575 & 0 & 0 & 0 & $48 \%$ & $0 \%$ & 3.08 \\
\hline October & 2,819 & 1,515 & 2,514 & 0 & 0 & 0 & $40 \%$ & $0 \%$ & 3.42 \\
\hline November & 1,892 & 964 & 1,144 & 36.27 & 15.65 & 21.41 & $16 \%$ & $27 \%$ & 4.09 \\
\hline December & 3,425 & 1,529 & 1,954 & 65.99 & 21.97 & 35.72 & $22 \%$ & $38 \%$ & 3.71 \\
\hline Total & $\mathbf{4 7 , 8 6 8}$ & $\mathbf{2 1 , 0 3 4}$ & $\mathbf{3 5 , 8 7 9}$ & $\mathbf{3 0 3}$ & $\mathbf{1 1 5}$ & $\mathbf{1 7 0}$ & $\mathbf{4 1 \%}$ & $\mathbf{3 3 \%}$ & $\mathbf{3 . 4 6}$ \\
\hline
\end{tabular}

Table 5.37: Summary of reduction of $\mathrm{CO}_{2}$ emission for Case $\mathrm{V}$

\begin{tabular}{|c|c|c|c|c|}
\hline & \multicolumn{2}{|c|}{ Site energy } & \multicolumn{2}{c|}{ Source energy } \\
\hline Energy source & $\begin{array}{c}\text { Electricity } \\
(\mathbf{k W h} / \mathbf{y r})\end{array}$ & $\begin{array}{c}\text { Natural gas } \\
(\mathbf{M M B t u} / \mathbf{y r})\end{array}$ & $\begin{array}{c}\text { Electricity } \\
(\mathbf{k W h} / \mathbf{y r})\end{array}$ & $\begin{array}{c}\text { Natural gas } \\
(\mathbf{M M B t u} / \mathbf{y r})\end{array}$ \\
\hline Base Case energy usage & 47,868 & 303 & 134,030 & 318 \\
\hline TEE Case energy usage & 35,879 & 170 & 100,461 & 179 \\
\hline Annual energy savings & 11,989 & 133 & 33,569 & 140 \\
\hline $\begin{array}{c}\mathbf{C O}_{2} \text { emission saved based } \\
\text { on energy source (lbs/yr) }\end{array}$ & 26,256 & 15,029 & 73,517 & 15,780 \\
\hline $\begin{array}{c}\text { Total CO } \mathbf{2} \text { emission saved } \\
\text { (lbs/yr) }\end{array}$ & \multicolumn{2}{|c|}{41,285} & \multicolumn{2}{c|}{89,297} \\
\hline
\end{tabular}

Table 5.37 shows the summary of reduction of $\mathrm{CO}_{2}$ emission for Case V. It can be seen that by upgrading the building to Case V from Base Case, the reduction of $\mathrm{CO}_{2}$ is 41,285 $\mathrm{lbs} / \mathrm{yr}$ and 89,297 lbs/yr for site energy and source energy, respectively.

Figure 5.42 and Figure 5.43 below show the graphical illustration of the difference in energy consumption between the three cases. 


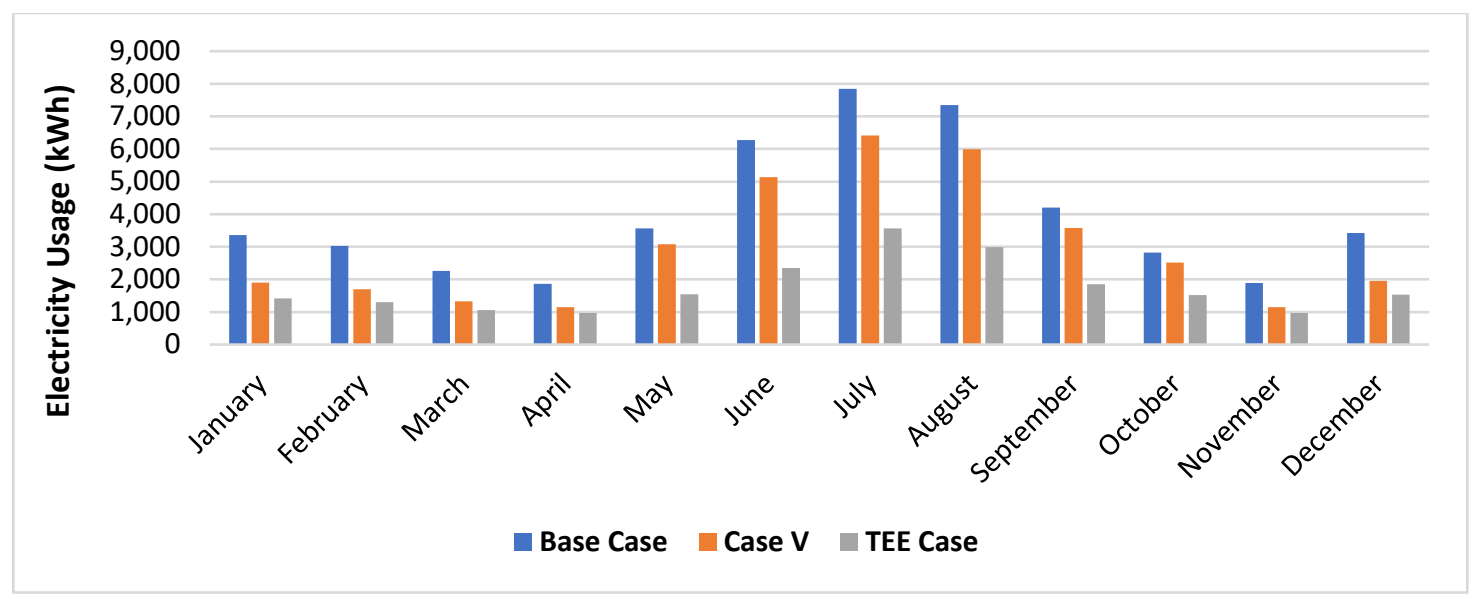

Figure 5.42: Comparison of electrical energy consumption between Base Case, Case $\mathrm{V}$, and TEE Case

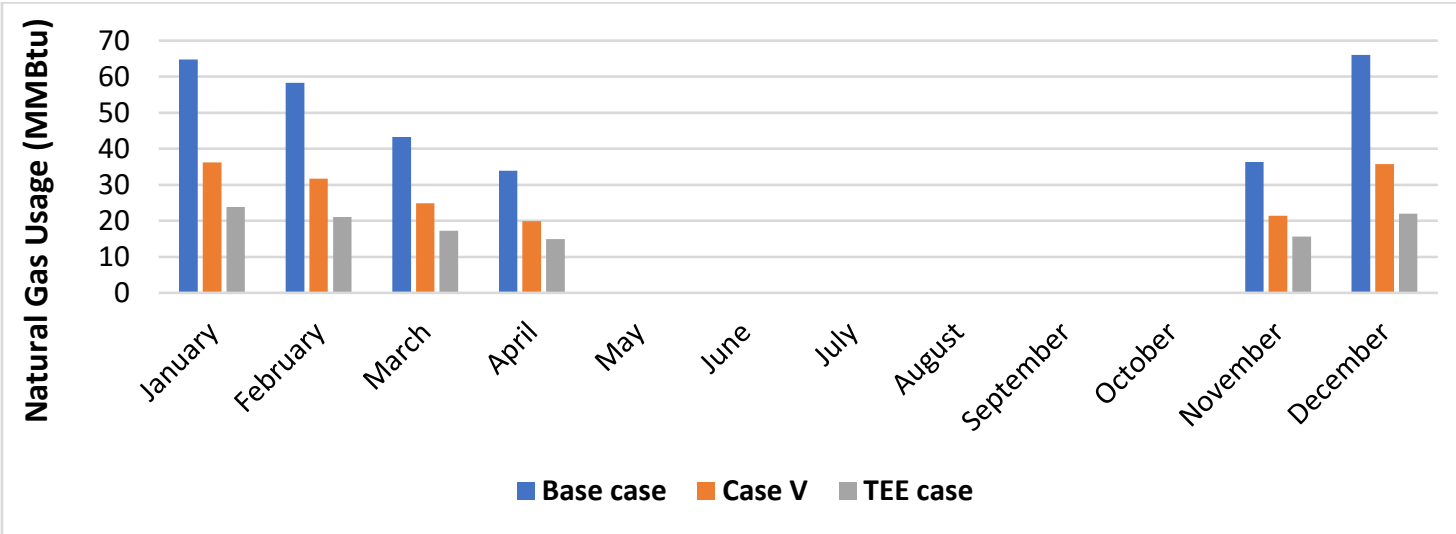

Figure 5.43: Comparison of natural gas consumption between Base Case, Case V, and TEE Case

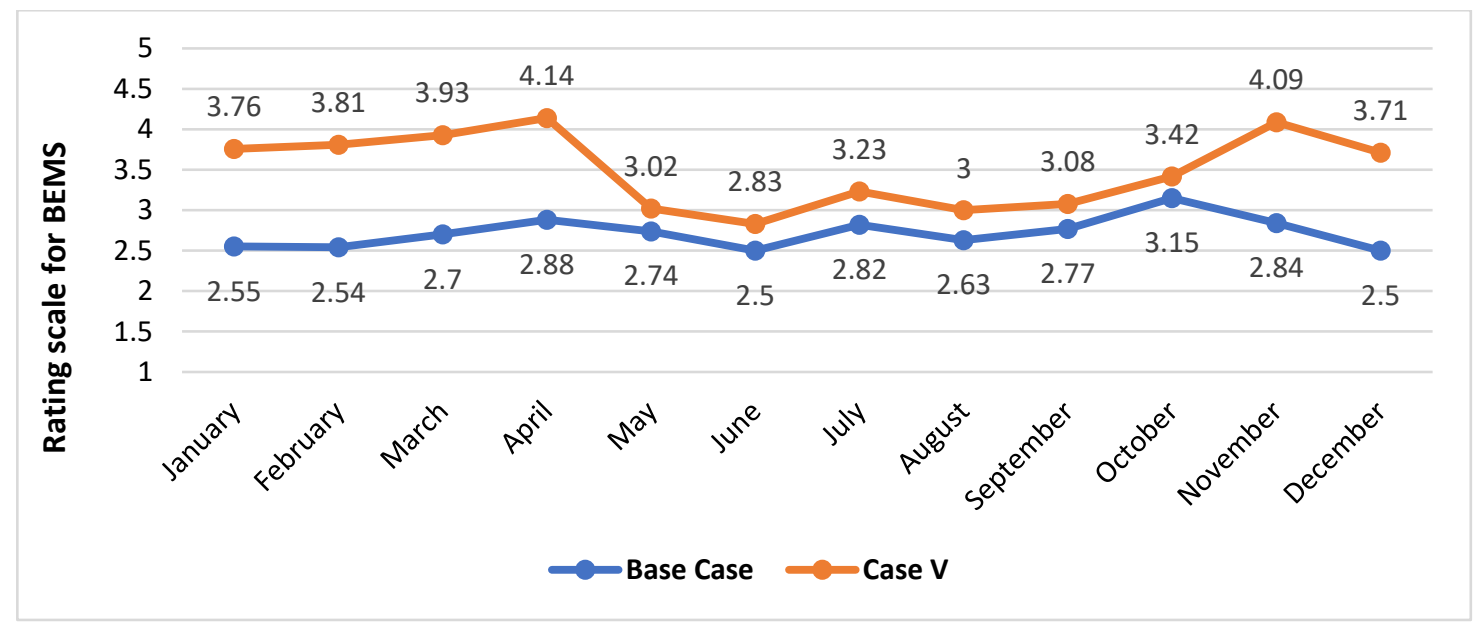

Figure 5.44: Change of effectiveness of BEMS from Base Case to Case V 
From Figure 5.44, it can be seen that the effectiveness of BEMS ranges from 2.83 to 4.14 for Case V. The overall efficacy of BEMS is determined to be 3.46, as shown in Table 5.36. According to the rating chart, as shown in Table 3.10, the effectiveness of BEMS is considered "Not Satisfactory". By analyzing the pattern of the efficacy of the BEMS chart, it can be seen that the improvement in the building envelope has further increased the rating of the BEMS.

\subsubsection{Case VI - With DCV and SATR controls but poor BE}

In this Case, the two BEMS controls, i.e., DCV and SATR controls, are added to the Base Case. However, the building envelope is still considered to be in poor condition. The summary of energy consumption obtained for space heating and cooling is shown in Table 5.38 .

Table 5.38: Energy consumption for space heating and cooling for Case VI

\begin{tabular}{|c|c|c|c|}
\hline Year & Month & $\begin{array}{c}\text { Energy Usage, } \\
\text { (kWh) }\end{array}$ & $\begin{array}{c}\text { Natural Gas Usage, } \\
\text { (MMBtu) }\end{array}$ \\
\hline \multirow{4}{*}{} & January & 1,788 & 33.01 \\
\cline { 2 - 4 } & February & 1,626 & 28.55 \\
\cline { 2 - 4 } & March & 1,349 & 23.79 \\
\cline { 2 - 4 } & April & 1,214 & 20.39 \\
\cline { 2 - 4 }$\underset{\widetilde{N}}{\text { M. }}$ & May & 1,710 & 0 \\
\cline { 2 - 4 } & June & 2,594 & 0 \\
\cline { 2 - 4 } & July & 3,963 & 0 \\
\cline { 2 - 4 } & August & 3,312 & 0 \\
\cline { 2 - 4 } & September & 2,034 & 0 \\
\cline { 2 - 4 } & October & 1,679 & 0 \\
\cline { 2 - 4 } & November & 1,227 & 21.71 \\
\hline Total & December & 1,915 & 29.88 \\
\hline
\end{tabular}

From Table 5.39, based on the annual energy consumption between Base Case and Case VI, the electrical energy consumption decreased by approximately $49 \%$, and natural gas consumption decreased by $48 \%$. However, to reach the TEE case, the electrical energy should be reduced by $14 \%$, and natural gas should be reduced by $27 \%$ from the Case VI energy consumption data. 
Table 5.39: Comparison of energy consumption between Base Case, TEE case, and Case VI

\begin{tabular}{|c|c|c|c|c|c|c|c|c|c|}
\hline \multirow{3}{*}{ Month } & \multicolumn{4}{|c|}{$\begin{array}{c}\text { Energy Usage, (kWh) } \\
\end{array}$} & \multicolumn{3}{|c|}{$\begin{array}{c}\text { Natural Gas Usage, } \\
\text { (MMBtu) }\end{array}$} & $\begin{array}{c}\text { Percentage } \\
\text { Reduction of } \\
\text { TEE case from } \\
\text { Case VI }\end{array}$ & $\begin{array}{c}\text { Rating } \\
\text { of } \\
\text { BEMS } \\
(\mathbf{1}-\mathbf{5})\end{array}$ \\
\cline { 2 - 12 } & $\begin{array}{c}\text { Base } \\
\text { Case }\end{array}$ & $\begin{array}{c}\text { TEE } \\
\text { Case }\end{array}$ & $\begin{array}{c}\text { Case } \\
\text { VI }\end{array}$ & $\begin{array}{c}\text { Base } \\
\text { Case }\end{array}$ & $\begin{array}{c}\text { TEE } \\
\text { Case }\end{array}$ & $\begin{array}{c}\text { Case } \\
\text { VI }\end{array}$ & kWh & MMBtu & \\
\hline January & 3,360 & 1,410 & 1,788 & 64.71 & 23.88 & 33.01 & $21 \%$ & $28 \%$ & 3.99 \\
\hline February & 3,028 & 1,297 & 1,626 & 58.32 & 21 & 28.55 & $20 \%$ & $26 \%$ & 4.04 \\
\hline March & 2,254 & 1,063 & 1,349 & 43.29 & 17.19 & 23.79 & $21 \%$ & $28 \%$ & 3.99 \\
\hline April & 1,865 & 968 & 1,214 & 33.93 & 14.89 & 20.39 & $20 \%$ & $27 \%$ & 4.03 \\
\hline May & 3,559 & 1,546 & 1,710 & 0 & 0 & 0 & $10 \%$ & $0 \%$ & 4.62 \\
\hline June & 6,269 & 2,345 & 2,594 & 0 & 0 & 0 & $10 \%$ & $0 \%$ & 4.62 \\
\hline July & 7,850 & 3,562 & 3,963 & 0 & 0 & 0 & $10 \%$ & $0 \%$ & 4.6 \\
\hline August & 7,342 & 2,982 & 3,312 & 0 & 0 & 0 & $10 \%$ & $0 \%$ & 4.61 \\
\hline September & 4,205 & 1,853 & 2,034 & 0 & 0 & 0 & $9 \%$ & $0 \%$ & 4.65 \\
\hline October & 2,819 & 1,515 & 1,679 & 0 & 0 & 0 & $10 \%$ & $0 \%$ & 4.61 \\
\hline November & 1,892 & 964 & 1,227 & 36.27 & 15.65 & 21.71 & $21 \%$ & $28 \%$ & 3.99 \\
\hline December & 3,425 & 1,529 & 1,915 & 65.99 & 21.97 & 29.88 & $20 \%$ & $26 \%$ & 4.05 \\
\hline Total & $\mathbf{4 7 , 8 6 8}$ & $\mathbf{2 1 , 0 3 4}$ & $\mathbf{2 4 , 4 1 1}$ & $\mathbf{3 0 3}$ & $\mathbf{1 1 5}$ & $\mathbf{1 5 7}$ & $\mathbf{1 4 \%}$ & $\mathbf{2 7 \%}$ & $\mathbf{4 . 2 5}$ \\
\hline
\end{tabular}

Table 5.40: Summary of reduction of $\mathrm{CO}_{2}$ emission for Case VI

\begin{tabular}{|c|c|c|c|c|}
\hline & \multicolumn{2}{|c|}{ Site energy } & \multicolumn{2}{c|}{ Source energy } \\
\hline Energy source & $\begin{array}{c}\text { Electricity } \\
(\mathbf{k W h} / \mathbf{y r})\end{array}$ & $\begin{array}{c}\text { Natural gas } \\
(\mathbf{M M B t u} / \mathbf{y r})\end{array}$ & $\begin{array}{c}\text { Electricity } \\
(\mathbf{k W h} / \mathbf{y r})\end{array}$ & $\begin{array}{c}\text { Natural gas } \\
(\mathbf{M M B t u} / \mathbf{y r})\end{array}$ \\
\hline Base Case energy usage & 47,868 & 303 & 134,030 & 318 \\
\hline Case VI energy usage & 24,411 & 157 & 68,351 & 165 \\
\hline Annual energy savings & 23,457 & 146 & 65,680 & 153 \\
\hline $\begin{array}{c}\mathbf{C O}_{2} \text { emission saved based } \\
\text { on energy source (lbs/yr) }\end{array}$ & 51,371 & 16,498 & 143,838 & 17,323 \\
\hline $\begin{array}{c}\text { Total CO2 } \mathbf{2} \text { emission saved } \\
\text { (lbs/yr) }\end{array}$ & \multicolumn{2}{|c|}{67,869} & \multicolumn{2}{c|}{161,161} \\
\hline
\end{tabular}

Table 5.40 shows the summary of the reduction of $\mathrm{CO}_{2}$ emission for Case VI. It can be seen that by upgrading the building to Case VI from Base Case, the reduction of $\mathrm{CO}_{2}$ is $67,869 \mathrm{lbs} / \mathrm{yr}$ and 161,161 lbs/yr for site energy and source energy, respectively.

Figure 5.45 and Figure 5.46 below show the graphical illustration of the difference in energy consumption between the three cases. 


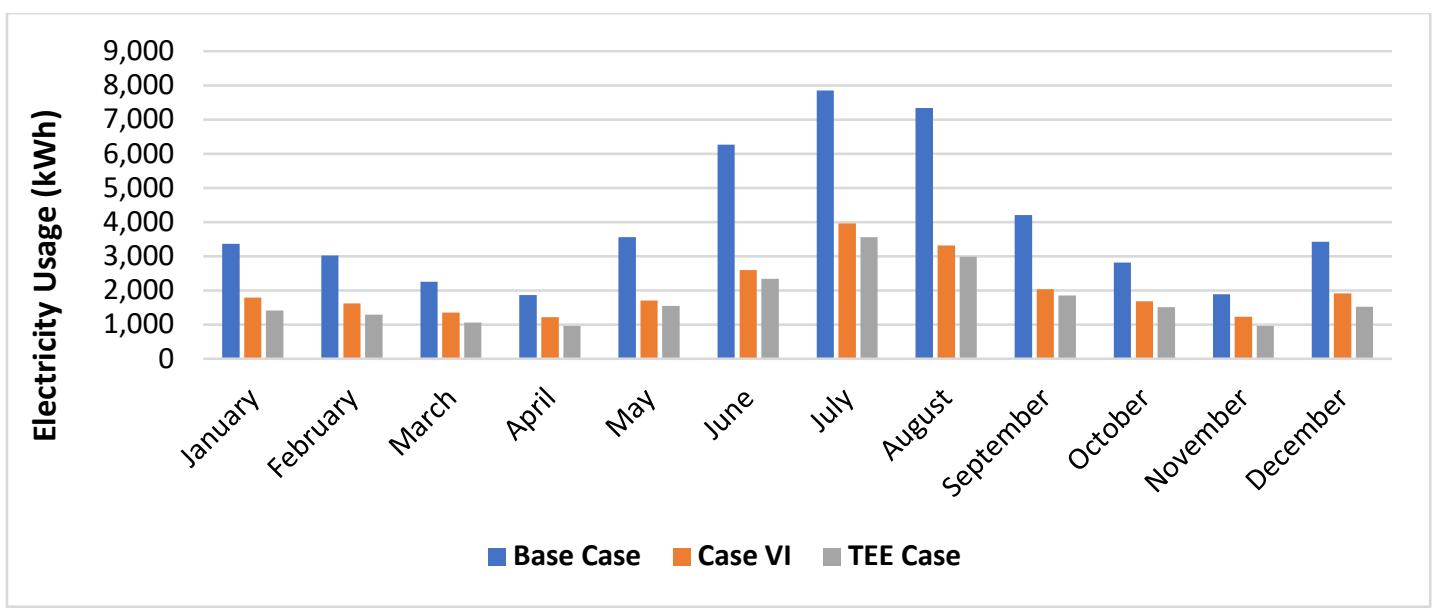

Figure 5.45: Comparison of electrical energy consumption between Base Case, Case VI, and TEE Case

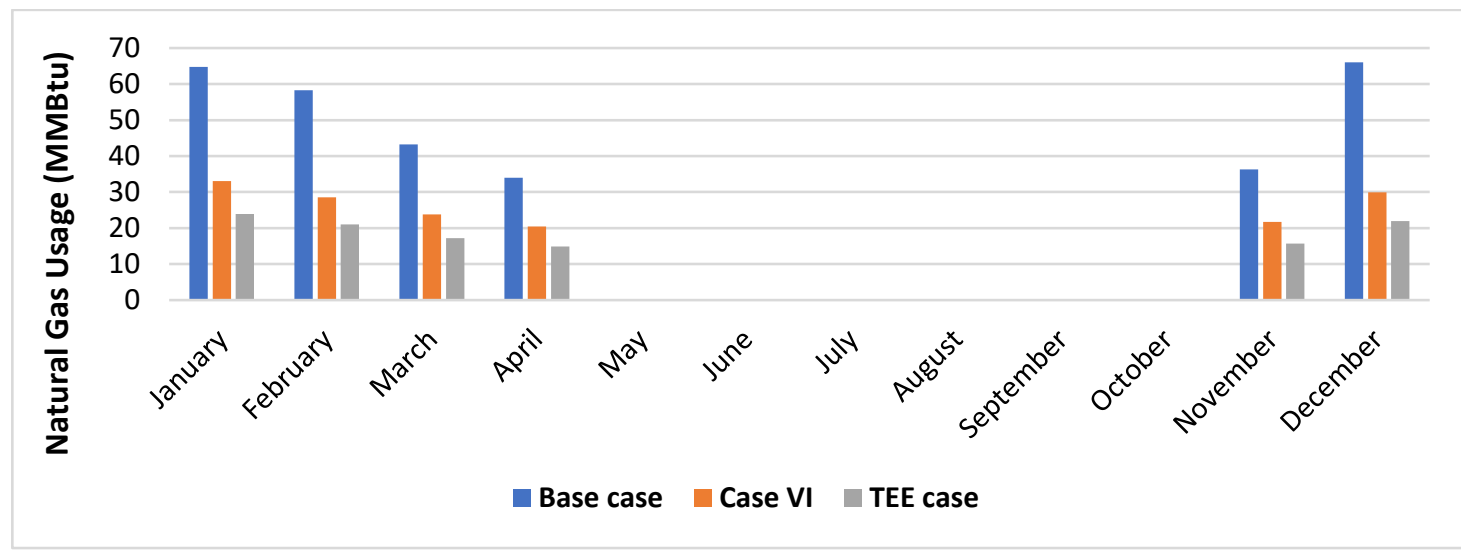

Figure 5.46: Comparison of natural gas consumption between Base Case, Case VI, and TEE Case

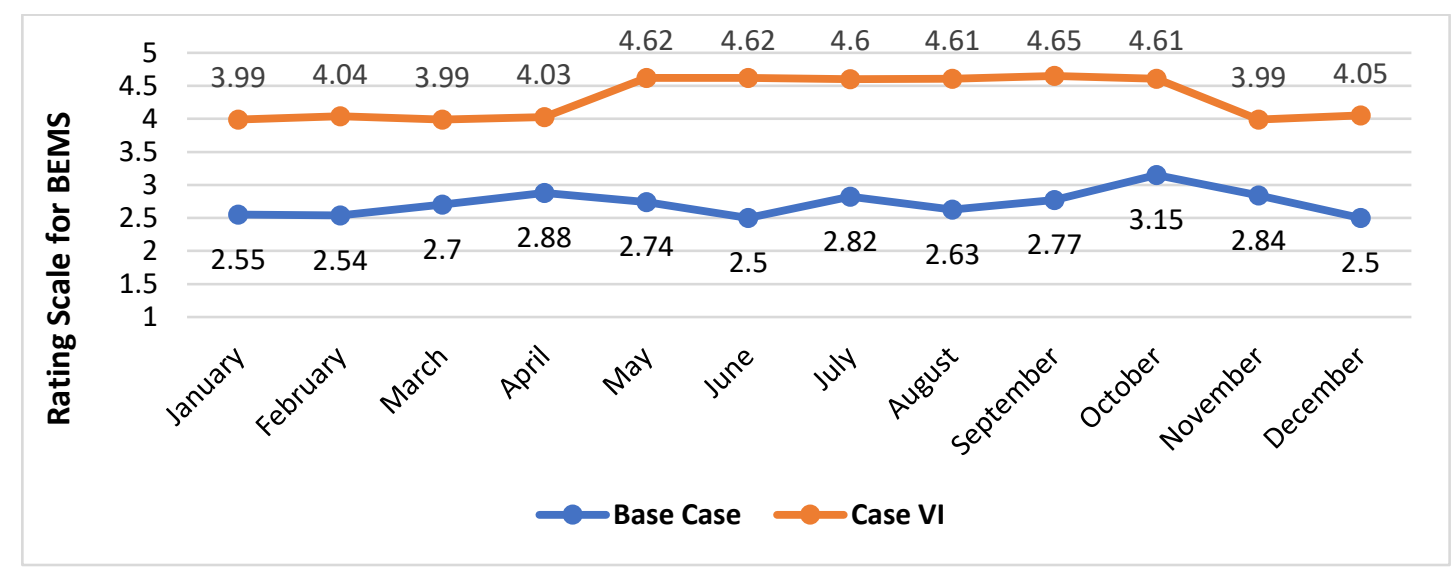

Figure 5.47: Change of effectiveness of BEMS from Base Case to Case VI

From Figure 5.47, it can be seen that the effectiveness of BEMS ranges from 3.99 to 4.65 for Case VI. The overall efficacy of BEMS is determined to be 4.25, as shown in Table 
5.39. According to the rating chart, as shown in Table 3.10, the effectiveness of BEMS is considered "Good".

With both DCV and SATR control, the rating has improved considerably during both the summer and winter months. The average BEMS ratings were 4.62 and 4.02 during summer months (May - October) and winter months (November - April). The earlier chart shows that the DCV control increased the rating more during the summer months while the SATR control increased the effectiveness rating more during the winter months. Still, by adding both controls, the effectiveness rating seems to be raised for both seasons.

\subsection{Interaction effects between BEMS controls}

The interaction effects between various BEMS controls are studied in this section. Figure 5.48 represents the interaction effect between building envelope improvement and the DCV control system. The rating increment during building envelope improvement and DCV control is the same as the addition of increment from individual improvements except for March, April, October, and November. Figure 5.49 represents the interaction effect between building envelope improvement and the SATR control system. The rating increment during building envelope improvement and SATR control is generally the same or lower than increment from individual improvement. Figure 5.50 represents the interaction effect between DCV control and the SATR control system. The rating increment during DCV control and SATR control is generally the same or higher than the increment from individual improvement. Figure 5.51 represents the interaction effect between building envelope improvement, DCV control, and the SATR control system. The rating increment during this case is higher than the addition of increment from individual improvements.

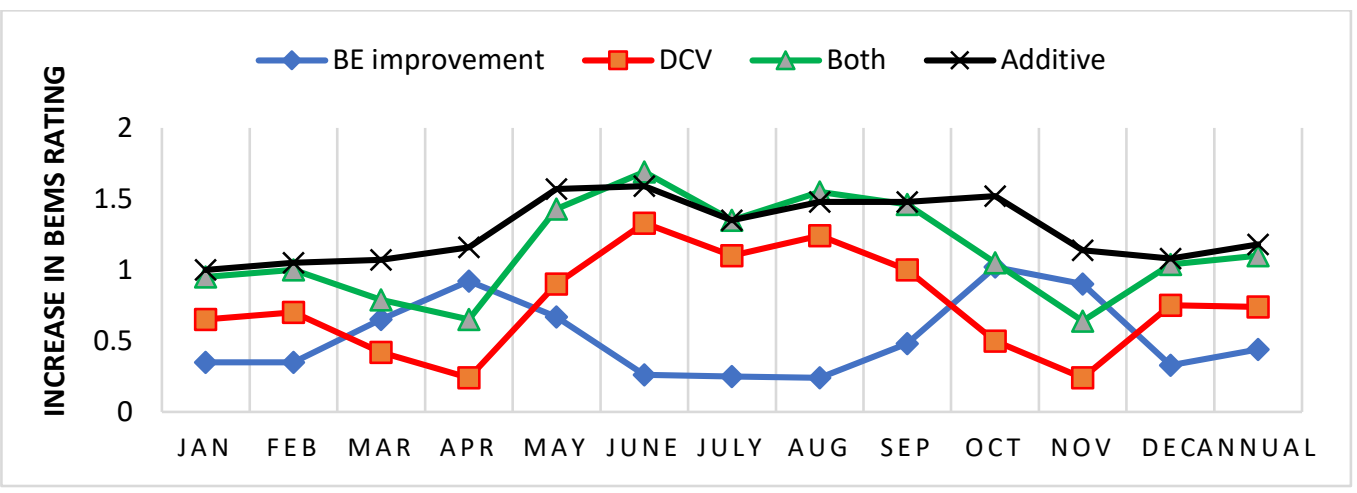


Figure 5.48: Interaction effect between BE improvement and DCV control

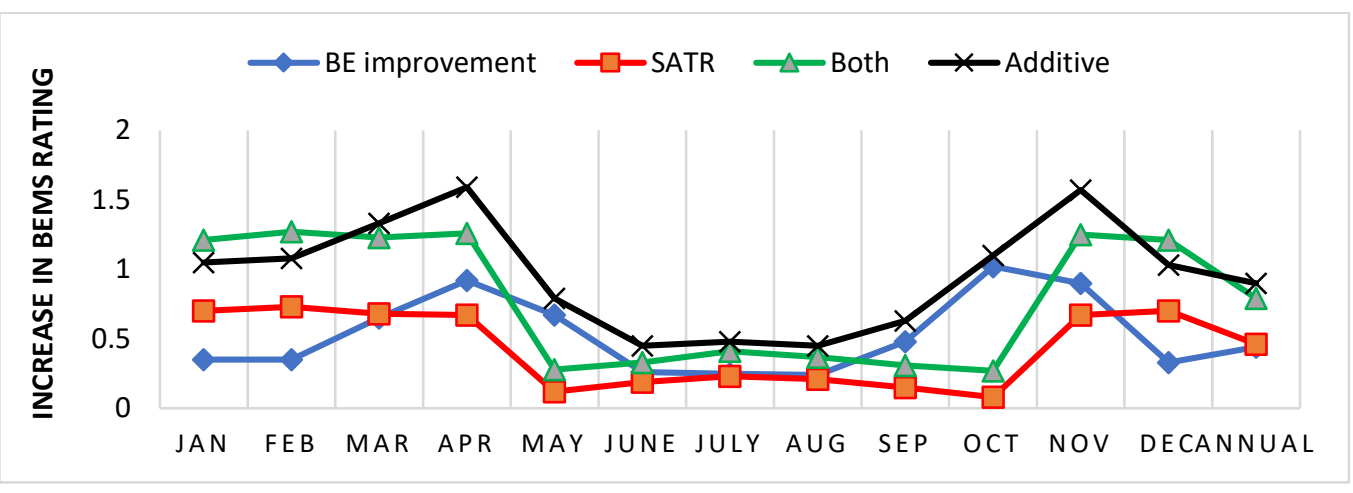

Figure 5.49: Interaction effect between BE improvement and SATR control

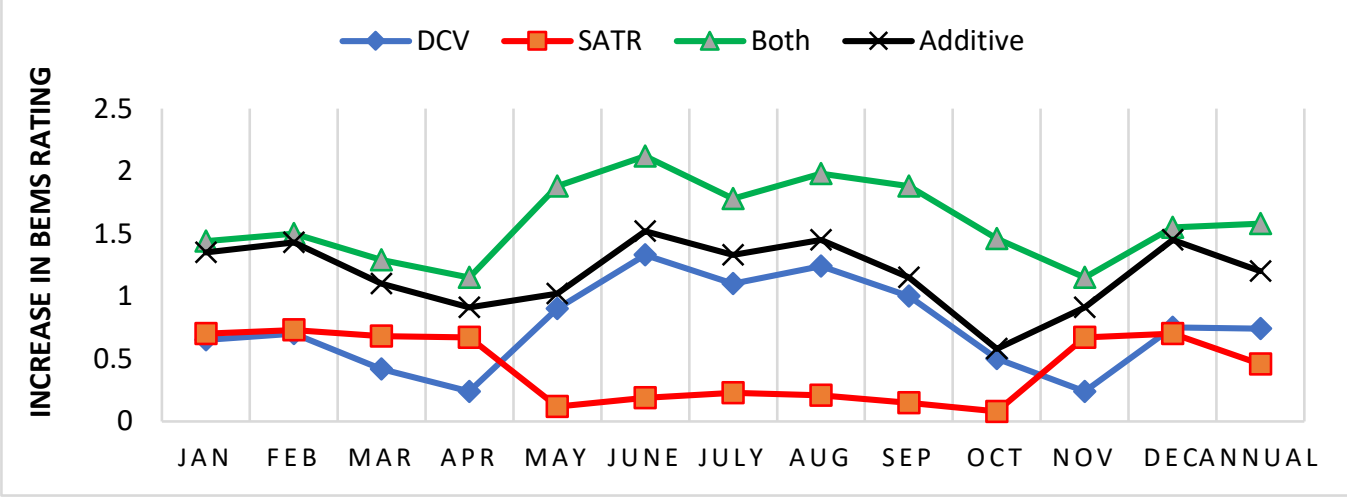

Figure 5.50: Interaction effect between DCV control and SATR control

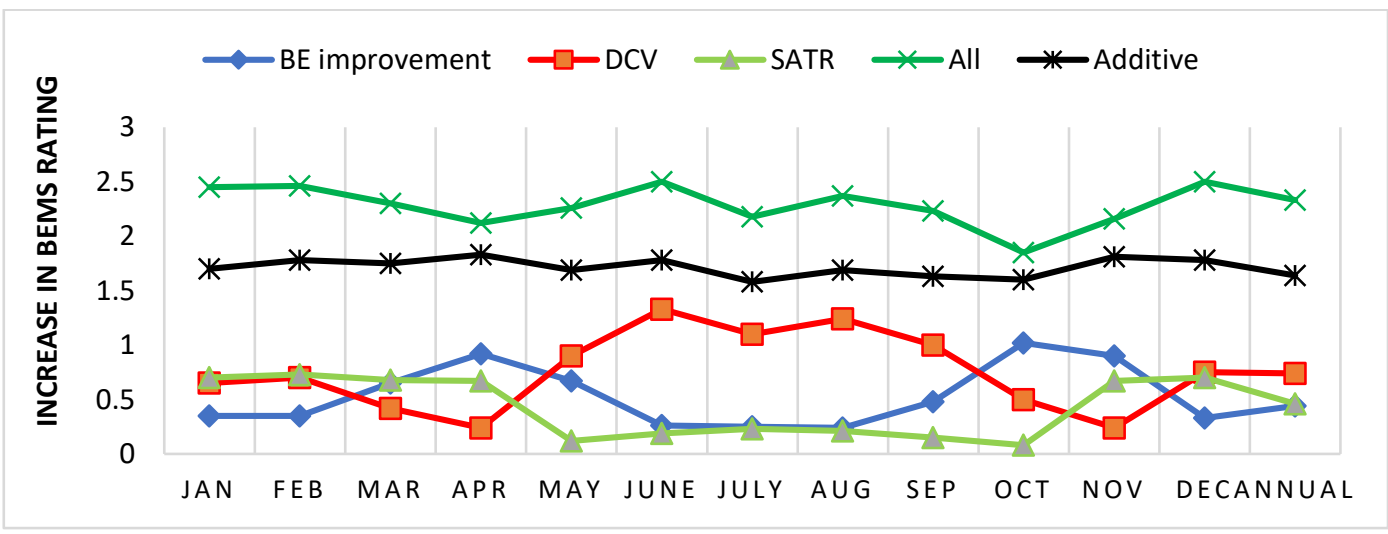

Figure 5.51: Interaction effect between BE improvement, DCV control, and SATR control

\subsection{Result Analysis}

The annual electrical and natural gas energy consumption obtained from Base Case, Case

I, Case II, Case III, Case IV, Case V, Case VI, and TEE case are illustrated in Figure 5.51 
and Figure 5.52, respectively. It can be seen that the total electrical energy consumption $(\mathrm{kWh})$ is highest during the Base Case where the building only has zoning control and temperature setback controls. Similarly, the building has the lowest energy consumption during the TEE case, where all BEMS controls are included along with improvement in the building envelope.

From comparing the Base Case with Case I, where only the building envelope is improved, the electrical energy reduction is $19 \%$, and natural gas energy reduction is $23 \%$. Also, the effectiveness of the BEMS increased from 2.67 to 3.11, as shown in Figure 5.50. Further, when only DCV control is added to the Base Case, it is found that the electrical energy decreased by $33 \%$ and the natural gas consumption reduced by $26 \%$. The effectiveness of BEMS also increased to 3.41. Here, we see that the energy savings is higher by adding DCV controls than improving the building envelope, but it should be kept in mind the cost associated with these two cases. Generally, improving the building envelope, such as replacing the single pane windows with double pane windows, sealing the infiltration of air, and improving insulation, is less expensive than adding the DCV system to the building. Hence, even though the saving is higher with DCV controls, the feasibility and capital involved with implementing the two systems should be considered.

Furthermore, with DCV controls and improving the building envelope, the electrical energy consumption was reduced by $41 \%$, and natural gas consumption was reduced by $36 \%$. Without the improvement in the building envelope, the DCV system does not work effectively. If air infiltration is significant in a building, the control of ventilation rates would not be precise by the DCV system. The heating and cooling units frequently run to maintain the thermal comfort condition when the building envelope is poor. Hence, with improvement in building envelope, the DCV controls work accurately to keep the indoor air quality and also helps in the reduction of energy consumption. The effectiveness of BEMS also increased to 3.77 from 2.67 for this case.

Moreover, with the addition of SATR controls to the Base Case, the electrical energy reduction was $16 \%$, and the natural gas reduction was $30 \%$. Also, the effectiveness of BEMS increased to 3.13 from the Base Case. With improvement in the building envelope and the SATR controls, electrical energy and natural gas reduction were $25 \%$ and $44 \%$, 
respectively. The effectiveness of the BEMS also increased to 3.46 for this case. Due to improvement in building envelope, the SAT can be varied more aggressively, and hence more energy savings are realized. However, it is essential to consult with the heating or cooling unit manufacturer before implementing the SATR controls since there are limits for varying the working fluid temperature for the unit to work efficiently.

Further, with DCV and SATR control to the Base Case, the electrical and natural gas consumption reduced by $49 \%$ and $48 \%$, respectively. The effectiveness of BEMS also increased to 4.25 for this case. However, with the improvement of the building envelope and these controls (i.e., TEE case), the electrical and natural gas consumption decreased by $56 \%$ and $62 \%$, respectively, compared to the Base Case. It is realized that without the improvement in the building envelope, the addition of BEMS controls does not work effectively to reduce energy consumption.

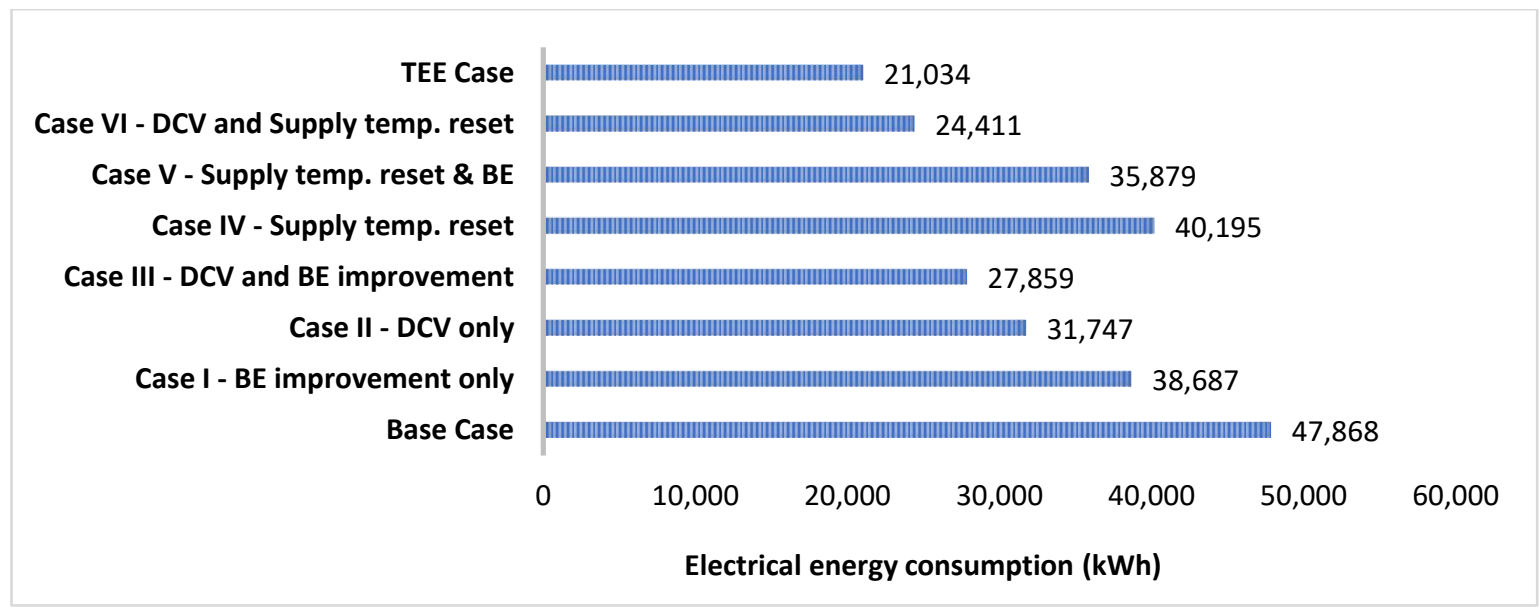

Figure 5.52: Annual electrical energy consumption (kWh) for various cases

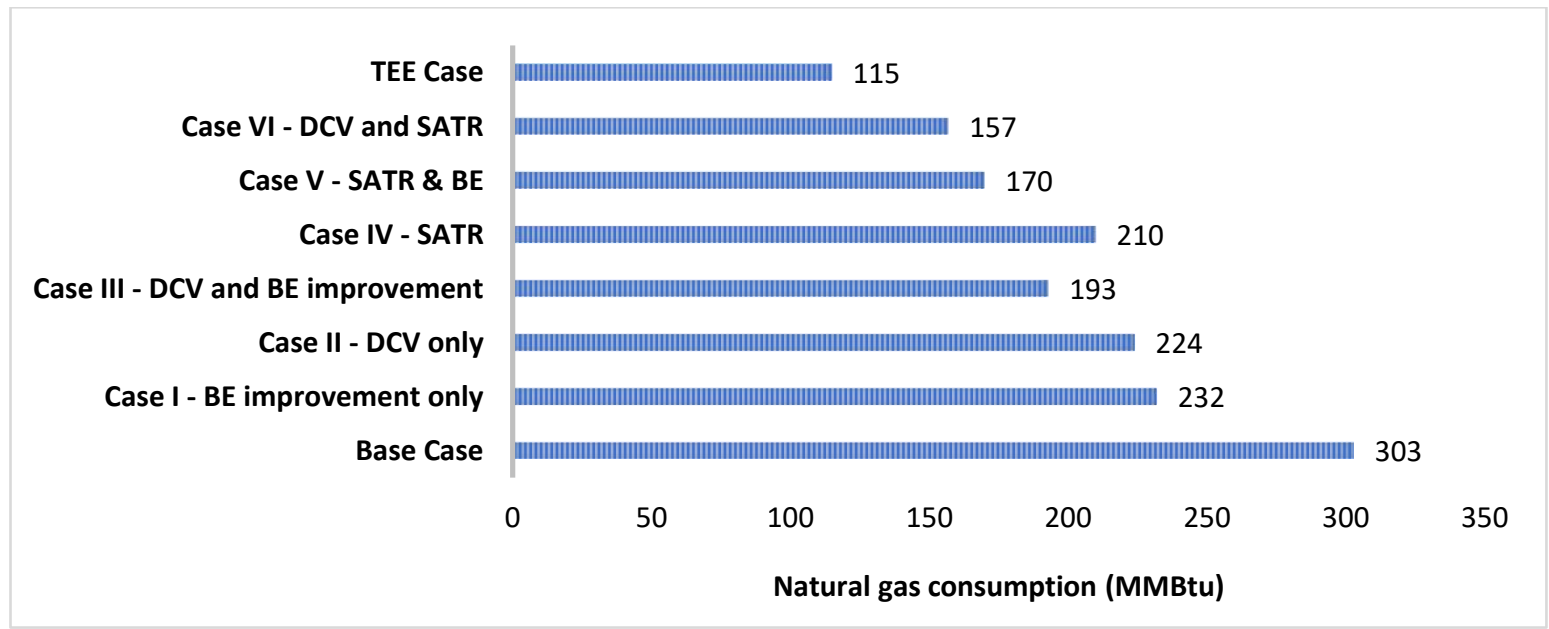


Figure 5.53: Annual natural gas consumption (MMBtu) for various cases

Figure 5.53 represents the annual cost savings for several cases. The highest total cost savings were achieved during the TEE case and the lowest during Case I. Moreover, the natural gas cost savings is higher than electrical cost savings during Case IV and Case V when SATR control is added to the Base Case.

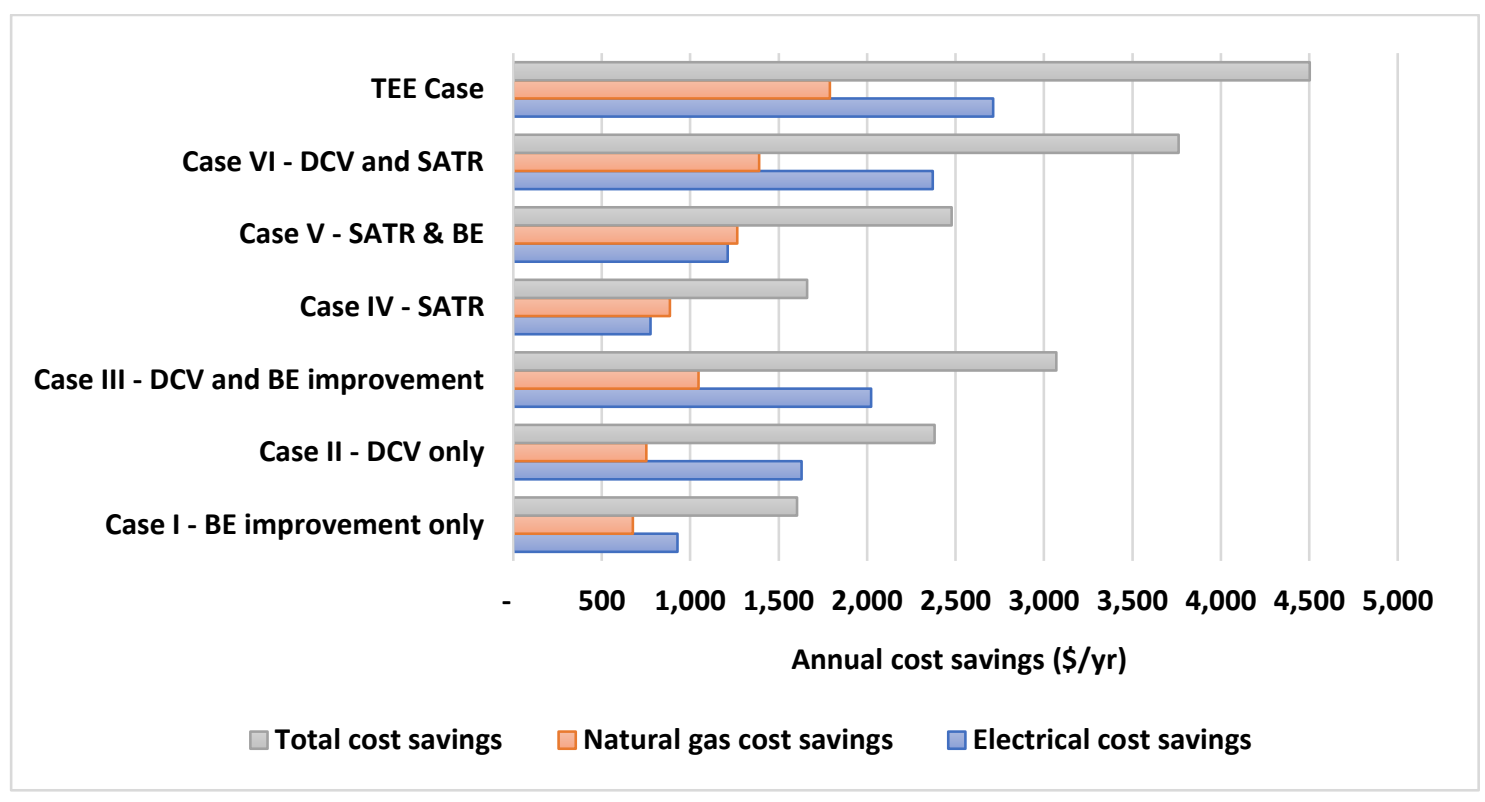

Figure 5.54: Annual cost savings (\$/yr) for various cases

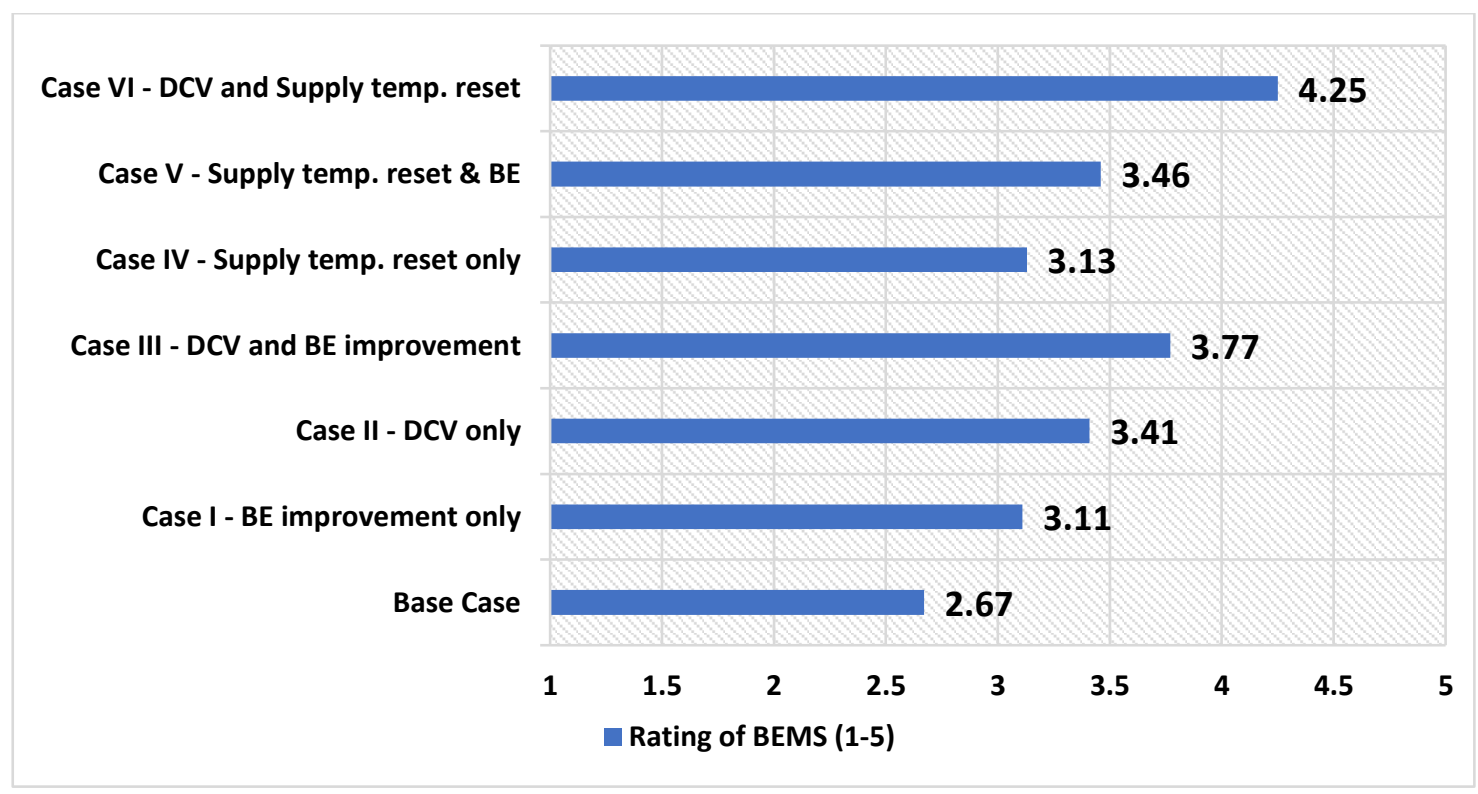

Figure 5.55: Rating of BEMS for various cases 
Here, in above Figure 5.54, it can see that the effectiveness of BEMS is relatively much higher in Case VI with addition DCV and SATR control. However, the cost associated with installing those controls and retrofitting the HVAC system of the building is not studied in this study. Hence, it is essential to consider the cost associated with the addition of any BEMS control and required retrofitting on the existing system and compare the potential effectiveness of BEMS that could be achieved from various cases.

\subsection{Key Findings}

The key findings from the analysis of the community center based on the simulation results are discussed below:

- Determination of an estimate of total energy consumption of a building required for space cooling and heating under different operating parameters and varying BEMS controls.

- Determination of the effectiveness of BEMS under different operating parameters and varying BEMS controls.

- Determination of ventilation requirements at different times during the day to maintain the IAQ according to ASHRAE 62.1-2019 standard.

- Determination of the impact of building envelope improvement on the effectiveness of BEMS. The effect is relatively higher during the off-peak season than peak seasons.

- Determination of the impact of the DCV system on the effectiveness of BEMS. For buildings using natural gas as a source of heating during winter and electrical energy as a source of cooling during summer, the impact on the effectiveness of BEMS by addition of DCV control was obtained to be much higher during summer than winter months.

- Determination of the impact of SATR control on the effectiveness of BEMS. As opposed to the DCV control system, the effect of the addition of SATR control on the efficacy of BEMS was seen to be relatively higher during the winter months than summer months. 
- Determination of the impact of BEMS controls and improvement on building envelope on the effectiveness of BEMS. It was observed that with the improvement of the building envelope, the energy reduction by the BEMS controls was higher than with poor building envelope conditions.

- Determination of reduction of GHG emissions by the addition of individual BEMS controls and building envelope improvement.

\subsection{Discussion on Limitations of Factors Used in Simulation Model}

To analyze the building BEMS, various factors are considered: occupancy level, type of rooms, number of rooms, dimensions of rooms, thermostat settings, weather, building envelope, supply air temperature, and sensible heat ratio.

The user can input the expected occupancy level at different periods on the Occupancy schedule chart based on the occupancy patterns of individual zones. Currently, there are sixteen different types of rooms and their corresponding people outdoor air rate, area outdoor air rate, occupant density, and air change per hour according to ASHARE standard 62.1-2019. Users can select the type of room among the sixteen different rooms available in the model. However, the building with varying rooms than present in the model cannot be analyzed.

There is no limitation in the number of rooms that can be input by the model. The model can handle the repetition of type of room. Hence, the user can select any number of rooms in the model from the sixteen types of rooms. The dimensions of each room can also be input into the model in terms of the area and height of the individual room. The thermostat setting (set temperature and setback temperature) can also be input in the model for winter and summer. Here, the thermostat setting may not be constant for any room throughout the year, but the model cannot handle the variation in the thermostat setting. Once the user inputs the thermostat settings in the model, the same values are used to calculate energy consumption for the complete year.

The random number range and weather factor used in the model are based on the energy consumption pattern of the community center building. The weather factor is determined based on the monthly energy consumption pattern. Users can modify the random number 
range and the weather factor if the calculated energy consumption pattern does not represent the actual building energy consumption pattern.

The building envelope factor is set for two different levels: level 1 and level 2. Level 1 represents the poor building envelope level, while level 2 represents the good building envelope level. The values of level 1 and level 2 building envelopes are different for different types of BEMS controls. These values were adjusted such the energy savings values obtained by the addition of the controls do not exceed the expected energy savings from the works of literature. Users can modify these values in the "Reference" worksheet if the energy savings obtained by adding the BEMS controls for their building represent considerably more or less than expected for the same type of buildings.

Supply air temperature is calculated based on varying levels of occupancy and building envelope level. The upper limit and lower limit of supply air temperature for winter and summer months, respectively, are defined by the user in the model. Based on the occupancy level and building envelope level, a specific load factor is assigned. The load factor is used in the calculation of the supply air temperature to each of the zones. The user can change the load factor values of the supply air temperature if desired.

Sensible heat ratio is also determined based on the building envelope level and varying occupancy level. Users can also modify the values of the sensible heat ratio if desired for each level of building envelope and occupancy level.

Therefore, the model was used to determine the effectiveness of BEMS of the community center building in this research study. Mainly, the weather factor may limit the analysis of other buildings by this model because the random number range and weather factor in the weather factor table were set. The energy consumption pattern of the community center building is matched according to the actual building energy consumption pattern. However, the user can change the random number range and weather factor values if the energy consumption pattern does not represent their actual building energy consumption pattern. The other factors used in the model do not limit the analysis of the building by the model. Based on the above discussion, it can be considered that if the user accounts for the modification of the required factors in the model, approximate energy consumption for space heating and cooling can be achieved by this model. However, due to the verification 
of only one community center building in this research, all the findings from this research cannot be considered general findings for any building. Further work regarding verification of the simulation tool is required for different other types of buildings as well.

\subsection{Suggestive Actions}

Considering the results obtained from various cases, the following are some of the suggestive actions for the community center to improve the effectiveness of BEMS:

- Initially, it is recommended to improve the building envelope level by reducing the infiltration of air, replacing the single pane windows with double panes, and measuring the saving obtained in energy consumption. It will help to make the existing temperature setback controls of the building work more efficiently.

- Considering the type of spaces in the building, it is recommended to install a DCV system based on $\mathrm{CO}_{2}$ level in areas such as Gymnasium, Breakroom, and Meeting room. These spaces have a variation of occupancy level and do not need ventilation at full capacity all the time. After realizing the energy savings, the building can expand the DCV system based on occupancy sensor or time of day control on other spaces such as office areas, lobby, kitchen, and storage areas.

- Furthermore, the building can also utilize the SATR controls that will help to vary the SAT based on outdoor air conditions and heat load demand from the spaces. This control system will reduce the load on the heating or cooling units by lowering the temperature of supply air during winter and increasing the temperature during summer. It will help to just meet the heating or cooling load of the spaces without wastage of excess energy.

- Moreover, it is also recommended to continually benchmark the energy consumption of the building and determine the effectiveness of BEMS as the control systems degrade over time and need continuous improvement to realize the potential benefits.

\subsection{Conclusion}

From the community center building analysis regarding the effectiveness of BEMS, it can be concluded that there is potential to increase the effectiveness of BEMS by adopting 
various methods. Whatever methods are considered, it is critical to do a further study incorporating the cost aspect for implementing those methods. It is essential to consider the expectation and goal of the building to know what effectiveness of BEMS are looking for and act according to adopting suitable practices for energy efficiency of the building. 


\section{Conclusion and Future Work}

In this study, the effect of building operating characteristics and BEMS controls on energy consumption for heating and cooling the building is studied and verified. The study was carried out by developing an MS Excel-based decision support system where users can enter the input parameters related to their building operating characteristics and BEMS controls.

This study considered the DCV system, zoning controls, temperature setback controls, and SATR as BEMS control aspects of simulating the energy consumption for a year. As mentioned earlier, this is a user-interactive process, as a user can select the operational parameter of the BEMS. Based on the chosen parameters, the tool will calculate the various results such as ventilation required to maintain the indoor air quality based on level of occupants, variation of SAT, energy consumption for every 30-minutes of interval. Moreover, a rating of the BEMS is calculated on a continuous scale of 1-5 based on the estimated annual energy consumption. These data could benefit energy managers or building owners to design the HVAC system and add control systems based on their necessity. Further, this rating could also help benchmark the energy consumption of the building against their past energy consumption data.

\subsection{Assumption and Limitation}

Several assumptions have been made during the development of this simulation program.

Moreover, there are some limitations to this simulation, as well. All the assumptions and limitation are described below:

\section{Assumption:}

- The time interval for the simulation has been considered 30 minutes. So, it will not detect any event in terms of occupancy between 0-30 minutes intervals.

- The temperature of the return air is assumed to be the same as that of the room temperature.

- The loss of energy for the return air is neglected, and the mixture of outside air and return air is considered an ideal mixture.

- The weather condition is considered to be constant for every 8 hours. 
- The values in the occupancy chart are assumed to be the same for similar types of the room but can be changed according to user requirements.

- Relative humidity of thermal comfort conditions is assumed to be at 50 percent.

- A natural disaster is ignored in this simulation.

\section{Limitations:}

- Only electricity and natural gas are accounted as a source of energy for cooling and heating the building.

- The model uses many input boxes, and none of them take any character (alphabet/words) or 0 or anything out of the range.

- The model is capable of handling only 16 different types of rooms/ spaces. If a building has a different kind of room than available in the model, then the analysis of the building cannot be performed.

- The thermostat settings are set constant throughout the year. Hence, the actual variation in the settings of a thermostat is not accounted for in the model.

- There are various BEMS controls, but only zoning controls, temperature setback controls, DCV system, and SATR control have been considered in the study.

- Nine climatic regions, two states from each climatic region, and two weather stations from each state only have been considered for this study.

- Only dehumidification is accounted for energy calculation and not the humidification process for simplicity in calculations.

- The seasonal factor is generated for zone 1 and will remain constant for all the other zones for particular hours.

- The feasibility of the DCV system depends on various factors according to ASHRAE 62.1-2019 standard, but the only area and occupant density of a room is considered. 


\subsection{Future work}

Future work on this research study involves increasing the number of operating parameters of BEMS controls to determine the effectiveness of a much complex building energy management system. A summary of possible forthcoming work related to this study are listed below:

1. Inclusion of more BEMS controls/ operating parameters such as advanced metering infrastructure to analyze electric demand and consumption patterns for a building, automated demand response controls, and benchmarking of energy consumptions.

2. Accounting for more energy sources other than electricity and natural gas. Many commercial buildings also use district steam and fuel \#2 oil.

3. Including all of the states of the United States for the study. This will help analyze the effectiveness of BEMS of commercial buildings from any part of the U.S.

4. Fine-tuning the data readings to every few minutes interval rather than a 30 -minute time interval. This would help to understand the building energy consumption pattern in much detail.

5. Development of algorithms that could analyze the occupancy patterns in the spaces and predict the time of occupancy. This would help to preheat or condition the areas just before the arrival of occupants. 


\section{References}

[1] U.S. Energy Information Administration, "2018 Commercial Buildings Energy Consumption Survey," U.S. Energy Information Administration, Washington, DCC, 2018.

[2] U.S. Energy Information Administration, "2012 Commercial Building Energy Consumption Survey," EIA, 2016.

[3] J. Leung, "DECARBONIZING U.S. BUILDINGS," Center for Climate and Energy Solutions (C2ES), Virginia, 2018.

[4] World Green Building Council, "2019 Global Status Report for Buildings and Construction," UN Environment and the International Energy Agency, Toronto, 2019.

[5] U.S. Energy Information Administration, "Electricity in the United States," U.S. Energy Information Administration, March 2021. [Online]. Available: https://www.eia.gov/energyexplained/electricity/electricity-in-the-us.php. [Accessed July 2021].

[6] J. Vespa, L. Medina, and D. M. Armstrong, "Demographic Turning Points for the United States: Population Projections for 2020 to 2060," U.S. CENSUS BUREAU, Maryland, 2020.

[7] National Action Plan for Energy Efficiency, "National Action Plan for Energy Efficiency Vision for 2025: A Framework for Change," U.S. Environmental Protection Agency, Washington, D.C, 2008.

[8] ENERGY STAR Portfolio Manager, "U.S. Energy Use Intensity by Property Type," April 2021. [Online]. Available:

https://portfoliomanager.energystar.gov/pdf/reference/US\%20National\%20Median \%20Table.pdf. [Accessed June 2021].

[9] ENERGY STAR, "About ENERGY STAR," ENERGY STAR, April 2021. [Online]. Available: https://www.energystar.gov/about. [Accessed June 2021].

[10] Office of Energy Efficiency \& Renewable Energy, "Innovation in Sensors and Controls for Building Energy Management," U.S. Department of Energy, Wahington, D.C., 2020.

[11] S. Cox, "BUILDING ENERGY CODES: POLICY OVERVIEW AND GOOD PRACTICES," National Renewable Energy Laboratory (NREL), Colorado, 2016. 
[12] US Department of Energy, "An Assessment of Energy Technologies and Research Opportunities," Quadrennial Technology Review, United States, 2015.

[13] C. J. Klaassen, "Geothermal Heat Pump Systems: GeoExchange Technology," April 2006. [Online]. Available:

https://www.michigan.gov/documents/CIS_EO_KC-MAY06-

Workshop_159640_7.pdf. [Accessed June 2021].

[14] G. D. Nugraha, A. Ardiansyah, K. Ramli and D. Choi, "Smart-Meter Data: A New Oil for the Smart and Sustainable Energy System," in International Conference on Science, Management, and Engineering 2018, Jakarta, 2018.

[15] J. Clements, "A Definitive Guide to Building Energy Management Systems," Greencoast, 25 June 2019. [Online]. Available: https://greencoast.org/buildingenergy-management-systems/. [Accessed 27 June 2021].

[16] Trane, "Demand-Controlled Ventilation," Trane Engineers Newsletter, 2018.

[17] North Carolina Energy Office, "Setback Temperature Control," April 2010. [Online]. Available: https://files.nc.gov/ncdeq/Environmental\%20Assistance\%20and\%20Customer\%20 Service/IAS\%20Energy\%20Efficiency/Opportunities/Setback_Temperature_Contr ol.pdf. [Accessed June 2021].

[18] Waste Reduction Partners, "Setback Temperature Control," April 2010. [Online]. Available:

https://wastereductionpartners.org/component/phocadownload/category/18?Itemid $=173$. [Accessed 6 April 2021].

[19] Pacific Northwest National Laboratory, "Building Re-tuning Training Guide: AHU Discharge-Air Temperature Control," Pacific Northwest National Laboratory, Washington, 2012.

[20] TRANE, "energy-saving control strategies for Rooftop VAV Systems," March 2006. [Online]. Available:

https://www.trane.com/content/dam/Trane/Commercial/global/productssystems/education-training/engineers-newsletters/control-systems-electricalconsiderations/admapn022en_1006.pdf. [Accessed June 2021].

[21] Desert Aire, "DX-DOAS Control Strategy," 20 September 2010. [Online]. Available: https://www.desert-aire.com/sites/default/files/Tech-Note-DX-DOASControl-Strategy-Technical-Bulletin-DA120.pdf. [Accessed June 2021].

[22] JOHNSON CONTROLS, "General Purpose Centrifugal Fan, Model US," JOHNSON CONTROLS, Ireland, 2015. 
[23] NORTHWEST ENERGY EFFICIENCY COUNCIL (NEEC), "Economizer Fact Sheet," NORTHWEST ENERGY EFFICIENCY COUNCIL (NEEC), Seattle, 2011.

[24] ASHRAE, "ASHRAE PSYCHROMETRIC CHART NO. 1," 1992. [Online]. Available:

https://www.ashrae.org/File\%20Library/Technical\%20Resources/Bookstore/UP3/I P-1.pdf. [Accessed 2021].

[25] U.S. Energy Information Administration (EIA), "Annual Energy Outlook 2017 with Projections to 2050," Washington, D.C., 2017.

[26] C. Ionescu, T. Baracu, g.-e. Vlad, H. Necula and A. Badea, "The historical evolution of the energy-efficient buildings," Renewable and Sustainable Energy Reviews, vol. 49, no. 22, pp. 243-253, 2015.

[27] N. N. Abu Bakar, M. Y. Hassan, H. Abdullah, H. A. Rahman, M. P. Abdullah, F. Hussin, and M. Bandi, "Energy efficiency index as an indicator for measuring building energy performance: A review," Renewable and Sustainable Energy Reviews, vol. 44, pp. 1-11, 2015.

[28] A. Huovila, P. Tuominen and M. Airaksinen, "Effects of Building Occupancy on Indicators of Energy Efficiency," energies, vol. 10, no. 5, 2017.

[29] E. Graiz and W. A. Azhari, "Energy Efficient Glass: A Way to Reduce Energy Consumption in Office Buildings in Amman," IEEE Access, vol. 7, 2019.

[30] A. Ucar and F. Balo, "Determination of the energy savings and the optimum insulation thickness in the four different insulated exterior walls," Renewable Energy, vol. 35, pp. 88-94, 2010.

[31] S. Wu, Y. Dai, X. Li and F. X. C. Oppong, "A review of ground-source heat pump systems with heat pipes for energy efficiency in buildings," Energy Procedia, vol. 152, pp. 413-418, 2018.

[32] Y. Bichiou and M. Krarti, "Optimization of envelope and HVAC systems selection for residential buildings," Energy and Buildings, vol. 43, pp. 3373-3382, 2011.

[33] M. Cai, S. Ramdaspalli, M. Pipattanasomporn, S. Rahman, A. Malekpour, and S. R. Kothandaraman, "Impact of HVAC Set Point Adjustment on Energy Savings and Peak Load Reduction in Buildings," in 2018 IEEE International Smart Cities Conference (ISC2), Kansas, 2018. 
[34] B. Thornton, W. Wang, M. Lane, M. Rosenberg, and B. Liu, "Technical Support Document: 50\% Energy Savings Design Technology Packages for Medium Office Buildings," United States, 2009.

[35] S. Nikoofard, U. V. Ismet and I. B. Morrison, "Effect of external shading on household energy requirement for heating and cooling in Canada," Energy and Buildings, vol. 43, pp. 1627-1635, 2011.

[36] J. Liu, W. Li, J. Liu, and B. Wang, "Efficiency of energy recovery ventilator with various weathers and its energy-saving performance in a residential apartment," Energy and Buildings, vol. 42, no. 1, pp. 43-49, 2010.

[37] S. Jaber and S. Ajib, "Optimum, technical and energy efficiency design of residential building in Mediterranean region," Energy and Buildings, vol. 43, pp. 1829-1834, 2011.

[38] D. Griegi, M. Krarti, and A. H. Guerrero, "Optimization of energy efficiency and thermal comfort measures for residential buildings in Salamanca Mexico," Energy and Buildings, vol. 54, pp. 540-549, 2012.

[39] M. Jamil and S. Mittal, "Building Energy Management System: A Review," in 14th IEEE India Council Internation Conference (INDICON), Roorkee, 2017.

[40] P. J. Mei, "Building Energy Management Systems (BEMS) - Energyzine," Energy in Building and Industry, UK, 2011.

[41] K. Sayed and H. A. Gabbar, "Building Energy Management Systems (BEMS)," in Energy Conservation in Residential, Commercial, and Industrial Facilities, John Wiley \& Sons, 2017, pp. 15-81.

[42] C.-N. Chen, M.-Y. Cho and C.-H. Lee, "Design and Implementation of Building Energy Management System," in 3rd Internation Conference on Green Technology and Sustainable Development, United States, 2016.

[43] D. M. Hernandez, L. H. Callejo, A. Z. Lamadrid, O. D. Perez, and F. S. Garcia, "A review of strategies for building energy management system: Model," Journal of Building Engineering, vol. 33, pp. 1-12, 2021.

[44] N. Djuric, V. Novakovic, and F. Frydenlund, "Heating system performance estimation using optimization tool and BEMS data," Energy and Buildings, vol. 40, pp. 1367-1376, 2008.

[45] Pacific Northwest National Laboratory, "Building Re-tuning Training Guide: Occupancy Scheduling: Night and Weekend Temperature Set back and Supply Fan 
Cycling during Unoccupied Hours," Pacific Northwest National Laboratory, Richmond, 2012.

[46] N. Verma and A. Jain, "Optimized Automatic Lighting Control in a Hotel Building for Energy Efficiency," in 2018 International Conference on Power Energy, Environment and Intelligent Control (PEEIC), Greater Noida, India, India, 2018.

[47] M. D. Sohn, D. R. Black, P. N. Price, Y. Lin, R. Brahme, A. Surana, S. Narayanan, A. Cerpa, V. Ericson and A. Kamthe, "occupancy-based Energy Management in Buildings: Final Report to Sponsors," Lawrence Berkeley National Laboratory, California, 2010.

[48] G. Liu and M. R. Brambley, "Occupancy Based Control Strategy for Variable-AirVolume (VAV) Terminal Box Systems," ASHRAE Transactions, vol. 117, no. 2, pp. 244-253, 2011.

[49] D. Ardiyanto, M. Pipattanasomporn, S. Rahman, N. Hariyanto and Suwarno, "Occupant-based HVAC Set Point Interventions for Energy Savings in Buildings," in Green Energy for Sustainable Development, Thailand, 2018.

[50] K. Mandlem, B. Gopalakrishnan, A. Nimbarte, R. Mostafa and R. Das, "Energy Efficiency Effectiveness of Smart Thermostat Based BEMS," Tech Science Press, vol. 117, no. 4, pp. 165-183, 2020.

[51] L. Zhang, "Experimental and simulation study of demand-controlled ventilation," Iowa State University, Iowa, 2008.

[52] E. Zio, The Monte Carlo Simulation Method for System Reliability and Risk Analysis, London: Springer London, 2013.

[53] ANSI/ASHRAE, "Ventilation for Acceptable Indoor Air Quality," ASHRAE, Atlanta, 2019.

[54] US Energy Information Administration, "Degree-Days - Energy Explained, Your Guide to Understanding Energy," Information Publication, Washinton, DC, 2017.

[55] ASHRAE, "2017 ASHRAE Handbook-Fundamentals," ASHRAE, 2017. [Online]. Available: https://www.ashrae.org/technical-resources/ashrae-handbook/table-ofcontents-2017-ashrae-handbook-fundamentals. [Accessed June 2021].

[56] CheCalc, "PSYCHROMETRIC CALCULATIONS," CHECALC, 2015. [Online]. Available: https://checalc.com/calc/wetBulb.html. [Accessed 1612 2020].

[57] ENERGY STAR, "What are the Site-to-Source Conversion Factors?," ENERGY STAR, September 2020. [Online]. Available: https://energystar- 
mesa.force.com/PortfolioManager/s/article/What-are-the-Site-to-SourceConversion-Factors-1600088532330. [Accessed July 2021].

[58] Weather Spark, "Average Weather in Huntington West Virginia, United States," Weather Spark, 2016. [Online]. Available:

https://weatherspark.com/y/17230/Average-Weather-in-Huntington-West-VirginiaUnited-States-Year-Round\#Sections-Sources. [Accessed June 2021].

[59] M. Alsaad and M. Hammad, Heating and Air Conditioning for Residential Buildings, 5th edition, Amman: Ajyal Press, 2011. 


\section{Appendix}

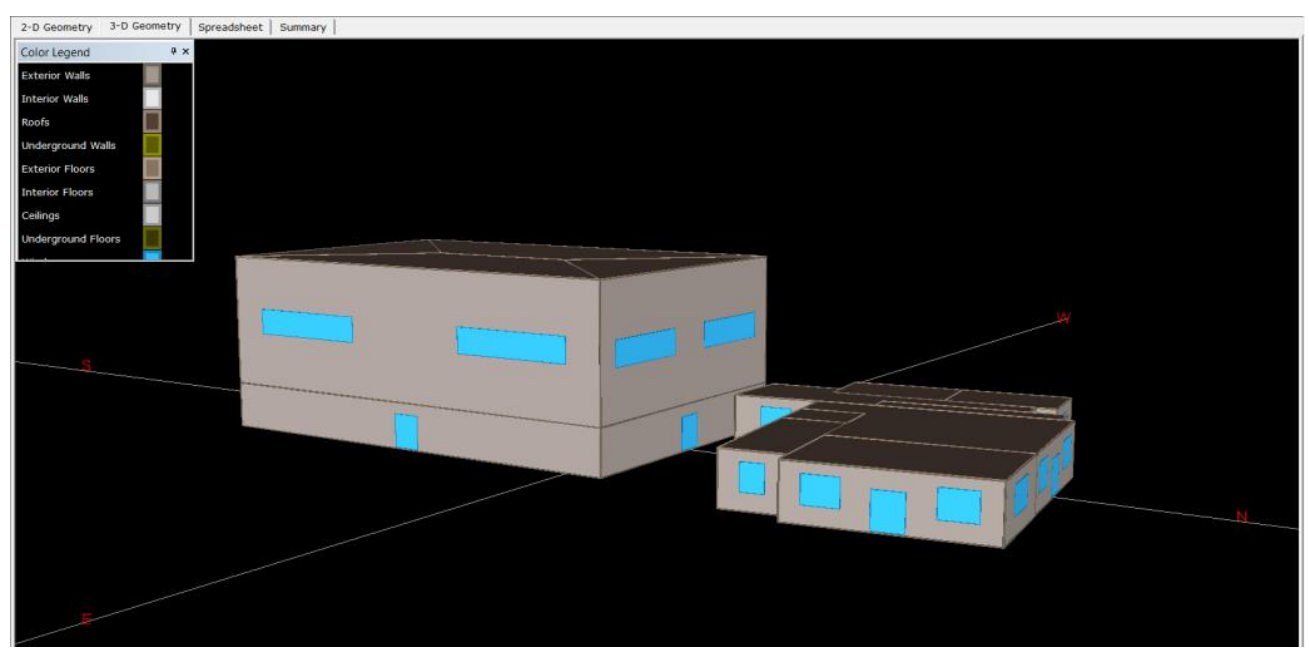

Figure A1: eQuest Model of the community center

Table A1: HDD data for nine climatic regions

\begin{tabular}{|c|c|c|c|c|c|c|c|c|c|}
\hline \multicolumn{10}{|c|}{ Heating Degree Days } \\
\hline & $\mathbf{1}$ & $\mathbf{2}$ & $\mathbf{3}$ & $\mathbf{1 5}$ & $\mathbf{5}$ & $\mathbf{6}$ & $\mathbf{7}$ & $\mathbf{8}$ & $\mathbf{9}$ \\
\hline Month & Pacific & Mountain & West North Central & West South Central & East North Central & East South Central & Middle Atlantic & South Atlantic & New England \\
\hline January & 526 & 842 & 1480.66 & 517 & 1167 & 735 & 1040 & 569 & 1103 \\
\hline February & 435 & 659 & 1158.85 & 361 & 1012 & 584 & 914 & 460 & 974 \\
\hline March & 389 & 519 & 912.66 & 211 & 759 & 385 & 754 & 322 & 840 \\
\hline April & 299 & 382 & 423 & 69 & 427 & 158 & 416 & 129 & 494 \\
\hline May & 179 & 222 & 186 & 11 & 182 & 48 & 165 & 39 & 218 \\
\hline June & 66 & 66 & 37 & 0 & 29 & 1 & 21 & 2 & 49 \\
\hline July & 16 & 13 & 13 & 0 & 10 & 1 & 4 & 1 & 6 \\
\hline August & 16 & 23 & 23 & 1 & 17 & 1 & 10 & 1 & 17 \\
\hline September & 49 & 97 & 95 & 4 & 78 & 15 & 60 & 11 & 87 \\
\hline October & 176 & 304 & 362 & 57 & 344 & 161 & 306 & 118 & 357 \\
\hline November & 365 & 552 & 694 & 232 & 661 & 416 & 595 & 315 & 639 \\
\hline December & 562 & 851 & 1106 & 442 & 987 & 597 & 847 & 445 & 917 \\
\hline
\end{tabular}

Table A2: CDD data for nine climatic regions

\begin{tabular}{|c|c|c|c|c|c|c|c|c|c|}
\hline \multicolumn{7}{|c|}{ Cooling Degree Days } \\
\hline & $\mathbf{1}$ & $\mathbf{2}$ & $\mathbf{3}$ & $\mathbf{4}$ & $\mathbf{5}$ & $\mathbf{6}$ & $\mathbf{7}$ & $\mathbf{8}$ & $\mathbf{9}$ \\
\hline Month & Pacific & Mountain & West North Central & West South Central & East North Central & East South Central & Middle Atlantic & South Atlantic & New England \\
\hline January & 9 & 1 & 0 & 13 & 0 & 6 & 0 & 29 & 0 \\
\hline February & 8 & 4 & 1 & 20 & 0 & 4 & 0 & 30 & 0 \\
\hline March & 13 & 18 & 7 & 61 & 3 & 25 & 1 & 53 & 0 \\
\hline April & 19 & 39 & 6 & 107 & 2 & 35 & 1 & 84 & 0 \\
\hline May & 42 & 99 & 58 & 246 & 57 & 142 & 31 & 189 & 11 \\
\hline June & 110 & 255 & 193 & 448 & 155 & 317 & 122 & 338 & 64 \\
\hline July & 211 & 356 & 285 & 519 & 227 & 380 & 250 & 412 & 200 \\
\hline August & 213 & 310 & 232 & 526 & 193 & 366 & 192 & 392 & 151 \\
\hline September & 142 & 187 & 97 & 351 & 73 & 216 & 73 & 264 & 41 \\
\hline October & 49 & 67 & 11 & 141 & 8 & 52 & 7 & 123 & 2 \\
\hline November & 14 & 10 & 1 & 36 & 0 & 5 & 0 & 47 & 0 \\
\hline December & 8 & 0 & 0 & 11 & 1 & 5 & 1 & 44 & 0 \\
\hline
\end{tabular}


Table A3: Occupancy schedule chart

\begin{tabular}{|c|c|c|c|c|c|}
\hline \multicolumn{6}{|c|}{ Meeting Room } \\
\hline \multicolumn{2}{|c|}{ Time Interval } & \multicolumn{2}{|c|}{ Weekdays } & \multicolumn{2}{|c|}{$\begin{array}{l}\text { Percentage of Total } \\
\text { Allowable Occupants }\end{array}$} \\
\hline & & & & Weekdays & Weekends \\
\hline \multirow{2}{*}{ 12:00 AM } & \multirow{2}{*}{ 8:00 AM } & 0 & 0.99 & $0 \%$ & $0 \%$ \\
\hline & & 0.991 & 1 & $5 \%$ & $2 \%$ \\
\hline \multirow{2}{*}{ 8:01 AM } & \multirow{2}{*}{ 9:00 AM } & 0 & 0.75 & $0 \%$ & $0 \%$ \\
\hline & & 0.751 & 1 & $60 \%$ & $5 \%$ \\
\hline \multirow{2}{*}{ 9:01 AM } & \multirow{2}{*}{ 10:00 AM } & 0 & 0.8 & $60 \%$ & $0 \%$ \\
\hline & & 0.81 & 1 & $0 \%$ & $10 \%$ \\
\hline \multirow{2}{*}{ 10:01 AM } & \multirow{2}{*}{ 12:00 PM } & 0 & 0.98 & $60 \%$ & $0 \%$ \\
\hline & & 0.981 & 1 & $90 \%$ & $20 \%$ \\
\hline \multirow{2}{*}{ 12:01 PM } & \multirow{2}{*}{ 1:00 PM } & 0 & 0.3 & $15 \%$ & $5 \%$ \\
\hline & & 0.31 & 1 & $0 \%$ & $0 \%$ \\
\hline \multirow{2}{*}{ 1:01 PM } & \multirow{2}{*}{ 4:00 PM } & 0 & 0.98 & $0 \%$ & $0 \%$ \\
\hline & & 0.981 & 1 & $60 \%$ & $10 \%$ \\
\hline \multirow{2}{*}{ 4:01 PM } & \multirow{2}{*}{ 5:00 PM } & 0 & 0.8 & $80 \%$ & $0 \%$ \\
\hline & & 0.81 & 1 & $25 \%$ & $5 \%$ \\
\hline \multirow{2}{*}{ 5:01 PM } & \multirow{2}{*}{ 6:00 PM } & 0 & 0.75 & $0 \%$ & $0 \%$ \\
\hline & & 0.751 & 1 & $25 \%$ & $5 \%$ \\
\hline \multirow{2}{*}{ 6:01 PM } & \multirow{2}{*}{ 8:00 PM } & 0 & 0.35 & $15 \%$ & $5 \%$ \\
\hline & & 0.351 & 1 & $0 \%$ & $0 \%$ \\
\hline \multirow[b]{2}{*}{ 8:01 PM } & \multirow{2}{*}{ 12:00 AM } & 0 & $\begin{array}{l}0.99 \\
\end{array}$ & $0 \%$ & $0 \%$ \\
\hline & & 0.991 & 1 & $5 \%$ & $2 \%$ \\
\hline
\end{tabular}

\begin{tabular}{|c|c|c|c|c|c|}
\hline \multicolumn{6}{|c|}{ Break Room } \\
\hline \multicolumn{2}{|c|}{ Time Interval } & \multicolumn{2}{|c|}{ Weekdays } & \multicolumn{2}{|c|}{$\begin{array}{l}\text { Percentage of Total } \\
\text { Allowable Occupants }\end{array}$} \\
\hline & & & & Weekdays & Weekends \\
\hline \multirow{2}{*}{ 12:00 AM } & \multirow{2}{*}{ 8:00 AM } & 0 & 0.99 & $0 \%$ & $0 \%$ \\
\hline & & 0.991 & 1 & $5 \%$ & $2 \%$ \\
\hline \multirow{2}{*}{ 8:01 AM } & \multirow{2}{*}{ 9:00 AM } & 0 & 0.75 & $60 \%$ & $0 \%$ \\
\hline & & 0.75 & 1 & $90 \%$ & $5 \%$ \\
\hline \multirow{2}{*}{ 9:01 AM } & \multirow{2}{*}{ 10:00 AM } & 0 & 0.8 & $0 \%$ & $0 \%$ \\
\hline & & 0.8 & 1 & $65 \%$ & $10 \%$ \\
\hline \multirow{2}{*}{ 10:01 AM } & \multirow{2}{*}{ 12:00 PM } & 0 & 0.98 & $60 \%$ & $0 \%$ \\
\hline & & 0.98 & 1 & $85 \%$ & $20 \%$ \\
\hline \multirow{2}{*}{ 12:01 PM } & \multirow{2}{*}{ 1:00 PM } & 0 & 0.3 & $75 \%$ & $5 \%$ \\
\hline & & 0.3 & 1 & $95 \%$ & $0 \%$ \\
\hline \multirow{2}{*}{ 1:01 PM } & \multirow{2}{*}{ 4:00 PM } & 0 & 0.75 & $0 \%$ & $0 \%$ \\
\hline & & 0.75 & 1 & $45 \%$ & $10 \%$ \\
\hline \multirow{2}{*}{ 4:01 PM } & \multirow{2}{*}{ 5:00 PM } & 0 & 0.75 & $0 \%$ & $0 \%$ \\
\hline & & 0.75 & 1 & $75 \%$ & $5 \%$ \\
\hline \multirow{2}{*}{ 5:01 PM } & \multirow{2}{*}{ 6:00 PM } & 0 & 0.75 & $45 \%$ & $0 \%$ \\
\hline & & 0.75 & 1 & $85 \%$ & $5 \%$ \\
\hline \multirow{2}{*}{ 6:01 PM } & \multirow{2}{*}{ 8:00 PM } & 0 & 0.75 & $15 \%$ & $5 \%$ \\
\hline & & 0.75 & 1 & $55 \%$ & $0 \%$ \\
\hline \multirow{2}{*}{ 8:01 PM } & \multirow{2}{*}{$12: 00 \mathrm{AM}$} & 0 & 0.99 & $0 \%$ & $0 \%$ \\
\hline & & 0.991 & 1 & $5 \%$ & $2 \%$ \\
\hline
\end{tabular}

\begin{tabular}{|c|c|c|c|c|c|}
\hline \multicolumn{6}{|c|}{ Office Private Space } \\
\hline \multicolumn{2}{|c|}{ Time Interval } & \multicolumn{2}{|c|}{ Weekdays } & \multicolumn{2}{|c|}{$\begin{array}{l}\text { Percentage of Total } \\
\text { Allowable Occupants }\end{array}$} \\
\hline & & & & Weekdays & Weekends \\
\hline \multirow{2}{*}{ 12:00 AM } & \multirow{2}{*}{ 8:00 AM } & 0 & 0.99 & $0 \%$ & $0 \%$ \\
\hline & & 0.991 & 1 & $5 \%$ & $2 \%$ \\
\hline \multirow{2}{*}{ 8:01 AM } & \multirow{2}{*}{ 9:00 AM } & 0 & 0.75 & $65 \%$ & $0 \%$ \\
\hline & & 0.751 & 1 & $85 \%$ & $5 \%$ \\
\hline \multirow{2}{*}{ 9:01 AM } & \multirow{2}{*}{ 10:00 AM } & 0 & 0.8 & $70 \%$ & $0 \%$ \\
\hline & & 0.81 & 1 & $90 \%$ & $10 \%$ \\
\hline \multirow{2}{*}{ 10:01 AM } & \multirow{2}{*}{ 12:00 PM } & 0 & 0.98 & $90 \%$ & $0 \%$ \\
\hline & & 0.981 & 1 & $95 \%$ & $20 \%$ \\
\hline \multirow{2}{*}{ 12:01 PM } & \multirow{2}{*}{ 1:00 PM } & 0 & 0.3 & $55 \%$ & $5 \%$ \\
\hline & & 0.31 & 1 & $15 \%$ & $0 \%$ \\
\hline \multirow{2}{*}{ 1:01 PM } & \multirow{2}{*}{ 4:00 PM } & 0 & 0.98 & $90 \%$ & $0 \%$ \\
\hline & & 0.981 & 1 & $95 \%$ & $10 \%$ \\
\hline \multirow{2}{*}{ 4:01 PM } & \multirow{2}{*}{ 5:00 PM } & 0 & 0.8 & $70 \%$ & $0 \%$ \\
\hline & & 0.81 & 1 & $90 \%$ & $5 \%$ \\
\hline \multirow{2}{*}{ 5:01 PM } & \multirow{2}{*}{ 6:00 PM } & 0 & 0.75 & $65 \%$ & $0 \%$ \\
\hline & & 0.751 & 1 & $85 \%$ & $5 \%$ \\
\hline \multirow{2}{*}{ 6:01 PM } & \multirow{2}{*}{ 8:00 PM } & 0 & 0.35 & $35 \%$ & $5 \%$ \\
\hline & & 0.351 & 1 & $15 \%$ & $0 \%$ \\
\hline \multirow{2}{*}{ 8:01 PM } & \multirow{2}{*}{$12: 00 \mathrm{AM}$} & 0 & 0.99 & $0 \%$ & $0 \%$ \\
\hline & & 0.991 & 1 & $5 \%$ & $2 \%$ \\
\hline
\end{tabular}


Table A4: Occupancy Schedule Chart

\begin{tabular}{|c|c|c|c|c|c|}
\hline \multicolumn{6}{|c|}{ Printing Room } \\
\hline \multicolumn{2}{|c|}{ Time Interval } & \multicolumn{2}{|c|}{ Weekdays } & \multicolumn{2}{|c|}{$\begin{array}{l}\text { Percentage of Total } \\
\text { Allowable Occupants }\end{array}$} \\
\hline & & & & Weekdays & Weekends \\
\hline \multirow{2}{*}{ 12:00 AM } & \multirow{2}{*}{ 8:00 AM } & 0 & 0.99 & $0 \%$ & $0 \%$ \\
\hline & & 0.991 & 1 & $5 \%$ & $2 \%$ \\
\hline \multirow{2}{*}{ 8:01 AM } & \multirow{2}{*}{ 9:00 AM } & 0 & 0.75 & $65 \%$ & $0 \%$ \\
\hline & & 0.75 & 1 & $85 \%$ & $5 \%$ \\
\hline \multirow{2}{*}{ 9:01 AM } & \multirow{2}{*}{ 10:00 AM } & 0 & 0.8 & $65 \%$ & $0 \%$ \\
\hline & & 0.8 & 1 & $85 \%$ & $10 \%$ \\
\hline \multirow{2}{*}{ 10:01 AM } & \multirow{2}{*}{ 12:00 PM } & 0 & 0.98 & $65 \%$ & $0 \%$ \\
\hline & & 0.98 & 1 & $85 \%$ & $20 \%$ \\
\hline \multirow{2}{*}{ 12:01 PM } & \multirow{2}{*}{ 1:00 PM } & 0 & 0.3 & $65 \%$ & $5 \%$ \\
\hline & & 0.3 & 1 & $85 \%$ & $0 \%$ \\
\hline \multirow{2}{*}{ 1:01 PM } & \multirow{2}{*}{ 4:00 PM } & 0 & 0.75 & $65 \%$ & $0 \%$ \\
\hline & & 0.75 & 1 & $85 \%$ & $10 \%$ \\
\hline \multirow{2}{*}{ 4:01 PM } & \multirow{2}{*}{ 5:00 PM } & 0 & 0.75 & $65 \%$ & $0 \%$ \\
\hline & & 0.75 & 1 & $85 \%$ & $5 \%$ \\
\hline \multirow{2}{*}{ 5:01 PM } & \multirow{2}{*}{ 6:00 PM } & 0 & 0.75 & $65 \%$ & $0 \%$ \\
\hline & & 0.75 & 1 & $85 \%$ & $5 \%$ \\
\hline \multirow{2}{*}{ 6:01 PM } & \multirow{2}{*}{ 8:00 PM } & 0 & 0.75 & $65 \%$ & $5 \%$ \\
\hline & & 0.75 & 1 & $85 \%$ & $0 \%$ \\
\hline \multirow{2}{*}{ 8:01 PM } & \multirow{2}{*}{ 12:00 AM } & 0 & 0.99 & $0 \%$ & $0 \%$ \\
\hline & & 0.991 & 1 & $5 \%$ & $2 \%$ \\
\hline
\end{tabular}

\begin{tabular}{|c|c|c|c|c|c|}
\hline \multicolumn{6}{|c|}{ Lobby } \\
\hline \multirow{2}{*}{\multicolumn{2}{|c|}{ Time Interval }} & \multirow{2}{*}{\multicolumn{2}{|c|}{ Weekdays }} & \multicolumn{2}{|c|}{$\begin{array}{l}\text { Percentage of Total } \\
\text { Allowable Occupants }\end{array}$} \\
\hline & & & & Weekdays & Weekends \\
\hline \multirow{2}{*}{$12: 00 \mathrm{AM}$} & \multirow{2}{*}{ 8:00 AM } & 0 & 0.99 & $0 \%$ & $0 \%$ \\
\hline & & 0.991 & 1 & $5 \%$ & $2 \%$ \\
\hline \multirow{2}{*}{ 8:01 AM } & \multirow{2}{*}{ 9:00 AM } & 0 & 0.75 & $55 \%$ & $0 \%$ \\
\hline & & 0.75 & 1 & $65 \%$ & $5 \%$ \\
\hline \multirow{2}{*}{ 9:01 AM } & \multirow{2}{*}{$10: 00 \mathrm{AM}$} & 0 & 0.8 & $65 \%$ & $0 \%$ \\
\hline & & 0.8 & 1 & $75 \%$ & $10 \%$ \\
\hline \multirow{2}{*}{ 10:01 AM } & \multirow{2}{*}{$12: 00 \mathrm{PM}$} & 0 & 0.98 & $80 \%$ & $0 \%$ \\
\hline & & 0.98 & 1 & $90 \%$ & $20 \%$ \\
\hline \multirow{2}{*}{ 12:01 PM } & \multirow{2}{*}{ 1:00 PM } & 0 & 0.3 & $25 \%$ & $5 \%$ \\
\hline & & 0.3 & 1 & $15 \%$ & $0 \%$ \\
\hline \multirow{2}{*}{ 1:01 PM } & \multirow{2}{*}{ 4:00 PM } & 0 & 0.75 & $80 \%$ & $0 \%$ \\
\hline & & 0.75 & 1 & $90 \%$ & $10 \%$ \\
\hline \multirow{2}{*}{ 4:01 PM } & \multirow{2}{*}{ 5:00 PM } & 0 & 0.75 & $75 \%$ & $0 \%$ \\
\hline & & 0.75 & 1 & $85 \%$ & $5 \%$ \\
\hline \multirow{2}{*}{ 5:01 PM } & \multirow{2}{*}{ 6:00 PM } & 0 & 0.75 & $45 \%$ & $0 \%$ \\
\hline & & 0.75 & 1 & $85 \%$ & $5 \%$ \\
\hline \multirow{2}{*}{ 6:01 PM } & \multirow{2}{*}{ 8:00 PM } & 0 & 0.75 & $35 \%$ & $5 \%$ \\
\hline & & 0.75 & 1 & $65 \%$ & $0 \%$ \\
\hline \multirow{2}{*}{ 8:01 PM } & \multirow{2}{*}{ 12:00 AM } & 0 & 0.99 & $0 \%$ & $0 \%$ \\
\hline & & 0.991 & 1 & $5 \%$ & $2 \%$ \\
\hline
\end{tabular}

\begin{tabular}{|c|c|c|c|c|c|}
\hline \multicolumn{6}{|c|}{ Kitchen } \\
\hline \multicolumn{2}{|c|}{ Time Interval } & \multicolumn{2}{|c|}{ Weekdays } & \multicolumn{2}{|c|}{$\begin{array}{l}\text { Percentage of Total } \\
\text { Allowable Occupants }\end{array}$} \\
\hline & & & & Weekdays & Weekends \\
\hline \multirow{2}{*}{ 12:00 AM } & \multirow{2}{*}{ 8:00 AM } & 0 & 0.99 & $0 \%$ & $0 \%$ \\
\hline & & 0.991 & 1 & $5 \%$ & $2 \%$ \\
\hline \multirow{2}{*}{ 8:01 AM } & \multirow{2}{*}{ 9:00 AM } & 0 & 0.75 & $60 \%$ & $0 \%$ \\
\hline & & 0.75 & 1 & $90 \%$ & $5 \%$ \\
\hline \multirow{2}{*}{ 9:01 AM } & \multirow{2}{*}{ 10:00 AM } & 0 & 0.8 & $0 \%$ & $0 \%$ \\
\hline & & 0.8 & 1 & $65 \%$ & $10 \%$ \\
\hline \multirow{2}{*}{ 10:01 AM } & \multirow{2}{*}{ 12:00 PM } & 0 & 0.98 & $60 \%$ & $0 \%$ \\
\hline & & 0.98 & 1 & $85 \%$ & $20 \%$ \\
\hline \multirow{2}{*}{ 12:01 PM } & \multirow{2}{*}{ 1:00 PM } & 0 & 0.3 & $75 \%$ & $5 \%$ \\
\hline & & 0.3 & 1 & $95 \%$ & $0 \%$ \\
\hline \multirow{2}{*}{ 1:01 PM } & \multirow{2}{*}{ 4:00 PM } & 0 & 0.75 & $0 \%$ & $0 \%$ \\
\hline & & 0.75 & 1 & $45 \%$ & $10 \%$ \\
\hline \multirow{2}{*}{ 4:01 PM } & \multirow{2}{*}{ 5:00 PM } & 0 & 0.75 & $0 \%$ & $0 \%$ \\
\hline & & 0.75 & 1 & $75 \%$ & $5 \%$ \\
\hline \multirow{2}{*}{ 5:01 PM } & \multirow{2}{*}{ 6:00 PM } & 0 & 0.75 & $45 \%$ & $0 \%$ \\
\hline & & 0.75 & 1 & $85 \%$ & $5 \%$ \\
\hline \multirow{2}{*}{ 6:01 PM } & \multirow{2}{*}{ 8:00 PM } & 0 & 0.75 & $15 \%$ & $5 \%$ \\
\hline & & 0.75 & 1 & $55 \%$ & $0 \%$ \\
\hline \multirow{2}{*}{ 8:01 PM } & \multirow{2}{*}{$12: 00 \mathrm{AM}$} & 0 & 0.99 & $0 \%$ & $0 \%$ \\
\hline & & 0.991 & 1 & $5 \%$ & $2 \%$ \\
\hline
\end{tabular}

